\title{
WestVirginiaUniversity
}

THE RESEARCH REPOSITORY @ WVU

Graduate Theses, Dissertations, and Problem Reports

2002

\section{Assessing the return on investment for various types of break-in training}

Kim L. Trenbath

West Virginia University

Follow this and additional works at: https://researchrepository.wvu.edu/etd

\section{Recommended Citation}

Trenbath, Kim L., "Assessing the return on investment for various types of break-in training" (2002). Graduate Theses, Dissertations, and Problem Reports. 1292.

https://researchrepository.wvu.edu/etd/1292

This Thesis is protected by copyright and/or related rights. It has been brought to you by the The Research Repository @ WVU with permission from the rights-holder(s). You are free to use this Thesis in any way that is permitted by the copyright and related rights legislation that applies to your use. For other uses you must obtain permission from the rights-holder(s) directly, unless additional rights are indicated by a Creative Commons license in the record and/ or on the work itself. This Thesis has been accepted for inclusion in WVU Graduate Theses, Dissertations, and Problem Reports collection by an authorized administrator of The Research Repository @ WVU. For more information, please contact researchrepository@mail.wvu.edu. 
Assessing the Return on Investment

for Various Types of Break-In Training

Kim L. Trenbath

\author{
Thesis submitted to the \\ College of Engineering and Mineral Resources \\ at West Virginia University \\ in partial fulfillment for the degree of
}

\begin{abstract}
Masters of Science
in

Industrial and Management Systems Engineering
\end{abstract}

Dr. Jack Byrd, Jr., Ph.D., Chair

Dr. Bhaskaran Gopalakrishnan, Ph.D.

David Lieving

Department of Industrial and Management Systems Engineering

Morgantown, West Virginia

2002 


\title{
ABSTRACT \\ Assessing the Return on Investment for Various Types of Break-In Training
}

\author{
Kim L. Trenbath
}

This thesis presents a Return on Investment, or ROI, model for various types of break-in training by utilizing employee learning curves as a factor of the cost. The model captures the additional profit earned when a company makes an investment in break-in training, training employees receive at the beginning of their employment. Research involves developing employee learning curves for break-in training vs. traditional training through experimentation. The thesis utilizes the improvement in the learning curve as the driving factor behind the profits. The ROI model is a comparison between the profits, or benefits minus cost, of a traditional and break-in training. The ROI model can be used to capture the exact profit that can be attributed to better training. 


\begin{abstract}
ABOUT THE AUTHOR
Kim Trenbath is a Management Analyst for BearingPoint, Inc., an international business analysis and systems integrations firm. Her accomplishments at BearingPoint include establishing a validation testing system for quality assurance methods in a government organization and streamlining engagement control processes. She attended the College of Engineering and Mineral Resources at West Virginia University, where she received her Master's of Science in Industrial and Management Systems Engineering with a concentration in Decision Science. She received her Bachelor's of Engineering in Civil and Environmental Engineering degree from Vanderbilt University. Throughout college she was an avid runner, participating in varsity cross country and track at both institutions.
\end{abstract}




\section{TABLE OF CONTENTS}

I. Chapter 1: Background and Research Methodology ........................................1

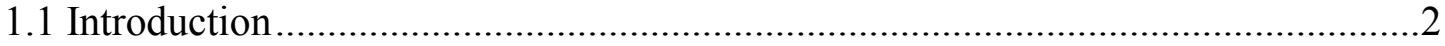

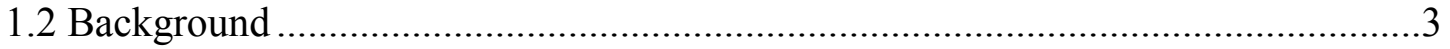

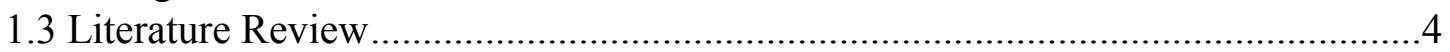

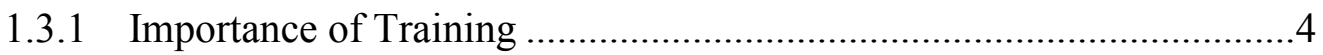

1.3.2 Need for ROI..............................................................................

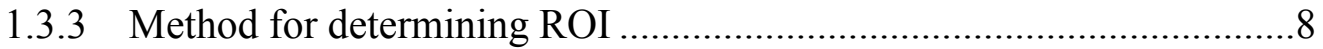

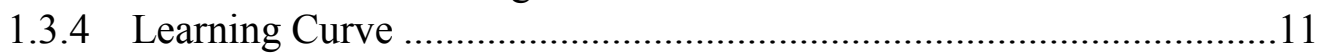

1.3.5 Determining ROI from the learning curve ............................................19

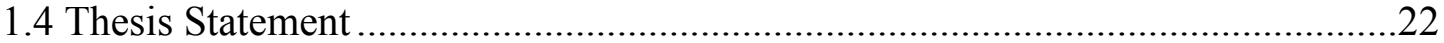

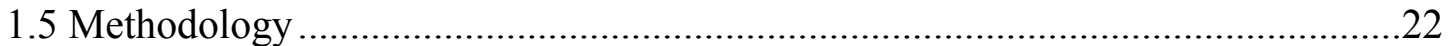

1.5.1 Identify three types of break-in training in use today............................22

1.5.2 Develop learning curves for these different break-in strategies using a

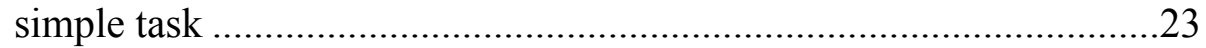

1.5.3 Develop a ROI model using learning curves as a basis ........................25

1.5.4 Estimate the ROI for the different break-in strategies ..........................28

1.5.5 Show how the model can be used on actual jobs ................................28

II. Chapter 2: Identify three types of break-in training in use today ..................30

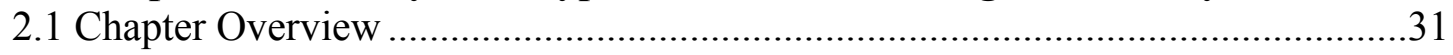

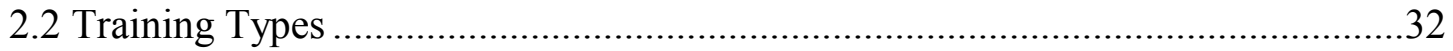

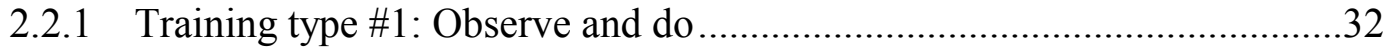

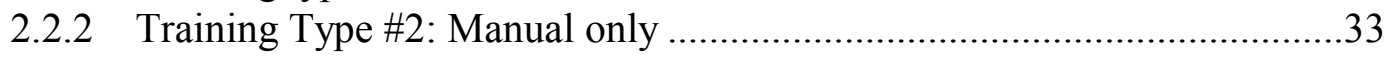

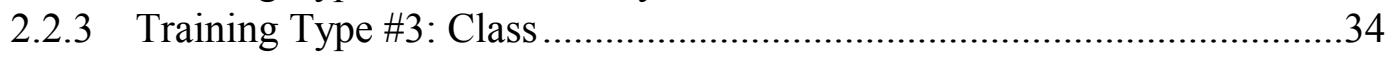

2.2.4 Training Type \#4: Manual with a mentor ...................................................35

\section{Chapter 3: Develop learning curves for these different break-in strategies} using a simple task ............................................................................................................37

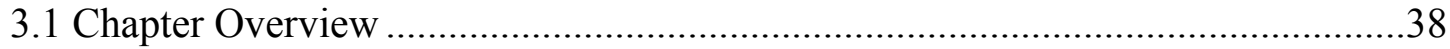

3.2 Repetitive Task: Binding Reports ....................................................................

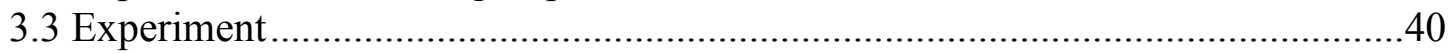

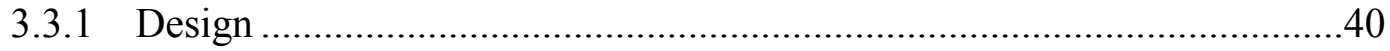

3.3.1.a Preparations ............................................................................40

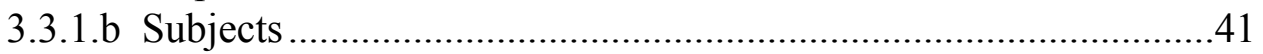

3.3.1.c Experimental Procedure ………………………............................41

3.3.1.d Correct Report Binding Process...................................................43

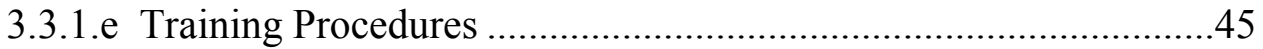

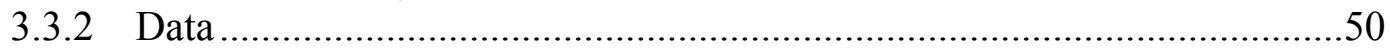

3.3.2.a Nuances due to subject background ............................................50

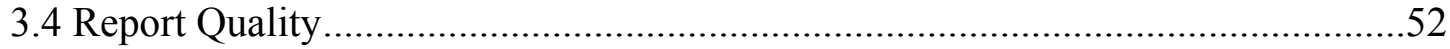

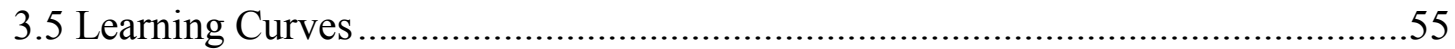

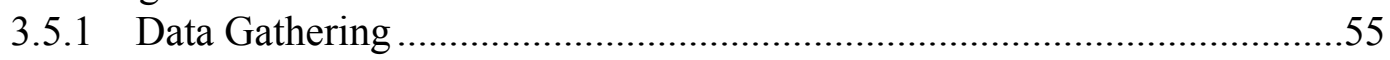

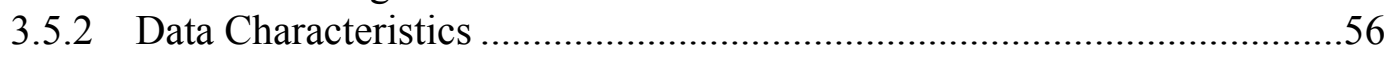


3.5.3 Fitting the data to Learning Curves......................................................59

3.5.4 Overall leaning curve for one training type ..............................................62

3.5.5 Comparing the learning curves of different training types ........................66

IV. Chapter 4: Develop a ROI model using learning curves as a basis..................70

4.1 Chapter Overview ………………..............................................................

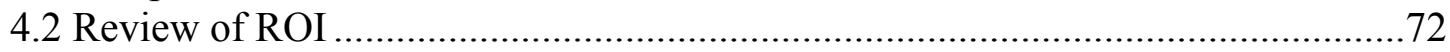

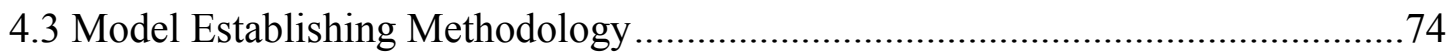

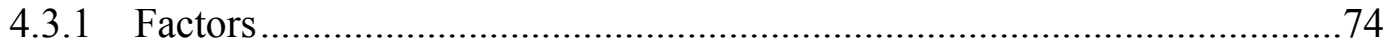

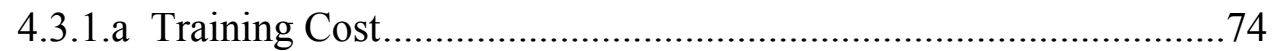

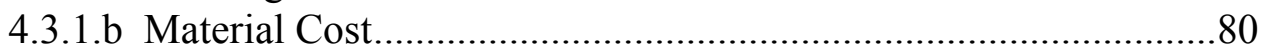

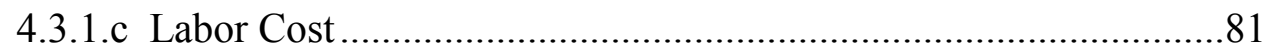

4.3.1.d Quality Cost ............................................................................83

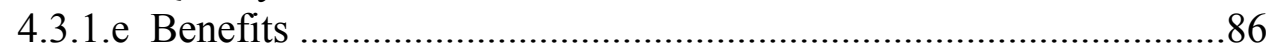

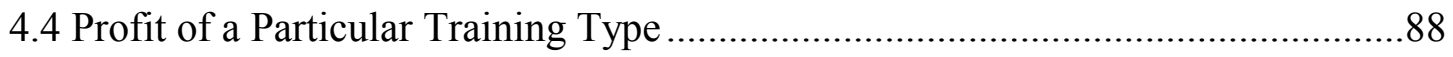

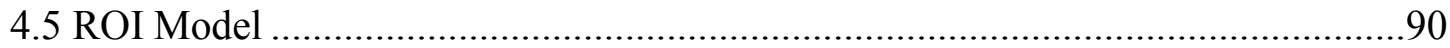

V. Chapter 5: Estimate the ROI for the different break-in strategies.................94

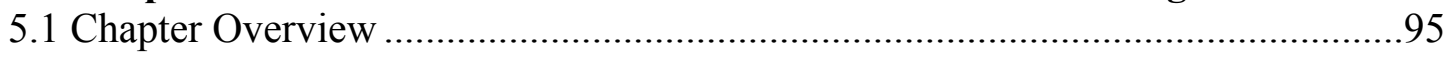

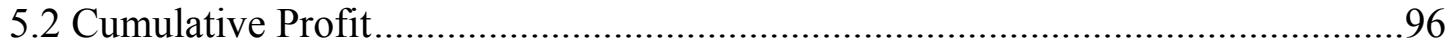

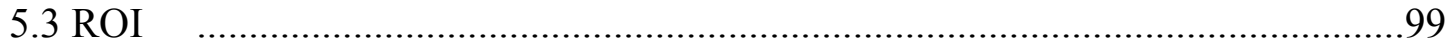

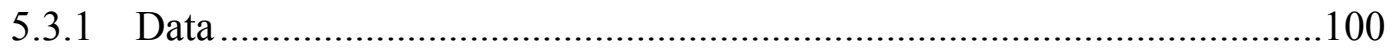

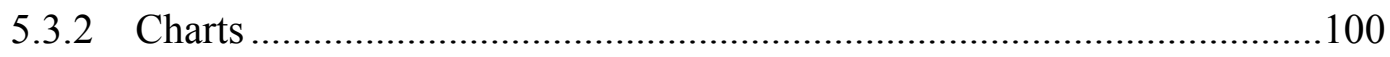

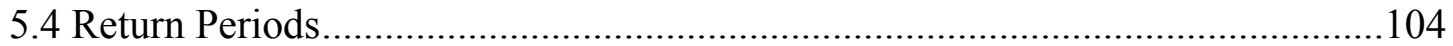

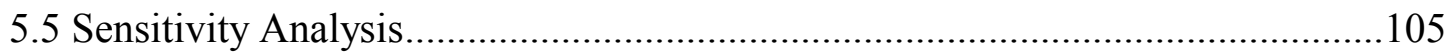

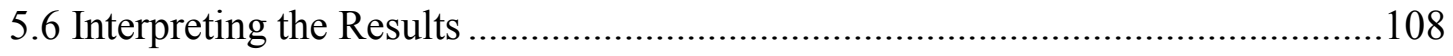

VI. Chapter 6: Show how the model can be used on actual jobs.........................111

VII. Suggestions for further research ...........................................................................115

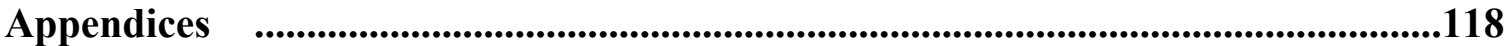

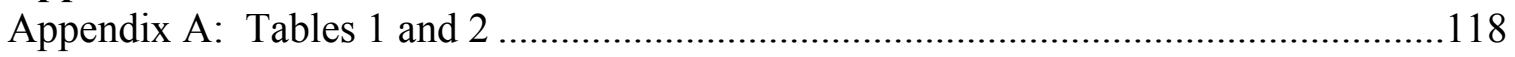

Appendix B: Data from each training type ………………..........................................121

Appendix C: Data with no defects and individual learning curves.................................126

Appendix D: Data and charts for projected times from learning curves and

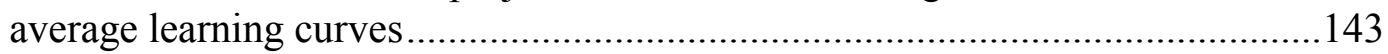

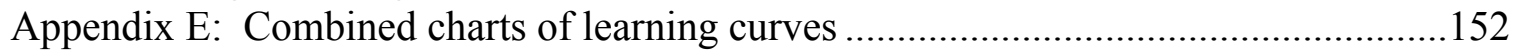

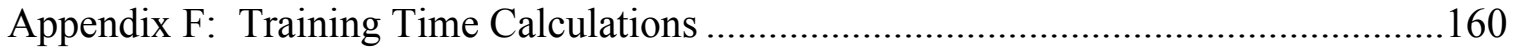

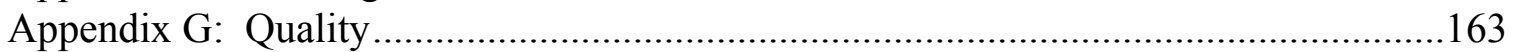

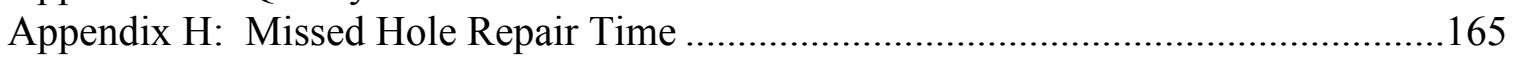

Appendix I: Factors in Cumulative Profit and ROI Equations ........................................167

Appendix J: Cumulative Costs, Cumulative Benefits, and Profit Calculations...............169

Appendix K: Benefit vs. Cost Charts and Profit Charts ................................................178

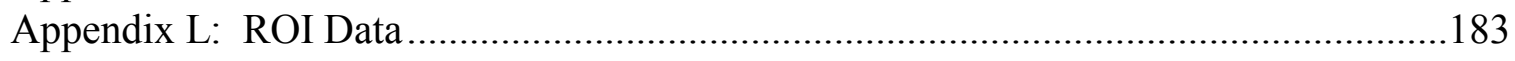




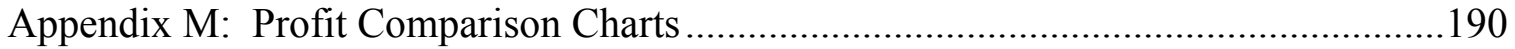

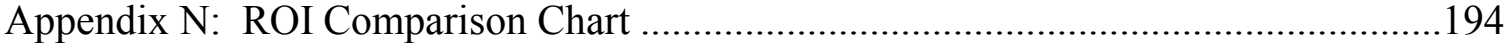

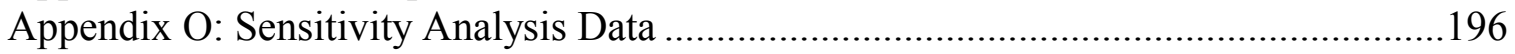

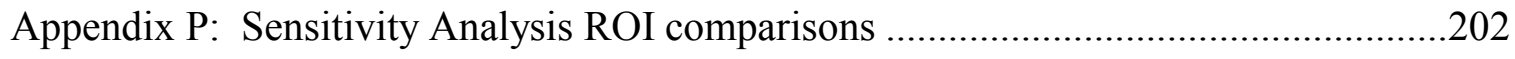

Works Cited 


\section{LIST OF CHARTS, FIGURES, AND TABLES}

\section{Chapter 1}

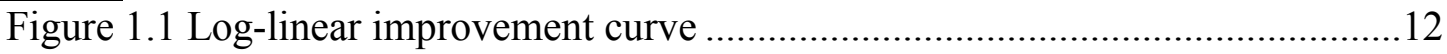

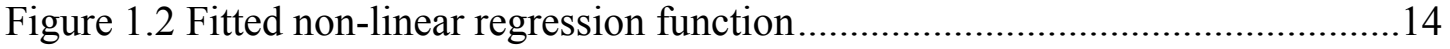

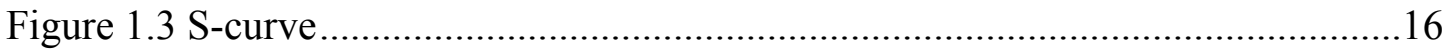

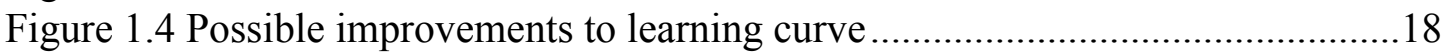

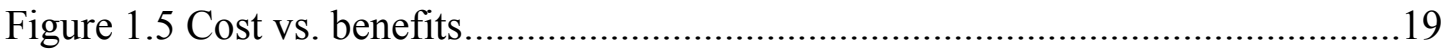

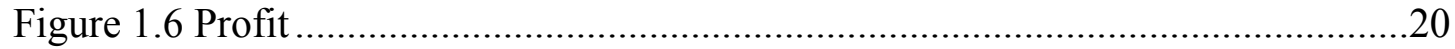

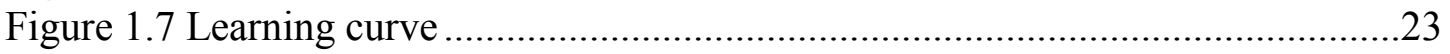

\section{Chapter 3}

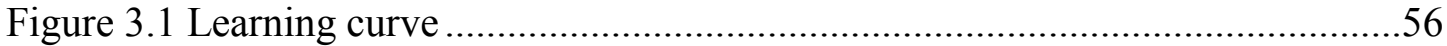

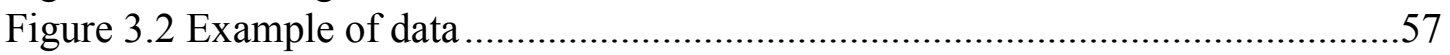

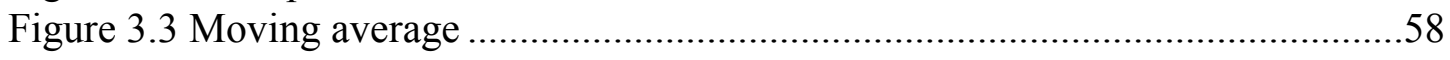

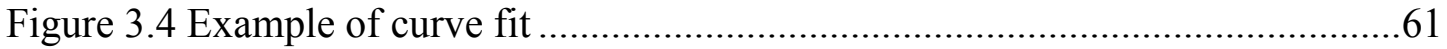

Table 3.5 Fitted learning curves for each individual training average of each type ....62

Figure 3.6 Observe and do: Projected times from learning curves and average learning

Curve. .63

Figure 3.7 Sample of individual learning curves of manual training type ..................65

Figure 3.8 Longer charts of overall learning curves ...............................................67

Figure 3.9 Overall learning curves of the different training types .............................68

\section{Chapter 4}

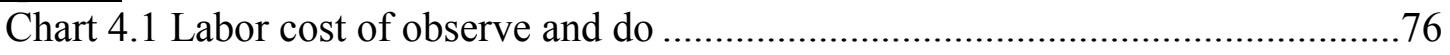

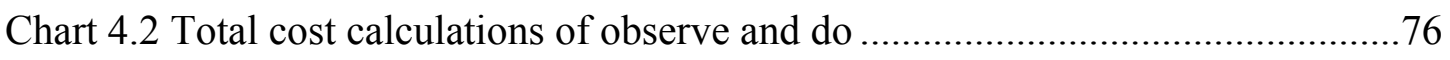

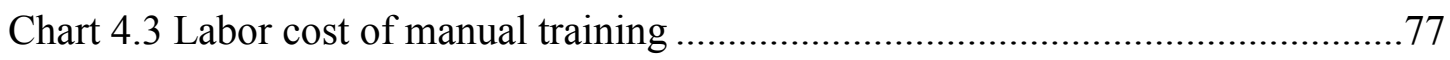

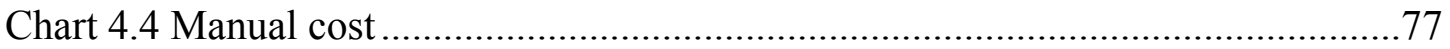

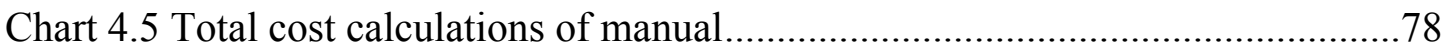

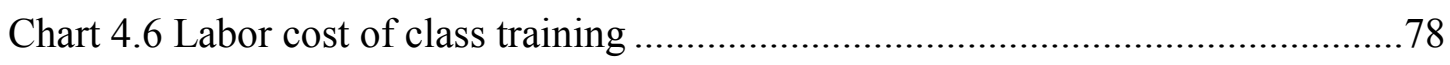

Chart 4.7 Material cost (for materials used in class)..............................................79

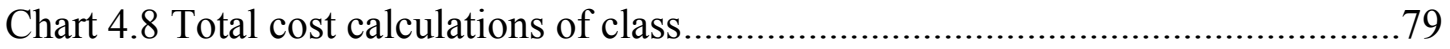

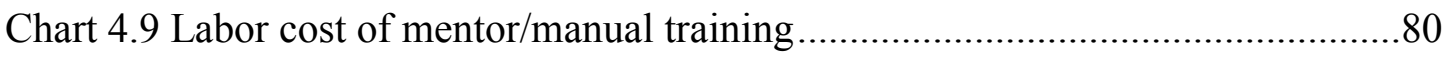

Chart 4.10 Total cost calculations of mentor/manual .............................................. 81

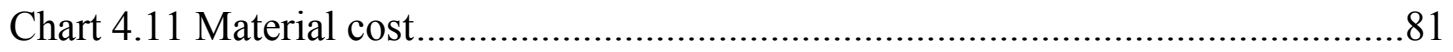

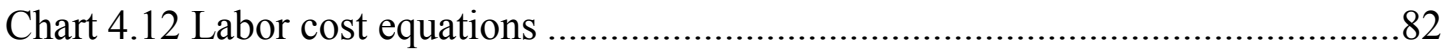

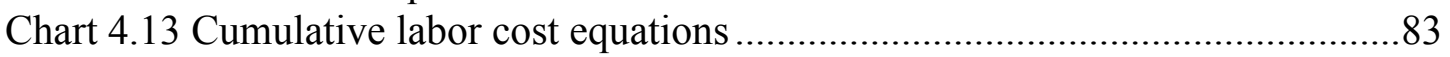

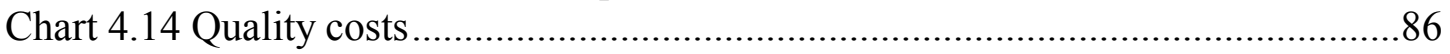

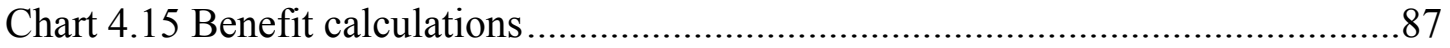

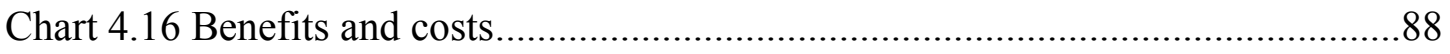

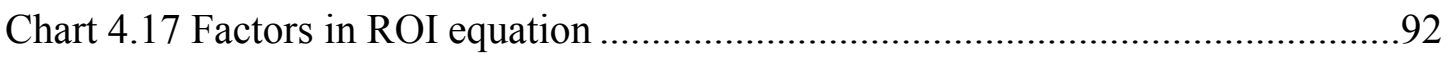

\section{Chapter 5}

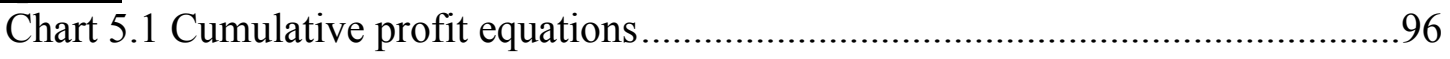

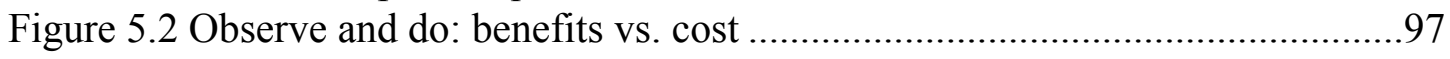




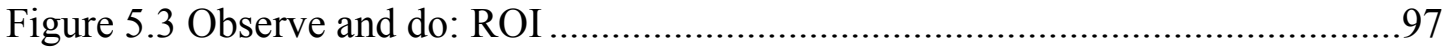

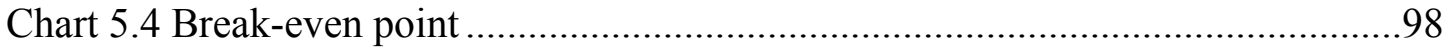

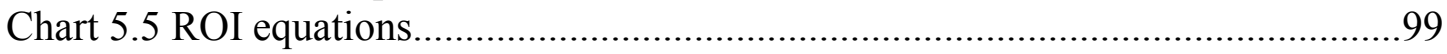

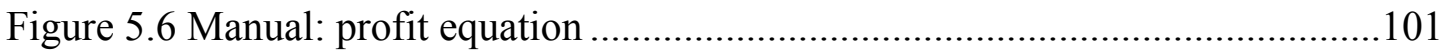

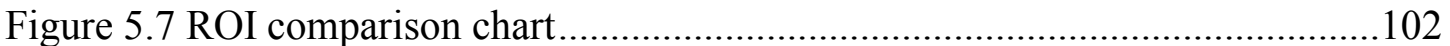

Chart 5.8 Break-even points for ROI equations.....................................................102

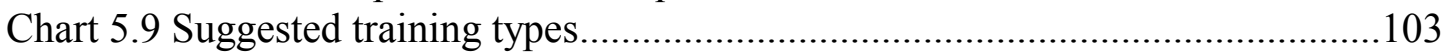

Chart 5.10 ROI of each return period according to training type...............................104

Table 5.11 Sensitivity analysis: Break-even point calculations..................................106 


\section{CHAPTER 1:}

\section{BACKGROUND AND RESEARCH METHODOLOGY}




\subsection{INTRODUCTION}

Employee training programs are becoming an important tool for enhancing productivity. Many companies have investments in skill training for new employees.

Studies have shown that employee training is beneficial to both employees and

employers, but training budgets are often reduced when economic conditions are difficult. Today, many Human Resources departments are challenged to show the return from their employee training by providing company leaders with estimates of money saved due to training. Of particular concern is money invested in training employees to do their jobs. During this break-even period, the employee is receiving wages but not producing product at a high level of performance. Determination of the return on investment from break-even training must be accurate and consistent. This thesis will develop a methodology for assessing the financial impact of different methods of developing work skills during the break-even time period. 


\subsection{BACKGROUND}

Many companies realize that employee training contributes to the success of their business. But a key question these companies may have is: how much does training contribute to the skills the employee needs? Another question may be: how much training should a company provide for a maximum rate of return on their investment in skills? The answers to these questions are extremely important. Company executives want to include training as part of their corporate strategies. But before implementing a training program, they should be aware of the program's cost and return in order to effectively allocate training resources.

Strategies successful for many manufacturers are innovative break-in training techniques, more advanced than the traditional "observe and do" training process. Breakin training is the initial training an employee receives when he or she is assigned to a new job. There are many break-in training strategies such as training manuals, observe-and-do practices, mentoring, etc. The break-in training requires an initial investment for employee education, but may help the company in achieving higher productivity gains and financial rewards that would have been found with limited break-in training. The question that needs to be asked is: How do you assess the best break-in training strategy for a specific task?

A methodology for determining the answer to the question posed above can be developed based on learning curves and a return on investment model. Learning curves need to be developed for different break-in training strategies. These curves can then be used to calculate the return on investment in training strategies. From the differences in the learning curves and return on investment calculations, the best break-in training strategy can be determined for a specific task. 


\subsection{LITERATURE REVIEW}

\subsubsection{Importance of training}

Training programs are used in business around the world to improve the skills of their workforce. Types of training include on-the-job training, company conducted classroom training sessions, Internet-based training, and even degree-training (college, high school, and vocational). All play a role in training employees in the skills necessary for today's work force. While the value of training is recognized, there are numerous unanswered questions about training. What type of training method(s) should a company use to obtain the best possible financial returns? How long should the training be? What is the best format for training? These are the important questions that need to be answered. Unfortunately, there is no universal best answer. Therefore a methodology for assessing a specific situation is needed.

Training needs to be viewed as an investment rather than a cost, as traditional accounting systems currently do. Calculating the ROI of training proves that there are financial benefits that come from training. The benefits, for the most part, exceed the costs but they are hard to measure. Mark E. Van Buren makes this point in "Training Goes to the Bottom Line." Looking at the total stockholder return, (TSR), of 575 USbased, publicly traded firms shows that an increase of $\$ 680$ in an firm's average peremployee training expenditure generates on the average a $6 \%$ improvement in TSR in the following year after accounting for other factors of influence. He goes on to state that "firms that spend more than average on training have $86 \%$ higher TSRs than firms that spend less than average, these firms have TSRs that are $45 \%$ higher than the market average" the year following the training. Studies like these empirically validate that the investment in training is more than worth the effort. ${ }^{1}$

\footnotetext{
${ }^{1}$ Mark E. Van Buren, “Training Goes to the Bottom Line," Manufacturing Engineering, January 2001, 134.
} 
Motorola determined that for every dollar invested in a training program, $\$ 8.40$ was generated in returns. The benefit-to-cost ratio for statistical processes control training was 30 to 1 . (The benefit to cost ratio is the ratio of the benefits of an investment over the cost of the investment for a determined time period). This was taken from "Best Practices, Best Plants” in Manufacturing Engineering's April 1999 issue. ${ }^{2}$

The above mentioned article focuses on the point that training is one of the most important objectives for top manufacturing companies. While companies report that they are spending 20 hours per employee per year or less on training, the "fully world class" companies tend to spend more than 40 hours per employee per year. Companies reported training amounts over 80 hours/year comparatively also had lower scrap costs, lower cycle times, lower customer lead times, higher first-pass yield on finished product, and higher inventory turn rates. ${ }^{3}$ While these statistics are impressive, it is important to note that a successful company cannot contribute all their success to training. Companies described in this article are also proficient in total quality management, use technology to enhance their business, and maintain open relationships with their customers. Yet, training is one of the front running strategies for many world-class companies and account for the difference in median revenue per employee. While companies with over 20 hours of training per employee per year reported a median revenue of $\$ 200,000$ per employee, companies with less than 20 hours of training per employee per year report a median revenue of $\$ 140,000$ per employee. ${ }^{4}$ If top companies attribute their competitive edge to training, other companies should follow suit with training programs designed to fit their employee's needs. But training for training's sake isn't enough. Training needs to address skills where there is an attractive return on investment.

The National Association of Manufacturers encourages companies to set 3\% of the payroll as the target training budget. Companies have been increasing the amount of their payroll spent on training from an average of less than .5\% in 1991 concludes a study

\footnotetext{
2 Jean V. Owen, "Best Practices, Best Plants," Manufacturing Engineering, April 1999, 66.

3 Ibid., 68-69.

${ }^{4}$ Ibid., 69.
} 
by Grant Thornton. In 1999, 30\% of the same group studied spent 2-3\% of payroll on training exempt employees, $6 \%$ spent $4-5 \%$, and $3 \%$ spent over $5 \%{ }^{5}$

Some companies report problems with employee retention. High employee turnover rates may tempt executives to think that employee training will go to waste because after training is completed, the employee may not stay at the company long enough for the business to get their anticipated return on investment. There is also a fear that trained employees may tend to leave the company and take their learned knowledge to the company's competitors. However, it can also be reasoned that employee training programs increase employee retention rates since training instills a commitment to company loyalty. In fact, in some instances not knowing how to do the job can increase employee turnover. Training can prevent this turnover by improving the skill set of each employee and boosting company morale. To illustrate this, $43 \%$ of the "supercompetitor" companies described in "Best Practices, Best Plants" who invest in training report a labor turnover rates under $3 \%$ annually. ${ }^{6}$

Training has also become a focus for manufacturing because of demographics. The skilled workforce is aging and interest in shop and mechanical arts classes at the high school level is decreasing. According to one study, $15 \%$ of 1982 high school graduates had taken three of more trade or industry related courses. The number dropped to less than $9 \%$ by $1994 .^{7}$ To account for these incoming skill deficiencies, some companies have integrated unique programs into their training regimen. The article, "Need Skilled Workers? Grow Your Own" describes an apprenticeship program tied in with an area high school. Komet of America Inc., the sponsoring company, funds high school programs for the development skilled employees out of high school. Program participants receive high school technical training, internship experience, and an out-ofschool job with pay starting at $\$ 10-\$ 17$ per hour. The program establishes a stream of skilled and experienced employees entering the company after high school. However, the

\footnotetext{
${ }^{5}$ Ibid., 65 .

${ }^{6}$ Ibid., 69.

${ }^{7}$ Richard L. Dunn, "Dealing with the Skills Problem," Plant Engineering, July 1999, 10.
} 
cost of the program is great, totaling $\$ 125,000$ per apprentice for wages, tuition, and books. The return on investment of the training is not explicitly stated. ${ }^{8}$

\subsubsection{Need for ROI}

Training investments need to have return on investment targets just as capital investments. Many companies realize that investing in a training program will benefit their company financially. Gains in productivity, quality, and customer service are recognizable assets of an effective training program. However, company executives need proof that these training programs are in fact producing these improvements, since other factors such as new technologies have significant influence. Return on investment is one way to validate training. When key decision makers notice that training is giving them the benefits that they need to be competitive, they will tend to put more emphasis, and more money in that area. A return on investment calculation is imperative to attribute savings to training.

In her article, "Why ROI?", Sabrina Hicks highlights other reasons ROI is in the spotlight for many companies. Programs for total quality management and continuous process improvement require many measures, and money spent on training is one of them. Since more money is being spent on training, there is more reason to show that the training is adding value to the organization. Yet another reason is that many training departments are going through the process of reengineering so that the training is better linked to business needs and enhancing efficiencies. Furthermore, top management pressures HR departments to realize their ROI to continue to receive their share of company funds. ${ }^{9}$ ROI's use will likely increase in the future, and these reasons give grounds for a standard method to calculate training's ROI.

However, executive level management should be involved in making key decisions in the training process. They must identify areas in the company where training

8 “Need Skilled Workers? Grow Your Own," Manufacturing Engineering, July 1998, 28-30. 
may be required for productivity improvement and/or general company knowledge. They must identify the amount of training that is needed and the amount of money that is to be spent on training. They should know what type of training to give their employees. Knowing the ROI of training can help steer the company training program to optimum performance levels by comparative analysis of different types of training.

\section{$\underline{\text { 1.3.3 Methods for determining ROI }}$}

There are many methods developed for determining the return on investment of training. Jack J. Phillips is a pioneer in this field and has written many books and articles on the topic. His methods are directed to human resource managers who may often have to prove the worth of their training programs.

Jack Phillips adds on to a training-evaluation model developed by Donald Kirkpatrick. The Kirkpatrick model evaluates employee-training on four different levels. Jack Phillips adds a fifth level, the determination of return on investment (ROI). The Five-Level Evaluation Model is shown in Table 1 in Appendix A. Phillips states that if measurements aren't taken at each level, it is difficult to show any improvement attributable to the training. ${ }^{10}$ In order to prove that ROI effects are from the training, the methodology shall include testing at the five levels.

Jack Phillips describes many options for determining ROI of training. These approaches are described in Table 2 of Appendix A. Mr. Phillips encourages that generally two approaches are better than one. From these options, the best method(s) should be selected to calculate the ROI of training for a particular manufacturing

\footnotetext{
9 Sabrina Hicks, "Why ROI?," Training and Development v 54 n 7 (July 2000): 59-60.

${ }^{10}$ Jack J. Phillips, “The Search for Best Practices," Training and Development v 50 n 2 (February 1995): $42-48$.
} 
company. They isolate business improvements due to training, which aid in the calculation of ROI. ${ }^{11}$

Mr. Phillips continues to describe calculations for determining return on investment. In his article, "How Much is the Training Worth?", he describes a process which calculates the ROI due to training. After isolating the effects of training, the monetary benefits of training must be calculated. Then, those monetary values will be compared with the costs of the training. There are two types of data, hard data and soft data, which can be used to determine the worth of the improvement. Hard data are traditional performance measures such as output, quality, time, and cost. Soft data are more subjective and are typically difficult to measure. Management tend to rely on hard data for the measurement of performance. Jack Phillips suggests the following process for converting data into monetary values.

1. Focus on a single unit

2. Determine a value for each unit

3. Calculate the change in performance

4. Obtain an annual amount

5. Determine the annual value

Mr. Phillips suggests identifying a certain performance measure, determining how much is saved or earned for a one unit improvement on that performance measure. After training, compare the difference in the performance measure before and after training. Spread that improvement over a year. In the case of training, improvement could be gradual and not necessarily constant as in a learning curve. The return on investment is then calculated from subtracting the training program cost from the net annual value of improvement. $^{12}$

An example of the process would be converting output to contribution. The organization can monitor performance output and the value of the increased output can be

\footnotetext{
${ }^{11}$ Jack J. Phillips, "Was it the Training?," Training and Development v 50 n 3 (March 1996): 28-33.

${ }^{12}$ Jack J. Phillips, "How Much is the Training Worth?," Training and Development v $50 \mathrm{n} 4$ (April 1996): 20-25.
} 
determined from accounting or operational records. Other methods to convert data to monetary values include: calculating the cost of quality, converting employees' time, using historic costs, using internal and external experts, using data from external studies, using estimates from participants, supervisors, senior mangers, and/or HR. ${ }^{13}$

In order to calculate the return on investment of a training program, there needs to be a training program specialized to the needs of the organization. Amy Purcell describes a situation method to tie in training with the improvement goals of the organization in her article, "20/20 ROI". She suggests asking "where is the pain?", or to pinpoint what aspect of the business is needs improvement, needs advancement, or is causing detriment. Examples of this detriment are lost sales, deficiencies, etc. Areas can be identified where training will make the company more successful such as achieving business goals. Then, training should be developed to target these improvements along with a method to test the effectiveness of the training. Ms. Purcell also suggests starting with a pilot experiment and isolating the performance improvements linked to training. Then the cost-benefit ratio, the benefit divided by the cost, can be calculated to represent the ROI. ${ }^{14}$

Though the need for return on investment calculations are apparent, many companies have yet to analyze the worth of their employee development programs, according to an article by Ann P. Bartel. A review of her article in the Monthly Labor Review states "The fact remains that few companies calculate the return on investment in employee training. And most that do...use fairly faulty methodologies that preclude relying on their results." Therefore there is a under-investment in employee training because the perceived return on investment is lower that actual. Bartel believes a system to determine the ROI of employee training will help solve firms' under-investment problems. $^{15}$

\footnotetext{
13 Ibid.

${ }^{14}$ Amy Purcell, "20/20 ROI," Training and Development v 54 n 7 (July 2000): 28-34.

15 "Precis," Monthly Labor Review 123 n 8 (August 2000): 40.
} 


\subsubsection{Learning Curve}

One way to isolate the effect of training on employees is to compare the learning curve for employees with training to a learning curve for employees without training. Traditionally, as an employee becomes more experienced with a particular task, they take less time to complete the task. The learning curve is a function that presents this phenomenon. A learning curve shows that the time spent to produce a unit decreases over time, therefore representing that the worker is learning the task. The curve follows a logarithmic function and begins to level off as experience increases. Another variation of the learning curve shows that as time increases, the production rate from an employee increases at a rate defined by the learning rate. The production rate increases with experience but tapers off eventually. These two variations of the learning curve are described below, in their respective order.

The first variation of the learning curve follows the equation:

$$
Y=A^{*} X^{N}
$$

Where:

$Y=$ time (or cost) to produce the xth unit

$A=$ time (or cost) required to do the first unit

$X=$ number of units

$N=\ln (I) / \ln (2)$

$I=$ learning rate

The learning curves of this type are often referred to as the log-linear learning curve model or constant percentage model. The learning rate is a percentage determined by statistical analysis of situations in which a learning curve applies. Generally, the higher the learning rate percentage, the slower the learning. One minus the learning rate is the improvement rate. The higher the improvement rate, the faster the learning. As an 
example, in the chemical industry the average learning rate determined from a comprehensive survey of over 200 products was $80 \%{ }^{16}$

A sample log-linear improvement learning curve of this form is shown in Figure 1. In this learning curve, the learning rate is $80 \%$ (improvement rate $20 \%$ ) and the time for the first unit is 616.5 hours. The learning curve represents the relationship between the number of units produced (plotted on the abscissa), and the time to produce the Xth unit (plotted on the ordinate). As figure 1.1 shows, the time to produce a unit decreases quickly at first, but the rate of decrease becomes less and less. In a way, the time to produce a product gets closer and closer to optimal as learning continues. (There cannot be a point where time to produce is zero.) The curve eventually follows a asymptote defined by the equation.

\section{Figure 1.1}

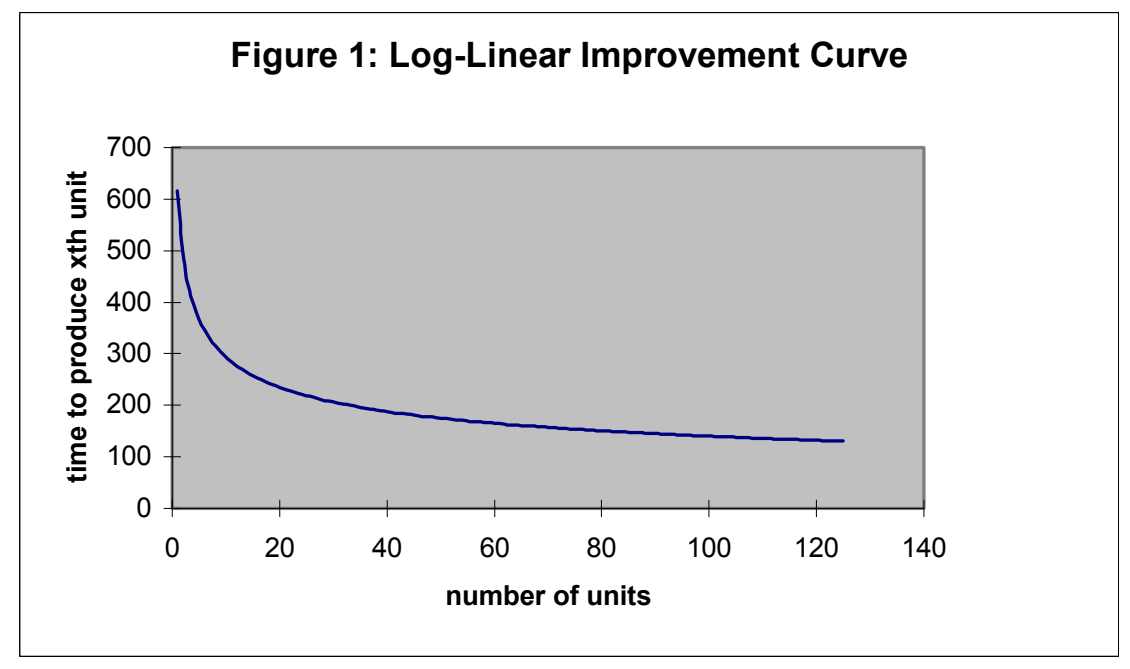

The second variation of the learning curve can be visually represented by a exponential nonlinear regression model. This model is good for fitting data, not for determining future values of the response variable. The general model is as follows:

\footnotetext{
${ }^{16}$ Gavin Sinclair, "Making the Learning Curve Work for You," Chemical Engineering Progress v $96 \mathrm{n} 2$
} 


$$
Y_{1}=G_{0}+G_{1} * \exp \left(G_{2} * T\right)+\text { error }
$$

Where,

$Y_{1}=$ relative production efficiency (units/time)

$T=$ time

$G_{0}=$ represents the upper asymptote (maximum growth value or maximum production efficiency)

$G_{1}=$ model parameter

$G_{2}=$ model parameter

This learning curve will be used to visually represent the improvement in performance from learning over time. The exact parameter values will be calculated using the method of least squares and direct numerical search (aka. the Gauss-Newton Method). Or parameter values can be determined through derivation of the Improvement Curve (first variation of the learning curve) described earlier. Figure 1.2 shows an example of a learning curve using the exponential non-linear regression model. The model is represented by the equation:

$$
Y_{1}=.9683-.5524 * \exp (-.1348 * T)^{17}
$$

(February 2000): 93

${ }^{17}$ John Neter and others, eds., Applied Linear Regression Models (The McGraw-Hill Companies, Inc., 1996), 555-559. 


\section{Figure 1.2}

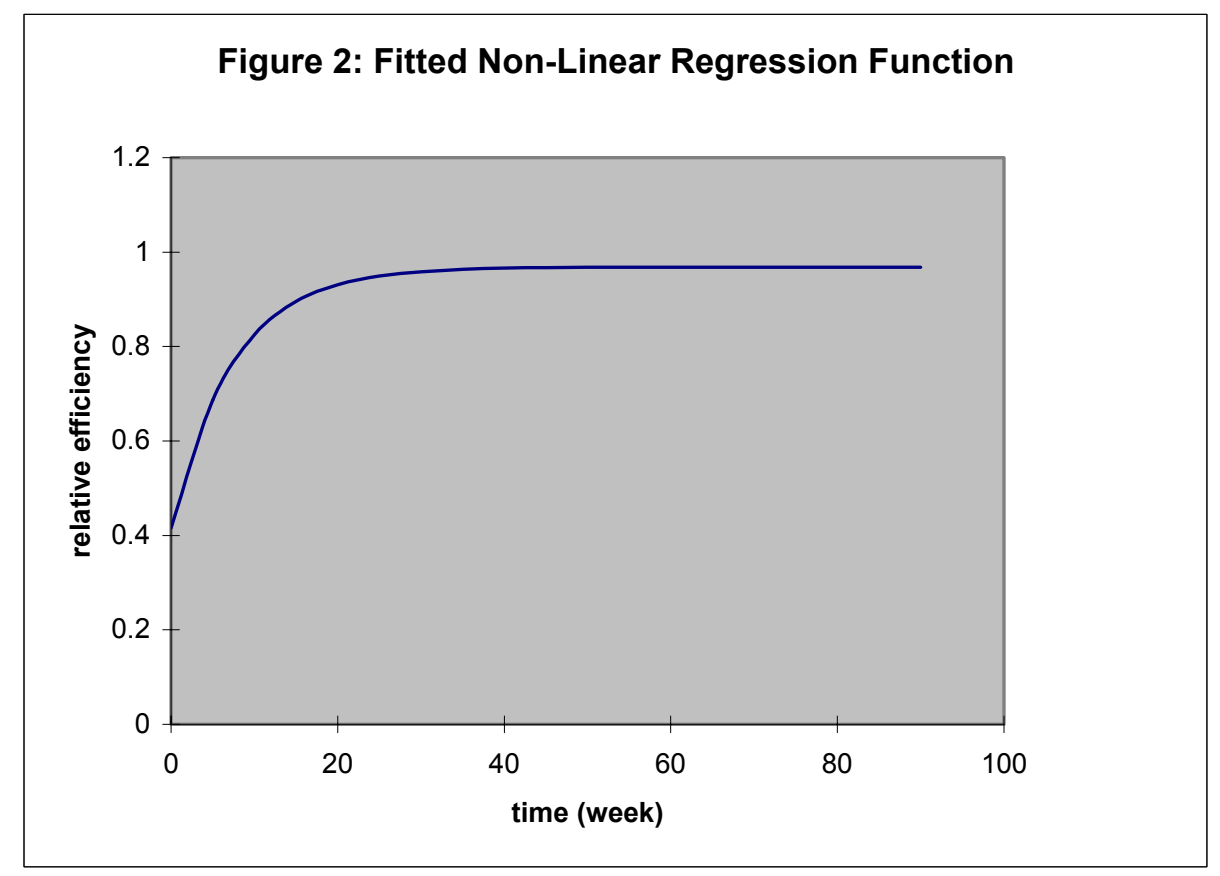

In addition to these two versions of the learning curve, there are many other variations. The Stanford-B learning curve variation adds a constant, or B-factor, to the log-linear model, or first variation discussed above. The constant is added to the number of units $(X)$ to address the assumptions that employees have some experience prior to the first unit of production. The Stanford-B model is described by the following equation:

$$
Y=A^{*}(X+B)^{N}
$$

Where,

$Y=$ direct man hours

$A=$ time (or cost) to produce the $1^{\text {st }}$ unit (a constant)

$N=$ the slope of the asymptote $\log ($ improvement $\%) / \log (2)$

$B=$ the number of units theoretically produced prior to the first unit acceptance (a constant) 
The Stanford B model prevents the initial cost of producing a unit from being unrealistically high. ${ }^{18}$

As the Stanford-B model prevents unrealistic initial costs, the "DeJong Learning Formula with Incompressibility Factor", causes the learning curve (log-linear model), to level off after a certain amount of improvement. In a realistic situation, an employee will improve performance, but begin to taper-off as he or she reaches the optimal efficiency levels. At these levels, it is extremely hard and sometimes impossible for an employee to produce the unit in less time. DeJongs's Formula takes this into account in the following equation by incorporating an incompressibility factor, $M$ :

$$
M C=A^{*}\left[M+\frac{(1+M)}{\left(X^{\wedge} N\right)}\right]
$$

Where,

$M C=$ the marginal time for the $X t h$ unit,

$A$ and $N$ are parameters analogous to the power function, and

$M$ is the factor of incompressibility. ${ }^{19}$

The Stanford-B and the DeJong Model curves can be combined to represent the learning curve that takes the shape of an "S." An example of a type of S-curve is shown in figure 1.3. The S-curve takes into account a development-phase in the learning process, where the financial returns or number of unit produced by an employee is initially low. This occurs at the beginning of employment and represents the time that is needed for the employee to become acquainted with the process. This time also represents the cost penalties from time compression that occurs during new product introduction. ${ }^{20}$ The learning curve in the model starts after this phase has passed. The

\footnotetext{
${ }^{18}$ Ahmed Belkaoui, The Learning Curve. (Westport, CT: Quorum Books, 1986), 10-11.

${ }^{19}$ Ibid., 11-12.
} 
other end of the s-curve tapers off to an optimal financial return level or production level, giving the model the s-shape.

\section{Figure 1.3}

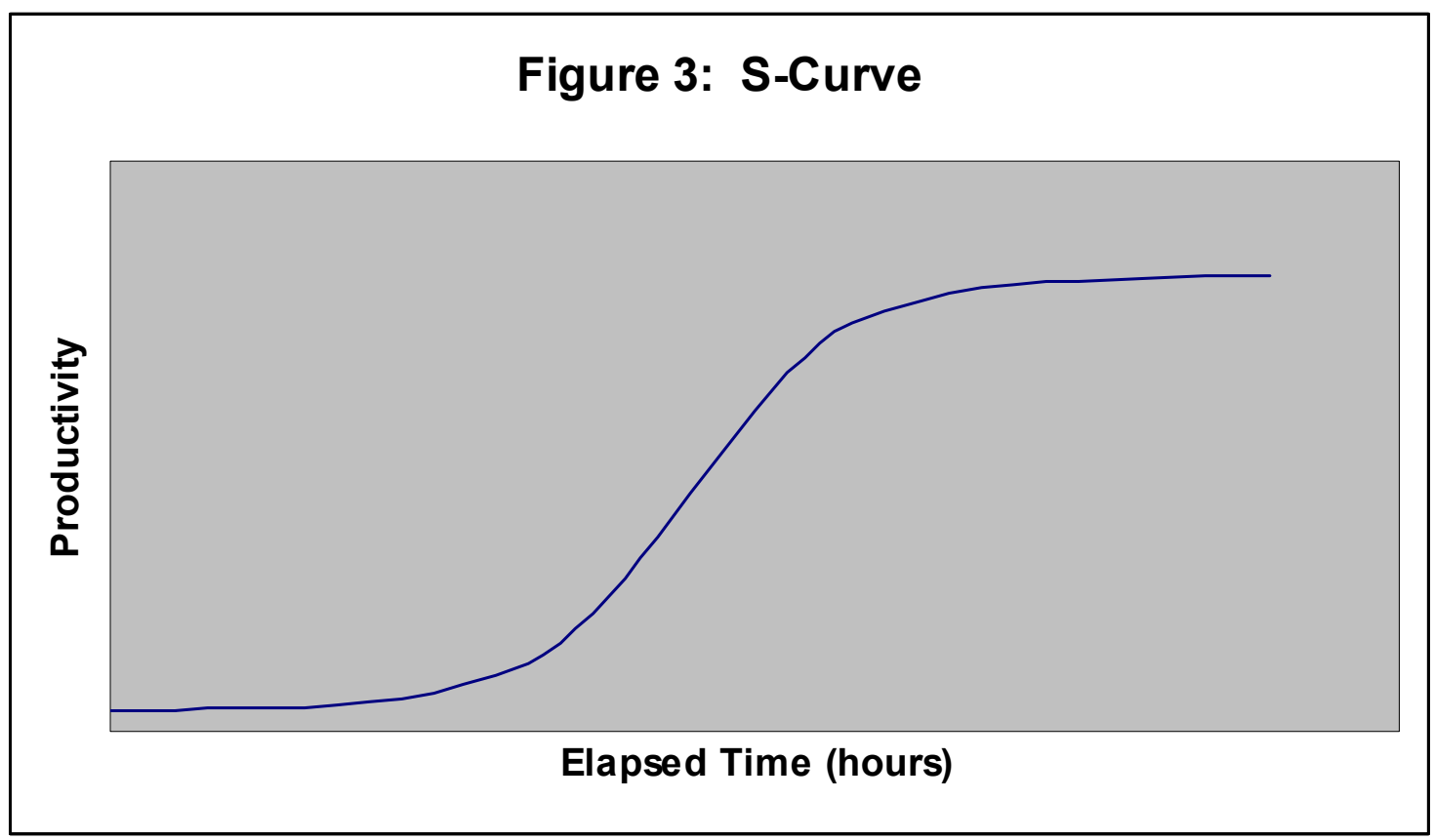

One type of S-curve combines the Stanford-B and DeJong Model in a way such that the Stanford-B fits the early part of the learning curve and the DeJong fits the latter part. The following equation is yielded:

$$
M C=A *\left[1+(1-M) *(X+B)^{N}\right]
$$

Where,

$M C=$ the marginal time for the Xth unit

$A=$ time (or cost) to produce the $1^{\text {st }}$ unit (a constant)

$M=$ the factor of incompressibility

$B=$ the number of units theoretically produced prior to the first unit acceptance (a constant)

${ }^{20}$ John P. Tanner, "The Learning Curve; A Line on Labor Cost,” Production Engineering 32 (May 1985): 
$N=$ the slope of the asymptote $=(\log ($ improvement $\%) / \log (2))$

Please note that the S-curve described in the above equation does not correspond to the curve in Figure $3 .^{21}$

The article, "Risks Associated with Learning Curve Estimates," warns that the parameters of the learning curve should be accurate. The article shows that slight variations in the learning rate can drastically change the values predicted by the curve. Analysis of the learning curve should be accurate and provide consistent results in order to accurately determine a Return on Investment. ${ }^{22}$

In IEEE Spectrum's December 1995 “technically speaking” column, readers expressed the case that the learning curve can be interpreted differently by individuals, depending on how the curve is configured. However a psychologically effective way of presenting the curve is by showing the curve with a positive slope. ${ }^{23}$

After the learning curve is determined, the curve can be utilized as a tool in cost reduction as described in a February 2000 article in "Chemical Engineering Progress by Gavin Sinclair. The article states a company can enhance their learning curve benefits by attention, priorities, and effort. ${ }^{24}$

Many articles validate that training will be reflected in the learning curve, meaning that break-in training can improve the productivity of an organization. Visually, an improvement in the training process might steepen the slope of the learning curve after the growth phase and/or raise the height in which the learning curve tapers off. Examples of improvements to the learning curve are shown in figure 1.4.

$72-78$.

${ }^{21}$ Belkaoui, 12-14.

${ }^{22}$ Byron J. Finch and Richard L. Luebbe, "Risk Associated with Learning Curve Estimates," Production and Inventory Management Journal v 32 n 3 (1991): 73-76.

${ }^{23}$ Kevin Self, "Learning Curve Boomerangs," IEEE Spectrum v 32 (December 1995): 17.

${ }^{24}$ Sinclair, 95-96. 
Figure 1.4

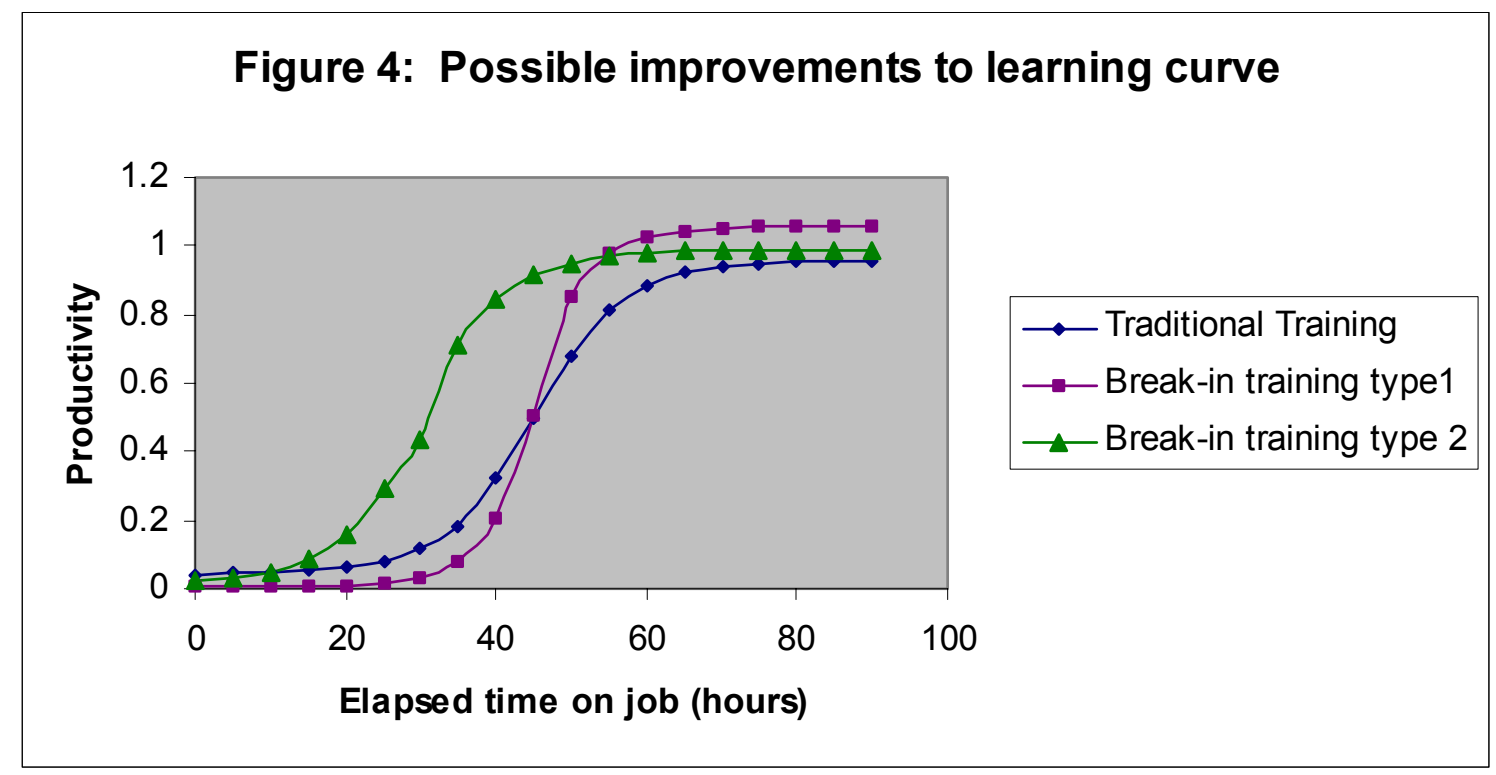

Break-in training type 1 has a longer development phase, but grows at a faster rate than the traditional training and matures at a higher productivity. Break-in training type 2 has a short development phase, grows rapidly and matures at a higher productivity than the traditional training.

Information Week's “Mentoring Speeds the Learning Curve" discusses the effectiveness of mentoring, an integral part of the training process, on the learning curve for IT workers. Mentoring benefits both companies and individuals. The employees benefit because they are able to learn quicker, and they learn skills early on in their career. The IT company benefits by shorter training periods for employees, and even though the mentor may lose regular work-time, that time is paid-back in the long run. The article also points out that many good companies have mentoring programs. ${ }^{25}$

\footnotetext{
${ }^{25}$ Teri Robinson, “Mentoring Speeds the Learning Curve,” Information Week, April 9, 2001, 77,80.
} 


\subsubsection{Determining ROI from the learning curve.}

The impact of the break-in training on an organization may be shown in a returnon-investment model. However, no research exists for a ROI model for break-in training. Therefore, this thesis will provide that information by testing different training types and developing ROI models from comparing the cumulative profit of one to another.

These models will be developed in order to determine the training ROI from a learning curve. Using time to complete task as a performance measure, that amount will be graphed verses report number. Then, the learning curves for the different types of break-in training and the traditional type of break-in training can be developed. The cumulative labor can be calculated by adding the labor time of each task from the first to the current task. These cumulative labor hours can be multiplied by a cost factor, such as labor rate or direct cost per labor hour. The cumulative of this amount is shown in the figure 1.5 as "cumulative cost".

\section{Figure 1.5}

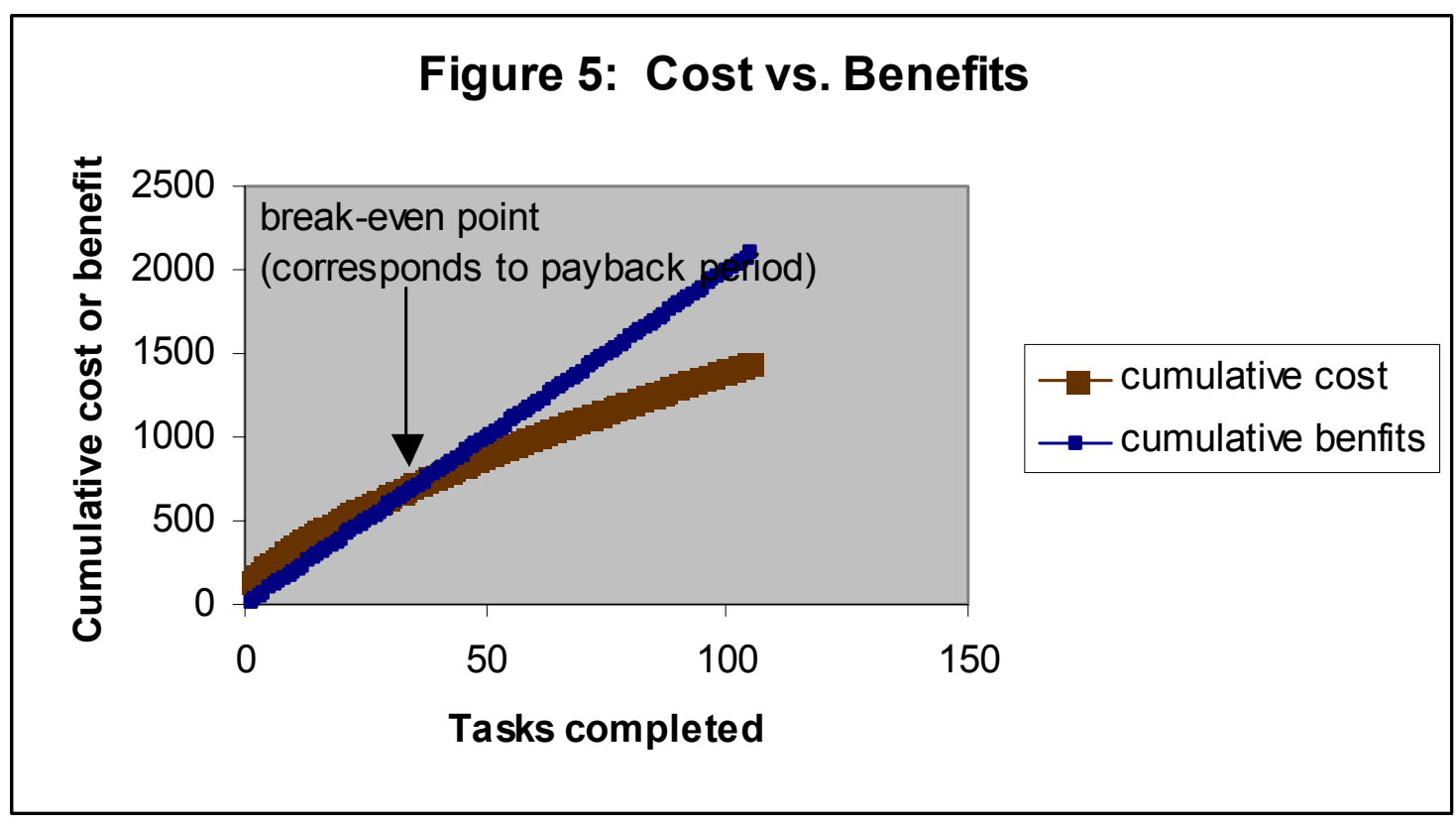


The cumulative benefits can be calculated by multiplying the financial gain from one item produced time the total items produced. Figure 1.5 graphs this cumulative amount. Corresponding to intersection of the two lines is the payback period of training for one particular training type. This payback period is when the organization breaks even on their investment in training. The difference between the two lines after the break-even point is the profit, or cumulative profit. Comparing the payback periods and profit of a break-in training investment vs. traditional "observe-and-do" training will show the benefits of the break-in training.

Figure 1.6 describes the profit from the investment in training. Initially, there will be negative profit since the organization made an investment. The payback period is where the profit line intersects the $\mathrm{x}$-axis. Later the profits from the training can be noticed.

\section{Figure 1.6}

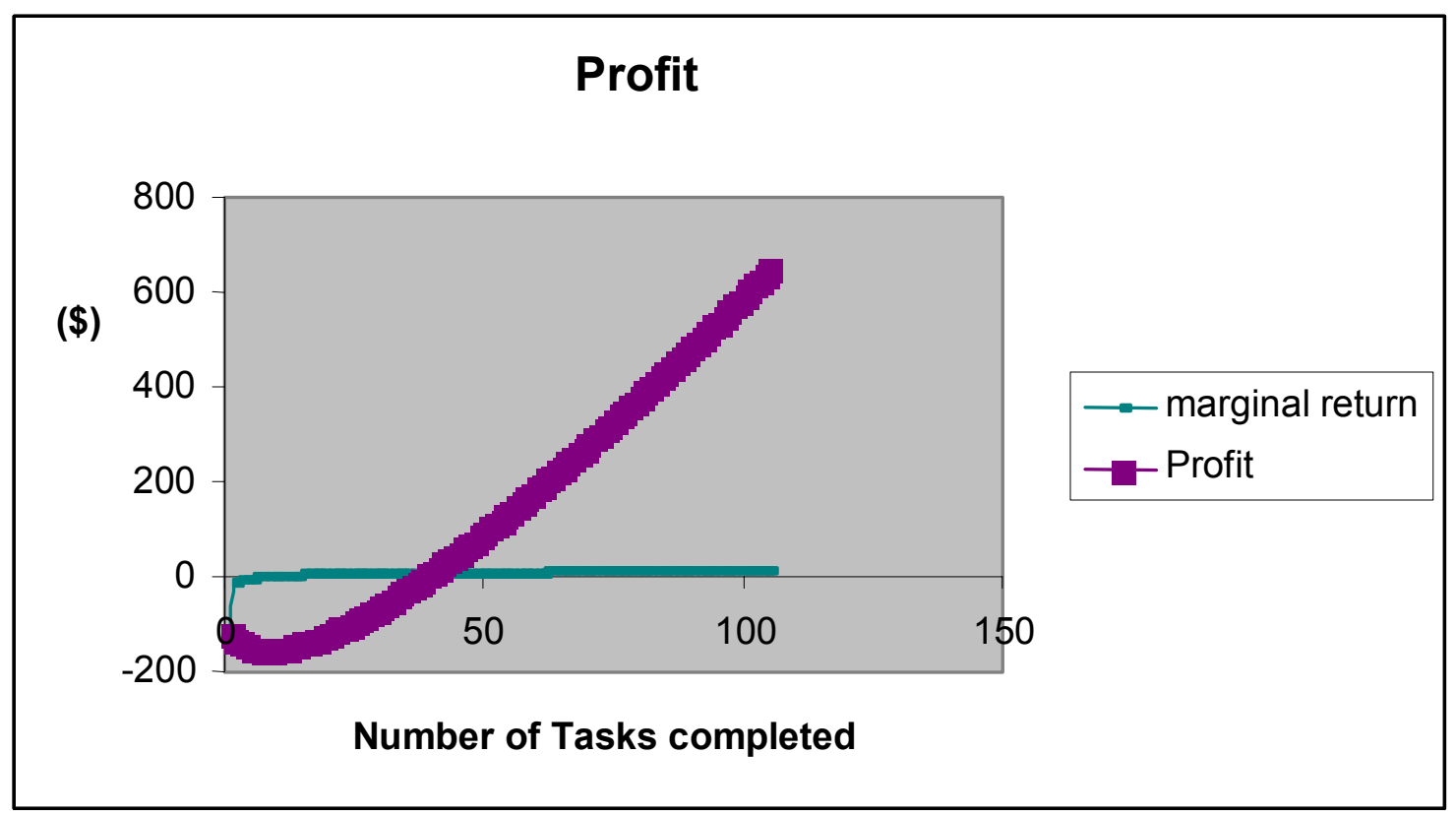

If calculating the return-on-investment for a certain timeframe, subtract the average financial impact of the trained employees minus the financial impact of the untrained employees for a designated time period (perhaps a year). The ROI for this period is this value minus the cost of training for that designated time period. In other 
words, ROI is also calculated by subtracting the cumulative profit of break-in training minus the cumulative profit of traditional training for the designated time period.

This thesis will combine ROI philosophies with the learning curves of break-in training strategies to help companies determine whether break-in training is a sound option. In the past, many organizations had to estimate the training's impact. The need for concise model that gets to the bottom line is apparent. 


\subsection{THESIS STATEMENT}

Develop an economic model to assess the return-on-investment for various types of break-in training for a specific job task.

\subsection{METHODOLOGY}

The methodology focuses on the calculating the break-in training ROI using a learning curve as the basis for the model. The methodology will have the following steps.

1. Identify 3 types of break-in training in use today.

2. Develop learning curves for these different break-in strategies using a repetitive task.

3. Develop a ROI model using learning curves as a basis.

4. Estimate the ROI for the different break-in strategies.

5. Show how the model can be used on actual jobs.

\subsubsection{Identify three types of break-in training in use today.}

This thesis will focus on three break-in training strategies. All three training strategies will be compared to each other and to the traditional method of training. The first step of the methodology will be identifying the three break-in training strategies by researching common training strategies currently in use in manufacturing organizations. Possible training strategies are: using a mentor to enhance training, giving the employee specific operating instructions in training manuals, teaching a skills class to the new employee so that the trade is learned before he or she starts on the production floor, or any combination of these. The three types of break-in training strategies will be selected to evaluate the learning rate and/assess the maximum financial return from the break-in training by being compared to the traditional method of break-in training. 
During the traditional method of training, employees observe the tasks and are expected to complete these tasks after the observation. There may be limited explanation and training on the skills and process prior to doing the job. With this "observe and do" process, the employee may take longer than desired to learn how to do the job.

\subsubsection{Develop learning curves for these different break-in strategies using a simple task.}

In order to compare the effects of each type of break-in training, learning curves for each break-in training strategy will be developed. These learning curves will show the change in time to complete a task as the number of tasks completed increases, as in figure 1.7 .

\section{Figure 1.7}

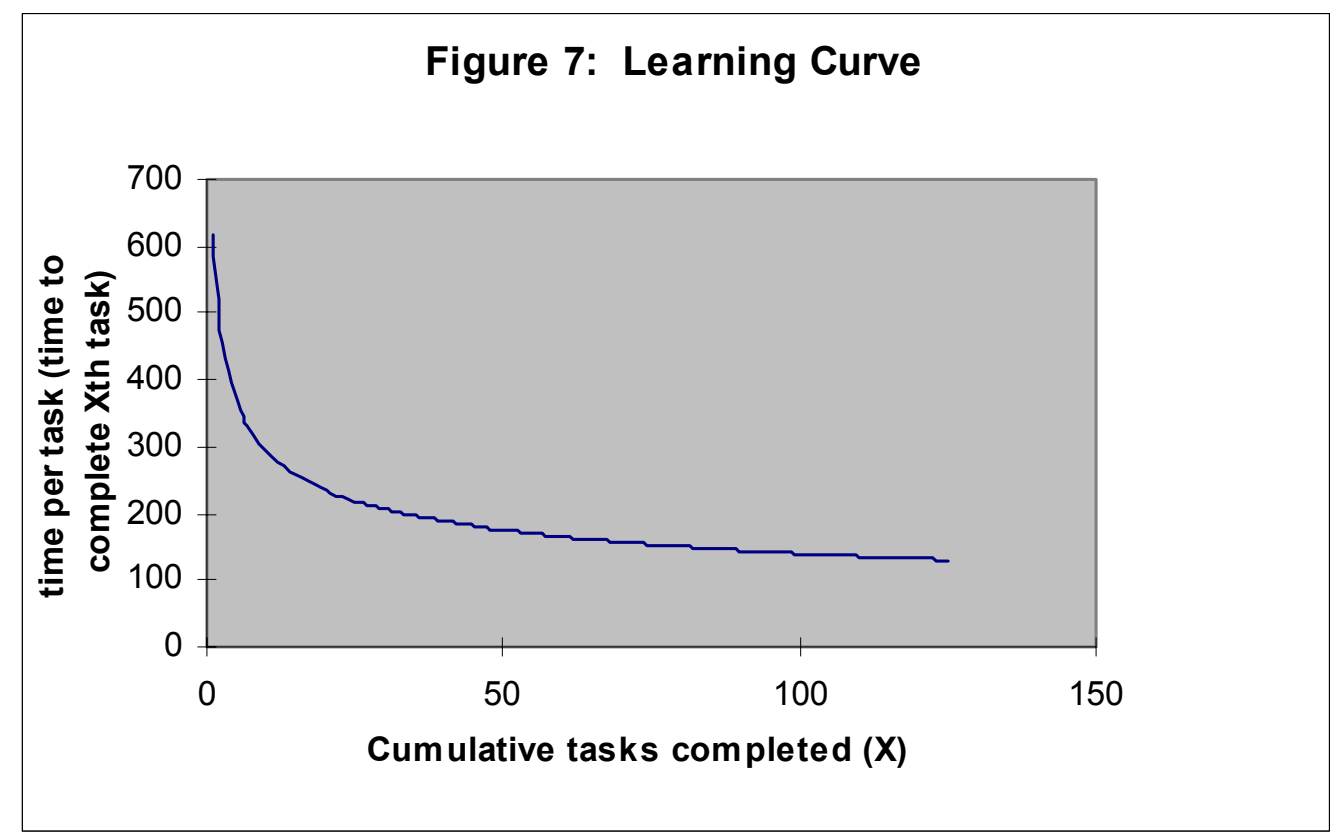

In order to properly develop the learning curves, each of the break-in training techniques, including the traditional technique will be simulated in an experiment designed to capture the return on investment of training for a specific task. 
In the break-in training simulation, a repetitive task will be used as a model for a manufacturing process. The task selected to use for the experiment will be binding reports with a document binding system. Volunteers will be requested to participate as subjects in the research. Groups of subjects with no prior experience with this task will be randomly selected and randomly put into four groups, representing the four break-in training techniques. Four different subjects will be assigned to each of the four groups. Each subject will represent an employee about to start work on a task. They will be required to repeatedly complete the task, binding reports, much like in many organizations.

A person experienced with the task will act as the "trainer". For each subject, the trainer will simulate one of the four training methods. Each individual will receive only one type of training. Training will be administered individually or in groups as to best represent the training style used by a manufacturing organization. The subject will then complete the task receiving guidance by the trainer as designated by their training program. Performance measurements will be taken on the individuals and their progress will be measured at predetermined time intervals. The experiment will continue until the subject has completed 30 tasks or has reached the plateau in the learning curve.

For example, the group who will receive the traditional break-in training, will be trained by the "observe and do" process. The trainer will complete one or two tasks and the subject must watch and listen to the brief instructions. Then, the trainer will step aside and leave the subject on his or her own to complete the task. No more help will be available from the trainer after the demonstration is over. The subject will complete the task 30 times or until they reach the plateau in the learning curve.

The data from the break-in training simulation will be used to develop learning curves, by plotting the cumulative number of tasks completed on the $\mathrm{x}$-axis, and the time per task on the y-axis. In other words, if the xth unit is represented on the x-axis, the time that the subject took to complete the $x$ th unit is plotted on the $y$-axis, such as in Figure 7. 
The learning curves for the different training methods will be compared to each other and the traditional break-in training method to show the effects of the break-in training on productivity. Effects of break-in training on the learning curve will be used to determine the financial returns of break-in training on employees.

\subsubsection{Develop a ROI model using learning curves as a basis.}

The true benefit of the analysis of break-in training will be realized in a ROI model using the learning curves as a basis. The ROI model will translate the effects of break-in training on the learning curves to financial effects for companies.

Return on Investment is normally associated with the time that it takes a company to payback an investment. In those cases, the return on investment is associated with a rate of return, or return percentage on usually a financial investment. In this thesis, the return on investment, or ROI, is the amount of money that is gained by the company for investing in break-in training. The ROI is dependent on the number of tasks completed by an employee, since this thesis focuses on the ROI of break-in training in a manufacturing organization. Therefore, in this paper, ROI refers to a dollar amount. This dollar amount is the determined by comparing the profit, or cumulative profit, from the break-in training to the profit, or cumulative profit of the traditional training. The ROI model in this thesis captures the exact amount of money the company will see from the investment in the break-in training according to the number of tasks that have been completed by the employee. Throughout the thesis, the term return on investment, or ROI, is considered to be a cumulative dollar amount corresponding to the number of tasks completed.

In this thesis, the ROI equation will be calculated by the following:

Financial return from training learning curve per time period - Financial return from traditional learning curve per time period - Difference in cost of training per time period 
$=$ Return on Investment

The ROI model will reflect the following:

1. The break-even period for the training investment

2. The future gains that will be realized from making the investment in training, or the overall benefit of the training

3. The most effective training method, or how each training method affects a company's financial returns, which can be useful for company budgeting

The break-even period is similar to the payback period of a single investment. The payback period is the length of time when cumulative rewards from the investment in training are less that the initial investment. After the payback period, all additional money made as a result of the investment is profit from the break-in training strategy. The time after the payback period is when the return on investment becomes greater than zero. In the simulation, an investment cost for each break-in training method will be determined so that the payback period for each can be determined and compared for each training type on an individual basis.

The break-even period is the period where the profit from the break-in training type equals and begins to exceed the profit from the traditional training as the number of tasks completed increases. At this point and beyond, designated by the task number, the company will be accumulating more profit from the break-in training than the traditional training. So, ROI, the profit gained from the company from investing in break-in training, increases from a negative amount to a positive amount.

The future gains that will be realized from making the investment in training is the amount of money that will be earned over a long period of time due to the investment. For example, one type of training may cause the learning curve to mature, or level off at a lower task completion time than the traditional break-in training method. In the long run, the learning curve that received the training will produce more units in the same time as 
the traditional learning curve, and thus save the company money in labor costs. Therefore this can also be called the overall benefit of the training or return on investment.

One break-in training method may stand out as the most effective break-in training method. Or different methods may have different benefits. For example, one method may have a long payback period, but huge future gains because the learning curve may decrease in task completion time slowly but over a long period of time and mature at a lower task completion time. Another break-in training method may have a short payback period and mature at a higher task completion time. Either option may save the company money as opposed to the traditional break-in training method, but the company must select the training strategy that matches their intended time and financial investment in the task. Long term and short term goals must be considered, so that the best break-in strategy will be selected.

The ROI model will be used to determine the factors discussed above. After the factors are calculated in the experiment, the different training methods can be compared and contrasted. The research will include discussion of the methods, including why they were chosen and their differences and similarities.

In order to develop the ROI model, a learning curve similar to the curve in the described in the literature review will be fitted to the data. The data for each break-in training type will be represented by the average of the four subjects learning curves. The fitted learning curve will have time per task, time to complete the xth task, plotted on the $y$-axis verses the cumulative total of tasks completed plotted on the $x$-axis. The curve will be fitted to the data.

The learning curves for all four types of training will be used to determine the cumulative profit curves for each training type. Then, the profit curves of the break-in training will be compared to the profit curve for the traditional method of training. The ROI model will be developed from differences between these two curves. 
The ROI model will be used to compare and contrast ROI of different periods of time. The financial returns of each break-in training type will be shown by taking into account the time that it takes to payback the investment in training. The ROI model will compare the financial returns of employees with training to the financial returns of employees without training and capture the actual benefit the company will receive from an employee from training them with break-in training.

\subsubsection{Estimate the ROI for the different break-in strategies.}

The process described in the previous section will be used to estimate the ROI for different break-in training strategies. Utilizing the results from the experiment and the economic model, learning curves will be determined for the four different groups. First, a learning curve will be fit to each group and the model parameters determined. Then, the economic return for each will be determined. The economic return of the traditional method of training will be subtracted from each of the economic return of each group. From each of these amounts, the cost of the specific training program will be subtracted. This gives the return on investment of each training program for a predetermined period of time. These break-in training strategies will be compared and contrasted. Comments will be made on determining the best strategy for a company.

\subsubsection{Show how the model can be used on actual jobs.}

This section will show how the ROI model developed in this thesis can be applies to actual jobs in a manufacturing organization. The section will also guide organizations on how to evaluate the break-in training method that best fits their needs. Then the organization can use the return on investment value, calculated by the model, to attribute financial return to employee development programs. This process of integrating the ROI model into manufacturing facilities is important because all companies need to benefit 
from break-in training investment strategies. This thesis provides the grounds to establishing more skills and higher productivity in the workplace. 


\section{CHAPTER 2:}

IDENTIFY THREE TYPES OF BREAK-IN TRAINING IN USE TODAY 


\subsection{CHAPTER OVERVIEW}

As discussed in Chapter 1, there are various break-in training methods that could be a beneficial investment to manufacturing companies. This chapter identifies three break-in training strategies that have proven to be useful in industry. Implementation of these training types has increased company profits after the initial payback period. The remainder of the thesis focuses on developing a methodology that captures this return on investment of each break-in strategy. 


\subsection{TRAINING TYPES}

After research of different types of break-in training, the following three types were identified as the types that will be used to develop the Return on Investment Model:

- The distribution of a training manual, which describes the process to the trainee,

- Involving the trainee in a training class of how to complete the task, and

- Providing a mentor to the trainee in addition to the training manual. The manual will describe the process to the trainee and the mentor will give on the job help with the task.

Each of these break-in training types will be compared to the traditional "observe-and-do" training type when developing the model. Throughout the research, each of the training types are sometimes referred to as a certain number. Here are the corresponding training type numbers:

Training type \#1: Observe and do;

Training type \#2: Manual only;

Training type \#3: Class;

Training type \#4: Manual with a mentor.

Each of these training types will be subsequently described in detail.

\subsubsection{Training type \#1: Observe and do}

The observe and do method of training is the traditional training used in many manufacturing organizations. During this method of training, the trainee will observe a individual perform the task. After this brief observation, the new hire is to begin functioning as a regular line worker in the manufacturing organization. There is no formal training on the correct process of the task. Therefore, key information that may be pertinent to the production speed of the employee or quality of the product they produce may be lacking. With the observe and do training type, the employee's learning curve may have a lot of room for improvement, since their time to produce a product may be 
high for the initial time period and then decrease to a level that is still not the optimum in terms of quality or efficiency.

The cost of this initial training type comes from the labor cost of the trainer and the new employee. This training cost only involves the financial cost of the training and at the beginning of the employee's work time. There is not much training cost involved with the observe and do training type because so little time is spent teaching the new employee the task.

It is critical that other training types tested in this research be compared to the observe and do training type in order to determine the return-on-investment for the breakin training. This observe and do training type is not a type of break-in training, so it doesn't require much initial financial support. After the comparison, the return from investing in break-in training may be so great that training investment is paid the company in a short period of time. The payback will be determined by the ROI model developed in this thesis.

\subsubsection{Training Type \#2: Manual only}

One type of break-in training practiced, is teaching employees a process by having them read a manual at the start of their employment for the task. The manual thoroughly describes the task to the employee by carefully walking them through the process. The manual mentions key information that will help the employee perform the task correctly, produce the product at the most efficient speed, and produce a high quality product.

During the manual training, the new employee is told to read the manual thoroughly. Then they observe a co-worker as he or she completes the task as in the observe and do training type. Then, the employee begins work. They are able to refer back to the manual anytime time that they have a question. 
The training cost of the manual includes the labor cost of the employee as he or she reads the manual and watches the trainer, the labor cost of the trainer as he or she demonstrates the task, and the cost of the manual. The manual cost involves the labor and materials used to produce the manual. Labor cost for the production of the manual and other overhead production costs are divided among all the employees that utilize the manual.

\subsubsection{Training Type \#3: Class}

The class training type incorporates a class into the training of the employee. Instead of beginning on the factory floor, the employee will attend a class where an instructor teaches them how to complete the task. Included in the class are explanations of the job they are to do, how it is incorporated into the entire company's production processes, and detailed demonstrations of the tasks they will perform. During the demonstrations, the trainer, or teacher of the class, presents the employees with key information that will help them perform that task correctly. Also during the class, the employees perform trials of the task and the trainer helps them learn the correct process. The trainer will observe the trainees as they perform the trials and comment on their performance, technique, and quality. The trainer will ensure that the trainee completes the task correctly before beginning on the factory floor.

The costs that are associated with the class training type are the labor cost of the new employee as he or she attends the class, the labor cost of the trainer as he or she teaches the class, and the cost of the materials used in the class. The cost of materials includes the cost of the paper and bindings used in the trial reports. 


\subsubsection{Training Type \#4: Manual with a mentor}

Recent studies have shown that mentors are an effective way of increasing the productivity of the workforce. A mentor is a co-worker in a more senior position who is available to assist new hires. The mentor usually has mastered the task and is available to assist the new hire when he or she has questions. Mentors are not usually the sole training used in a company. Along with other break-in training types, they have proven to be effective in upholding the quality of the product, the efficiency of the labor, and even the company morale. Therefore, the fourth training type tested is a utilizing a mentor along with a manual.

During the manual with a mentor training type, the new hire receives break-in training by reading a manual that clearly describes the task they must complete. The manual presents key information that is helpful to the employee's complete understanding of the process. This information explains how to produce quality products in a timely manner. After the employee has completed reading the manual, they watch a quick demonstration, much like the observe and do demonstration. Then, the employee can begin his or her production. The manual is available for the employee to refer back to at any time if he or she has any questions about the process.

Not only can the new hire refer back to the manual, but also he or she can ask for assistance from his or her mentor. The mentor is available to him or her on the job to assist the new hire with any question that he or she may have with the task, company, etc. The mentor can demonstrate the process to the new hire, assist the new hire with the correct process, or prevent the new hire from completing the process incorrectly if the mentor sees that the new hire is having problems. The mentor can assist the new hire at anytime during the production process and is usually in a close proximity for the new hire to contact. 
The cost of the Mentor/Manual training type includes the labor cost of the trainer as he or she demonstrates the task, the labor cost of the new employee as he or she watches the demonstration and reads the manual, the cost of the manual, and the labor cost of the mentor for the time that he or she assists the new employee. The manual cost is the labor and material cost of producing the manual. This preparation cost of the manual is divided among the employees that utilize the manual. The labor cost of the mentor only comes into play when help is given to the new hire. This is a cost because the mentor could possibly be performing a task at his or her own workstation but has to stop in order to assist the new hire. Therefore, the labor cost for assisting the new hire has to be attributed to the training cost.

Chapter 3 of this thesis describes how each of these training types was tested in an experiment that will eventually lead to the ROI model for break-in training. For that model, the initial cost of each break-in training method was developed. The actual costs of each break-in training type, calculated during the experiment, will be stated Chapter 4 . 


\section{CHAPTER 3:}

DEVELOP LEARNING CURVES FOR THE BREAK-IN STRATEGIES USING A REPETITIVE TASK 


\subsection{CHAPTER OVERVIEW}

Chapter 3 covers the development of learning curves for the four training strategies. First, the task for determining the learning curves will be described, followed by details of the experiment and the data collected. Finally, the process of fitting the learning curves will be described along with the developed learning curves themselves.

As described earlier, learning curves illustrate the time an individual takes to complete each task of a repetitive process starting with their first attempts at with the task. The learning curves will show the time that it takes the employee to complete each task, and this time will be translated into a labor cost for each task. The ROI model will compare labor costs of individuals with and without break-in training and will show the financial gains for making an investment in training.

This chapter contains the description and results of the experiment that was conducted for this thesis research. The experiment tested the effect of each type of training on the individuals completing a repetitive task for the first time. The task used to test the training types, defined in Chapter 2, was binding reports with a document binding system. Subjects that participated in the experiment were trained by one of the training types and timed as they bound reports. The data from this experiment was used to develop the learning curves described in the "Learning Curves" Section.

The leaning curves are then used to develop the ROI of the three different types of break-in training, which is presented in Chapter 4 and 5. As stated earlier, the ROI model was calculated using the difference in learning curves of the break-in training and the tradition training type. This chapter discusses the experimental design and develops the learning curves of the different break-in training strategies to be used in future chapters. 


\subsection{REPETITIVE TASK: BINDING REPORTS}

In order to capture the learning curves in a manufacturing organization, a repetitive process has to be simulated. The experiment used binding reports with a document binding system as the repetitive task. A document binding system is a manual machine found in many offices used to punch holes in a report and attach plastic bindings to the edge of the pre-punched papers. The final result is a professional, bound report. The subjects that participated in the experiment were asked to bind 20 page reports with a Docubind P100, a document binding system produced by the General Binding Corporation. The subjects were to bind these reports repeatedly using a process described to them by their designated training type. The time they took to bind each report was recorded as well as the quality of the reports and any subject behavior instances. This data was used to develop the learning curves of each training type.

Binding reports with the document binding system was selected as the repetitive task for the reasons highlighted below:

- Uncommon task - Binding reports is a task that is not common to many people. Since break-in training is the training that first teaches employees the task, a task that was uncommon to most people was selected. This yielded a better chance that many volunteers would be eligible. All subjects in the experiment were not to have had any prior experience with the document binding machine.

- $\quad$ Room for improvement - The task is a simple, but may take a while to get accustomed to when completing for the first time. So, after the first completions, there was a lot of room for improvement.

- $\quad$ Process needed - In order to reach optimal production times when completing the task, a process must be followed. Variations of the correct process that was described in the training, depended on the training type.

- Multiple Steps - The task contained several different steps (the punching and the actual binding) and took a length of time adequate for simulating a workstation in a manufacturing organization. 


\subsection{EXPERIMENT}

Each of the four training types was tested by having the subjects bind documents with the document binding system. Each subject was trained by only one training type and was asked to bind documents for an unspecified period of time, but for no longer than the three-hour time period allocated for each subject. The length of time for the subject to bind each report was recorded and kept in consecutive order with the completed report count. Subjects were tested one at a time on one of seven testing days.

This section describes the experimental design of each of the four training types. Four subjects were used to test each training type, and their learning curves developed. The average of their learning curves was used to determine a training type's learning curve.

\subsubsection{Design}

The design section contains details of the experiments such as descriptions of the four training types, acquiring subjects, and the correct binding process.

\subsection{1.a Preparations}

Preparations for the experiment included:

1. Establishing the binding process;

2. Determining what each training type included;

3. Coordinating with the individual who trained the subjects in the experiment or the "trainer"; and,

4. Preparing the training manual used in training types \#2 and \#4. 
These preparations resulted in the training procedures of the 4 different training types, described in the "Training Procedures" section. Other preparations included establishing a room that will serve as the experiment station for all subjects, gathering materials by obtaining the plastic bindings and photocopying the 20 page reports, coordinating schedules, and acquiring subjects.

\subsection{1.b Subjects}

In order to acquire volunteers for the experiment, advertisements were placed throughout the engineering classroom buildings. Volunteers that signed up and participated were compensated $\$ 6.00$ per hour of their time spent participating in the experiment. All subjects had to be physically able to operate the document binding system, but weren't allowed to have any prior experience. Subjects signed up for individual time-slots as they were to be tested one at a time. There was no discrimination based on gender, race, or age. (Most of the volunteers were coincidentally graduate students at West Virginia University's College of Engineering and Mineral Resources.

A total of 16 subjects were hired for the experiment. The subjects were divided into groups of 4. Each group received a different one of the four training types. Training and testing was administered on an individual basis. The training types were tested in no particular order.

\subsection{1.c Experimental Procedure}

The experiment was held in an office at the College of Engineering and Mineral Resources. Subjects were tested individually, and they were allocated a time slot of 3 hours each. However, the testing usually took between an hour and a half to two hours, so the full three hours was rarely used. Before a subject arrived, the materials were laid out on the table where he or she would work. Materials included a pile of reports that was divided into the 20 page reports, plastic bindings, and the document binding system. 
When the subject entered the room, he or she was instructed to read and sign the consent form. After this was completed, the experiment commenced. Each subject was trained by the one of the four training types, predetermined upon his or her arrival. The experimental procedure for each training type is described in detail in the "Training Procedures Section." The entire experiment consisted of the following:

1. Introduction - The task was presented to the subject along with what the experiment entailed. The subject read and signed the consent forms.

2. Training - The report binding process was described or demonstrated to the subject by the trainer and/or manual.

3. Task completion - The subject repeatedly bound reports using the document binding system. The facilitator collected relevant data.

4. Post experiment discussion - The subject was asked questions about their experience during the experiment.

Each subject followed the same experimental design as described above.

The experimental design also called for consistency among other factors that could possibly affect the outcome of the experiment. All experimental procedures (i.e. help that the mentor gave to the subject) were noted. Measures used to help ensure consistency included holding all experiments at the same location with the same set-up, presenting the same information to each individual, regardless of training type, and presenting the same information that was consistent across the board. The selection of the training type was predetermined before the subject arrived at the site, and therefore was random. Characteristics such as age, race, and gender of the individual were not taken into consideration at any time during the experiment, including selection of subjects per training type. This is because these characteristics were not considered to have played a role in influencing the productivity of the individual. Each individual will produce his or her individual results, different background is added into the error resulting from the diversified individuals. Since the task is so simple, it should not be impacted by characteristics of the subjects at hand. 
During the experiment the time to produce each report was recorded along with comments about the behavior or actions of the subject. Also recorded was the initial training time used by the trainer. After the experiment was over, the subjects were asked questions about their behavior during the experiment and their opinions about the experiment.

When the subject was finished with the experiment and left the room, the reports were checked for quality since quality was a training-dependent factor that affected the return on investment. During the quality check, each report was inspected and given a quality designation. Each report's corresponding report number was noted so that the production time for that particular report would match that report's quality designation. Most the reports passed the quality check, but those that didn't had to be accounted for in the model. The reports receiving non-passing designations were highlighted in the data gathered from the experiment. More about quality designations and report quality is described in the "Report Quality" Section.

\subsection{1.d Correct Report Binding Process}

This section describes the report binding process developed for the experiment. The correct process is explained before the training procedures for the different training types in order to better distinguish among the information dispersed for different training types.

To properly bind reports, the subject should follow the 18-step process described below:

1. Stand facing the front of the document binding system.

2. Gather 6 to 7 sheets of paper and straighten then so that all their edges line with each other.

3. Ensure that the handle of the document binding system is perpendicular to the table. 
4. Place the side of the report that needs to be bound towards the punching section of the document binding system and align the papers to be punched up with the ledge on the left-hand of the document binding machine.

5. Insert the papers into the punching section of the document binding system. Ensure that all papers are aligned in the punching section.

6. Punch holes in the document binding system by lowering the lever on the right hand side of the Docubind P100

7. After the holes are punched, raise that handle until it is once again perpendicular to the base of the document binding machine.

8. Remove the punched papers by sliding them out of the punching section and lay facedown to the side.

9. Repeat the punching process on approximately 6-7 pages of the report until all pages of the report are punched.

10. Ensure that the document binding system's handle is perpendicular to the base of the machine.

11. Obtain the binding. Hold binding with teeth open-side up.

12. Insert binding into machine.

13. Open the teeth of the bindings by pushing slowly back on the handle of the document binding system until the teeth are separated from the rest of the binding and pointing straight up.

14. Gather ordered papers and straighten.

15. Insert the punched report into the teeth of the bindings.

16. Close the binding by pulling forward on the handle. Pull the handle forward until there is less than a 90 degree angle between it and the base (on the front side) of the document binding system.

17. Push back on the handle until it is perpendicular with the base of the document binding system.

18. Remove the bound report from the document binding system by lifting the report up and out of the metal prongs. Wiggle the report if it is stuck. 


\subsection{1.e Training Procedures}

During all training types, the experiment facilitator presented the task of binding 20 page reports to the subject and explained that the reports were already separated into the their respective piles. The facilitator explained that the subject will be binding report for no longer than 3 hours and gave the subject the option to sit or stand. The facilitator also told the subject that he or she would receive $\$ 6.00 /$ hour for his or her time and that there are no known safety issues associated with the P100 Document Binding System.

Each training type has its own specific training characteristics. These are described in detail under the training type headings below.

\section{Training type \#1: Observe and Do}

During the observe and do training type, the trainer demonstrated the training process to the subject once with limited explanation. While the trainer was doing so, she appeared to express inattentiveness and boredom. The observe and do training process included the trainer:

1. Stating that she will demonstrate the task to the subject,

2. Punching holes in a group of papers from the first report in the pile,

3. Opening the binding,

4. Inserting the papers,

5. Closing the binding, and

6. Taking the report off of the machine.

The report, however, was not complete because not all 20 sheets were punched and inserted into the bindings. The trainer put the report back on the machine and took it apart so that the subject could begin their production with the same report. During the demonstration, the trainer briefly explained the binding process. 
The explanation included:

- The teeth on the bindings go on top, and

- The subject should line up the paper on the left hand ledge of the document binding system before punching.

The explanation did not include the following details that come from experience:

- The handle of the document binder should be perpendicular to the table as the subject inserts the paper into the hole punch, and

- The subject should only punch 6 to 7 sheets of paper at a time.

The trainer did not offer to answer any questions and reflected this in her attitude. When she was done with the demonstration, the trainer told the subject that the subject is on his or her own to continue binding reports and left the room. After the trainer exited, no other help was offered or given to the subject.

\section{Training type \#2: Manual}

The manual training type combined a manual that explains the binding process in detail with the "observe and do" demonstration from the trainer. During this training type, the trainer has a friendly attitude, but didn't explain too many details about the process. The purpose of the manual is to define that process.

The training process for the manual training type included the subject reading the manual and then watching a demonstration from the trainer almost identical to the "observe and do" training type demonstration. Differences were that the trainer had a friendlier attitude during the experiment and offered to answer any questions at the end of the demonstration. At the beginning of experimentation of the manual training type, the facilitator explained the training process to the subject and reminded the subject to use the manual as a guide when binding the reports. 
The facilitator also stated that the subject should attempt to produce quality reports as efficiently as possible since this experiment simulates a manufacturing organization. The subject was informed that they had to produce one report at a time and finish each report before continuing to the next. If the subject had any questions during the process, the facilitator directed the subject back to the manual. The facilitator did not offer any personal help during the experiment.

The manual used in this experiment was a 14-page manual explaining the correct report binding process. The instructions were complemented with step by step pictures of a subject binding reports. The manual instructed the subject on the steps of the experiment, describes the document binding system, presents the materials, introduces the task, and describes the procedure in detail. The procedure contained information about the binding "tricks" that help the subject produce reports faster. The manual also contained a section on quality assurance that showed examples of incorrect processes that can ruin a report. The manual was a stand-alone explanation of the how to operate the document binding system and produce reports.

\section{Training Type \#3: Training Class}

The class training type required subjects to attend a training class provided by the trainer. Because only one subject could be tested at a time, the training class was one-onone. During the class, the trainer demonstrated the binding process in detail to the subject and guided the subject through the process by assisting him/her with binding two reports. During this training type, the trainer was directed to foster an attitude that was extremely nurturing because it was important to the trainer that the subjects learn the process and produce quality reports efficiently.

Before the training class, the facilitator stated that the subject should attempt to produce quality reports as efficiently as possible since this experiment simulated a 
manufacturing organization. Therefore, the subjects must follow the process and produce one report at a time.

During the class, the trainer explained the report binding process in detail while demonstrating on the document binding system. In this explanation the trainer reviewed all details ensuring the correct report binding process such as:

- Mentioning that the teeth on the binder go up,

- Mentioning to line up the papers on the ledge,

- Mentioning to punch 6-7 pages at a time, and

- Mentioning to keep the handle straight up (perpendicular with the table).

The trainer also reviewed examples of bad quality reports by showing the subject what not to do and the outcome of a bad process. The trainer showed that inserting the papers into the machine while the handle is not completely perpendicular will cause the papers to be incorrectly punched. The trainer advised the subject to set aside any of these "mispunches" and continue on to the next reports since "mispunches" would not pass the quality test in a manufacturing company.

After the demonstration, the trainer walked through the binding of two reports with the subject. During these trial reports, the trainer assisted the subject by answering questions, correcting the subject if they made a mistake with the binding, and demonstrating steps the subject has trouble with. At the end of the training class, the trainer offered to answer any questions that the subject because once the trainer left, there was no one available to assist the subject if he or she had any questions. However, if the subject had any further questions during the experiment, the facilitator gave brief, but friendly answers to them.

\section{Training Type \#4: Manual with a Mentor}


The manual with a mentor training type combines the training from a manual with a mentor, who is present throughout the experiment to help the subject any document binding needs. During this training type, the trainer attitude was friendly and approachable. The trainer always was willing to help if the subject should have a question

During this training type the subject was trained using the same training as in the manual only training type. Initially, the facilitator stated that the subject should attempt to produce quality reports as efficiently as possible since this experiment is to simulate a manufacturing organization. Therefore, the subject must follow the process by producing one report at a time. For the training, the subject read the manual describing the binding process and watched a brief demonstration by the trainer. The manual thoroughly described the binding process and even showed examples in pictures. The trainer demonstration was much like the observe and do demonstrations except the trainer offered to answer any quick questions at the end of the process and reflected a friendlier attitude.

When the training was over, the trainer left, but the facilitator became a mentor to the subject. The mentor offered to answer any questions that the subject might have periodically throughout the binding process and did the following:

- Answered all questions thoroughly,

- Was available often to help during the binding process,

- Revealed the binding tricks, and

- Encouraged the subject to produce quality reports at an efficient speed

The mentor also offered help if she thought that the subject was having difficulties with the process and sometimes demonstrated the process to the mentor. Many times the subjects asked the mentor for demonstrations or help during the binding process. The manual was also available for the subject to refer to if he or she needed assistance, but the use of the mentor was much more prevalent. 


\subsubsection{Data}

The data that was gathered as a result of the experiment was the time that each subject took to complete each report, the time for the different parts of training, and the amount of time that the subject utilized the mentor. Other notes on the behavior of the subject were taken as well, such as factors that could influence the quality of the reports. All of this information is important for determining the ROI for the break-in training.

The number of reports that each subject completed varied on the subject. The facilitator made the subject continue to bind reports until he or she reached the plateau in the learning curve, meaning that the time the subject took to complete each report was no longer decreasing. Most of the subjects completed around 30 to 35 reports. Some subjects produced as many as 45 reports.

The data gathered from the experiment is shown in Appendix B. Each training type has the report binding times for its four subjects. All times are recorded in these charts, including binding times of reports that had defects (received bad quality designations). Also, the training time for each subject is indicated at the beginning of the data. Each subject is distinguished by the date and time that they performed the experiment. This data was used as basis for developing the learning curves of each type, calculating the training costs, and calculating the return from each report produced.

\subsection{2.a Nuances due to subject background}

The experiment did not discriminate according to race, gender, culture, and demographics. However, these factors may have had an impact in the subject's data. Though these were not closely monitored, some trends involving these factors became apparent. First of all, the experiment was designed so that these characteristics would not make an impact in the results. The training type that the subject received was distributed randomly to reduce subject background error. Despite the selection a gender-neutral task, 
and a required experience level of none, and other precautions, slight background trends were a little apparent.

The report completion time and report quality seemed to be affected by the background of the subject, though these differences were not formally calculated. For example, many of the Indian subjects tended to produce reports that were higher quality, but many of them took a long time to do so. Subjects from America took less time that the Indian subjects, but produced reports of lesser quality.

Another issue that could have slightly affected the results of the experiment was the language and culture barrier that many of the subjects could have experienced during the testing. For example, the foreign students may have had a hard time interpreting the manual because they were not born with English as their first language. According to our after experiment discussions, many of the foreign students found the manual a little confusing, and felt as if the demonstration or the mentor was a lot more helpful than the manual. This difficulty could have caused an error in the actual data captured from the testing.

Some of these cultural differences may have hindered the data, and some of the conclusions made with the data in this thesis may change, causing some of the related conclusions and discussions to change. Despite these data nuances, the ROI model will remain the same. 


\subsection{REPORT QUALITY}

In order to take into account the defects and other quality issues with the reports, the report quality was tracked during the experiment. After the subject had completed the experiment, each of the reports that he or she produced underwent a quality inspection. Each report was given one of four quality designations:

1. A check - Indicated a report with good or excellent quality.

2. "S" - The "S" means "Satisfactory." This designation represents reports with a level of quality that is satisfactory and able to pass the quality inspection.

3. "S-" - The "S-" represents a less than satisfactory designation and means that the report needs some improvement before it passes the quality check. These reports can be reworked and sold as a normal reports.

4. "X" - An "X" represents a defect and signifies bad quality reports that are beyond repair. Reports with this designation are considered to be scrapped. .

The designations of the reports was recorded in the data.

Reports that passed the quality inspection (designated by an check or a "S") are considered sold to a distributor. Most of the reports fell into these categories and are treated as normal reports in the model. The reports that need special attention in the model are the defects," $X$ " and the reworks ("S-" designation). There were only a few of these for each subject, but ROI model takes into account the time that is needed to produce and/or fix these defects and reworks. Reports with the "S-"designation were considered to be sold to a distributor after the quality problems were fixed. Receiving an " $\mathrm{X}$ " designation meant that the report had to be scrapped without any repair time, so no money was received for them.

Missing holes with the binding teeth is the main cause of reports receiving an "S-" designation. In order to fix this problem, the document binding machine was used to take all the pages were taken out of the binding and repositioned on the teeth. The average time for a worker to correct this deficiency was 36 seconds. 
Mispunched holes in the papers was the main reason for " $X$ " designations. The mispunches were caused by the subject incorrectly inserting the pages into the document binding system's hole punch or punching the holes on the wrong side of the document. Cases like these could not be fixed so the materials for these particular reports had to be scrapped. (In the model, the scraps were considered financially a waste.)

The data gathered from the experiment was adjusted due to the defects ("X") and reworks ("S-"). In the break-in training types, the subjects were instructed to discontinue production of a report if they it identified is as a defect (" $\mathrm{X}$ " designation only) and place the defect report in the pile. The subjects trained by the observe-and-do training type were not advised of this so they completed reports with incorrect punches. Therefore, the time wasted due to this defect varied depending on training type. The learning from producing that report still took place, so eliminating reports that were defects from the data is not a good option. Instead, the time to produce the defect and defect count was cleared from the data (to be taken into account later in the model) but the next report was still considered its correct production number. When the learning curve was fit to the data, the time for the defect did not impact production time, but impacted the count of reports.

Reports given an "S-" designation did not need to be taken out of the data because these binding times reflected the entire time needed to complete all steps of the binding. The time for reworking these reports is reflected in the ROI model, but not immediately in the data used to fit the learning curve.

The data that was adjusted because the defects were removed can be seen in Appendix C. There are some blanks in the data due to the elimination of the reports that were defects. This data is used to fit the learning curves for the 16 subjects. This process will be described in the "Learning Curves" Section. 
In general, the reports produced by individuals who received break-in training were of better quality than reports from subjects trained by the observe and do training type. The costs of the " $\mathrm{X}$ " and "S-" reports are indicated in the ROI model. The way that these are integrated in the model will be described in detail in Chapter 4, the chapter that shows how the ROI is calculated using the learning curves. 


\subsection{LEARNING CURVES}

This section discusses the methodology behind fitting learning curves of the break-in training to the data gathered by experimentation. First, the data characteristics will be described, followed by a description of the type of learning curve that will be fit. Finally, the method of developing a learning curve representative to the training type will be described and the learning curves will be presented.

\subsubsection{Data gathering}

As stated earlier, four subjects were trained and tested individually for each training type. The testing was completed over a span of seven non-consecutive days. Though each subject was allocated a period of 2 to 3 hours to complete the experiment, most of the experiments did not require the full allocated time. Subjects were tested individually because there was only one Docubind P100 available.

During the testing, the time that each subject needed to complete each report was recorded. After the testing, the time (in seconds) per each report was plotted on a graph. Generally, the subjects took the longest time to complete the first reports. Their time to complete a report decreased as they completed more and more reports. This is characteristic of a traditional learning curve, shown in figure 3.1, where the time to complete the task decreases greatly during the first couple of tasks and slowly tapers off as the subject reaches his or optimal performance level. So the decrease in time to produce reports 3 to 4 is greater than the decrease in time to produce report 15 to 16 , as seen in Figure 3.1, an example of a traditional learning curve. 


\section{Figure 3.1}

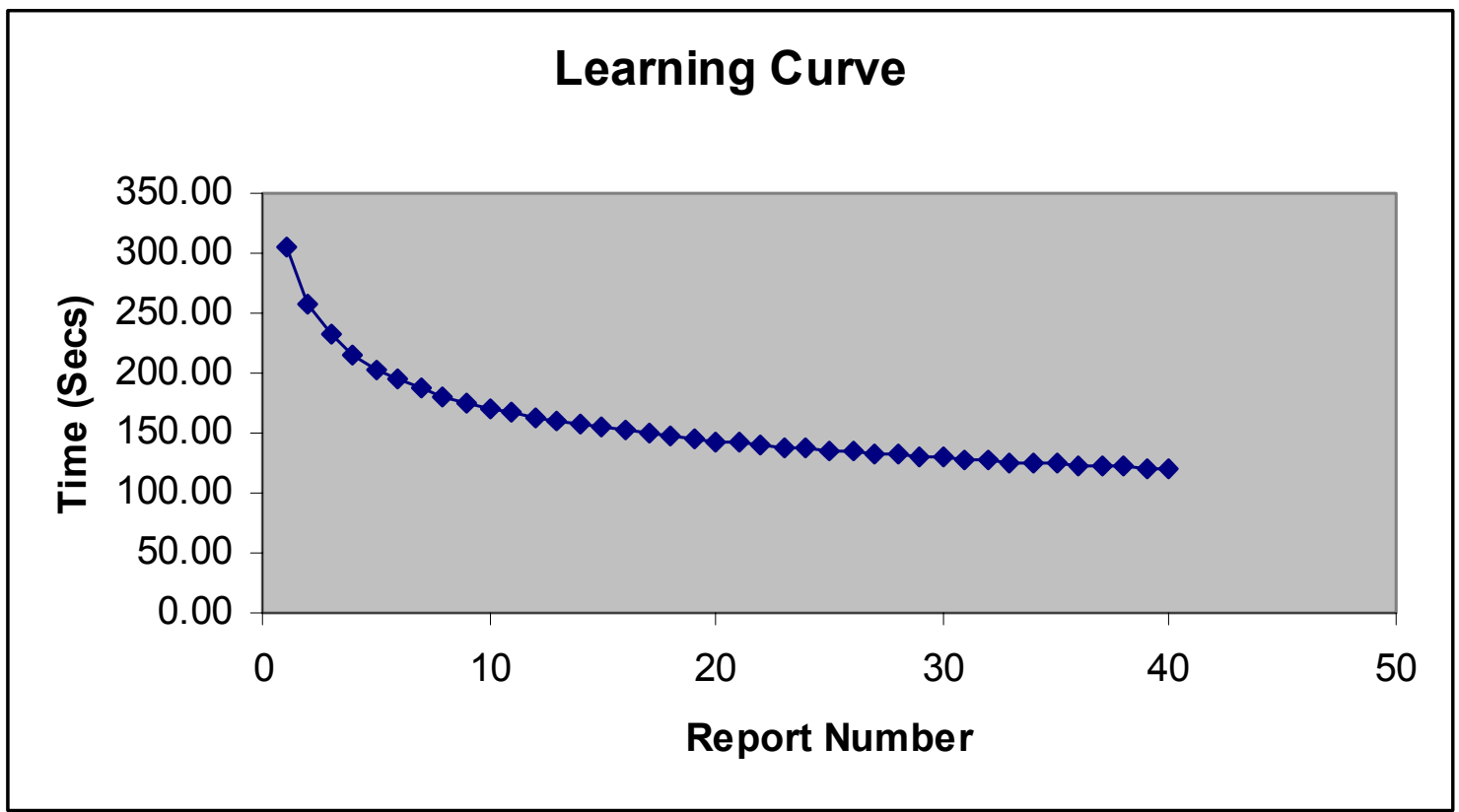

\subsubsection{Data characteristics}

The data gathered during the experiment followed the pattern described in the learning curve above. The time to produce one report generally decreased as the subject became more experienced with the report binding task. However, the actual decrease for each subject was by no means a smooth curve like the one in Figure 3.1. The actual data showed peaks and valleys in the time to produce as the reports were completed. Figure 3.2 shows the data of a subject trained by training type \#2: Manual only. 


\section{Figure 3.2}

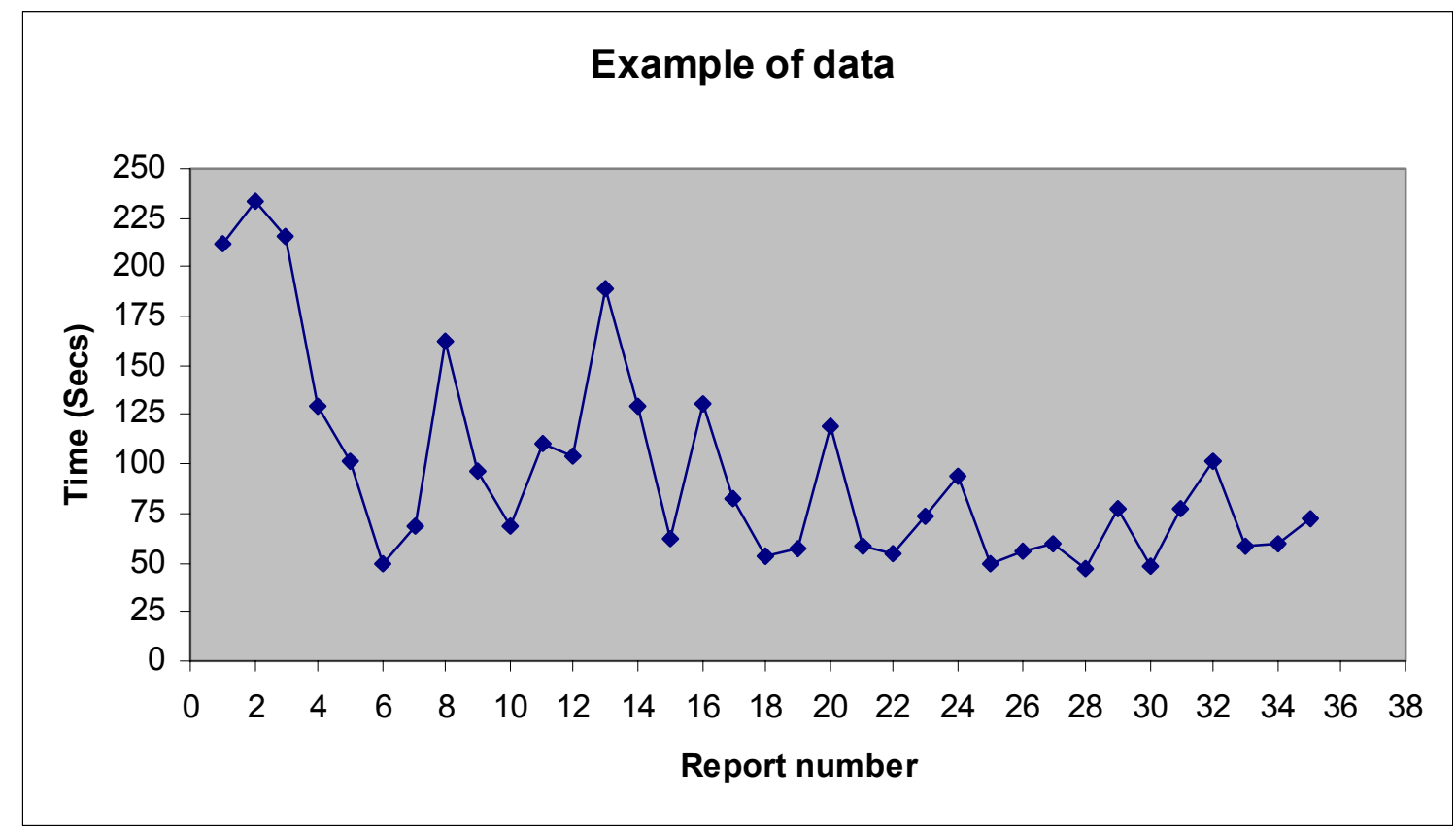

As can be seen in figure 3.2, the subject takes a more time to complete the first reports than the later reports. The time to produce each report generally decreases as more reports are made, but not evenly report to report. The time that this subject took to produce report after report can jump from a low value to a high value and back again. The chart shows that the subject is not very consistent in producing report after report. During the experiment, notes were taken on the techniques, progress, and problems that the subjects had and were referred to when identifying the reasons for the inconsistencies. The up and down nature of the data is seen throughout the subjects and most likely caused by a faulty document binding machine. For example, many times, the reports were stuck in the document binding system, so when the subject tried to remove the report, they encountered setbacks. Sometimes, the papers came out of the bindings and the subject had repeat the process of inserting the papers into the bindings. Other times, the subject had to work with the machine so that they could remove the reports with no damage. These setbacks took time and can be blamed for the up and down nature of the data. Report binding times noted for these setbacks were still included in the data because all of the subjects experienced a lot of them and to maintain the integrity of the data. 
Even though the report binding time varies, the average time for a few consecutive reports decreases in the shape of a learning curve as the number of reports increases. Figure 3.3 shows this by plotting the average time for five consecutive reports on the y-axis. Each group (labeled on the $\mathrm{x}$-axis) contains the average of the times of the last four report of the previous group and the next report produced. Therefore group number 1 contains the average production time of reports 1 through 5 , group 2 contain the average production time of groups 2 through 6 , etc. This is a method of smoothing data called the moving average. In this case, the purpose of using the moving average is to show that the data follows the general trend of the learning curve. The moving average smoothing technique will not be used when applying learning curves to the data. Instead, a learning curve for each subject will be fit to the data. The moving average example is used to indicate that the learning trend exists and that the learning curve equations fit to the data are adequate representations of the trend.

\section{Figure 3.3}

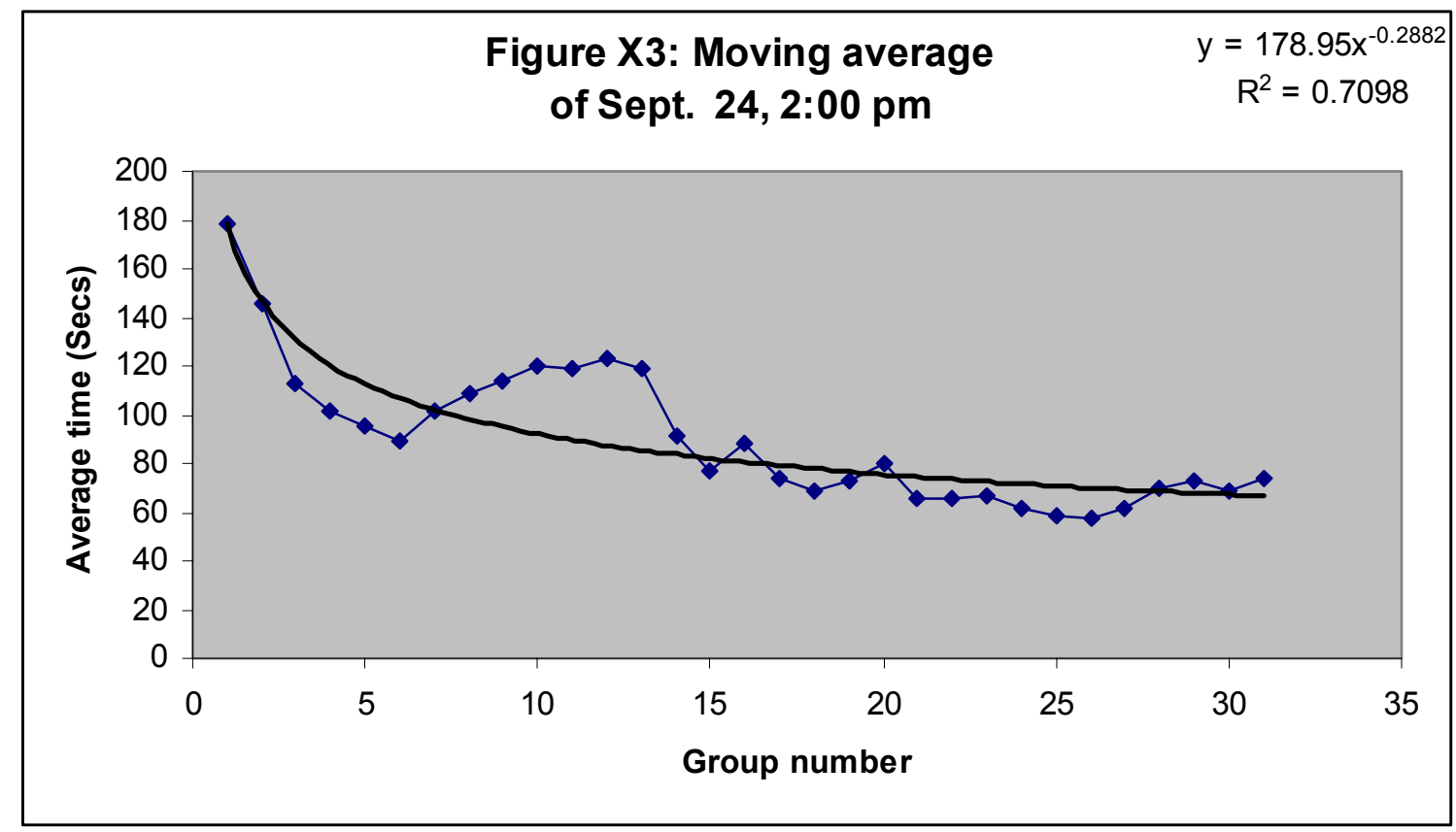

The points on the graph indicate the group averages. As shown by the learning curve trendline (the line without any dots), the moving average of the times fit to a 
learning curve fairly well because the R-squared value is .71. (R-squared values will be discussed in the next section.) This demonstrates that this curve shows the effect of learning in production time. As this is merely an example, the learning curves will be fit to unsmoothed data in this project.

\subsubsection{Fitting the data to Learning Curves}

The equation that was used to fit the data is represented by the equation below. This learning curve equation represents curve like the one in Figure 3.1.

$$
Y=A^{*} X^{N}
$$

Where:

$Y=$ time (or cost) to produce the $\mathrm{xth}$ unit

$A=$ time (or cost) required to do the first unit

$X=$ number of units

$N=\ln (I) / \ln (2)$

$I=$ learning rate

This is one of the variations of the learning curve described in the learning curve section of Chapter One. During the experiment, the data gathered was the time required to complete each consecutive report. The report number, or count, and the time to produce that report represented the $X$ and $Y$ values of this equation and were plotted using Microsoft Excel. Learning curves of the above type were fitted to the data, yielding the $A$ and $N$ coefficients of the learning curve equations. ${ }^{26}$ These learning curves were used to as a basis for the ROI models developed for each training type.

From the fitted value of $N$, the corresponding learning rate for each learning curve was calculated from the following equation. 


$$
I=e^{\left(N^{*} \ln 2\right)}
$$

Where $I$ is the learning rate and $N$ is the coefficient calculated by fitting the learning curve equation to the data. Learning rates are often represented in percentages. Lower learning rates imply faster learning, meaning that the time to produce consecutive units decreases more drastically with a lower learning rate. So, a learning rate of $80 \%$ yields faster decreases in production times than a learning rate of $90 \%$

Figure 3.4 shows the learning curve fit to the data from the Figure 3.2 using the method described in the previous paragraph. The learning curve for this subject's data is indicated in the upper right hand corner of the graph. Along with the learning curve equation is the R-Squared value for the curve, which represents how well the curve represents the actual data. The higher the R-squared value, the more the data fits the learning curve drawn by the equation. Higher R-squared values are more desirable than lower ones.

For the learning curves fit to the data gathered by these experiments, the RSquared values are fairly low because of the variety in times taken to produce consecutive reports. It is proven that the equation, $Y=A^{*} X^{N}$, fitted to the data represents the learning phenomenon, so these learning curves are appropriate for the data. The smoothing of the data also helps show that the learning curve equations are appropriate. When comparing the curve from the smoothed data to the actual data, the smoothed data has a higher R-Squared value. Since the smooth data is a smoothed version of the actual and has a pretty good R-Squared value (.71), through association the learning curve represents the learning phenomenon caught by the actual data.

\footnotetext{
${ }^{26}$ The coefficients $A$ and $N$ are later designated $C a$ and $C b$ respectively when calculating the ROI equation.
} 
Figure 3.4

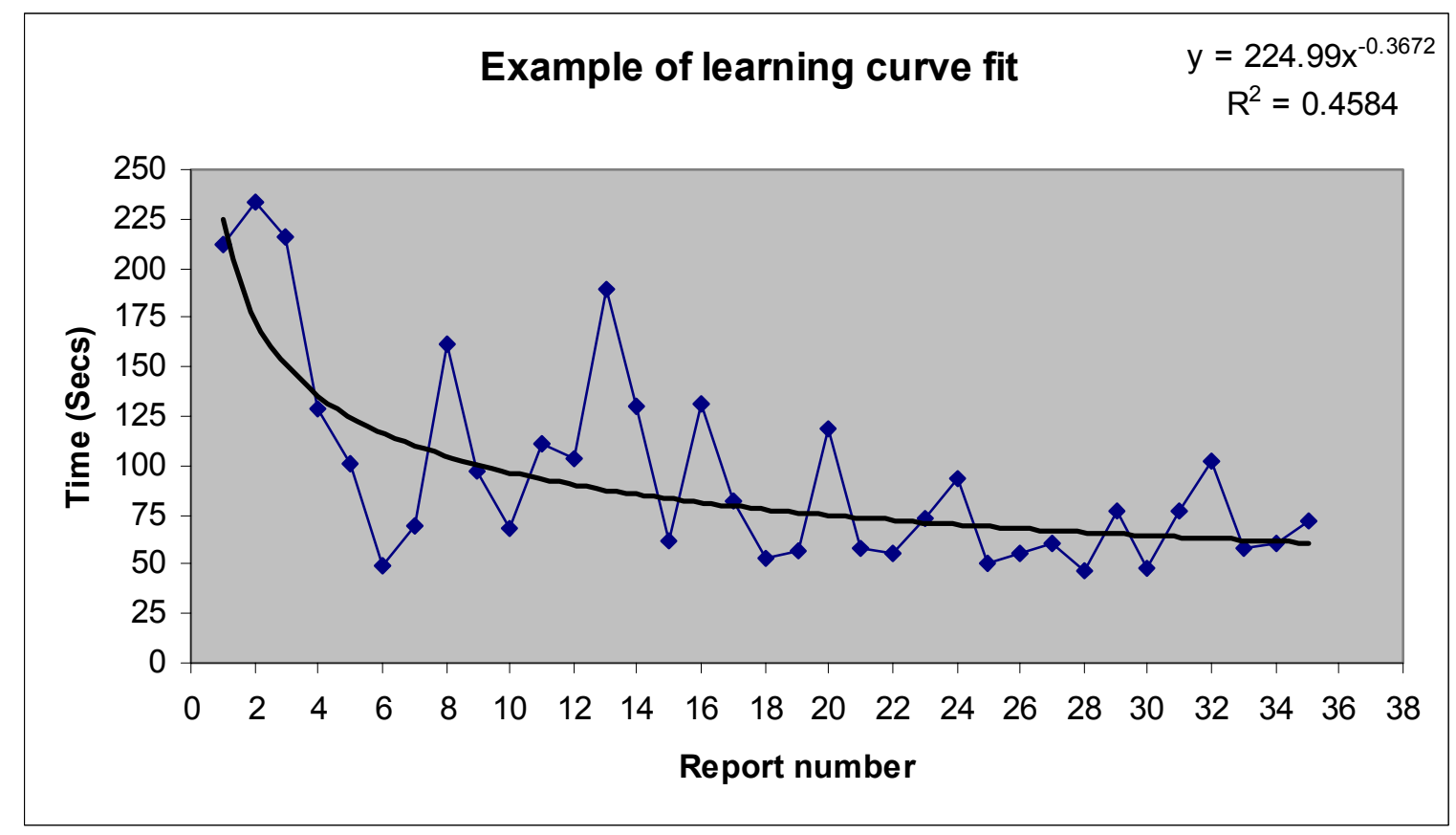

Learning curves of the type described and shown in the graph above were fit to the data of each subject in the experiment. The data used was the data that took into account the defects, found in Appendix C. Appendix C also contains the graphs of each subject's data with a fitted learning curve. The data for a subject trained by specific training type corresponds with the graph next to it. The equation on the graph corresponds to the learning curve fit to that particular data. Table 3.5 below lists all the learning curves, Rsquared values, and learning rates of the 16 subjects according to their training type.

Table 3.5 also lists the overall curve and learning rate for the training type. The explanation of the determination of this overall learning curve is discussed in the following section. 
Table 3.5

\begin{tabular}{|c|c|c|c|}
\hline \multicolumn{4}{|c|}{ Fitted Learning Curves for each individual and average of training type } \\
\hline \multicolumn{4}{|c|}{ Observe and Do } \\
\hline Subject & Equation & R-squared value & Learning Rate \\
\hline Aug. 26, 8:00 am & $Y=196.65^{\star} X^{\wedge}(-.0603)$ & 0.0149 & $95.9 \%$ \\
\hline Aug. 26, 2:00 pm & $Y=194.47^{\star} X^{\wedge}(-.2686)$ & 0.2746 & $83.0 \%$ \\
\hline Aug. 26, 5:00 pm & $\mathrm{Y}=121.94^{\star} \mathrm{X}^{\wedge}(-.1227)$ & 0.124 & $91.8 \%$ \\
\hline Aug. 27, 8:00 am & $Y=306.18^{*} X^{\wedge}(-.2538)$ & 0.5576 & $83.9 \%$ \\
\hline Average & $Y=201.71^{\star} X^{\wedge}(-.1737)$ & N/A & $88.7 \%$ \\
\hline \multicolumn{4}{|c|}{ Manual } \\
\hline Subject & Equation & R-squared value & Learning Rate \\
\hline Aug. 27, 2:00 pm & $Y=187.73^{*} X^{\wedge}(-.1097)$ & 0.1275 & $92.7 \%$ \\
\hline Sept. 3, 5:00 pm & $Y=342.95^{\star} X^{\wedge}(-.3467)$ & 0.3338 & $78.6 \%$ \\
\hline Sept. 4, 8:00 am & $Y=226.05^{\star} X^{\wedge}(-.1576)$ & 0.2829 & $89.7 \%$ \\
\hline Sept. 24, 2:00 pm & $\mathrm{Y}=224.99^{\star} \mathrm{X}^{\wedge}(-.3672)$ & 0.4584 & $77.5 \%$ \\
\hline Average & $Y=239.86^{*} X^{\wedge}(-.2357)$ & N/A & $84.9 \%$ \\
\hline \multicolumn{4}{|c|}{ Class } \\
\hline Subject & Equation & R-squared value & Learning Rate \\
\hline Sept. 5, 2:00 pm & $Y=120.31^{\star} X^{\wedge}(-.1991)$ & 0.3071 & $87.1 \%$ \\
\hline Sept. 23, 3:30 pm & $Y=61.595^{\star} X^{\wedge}(.0429)$ & 0.0213 & $103.0 \%$ \\
\hline Sept. 24, 10:00 am & $Y=133.64^{\star} X^{\wedge}(-.0871)$ & 0.0376 & $94.1 \%$ \\
\hline Sept. 24, 4:30 pm & $Y=165.70^{\star} X^{\wedge}(-.2512)$ & 0.3642 & $84.0 \%$ \\
\hline Average & $Y=117.70^{\star} X^{\wedge}(-.1333)$ & N/A & $91.2 \%$ \\
\hline \multicolumn{4}{|c|}{ Mentor/Manual } \\
\hline Subject & Equation & R-squared value & Learning Rate \\
\hline Sept. 3, 8:00 am & $Y=217.85^{\star} X^{\wedge}(-.2232)$ & 0.3446 & $85.7 \%$ \\
\hline Sept. 3, 11:00 am & $Y=202.02^{*} X^{\wedge}(-.1775)$ & 0.2322 & $88.4 \%$ \\
\hline Sept. 3, 2:00 pm & $Y=124.20^{\star} X^{\wedge}(-.0488)$ & 0.0211 & $96.7 \%$ \\
\hline Sept. 4, 2:00 pm & $Y=270.97^{\star} X^{\wedge}(-.3373)$ & 0.5484 & $79.2 \%$ \\
\hline Average & $\mathrm{Y}=200.03^{\star} \mathrm{X}^{\wedge}(-.2017)$ & N/A & $87.0 \%$ \\
\hline
\end{tabular}

\subsubsection{Overall learning curve for one training type}

The overall learning curve for each training type was a combination of the learning curves for the four subjects of that training type. The learning curve for each training type was determined by using the equations of the individual learning curves. First, the equations of the four subject's learning curve for a particular training type were used to estimate a time corresponding to each report number. For instance, the equation determined the amount of time to produce $1,2,3 \ldots 40$ reports. This was done for each subject's learning curve up to 40 reports. Then, the average of the times for each report 
number was calculated. A new learning curve was fit to the average points. This learning curve was the learning curve of that training type.

Appendix D shows points projected from the learning curves fitted to each subject. The averages for the training type are in the last column. Figure 3.6 below shows the learning curves fitted to each subject's data for the observe and do training type. In this case, the average data falls in the middle of two of the individual subject's learning curves. The fitted learning curve for the average data is denoted by the equation in the upper right hand corner of the figure.

\section{Figure 3.6}

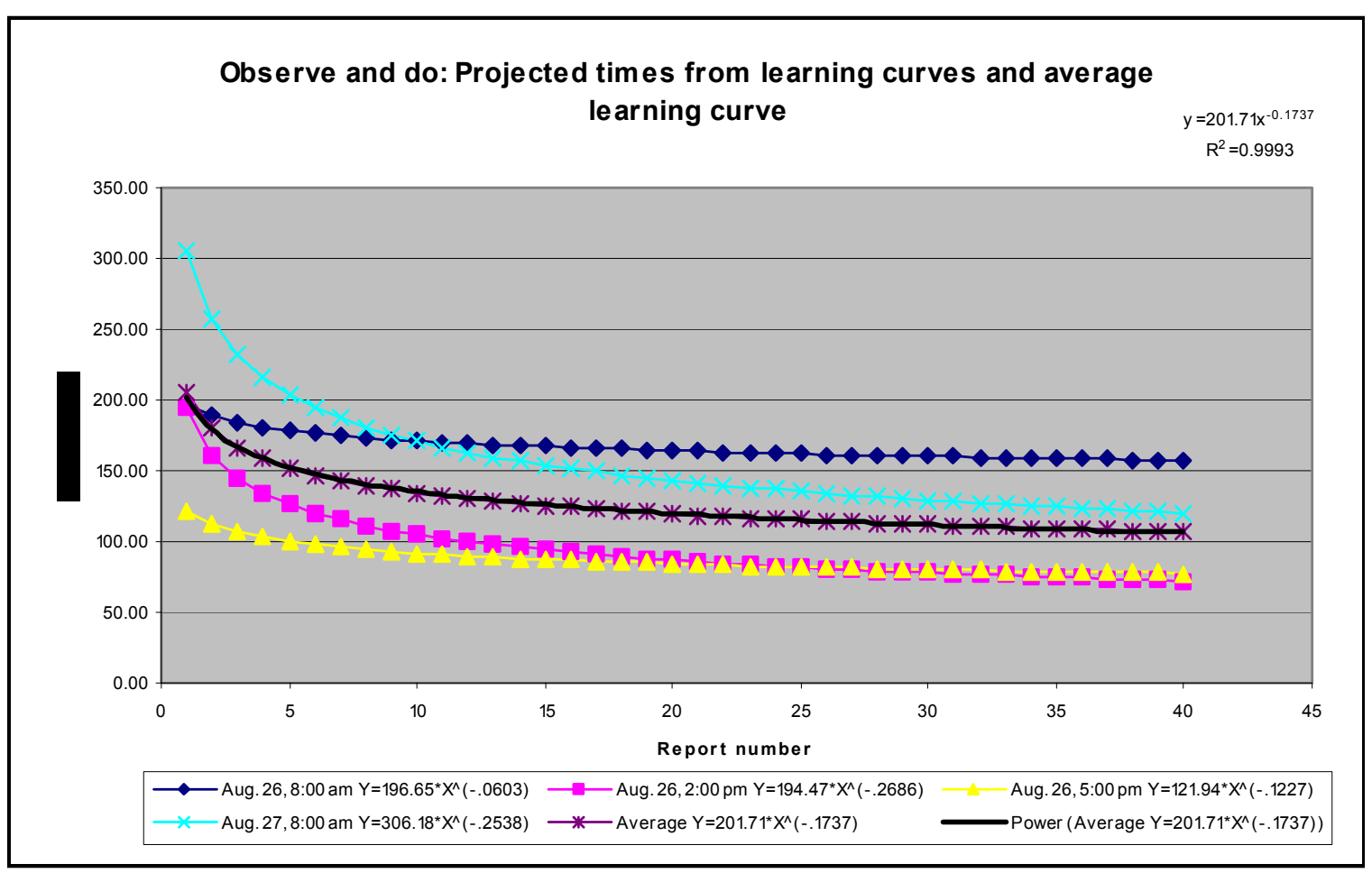

This and the other charts that show the fitting of the learning curve to the average data are located in Appendix D.

This method of calculating the average learning curve by projecting the four subject's learning curves and fitting the overall learning curve to the results was selected 
over other options. Two other options are using the average data in a regression model and using all the data in a regression model.

Using the average data in a regression model to calculate the learning curve involved averaging all the values for the different training types for each report number then fitting the learning curve to the average points. This option was not selected due to the up and down nature of the subject's individual data. With this method, the jumping of the data can cause inaccuracies in the overall learning curve. For example, if the time to produce report number 5 for all of the subjects was high for all of the subjects compared to the surrounding data points, and report number 6 for two of the subjects was high compared to the surrounding data point and low for the other two, calculating the learning curve with this method can cause report number 5 to be irregularly high. Averaging all the points could cancel out the inconsistencies in one report number (report number 6 in this example) and the high and low variation in the data could be smoothed, but increase the effects of the inconsistencies in another case (report number 5). With the average of the data points possibly being more inconsistent that the original data sets, simply averaging the actual data points cannot be a good method for determining the overall learning curve for a particular training type because the averaging can cause key data characteristics to be lost or flawed. Figure 3.7 illustrates this phenomenon. 


\section{Figure 3.7}

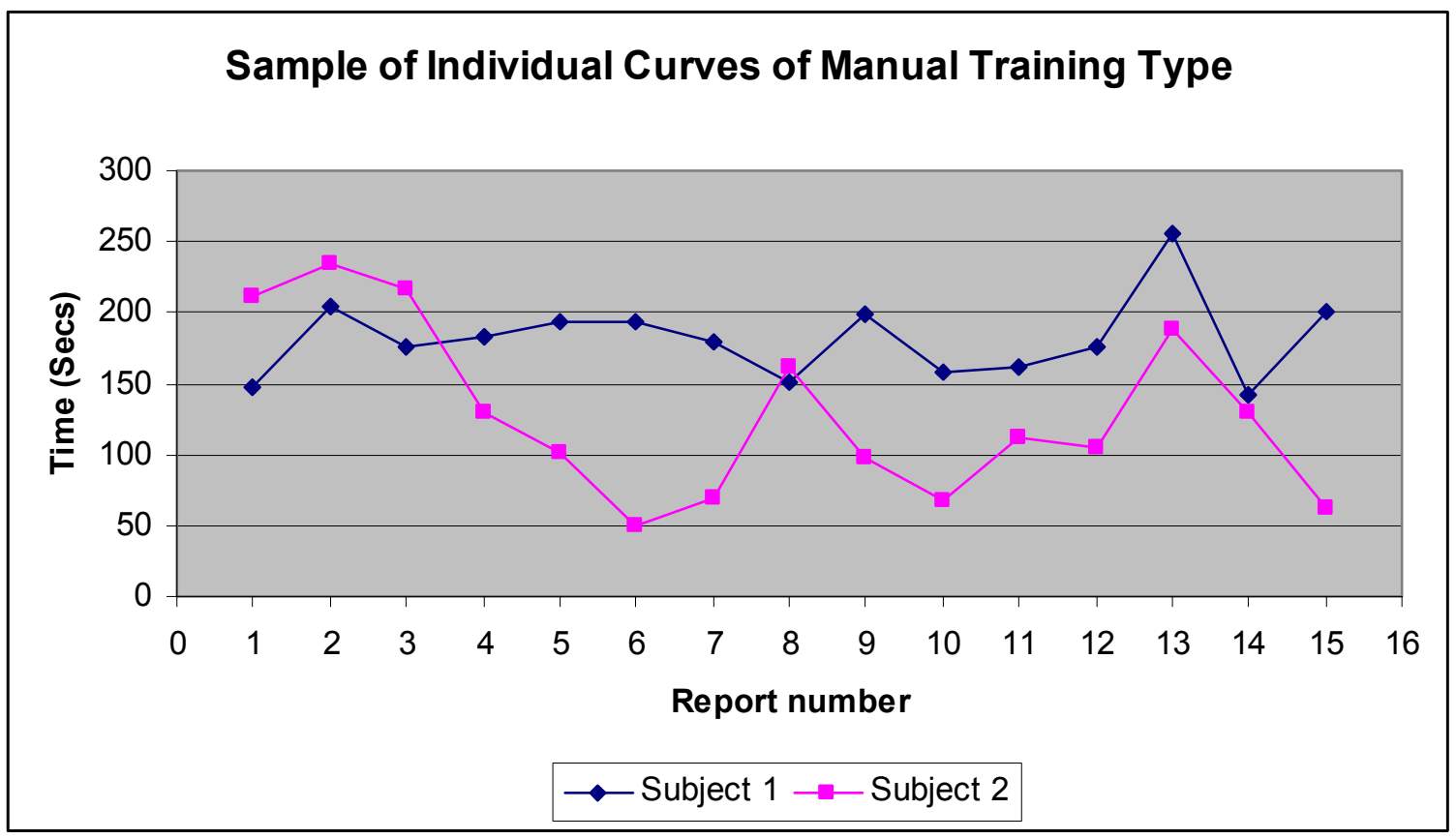

The data for this chart is a sample of two subjects from the manual training type. The data from these two curves does not decrease consistently. Subject 2's time starts out higher than subject 1's but ends up lower. The average of report number 6 will cause be a point that is consistent with the overall learning curve because subject 1's point is high and subject 2's point is low. However, averaging report number 13 will yield a point that is not consistent with the learning curve pattern because both subject 1's and subject 2's points are high. Some of the point averages will cancel the effects of uncharacteristic high or low points, but some will not. Therefore, averaging the raw data may not yield the best overall learning curves.

Likewise, using all data in a regression model is not the method of choice for determining the overall learning curve of a training type. Similar to the previous method discussed, key data characteristics may be lost or the data may be flawed from using all data points together in a regression model because some of the points for a particular report number will cancel each other out, while could increase high or low effects of the 
data. Again, the inconsistencies in the data cause this method to be inaccurate since essentially, the raw data of the subjects are compared to each other.

The method of choice, projecting individual learning curves and averaging the projects for the overall learning curve, rids the data of all inconsistencies caused by the up and down nature of the data. This method gives the most accurate representation of the overall learning curve.

\subsubsection{Comparing the learning curves of different training types}

The following chart contains the overall learning curves of each of the training types. The learning curve equations were used to interpret the data to 275 reports. Two hundred and seventy-five reports corresponds to the approximate number of report that would be completed by a worker trained by the observe and do training type in one day ( 7 production hours), and therefore is selected as one of the time periods that this paper will discuss for determining the Return on the investment in training. 


\section{Figure 3.8}

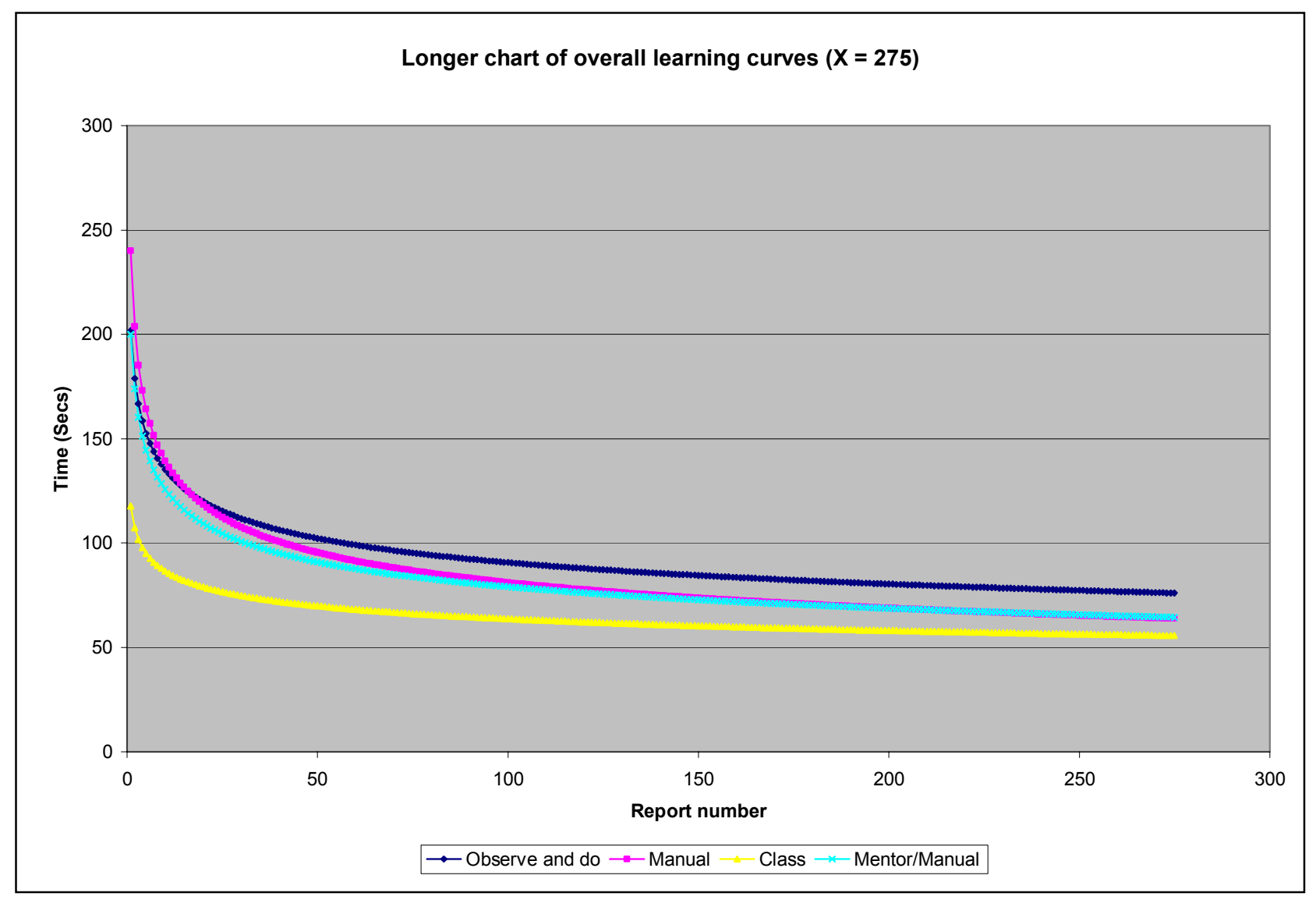

Figure 3.8 shows that the effect of break-in training on the learning curve of the individuals is apparent. The observe and do curve has a higher report production time than all of the three training types.

In order to focus on the immediate impacts of the break-in training, the production time of the first 40 reports was examined. Because the differences among these production time can be hard to see in figure 3.8, another figure, figure 3.9 is presented below. 


\section{Figure 3.9}

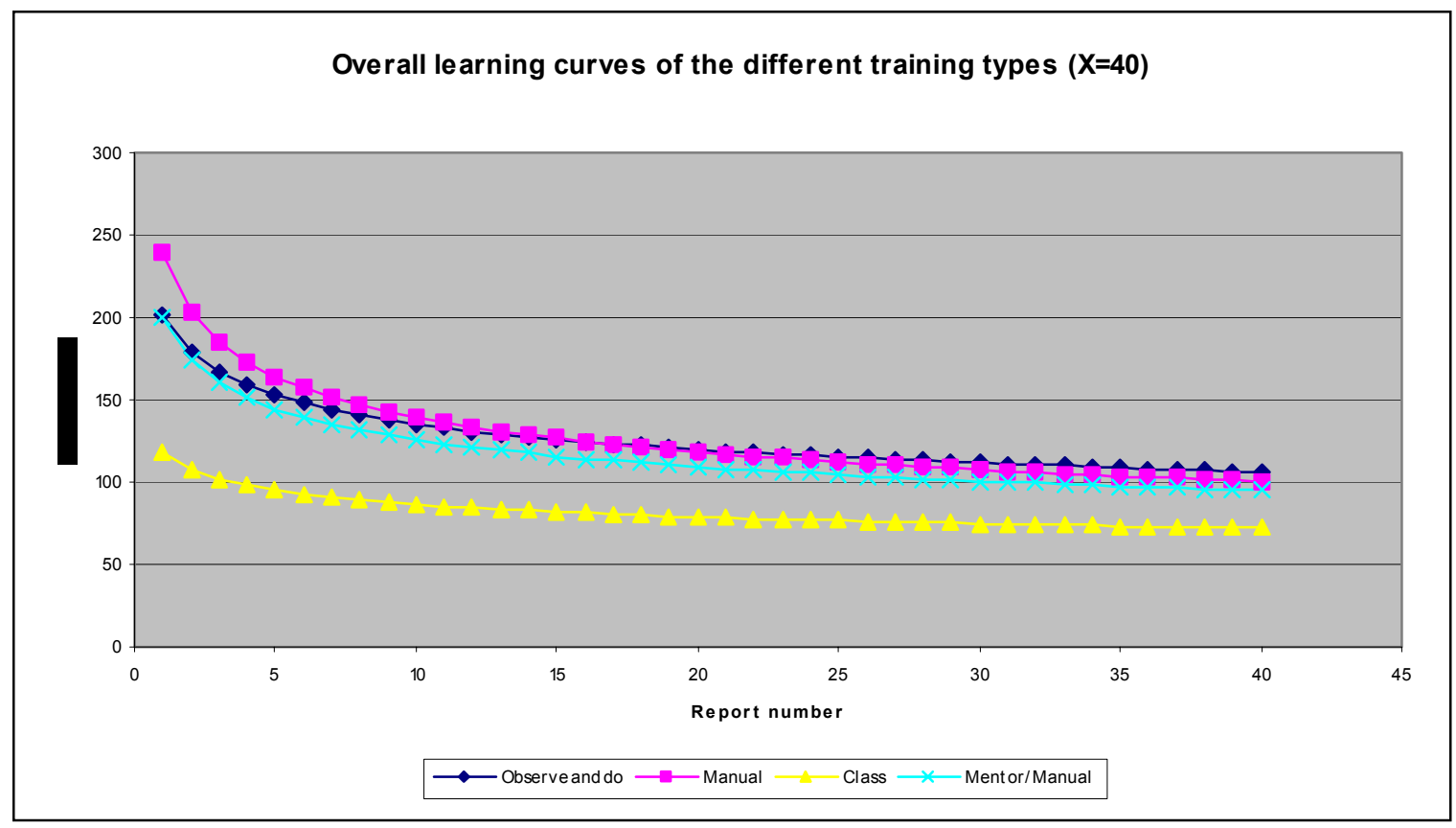

The comparisons of the initial learning curves show that the initial time to produce a report with the observe and do training is less than the initial time to produce a report with the manual training. Time to produce report numbers 1 though 16 take more time for those trained by the manual than those trained by observe and do. However, the slope of the learning curve of the manual training is initially steeper than the slope of the observe and do, so that the production time of the those trained with the manual dips lower than those trained with observe and do at the $17^{\text {th }}$ report.

Individuals trained by class training type do not have such a steep slope in their learning curve. However, the initial production times of those trained by the class is significantly lower than the traditional training type. Since the production times of the class training type are so low, they stay consistently lower than the observe and do training type's production times.

The manual training type's initial production time is approximately 2 times the class training type's initial training time. One reason for the large difference is that the 
subjects trained by the class already had two trials to practice binding the report so their initial times are lower. The hands-on experience from the class allows them to reduce their report binding time before they bind the first report in production. The two trial reports do not count towards the total number of reports bound in the experiment since they were meant specifically for training. Another for the large difference is because subjects who were trained with the manual completed their first reports directly in production and sometimes took time to refer back to the manual, causing the initial production time to be high. On the other hand, the improvement rate of the subjects with the manual $(15.1 \%)$ is greater than the improvement rate of the subjects trained by the class $(8.8 \%)$ so that eventually, the learning curve of the manual meets and crosses the learning curve of the class.

The mentor/manual training type's production times may start out similar to the observe and do's, but the mentor/manual has a steeper slope. The mentor/manual's production time become significantly lower than the observe and do's by the $5^{\text {th }}$ report.

Appendix E contains these charts and more that correspond to approximately 1 week of work (1921 reports) and close to 4 weeks of work (10000 reports). These additional charts were developed in order to project the extended effects of the training if learning continues at the rate charted by the learning curves. Even though the report times are not expected to completely follow the curves that are projected to the $10,000^{\text {th }}$ report, they are expected to follow the general trend that trained employees take less time to produce quality reports than untrained employees. The immediate effects in production time are apparent from the experiment and learning curves that resulted. Financial effects on the company as a result of the investment in training will be developed in the following chapters. 


\section{CHAPTER 4:}

DEVELOP ROI MODEL USING LEARNING CURVES AS A BASIS 


\subsection{CHAPTER OVERVIEW}

In Chapter 4, a return on investment model is developed using the learning curves as a basis. The chapter identifies the different factors that are involved with determining the return for the investment in training. The learning curves developed in chapter 3 are some of these factors. The other factors that affect the return are training cost, material costs, quality cost, and money obtained from selling the reports. This chapter shows how these factors are established in the model as well as their actual numerical values for the different training types. Finally, these factors are included together in a model that will determine the ROI for different training types. The final result of this chapter will be equation that will yield the return on investment of break-in training. The data for many of the factors will be presented as they are discussed in this chapter. Inputting the data into the model and determining the return is part of Chapter 5. 


\subsection{REVIEW OF ROI}

Previously, ROI was discussed to be the financial return of an investment after a specified time period. ROI is calculated by subtracting the profit of the traditional training from the profit from the break-in training during that time period. Profit is determined from subtracting the cumulative costs from the cumulative benefits of an individual training type. The break-even point is the place where the profit of both equals each other. At the break-even point, the investment has paid for itself in returns. During the time period before the break-even point, the company has not made enough money to rationalize spending money on a particular investment. But in this and most models, continuing production after the break-even point yield profits above and beyond the profits that the company would have seen if not making the investment. The break-even point is critical because knowing it can help the company make critical decisions on investments. For example, if company executives do not see the company reaching the break-even point in an investment (such an occurrence would be an employee leaving the firm before the effect of the investment in his or her training is made up in performance), then the company should decide not to make the investment.

The ROI model will also determine the return from an investment at different time periods. This is useful because the company managers can use this model to project profits or losses due to the investment at different times. This is especially useful when the profits of two investment alternative need to be compared. In our training example, if a manager predicts that an employee will stay at a certain job for a period of time, they can compare the profit for each training type at that designated time period. The type with the highest amount should be selected.

The ROI model in this chapter will aid managers that are investing in break-in training. As with the learning curves, the count of reports will represent the passing of time, and will be charted on the $\mathrm{x}$-axis. The factors that could influence the cumulative benefits or cumulative cost can either be fixed or variable. A fixed cost or benefit means 
that that amount occurs at one designated period of time. A variable cost or benefit means that it is reoccurring over time. In the model, the training cost is fixed. The variable benefits include money received from selling each report. These fixed and variable factors play a huge role in the ROI model and will be discussed in the "Factors" section. 


\subsection{MODEL ESTABLISHING METHODOLOGY}

The following steps were taken to establish the ROI model for break-in training:

1. Determine factors that influence the model

2. Determine the Return (Benefits-Cost) for each training type individually.

3. Determine the Return for break-in training by subtracting the return from the traditional training type from the return of one of the break-in training types.

This methodology develops an equation that can be used to determine the ROI of the various training types. The three steps are described in detail in the next sections. Actual numbers for the factors are presented.

\section{$\underline{4.3 .1 \text { Factors }}$}

In this section, the factors influencing the ROI model are identified and discussed in detail. Numbers corresponding with the factor for the four training types will be presented. The factors that influence the model are the training cost, the material cost, the labor cost, the cost of quality, and the money received for reports sold.

Each of the factors will be given a letter to represent that amount in the model. Also, the model will use the numbers " $1,2,3$, and 4" after each letter to indicate the training type represented in that model. For example, the symbol "T1" indicates the cost of training for the observe and do training type.

\subsection{1.a Training cost}

The training cost is a fixed cost that occurs at the beginning of production. The training cost reflects all costs involved with the break-in training of the employee new to the task. This includes all training labor and material costs. Each of the four training 
types incurred a different training cost. The data used to determine these training costs was gathered during the experiment.

Data for the labor cost of training was determined by timing the training. Any time utilized by the employee for training was charged at a rate of $\$ 6.00 /$ hour. The labor rate of the trainer is $\$ 12.00 /$ hour. The labor rate of the mentor was $\$ 9.00 /$ hour.

Data for the material cost, if any, was $\$ .13$ for each binding used and $\$ .02$ for printing a paper cost of each page.

The determination of training costs for each type is described in its respective section. All of the training costs are fixed and occur once at the beginning of production. The symbol for training cost is: $\quad T(\$)$

\section{Training type \#1: Observe and Do}

The cost of training for the observe and do training type is probably the least complicated of all the training type cost. The only cost involved with this training type are the labor costs of the trainer and subjects.

In order to determine the average training cost the training time for had to be calculated using the data gathered in the experiment. The training times for all training subjects and the corresponding averages for the type can be seen in Appendix F. Here the average training time was 71.75 seconds. Both the trainer and the worker participated in the training for the 71.75 seconds. Chart 4.1 shows the labor amount calculations. Note that the average time is multiplied by the labor rate for both the trainer and the employee. The total labor cost is added together. 


\section{Chart 4.1}

\begin{tabular}{|l|c|l|c|c|}
\hline \multicolumn{4}{|c|}{ Labor cost of Observe and Do } \\
\hline & Training labor cost & $\begin{array}{c}\text { Average } \\
\text { training time } \\
\text { per } \\
\text { employee } \\
\text { (secs) }\end{array}$ & $\begin{array}{c}\text { Cost for } \\
\text { training per } \\
\text { employee }\end{array}$ \\
\cline { 1 - 3 } Training cost & per hour & per sec & 71.75 & $\$ 0.24$ \\
\hline trainer & $\$ 12.00$ & $\$ 0.00333$ & 71.75 & $\$ 0.12$ \\
\hline worker & $\$ 6.00$ & $\$ 0.00167$ & & $\$ \mathbf{0 . 3 6}$ \\
\hline TOTAL
\end{tabular}

Then, chart 4.2 adds the different costs associated with training. Since the labor cost is the only cost, this math is quite easy, yielding a cost of $\$ .36$. This amount will be considered an initial fixed cost in the model.

\section{Chart 4.2}

\begin{tabular}{|l|r|}
\hline \multicolumn{2}{|c|}{ Total cost calculations } \\
\hline Labor cost of training per subject & $\$ 0.36$ \\
\hline TOTAL cost of training per subject & $\mathbf{\$ 0 . 3 6}$ \\
\hline
\end{tabular}

\section{Training type \#2: Manual Only}

The training cost for the Manual training type involves the following: labor cost for the employee, labor cost of the trainer, and cost of the manual. Since the trainer is not present while the employee reads the manual, the time that the hourly wage is multiplied for the trainer is different than that of the employee.

Again, the training times were gathered during the experiment and the average training time for the trainer and the worker is calculated in Appendix F. The average training time for the trainer was 96 seconds and the average time spent on training for the worker was 675 seconds. Chart 4.3 below uses this information to calculate the total labor cost of the manual training type per employee. 


\section{Chart 4.3}

\begin{tabular}{|c|c|c|c|c|}
\hline \multicolumn{5}{|c|}{ Labor Cost of Manual Training } \\
\hline \multirow{2}{*}{$\begin{array}{c}\text { Training } \\
\text { cost }\end{array}$} & \multicolumn{2}{|c|}{ Training labor cost } & \multirow{2}{*}{$\begin{array}{c}\text { Average } \\
\text { training time } \\
\text { per employee } \\
\text { (secs) }\end{array}$} & \multirow{2}{*}{$\begin{array}{l}\text { Labor cost for } \\
\text { training per } \\
\text { employee }\end{array}$} \\
\hline & per hour & per sec & & \\
\hline trainer & $\$ 12.00$ & $\$ 0.00333$ & 96.25 & $\$ 0.32$ \\
\hline worker & $\$ 6.00$ & $\$ 0.00167$ & 675.25 & $\$ 1.13$ \\
\hline \multicolumn{4}{|l|}{ TOTAL } & $\$ 1.45$ \\
\hline
\end{tabular}

Along with the labor cost, the cost of preparing the manual and the material cost of the manual had to added together to get the total training cost for the manual training type.

The calculations for the manual cost are shown in chart 4.4 below. These costs include the labor, materials, and photo-developing costs associated with the preparation of the manual. The preparation costs were divided among the eight individuals who used the manual as part of their training. Each of the workers trained with a manual received their own copy of the manual, so the material cost is not divided among the group. The chart also offers the manual cost calculations for those trained by the mentor/manual training type.

\section{Chart 4.4}

\begin{tabular}{|c|c|c|}
\hline \multicolumn{3}{|c|}{ Manual Cost } \\
\hline \multicolumn{3}{|c|}{ Preparation cost (divided among 8 subjects) } \\
\hline preparation time (hours) & & 3 \\
\hline preparation cost per hour & $\$$ & 12.00 \\
\hline photo developing & $\$$ & 6.00 \\
\hline Total preparation cost & $\$$ & 42.00 \\
\hline Preparation cost per subject & $\$$ & 5.25 \\
\hline \multicolumn{3}{|c|}{ Material cost (each subject receives his/her own manual) } \\
\hline binding & $\$$ & 0.13 \\
\hline papers & $\$$ & 0.28 \\
\hline Material cost per subject & $\$$ & 0.41 \\
\hline TOTAL MANUAL COST & $\$$ & 5.66 \\
\hline
\end{tabular}

Chart 4.5 summarizes the total training cost for the manual training type. 


\section{Chart 4.5}

\begin{tabular}{|l|l|}
\hline \multicolumn{2}{|c|}{ Total cost calculations } \\
\hline Cost of manual per subject & $\$ 5.66$ \\
\hline Labor cost of training per subject & $\$ 1.45$ \\
\hline TOTAL cost of training per subject & $\$ 7.11$ \\
\hline
\end{tabular}

\section{Training Type \#3: Class}

The class training cost includes labor cost and the material cost for the reports that are bound during the class. The time for the training was recorded during the experiment and the average training time was calculated. This can be seen in Appendix F. Both the trainer and the worker participate in the same amount of training, so their labor rates both have to be multiplied by 527 seconds, the average training time. The calculations for the labor cost of training can be seen in chart 4.6.

\section{Chart 4.6}

\begin{tabular}{|c|c|c|c|c|}
\hline \multicolumn{5}{|c|}{ Labor Cost of Class Training } \\
\hline \multirow[b]{2}{*}{ Training cost } & \multicolumn{2}{|c|}{ Training labor cost } & \multirow{2}{*}{$\begin{array}{c}\text { average training } \\
\text { time per } \\
\text { employee (secs) }\end{array}$} & \multirow{2}{*}{$\begin{array}{l}\text { labor cost for } \\
\text { class training } \\
\text { per employee } \\
\end{array}$} \\
\hline & per hour & per sec & & \\
\hline trainer & $\$ 12.00$ & $\$ 0.00333$ & 527 & $\$ 1.76$ \\
\hline worker & $\$ 6.00$ & $\$ 0.00167$ & 527 & $\$ 0.88$ \\
\hline \multicolumn{4}{|l|}{ TOTAL } & $\$ 2.64$ \\
\hline
\end{tabular}

The cost of the materials used to train each employee is calculated in chart 4.7 below. 


\section{Chart 4.7}

\begin{tabular}{|l|c|cc|cr|}
\hline \multicolumn{5}{|c|}{ Material cost (for material used in class) } \\
\hline Item & Amount used & \multicolumn{2}{|c|}{ Cost } & \multicolumn{2}{|c|}{ Total } \\
\hline Bindings & 3 & $\$$ & 0.13 & $\$$ & 0.39 \\
\hline Paper & 60 & $\$$ & 0.02 & $\$$ & 1.20 \\
\hline TOTAL & \multicolumn{7}{|c|}{} & $\$$ & 1.59 \\
\hline
\end{tabular}

The labor cost and material cost for each employee is summarized in chart 4.8.

\section{Chart 4.8}

\begin{tabular}{|l|l|}
\hline \multicolumn{2}{|c|}{ Total cost calculations } \\
\hline Cost of materials per subject & $\$ 1.59$ \\
\hline Labor cost of training per subject & $\$ 2.64$ \\
\hline TOTAL cost of training per subject & $\$ 4.23$ \\
\hline
\end{tabular}

\section{Training type \#4: Mentor/Manual}

The labor cost calculation for the mentor/manual training type is the most extensive of all the training types. The calculation included the labor cost of the worker, trainer, and mentor, and the material cost of the manual. The material cost of the manual is calculated the same was as in the Manual only training type. The labor cost of the mentor is $\$ 9.00$ /hour because the mentor is usually a more senior member of the team, therefore receiving a bigger salary than the new employee. The time that the mentor spends aiding the new worker is the time that is multiplied by his/her hourly rate to get the mentor labor cost. The time the mentor spends aiding the employee was recorded during the experiment. Different subjects required different amounts of help so the average of the four subject's mentor time was tabulated for the mentor labor time in the model. The model assumes that all mentoring is completed during the time measured in the experiment because mentors are usually no longer needed after the subject reached a mature production time. The time that the employee spends with the mentor does not count towards the employee's training time because during that time, he or she is completing reports on the line. The calculation of the training time for the worked, mentor and trainer for the mentor/manual training type is calculated in Appendix F. 
The times retrieved from the calculations in Appendix F are used in chart 4.9 below to calculate the total labor cost associated with the mentor/manual training.

\section{Chart 4.9}

\begin{tabular}{|l|c|c|c|c|}
\hline \multirow{2}{*}{} & \multicolumn{3}{|c|}{ Labor Cost of Mentor and Manual Training } \\
\hline Training cost & per hour & per sec & $\begin{array}{c}\text { Average training } \\
\text { employee (secs) }\end{array}$ & $\begin{array}{c}\text { Labor cost for } \\
\text { training per } \\
\text { employee }\end{array}$ \\
\hline trainer & $\$ 12.00$ & $\$ 0.00333$ & 70.25 & $\$ 0.23$ \\
\hline worker & $\$ 6.00$ & $\$ 0.00167$ & 653 & $\$ 1.09$ \\
\hline mentor & $\$ 9.00$ & $\$ 0.0025$ & 818.375 & $\$ 2.05$ \\
\hline TOTAL & \multicolumn{3}{|l}{} & $\$ 3.37$ \\
\hline
\end{tabular}

The total time for the mentor/manual training cost involves the $\$ 3.37$ of labor and $\$ 5.66$ for the manual. The calculations for the manual cost are in chart 4.4 in the section for training type \#2. Chart 4.10 below shows the total training costs of the mentor/manual training type.

\section{Chart 4.10}

\begin{tabular}{|l|l|}
\hline \multicolumn{2}{|c|}{ Total cost calculations } \\
\hline Cost of manual per subject & $\$ 5.66$ \\
\hline Labor cost of training per subject & $\$ 3.37$ \\
\hline TOTAL cost of training per subject & $\$ 9.03$ \\
\hline
\end{tabular}

\subsection{1.b Material Cost}

The material cost is a factor in the model that deals with the cost of the materials used to produce each report. Because the material cost changes according to the number of report produced, the material cost is a variable cost. The total material cost is the material cost of one report multiplied by the total number of reports produced (including defects). The material cost of each training type is the same because all subjects are completing the same task. The breakdown of the material cost for one report is show in chart 4.11 below. 


\section{Chart 4.11}

\begin{tabular}{|c|c|}
\hline \multicolumn{2}{|l|}{ Material cost } \\
\hline paper and printing (\$0.02/page) & $\$ 0.40$ \\
\hline binding & $\$ \quad 0.13$ \\
\hline TOTAL & $\$ 0.53$ \\
\hline
\end{tabular}

In the model the material cost is represented by the letter: $M(\$ /$ report $)$ The total cumulative material cost will be determined by the equation:

\section{Total cumulative material cost $=M * X$}

Where $X$ is the total number of reports produced. In the ROI model associated with this experiment, the total material cost $=\$ .53^{*} X$.

\subsection{1.c Labor Cost}

The labor cost utilizes the learning curves developed in the previous chapter. The labor cost for one report is the cost of the labor for the worker, usually in a $\$ /$ hour form, multiplied by the time that the worker takes to produce that report, determined by the overall learning curve for a particular training type. The cumulative cost of labor is the labor cost of the current report plus all the labor costs of the previous reports. Since the time to produce one report changes according the report number, the overall labor cost is a summation of the previous and current reports' labor cost. The labor cost is a variable cost since it occurs with each report. The actual amount varies also with each report. The labor cost for a particular report is represented by the symbol: $\quad L$ (\$/report)

Where $L=(D / 3600) * C a * X^{C b}$

And $D$ equals the dollars per hour labor rate of the worker, $X$ equals the report number, and $C a$ and $C b$ are constants from the learning curve equation calculated in Chapter 3. The learning curve equation is also represented my the symbol, $Y$, which signifies the 
time to produce a report in seconds. The following equation represents the learning curve and the time to produce the $X$ th report.

$$
Y=C a * X^{C b}
$$

Where $Y=$ time (secs)

$X=$ report number

And $C a$ and $C b$ are constants of the learning curve. ( $C a$ and $C b$ are the same as $A$ and $N$, which were described in an earlier learning curve equation. The symbols $C a$ and $C b$ will be used in the remainder of this thesis.)

This equation can be substituted in to labor cost equation so that:

$$
L=(D / 3600) * Y
$$

The labor rate is divided by 3600 to convert from the labor rate $\$$ hours to $\$ /$ seconds.

The labor rate for each worker is the same, $\$ 6.00 /$ hour. Inputting this value into the above equation yields the following labor costs for each training type:

\section{Chart 4.12}

\begin{tabular}{|l|l|}
\hline \multicolumn{1}{|c|}{ Training type } & \multicolumn{1}{c|}{ Labor cost } \\
\hline Observe and Do & $\mathrm{L}=.3361833^{\star} \mathrm{X}^{\wedge}(-.1737)$ \\
\hline Manual & $\mathrm{L}=.3997667^{\star} \mathrm{X}^{\wedge}(-.2357)$ \\
\hline Class & $\mathrm{L}=.1961667^{\star} \mathrm{X}^{\wedge}(-.1333)$ \\
\hline Mentor/Manual & $\mathrm{L}=.3333833^{\star} \mathrm{X}^{\wedge}(-.2017)$ \\
\hline
\end{tabular}

Where $X=$ the report number, and $L=$ the labor cost per report corresponding with $X$ 
To calculate the cumulative effects of the labor cost on the model, the labor cost for all reports completed must be summed. The following equations describe the total cumulative labor costs for each training type.

\section{Chart 4.13}

\begin{tabular}{|l|l|}
\hline \multicolumn{1}{|c|}{ Training type } & \multicolumn{1}{c|}{ Cumulative Labor Cost } \\
\hline Observe and Do & Total cumulative labor cost $=$ Sum from $(I=1)$ to $X\left[.3361833^{*} X^{\wedge}(-.1737)\right]$ \\
\hline Manual & Total cumulative labor cost $=$ Sum from $(I=1)$ to $X\left[.3997667^{\star} X^{\wedge}(-.2357)\right]$ \\
\hline Class & Total cumulative labor cost $=$ Sum from $(I=1)$ to $X\left[.1961667^{\star} X^{\wedge}(-.1333)\right]$ \\
\hline Mentor/Manual & Total cumulative labor cost $=$ Sum from $(I=1)$ to $X\left[.3333833^{*} X^{\wedge}(-.2017)\right]$ \\
\hline
\end{tabular}

Or in general:

$$
\text { Total cumulative labor cost }=\sum_{i=1}^{X}\left[\left(\frac{D}{3600}\right) * C a * X^{C b}\right]
$$

Where the total cumulative labor cost is in dollars.

The learning curves become extremely important in the labor cost equation because they capture the financial effect of the training on the labor cost. This will be useful in the model because the curves allow the changing labor costs of training types to be compared.

\subsection{1.d Quality Cost}

The previous chapter discussed the issue of quality and how the quality of the reports was noted in the model. This section converts the quality designations in the data into costs and benefits. This section will show how the quality of the reports affects the ROI model.

Chapter 3 identified two quality designations that affect the model. The reports that have the "X" designation and the "S-" designation will have a financial impact on the 
model. Note that the " $\mathrm{X}$ " designation stands for a defect that cannot be repaired. The "S-" designation represents reports that can be repaired, but will utilize labor hours to do so.

During the experiment the reports that were given an " $\mathrm{X}$ " and a "S-" were tracked, along with other designations. As stated earlier, the " $\mathrm{X}$ " reports were not used to fit the learning curves for an individual subject because the times in the data may not be representative of the production time for that particular number report. Regardless, at the end of the experiment, there was a total number of defects tallied for each report type. The count of "X" and "S-" designations can be seen in Appendix G.

In order to take the defects into account in the model, the number of " $\mathrm{X}$ ' $\mathrm{s}$ " per report made and "S-'s" per report made had to be calculated. These were calculated in Appendix $\mathrm{G}$ in the latter columns. The $\mathrm{X}$ and $\mathrm{S}-\mathrm{defect} /$ total report ratio was calculated for each training type's four subjects. Then these were averaged to get the average ratio for each training type.

Reports with the " $\mathrm{X}$ " designation were reports that cannot be sold to the distributor nor can be fixed because the defect is too great. Thus, these reports had to be scrapped. The company cannot make any money from these reports, so these bad reports had to be taken away from the benefits in the model. This cost is spread evenly among the reports developed by the model. Therefore, the " $X$ " defect/report made ratio was multiplied by the benefit from each report to get the cost of the defects per report. Then, that value was subtracted from the financial gain from each report from each report made, yielding the total benefit from the report. More will be discussed about the financial gain from each report in the Benefits section.

The "X" defect per report is represented by the symbol: $\quad F$ 
The price of each report (supposed financial gain from each report made) is represented by the symbol: $P$

So, the cost of the " $\mathrm{X}$ " defect per report that is to be subtracted from the price of the report is: $\quad F^{*} P$

In the model, reports sold for $\$ 1.00$ each $(P=\$ 1.00)$. This will be discussed more in the benefits section.

Reports with the "S-" designation had to be reworked before they could be sold to the distributor. Therefore an extra cost is added to these reports. That extra cost is the labor cost for repairing the reports with the "S-" designation. The extra cost is spread evenly among the reports produced. Therefore, the time to repair one of the "S-" defects is multiplied by the labor cost per second times the "S-" defect/report ratio to express the effect of the "S-" defects on the model. The time to repair a "S-" defect was determined in testing with the document binding system. This time was determined to be 36 seconds and was an average of 8 repair trials. The time to repair a "S-" reports is calculated in Appendix $\mathrm{H}$.

In the model, the "S-" defect/report ratio is represented by: $S$

The report repair time is represented by: $\quad R$

The labor rate is represented by: $\quad D$

The cost for quality repair for each report is represented by the equation:

$$
Q=S * R *\left(\frac{D}{3600}\right)
$$


Where $Q$ is the cost for quality repair for each report. $D$ has to be divided by 3600 to convert from $\$ /$ hour to $\$ / \mathrm{sec}$. The $Q$ values for each of the training types are calculated in chart 4.14.

\section{Chart 4.14}

\begin{tabular}{|c|c|c|c|cc|}
\hline & $\begin{array}{c}\text { S- } \\
\text { defect/report } \\
\text { ratio }\end{array}$ & $\begin{array}{c}\text { Report } \\
\text { repair time }\end{array}$ & Labor rate & $\begin{array}{c}\text { Lost to repair off } \\
\text { quality reports } \\
\text { per report }\end{array}$ \\
\cline { 2 - 7 } Training type & $\mathbf{S}$ & $\mathbf{R}$ & $\mathbf{D}$ & $\mathbf{Q}=\mathbf{S}^{*} \mathbf{R}^{*} \mathbf{D} / 3600$ \\
\hline Observe and Do & 0.124 & 36 & $\$ 6.00$ & $\$$ & 0.0074 \\
\hline Manual & 0.029 & 36 & $\$ 6.00$ & $\$$ & 0.0017 \\
\hline Class & 0.038 & 36 & $\$ 6.00$ & $\$$ & 0.0023 \\
\hline Mentor/Manual & 0.064 & 36 & $\$ 6.00$ & $\$$ & 0.0038 \\
\hline
\end{tabular}

\subsection{1.e Benefits}

The benefits factor is the represents the amount of money that the company is going make from selling the reports. The model will compare the cumulative benefits minus the cumulative costs to determine the profit of the operation. As stated in the previous section, each report will be sold for $\$ 1.00$ each. In the model, the price of the report is represented by the symbol: $P$

The total benefit from selling the reports cannot be equal to the price of the reports times the number of reports produced $\left(P^{*} X\right)$ because some of the reports produced were defects that could not be reworked. In the previous section, the ratio of these defects per report produced was multiplied by the price of each report to obtain the cost of the defects per each report sold distributed among all reports. This cost is subtracted from the price of the report to get the total benefit per report. The benefit per report is represented by the symbol: $B$

Where $B=P-\left(F^{*} P\right)$ 
This concept takes the total possible money from the reports, subtracts the amount that is wasted because of the defects to get the benefit for each report. It is beneficial for the company to have to lowest amount of defects possible so that they gain for the reports they produce.

The values of $F$, and the calculations for $B$ for each training type are contained in Chart 4.15 below:

\section{Chart 4.15}

\begin{tabular}{|l|cc|c|cc|cc|}
\hline \multicolumn{1}{|c|}{ Training type } & $\begin{array}{c}\text { Report price } \\
(\mathbf{P})\end{array}$ & $\begin{array}{c}\mathbf{X} \text { defect/report ratio } \\
(\mathbf{F})\end{array}$ & $\begin{array}{c}\text { cost of defect } \\
\left(\mathbf{P}^{*} \mathbf{F}\right)\end{array}$ & $\begin{array}{c}\text { Total benefit per } \\
\text { report (B) }\end{array}$ \\
\hline Observe and Do & $\$$ & 1.00 & 0.0746 & $\$$ & 0.075 & $\$$ & 0.93 \\
\hline Manual & $\$$ & 1.00 & 0.0000 & $\$$ & - & $\$$ & 1.00 \\
\hline Class & $\$$ & 1.00 & 0.0351 & $\$$ & 0.035 & $\$$ & 0.96 \\
\hline Mentor/Manual & $\$$ & 1.00 & 0.0278 & $\$$ & 0.028 & $\$$ & 0.97 \\
\hline
\end{tabular}




\subsection{PROFIT OF A PARTICULAR TRAINING TYPE}

Before the return on the investment in break-in training can be calculated, the return for each training type needs to be determined. This profit is the money that the company will see from the worker. Companies are already seeing some of this profit if they utilize the traditional training type. However, using a different training type by investing in break-in training may help the company see more profits over time. The additional profit (or loss, depending on the point in time) for implementing the break-in training can be calculated by finding the difference from the profits of the break-in training and the traditional training. This section develops the model that calculates the profit for each training type individually. The next section will compare two different training types to establish the ROI model. Finally, the data from the experiment will be entered into the model in Chapter 5 to estimate the ROI of the break-in training used in this experiment.

The Profit at a given time is the cumulative benefits up to that time minus the cumulative costs. The following chart lists the benefits and costs associated with the model and their representative symbols:

Chart 4.16

\begin{tabular}{|c|c|c|c|c|}
\hline \multicolumn{5}{|c|}{ Benefits and Costs } \\
\hline & Per report & Units & Cumulative & Units \\
\hline \multicolumn{5}{|l|}{ Fixed Costs } \\
\hline Training & -- & -- & $\mathrm{T}$ & $\$$ \\
\hline \multicolumn{5}{|l|}{ Variable Benefits } \\
\hline Price of each unit & $\mathrm{P}$ & $\$ /$ report & $P^{*} X$ & $\$$ \\
\hline Less cost of defects & $-F^{*} P$ & $\$ /$ report & $-\mathrm{F}^{*} \mathrm{P}^{*} \mathrm{X}$ & $\$$ \\
\hline \multicolumn{5}{|l|}{ Variable Costs } \\
\hline Material Costs & M & \$/report & $M^{*} X$ & $\$$ \\
\hline Repair of off-quality reports & $Q$ & \$/report & $Q^{*} X$ & $\$$ \\
\hline Labor Cost & L & \$/report & sum of $(I=1$ to $X)\left[(D / 3600)^{*} \mathrm{Ca}^{*} \mathrm{X}^{\wedge}(\mathrm{Cb})\right]$ & $\$$ \\
\hline
\end{tabular}

Substituting these factor into the equation: 
Profit for one training type $=$ Cumulative Benefits - Cumulative Losses

Yields the equation:

Profit $=P^{*} X-F^{*} P^{*} X-T-M * X-Q^{*} X-\sum_{i=1}^{X}\left[(D / 3600) * C a^{*} X^{C b}\right]$

Where $Q=S * R *(D / 3600)$

Separating this equation into Benefit and cost sections and substituting the equation for $\mathrm{Q}$ yields:

Profit $=\left[P^{*} X-F^{*} P^{*} X\right]-\left[T+M * X+S^{*} R^{*}(D / 3600) * X+\sum_{i=1}^{X}\left[(D / 3600) * C a * X^{C b}\right]\right]$ (Cumulative Benefits) (Cumulative Costs)

In the next section, this equation will be used to determine the ROI of a break-in training type. The data from the experiment it fit to this model in Chapter 5. 


\subsection{ROI MODEL}

The return of investment model can be used to determine the additional profit that from investing in a type of break-in training as opposed to not investing in break-in training. In order to utilize the ROI model, a return period must be specified. The return period is denoted by the letter $\mathrm{X}$ and signifies the number of reports. This thesis will examine the following different return periods:

1. 275 reports, which corresponds to about one day's work for an employee trained by the observe and do training type,

2. 1921 reports, representing approximately one week for an employee trained by the observe and do training type,

3. 4443 reports, representing approximately 2 weeks for an employee trained by the observe and do training type, and

4. 10000 reports, representing a little less than 4 weeks for an employee trained by the observe and do training type.

The last options may not follow the model exactly because the production time actually levels off more than the learning curves indicate. However, the model still holds enough validity to be used to determine the effects of the training over a long period of time.

These periods were selected because they correlate to the approximate time periods for the observe and do training type if the employee is considered to complete 7 hours of binding each day, five days a week.

In addition to examining these return periods, the return on investment for each breakin training will be charted on a graph so that the trends can be identified. One of the things identified from this is the break-even point of the investment in the break-in training. This is when the cumulative profit made from the break-in training exceeds the cumulative profit realized from the traditional training. This break-even point can be 
compared to the expected amount of report that the employee will produce for the company to see if the investment is worth making.

As stated earlier, the each symbol with a number signifying the training type will be used each factor. For example, a L1 represents the labor cost associated with the observe and do training type, and a L2 represents the labor cost associated with the manual training type.

The equation that determines the ROI for a type of break-in training is:

ROI $=$ Cumulative Profit of break-in training - Cumulative Profit of traditional break-in training

The independent variable in this equation is $\mathrm{X}$, representing the number of reports completed.

The factors in the equation are represented by the corresponding symbols in chart 4.17. 


\section{Chart 4.17}

\begin{tabular}{|c|c|c|c|c|}
\hline \multicolumn{5}{|c|}{ Factors in ROI Equation } \\
\hline & Training type 1 & Training type 2 & Training type 1 & Training type 2 \\
\hline & Per report & Per report & Cumulative & Cumulative \\
\hline \multicolumn{5}{|l|}{ Fixed Costs } \\
\hline Training & & & $\mathrm{T} 1$ & $\mathrm{~T} 2$ \\
\hline \multicolumn{5}{|l|}{ Variable Benefits } \\
\hline Price of each unit & $\mathrm{P}$ & $\mathrm{P}$ & $P^{*} X$ & $P^{*} X$ \\
\hline Less cost of defects & $-F 1^{*} \mathrm{P}$ & $-F 2^{*} \mathrm{P}$ & $-F 1^{*} P^{*} X$ & $-F 2^{*} P^{*} X$ \\
\hline \multicolumn{5}{|l|}{ Variable Costs } \\
\hline Material Costs & $\mathrm{M}$ & $\mathrm{M}$ & $M^{*} X$ & $M^{*} X$ \\
\hline Repair of off-quality reports & $\mathrm{Q} 1=\mathrm{S} 1^{*} \mathrm{R}^{*} \mathrm{D} / 3600$ & $\mathrm{Q} 2=\mathrm{S} 2^{*} \mathrm{R}^{*} \mathrm{D} / 3600$ & $\mathrm{Q} 1^{*} \mathrm{X}$ & $\mathrm{Q} 2 * \mathrm{X}$ \\
\hline Labor Cost & L1 & L2 & $\begin{array}{c}\text { sum of }(\mathrm{I}=1 \text { to } \mathrm{X}) \\
{\left[(\mathrm{D} / 3600)^{*} \mathrm{Ca} 2^{*} \mathrm{X}^{\wedge}(\mathrm{Cb} 2)\right]}\end{array}$ & $\begin{array}{c}\text { sum of }(\mathrm{I}=1 \text { to } \mathrm{X}) \\
{\left[(\mathrm{D} / 3600)^{*} \mathrm{Ca} 2^{*} \mathrm{X}^{\wedge}(\mathrm{Cb} 2)\right]}\end{array}$ \\
\hline
\end{tabular}

Some of the factors are not followed by a " 1 " or " 2 " that is supposed to indicate their training type. This factors have the same value for both training types in the model.

Therefore, these factors can be substituted into the ROI equation.

The equation for the ROI of training type 2 is as follows:

$$
\begin{aligned}
\mathrm{ROI}= & \left\{\left[P^{*} X-F 2 * P^{*} X\right]-\left[T 2+M * X+S 2 * R *(D / 3600) * X+\sum_{i=1}^{X}\left((D / 3600) * C a 2 * X^{C b 2}\right)\right]\right\} \\
& -\left\{[P * X-F 1 * P * X]-\left[T 1+M * X+S 1 * R *(D / 3600) * X+\sum_{i=1}^{X}\left((D / 3600) * C a 1 * X^{C b 1}\right)\right]\right\}
\end{aligned}
$$

This can be separated out of the brackets to:

$$
\begin{aligned}
\mathrm{ROI}= & P * X-F 2 * P * X-T 2-M * X-S 2 * R *(D / 3600) * X-\sum_{i=X}^{X}\left[(D / 3600) * C a 2 * X^{C b 2}\right] \\
& -P^{*} X+F 1 * P * X+T 1+M * X+S 1 * R *(D / 3600) * X+\sum_{i=1}^{X}\left[(D / 3600) * C a 1 * X^{C b 1}\right]
\end{aligned}
$$


Some of the numbers can be canceled to yield:

$\mathrm{ROI}=T 1-T 2+(F 1-F 2) * P * X+(S 1-S 2) * R *(D / 3600) * X+\sum_{i=1}^{X}\left[(D / 3600) *\left(\left(C a 1 * X^{C b 1}\right)-\left(C a 2 * X^{C b 2}\right)\right)\right]$

Likewise, to determine the ROI for training type 3, substitute all the "2"s for " 3 "s in the ROI model. The symbols with no number behind them can stay constant. The same substitution shall be used for training type 4 .

The data gathered in the experiment and learning curves developed in Chapter 3 will be entered in this ROI model to determine the return for the investment in training simulated by the experiment. This will be included in Chapter 5 . 


\section{CHAPTER 5:}

ESTIMATE THE ROI FOR THE DIFFERENT BREAK-IN STRATEGIES 


\subsection{CHAPTER OVERVIEW}

In this chapter, data gathered from the experiment is inputted into the model to capture the return on investment of the different training types. First, the data gathered in the experiment will be put into the cumulative profit equations for each training type. This set of four equations will represent the profit equation and have $\mathrm{X}$ (report number) as the independent variable. The cumulative profit vs. report number will be graphed to show the effect of the profit trend for each individual training type.

Secondly, the ROI equations of the three different training types will be developed by inputting the factor values in to the ROI equation developed in Chapter 4. The ROI equations contain X (report number) as the independent variable. Charts of ROI vs report number will show the ROI trends of the different training types.

Third, the model will be used to determine the return at different periods: 275 reports, 1921 reports, 4443 reports, and 10,000 reports. The results of these findings will be discussed. 


\subsection{CUMULATIVE PROFIT}

The factors for the cumulative profit equations and the ROI equations were presented in chapter 4. Appendix I reviews this data in charts for each training type. Placing the values from Appendix I in the cumulative profit equation yields the following equations for each training type:

\section{Chart 5.1}

\begin{tabular}{|l|l|}
\hline \multicolumn{1}{|c|}{ Training Type } & \multicolumn{1}{c|}{ Cumulative Profit Equation } \\
\hline Observe and Do & Cumulative Profit $=.38756^{\star} X-.36$ - sum from $(I=1$ to $X)$ of $\left[.3361833^{\star} X^{\wedge}(-.1737)\right]$ \\
\hline Manual & Cumulative Profit $=.46826^{\star} X-7.11-$ sum from $(I=1$ to $X)$ of $\left[.3997667^{\star} X^{\wedge}(-.2357)\right]$ \\
\hline Class & Cumulative Profit $=.43272^{\star} X-4.23-$ sum from $(I=1$ to $X)$ of $\left[.1961667^{\star} X^{\wedge}(-.1333)\right]$ \\
\hline Mentor/Manual & Cumulative Profit $=.43816^{\star} X-9.03$ - sum from $(I=1$ to $X)$ of $\left[.333383^{\star} X^{\wedge}(-.2017)\right]$ \\
\hline
\end{tabular}

Appendix J contains the values of the cumulative benefits, costs, and profit calculated in a spreadsheet. Two types of charts were developed in conjunction with the data.

First, the Benefits vs. Cost Chart graphs the cumulative benefit and cumulative costs verses report number. This chart compared the costs and benefits as each report is completed. The break-even point for an individual training type is the point when the benefits meet the cost. Figure 5.2 below shows the Benefits vs. Costs for the observe and do training type. Note that the break-even point occurs fairly early in the report binding process. 


\section{Figure 5.2}

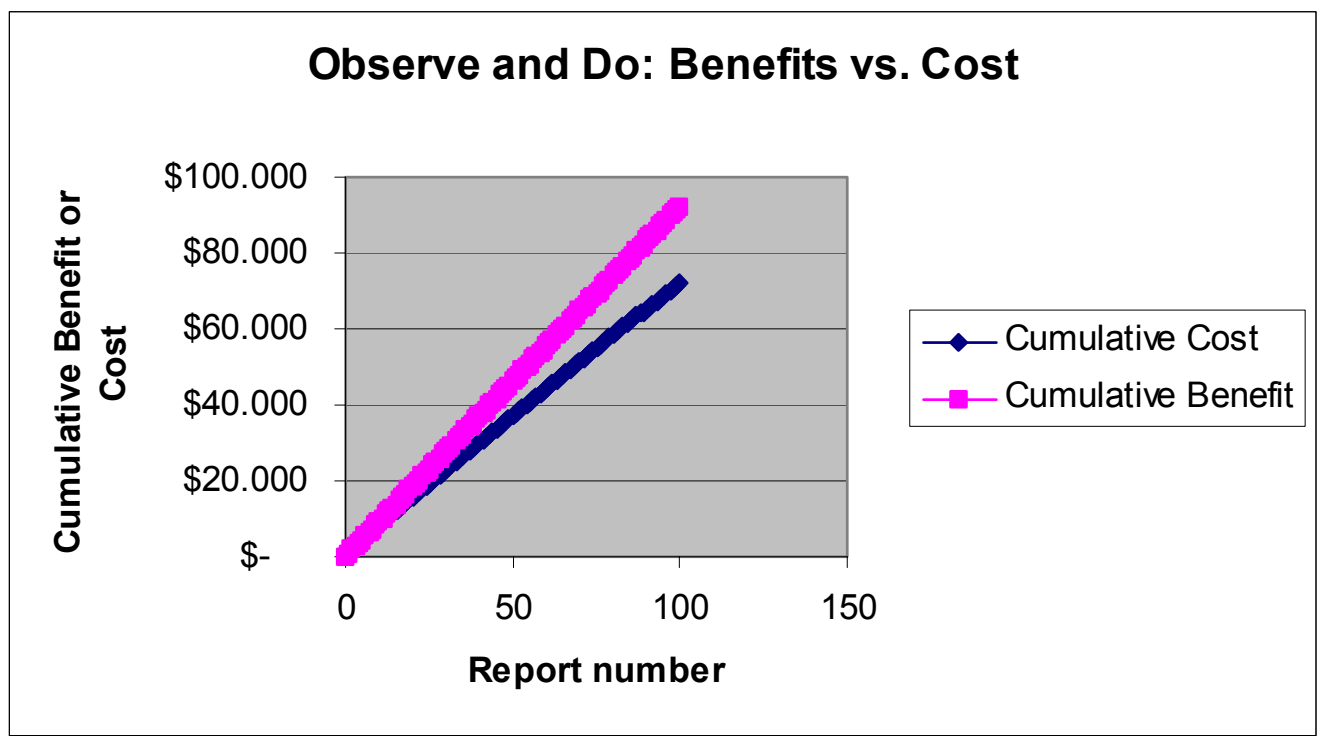

Another chart from the data shows the difference between the cumulative benefits and cumulative costs. This ROI chart shows the Cumulative profit for the employee according the number of reports he or she has completed. Figure 5.3 shows the ROI chart for the observe and do training type only. The break-even point is when the line crosses the $\mathrm{x}$-axis and goes from a loss to a profit.

\section{Figure 5.3}

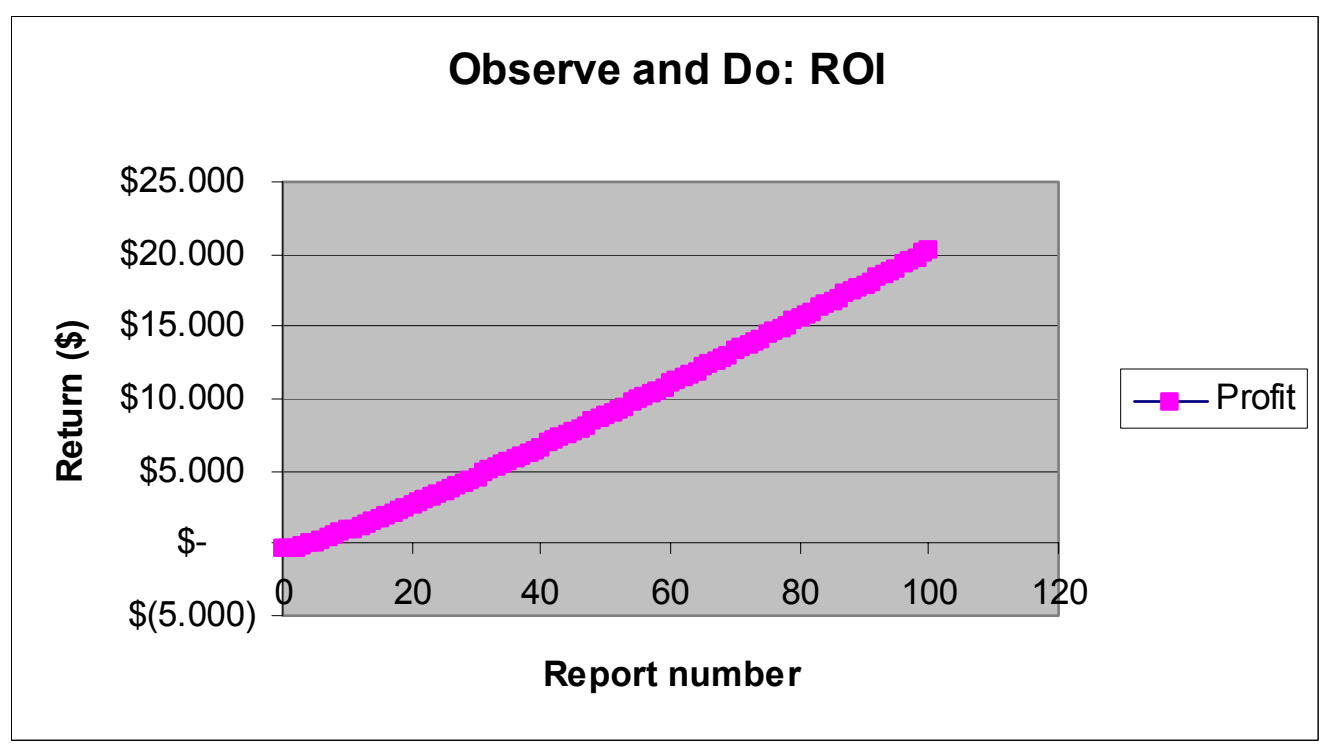


Charts like the two above for the other training types can be found in Appendix K

From these charts, the break-even points were calculated for the individual training types. These break-even points are listed in the chart below:

\section{Chart 5.4}

\begin{tabular}{|l|l|}
\hline \multicolumn{2}{|c|}{ Break-even Points } \\
\hline Training Type & Break-even point \\
\hline Observe and Do 4 reports \\
\hline Manual & 30 reports \\
\hline Class & 16 reports \\
\hline Mentor/Manual & 38 reports \\
\hline
\end{tabular}

The break-even occurrences can be seen in either the data or the charts. 


\subsection{ROI}

In order to capture the true ROI of an investment in break-in training as opposed to just the ROI of a single training type, the cumulative profit of the traditional training must be subtracted from the cumulative profit of the break-in training. The result will show the financial returns for the break-in training investment at different time periods. The difference can be expressed in a graph to show the trend as more and more reports are bound. The charts will be discussed later in this section.

In the previous section, cumulative profit equations were developed using data from the factors in Chapter 4. The ROI equations are simply the cumulative profit equation of the break-in training type minus the cumulative profit of the traditional training type, or:

$\mathrm{ROI}=$ Cumulative profit of break-in training - Cumulative profit of traditional training

The independent variable in these equations is " $\mathrm{X}$ ", or the number of reports.

The cumulative profit equations from above are substituted into the ROI equation to yield the following ROI equations for each training type:

\section{Chart 5.5}

\section{ROI equations}

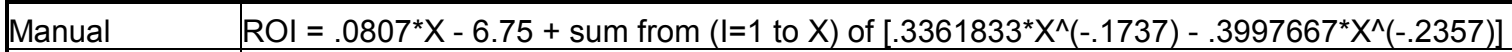

Class $\quad$ ROI $=.04516^{\star} X-3.96+\operatorname{sum}$ from $(I=1$ to $X)$ of $\left[.3361833^{\star} X^{\wedge}(-.1737)-.1961667^{\star} X^{\wedge}(-.1333)\right]$

Mentor/Manual $\mathrm{ROI}=.0506^{\star} \mathrm{X}-8.67+\operatorname{sum}$ from $(\mathrm{I}=1$ to $\mathrm{X})$ of $\left[.3361833^{*} \mathrm{X}^{\wedge}(-.1737)-.333383^{*} \mathrm{X}^{\wedge}(-.2017)\right]$

These equations can also be obtained by inputting the factors developed in chapter 4 into the ROI model developed in chapter 4. 


\section{$\underline{\text { 5.3.1 Data }}$}

The data from the cumulative profit determinations was used to develop curves of the ROI. This data can be seen in Appendix L. Please note that not all of the data used in developing the curves is contained in the appendix because of the curves are projected to $10,000^{\text {th }}$ reports, which is too much information to print in this paper.

In order to get the ROI data, the cumulative profit data was used to subtract the cumulative profit of the traditional training from the break-in training. Charts of the ROI data are shown in the appendix as well.

\subsubsection{Charts}

The return for break-in training vs. traditional training compared by graphing the cumulative profit for the two individual training types on a chart vs. report number. The ROI is the difference between these two lines figure 5.6 below shows the graph of both Cumulative Profits and the difference between them. The point where the cumulative profit of the break-in training meets and begins to exceed the cumulative profit of the traditional training is the break-even point. This is also the point where the difference (or ROI) crosses the $\mathrm{x}$-axis from negative into positive. This means that at this point, the investment in break-in training is bringing in extra cumulative profits above the amount of profits that the traditional training type would bring. A company must exceed this point in report number in order to experience to full financial benefit in additional training. 
Figure 5.6

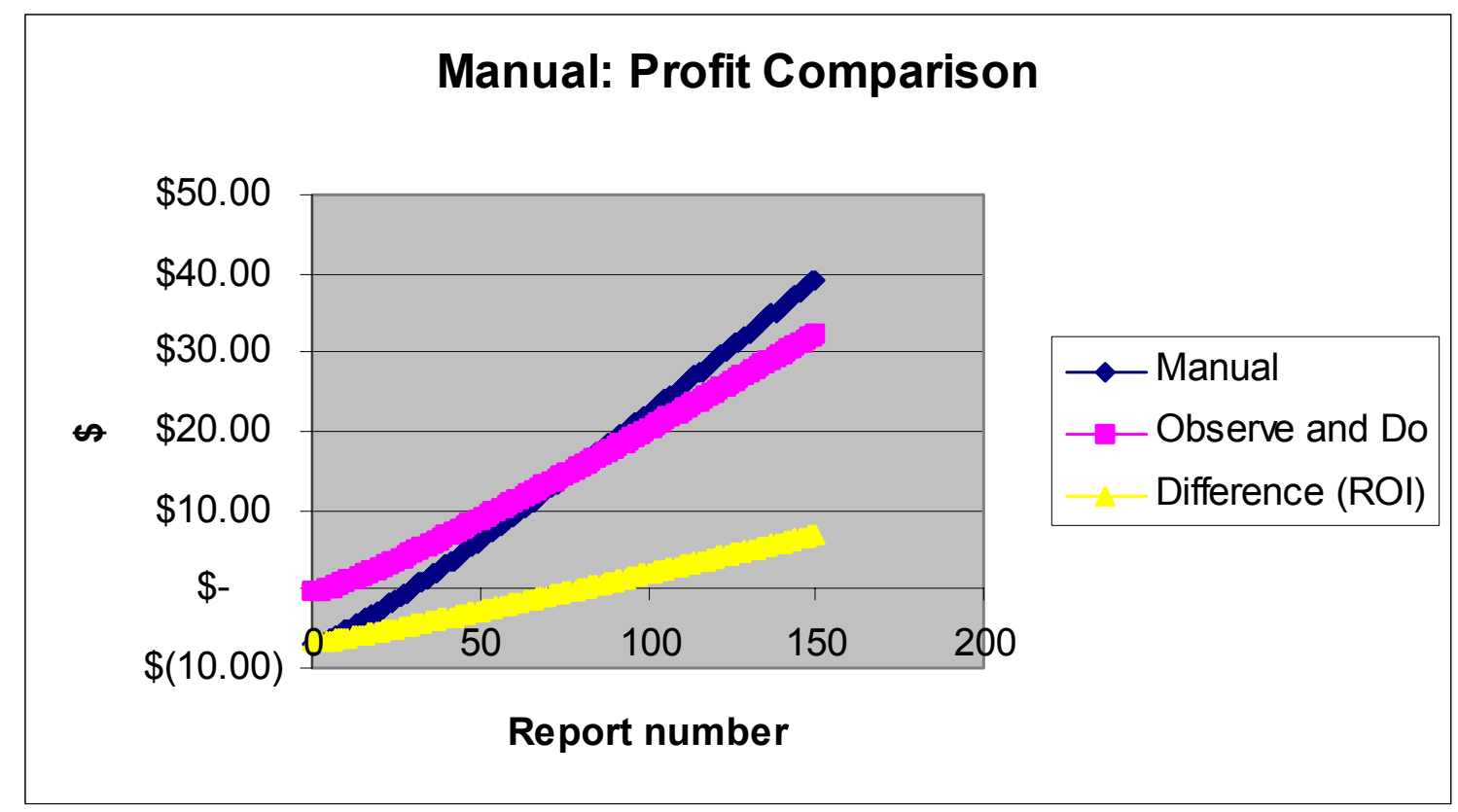

The profit comparison charts for the other training types are included in Appendix M. There are two profit comparison charts, one that expands until 150 reports, and one that expands until 1000 reports. The reason for developing the two charts is because the details of the break-even point can be seen clearly on the smaller chart. The extended chart shows how the extra benefit from an investment in training soars after exceeding the break-in period.

The information developed in the ROI charts for each break-in training type is combined in a comparison chart that can be used to determine the most worthwhile breakin training investment for different time periods. (Time periods in this case, means the amount of time that the employee is expected to stay with the task or the company).

Figure 5.7 below shows the return comparisons of different break-in training types. 
Figure 5.7

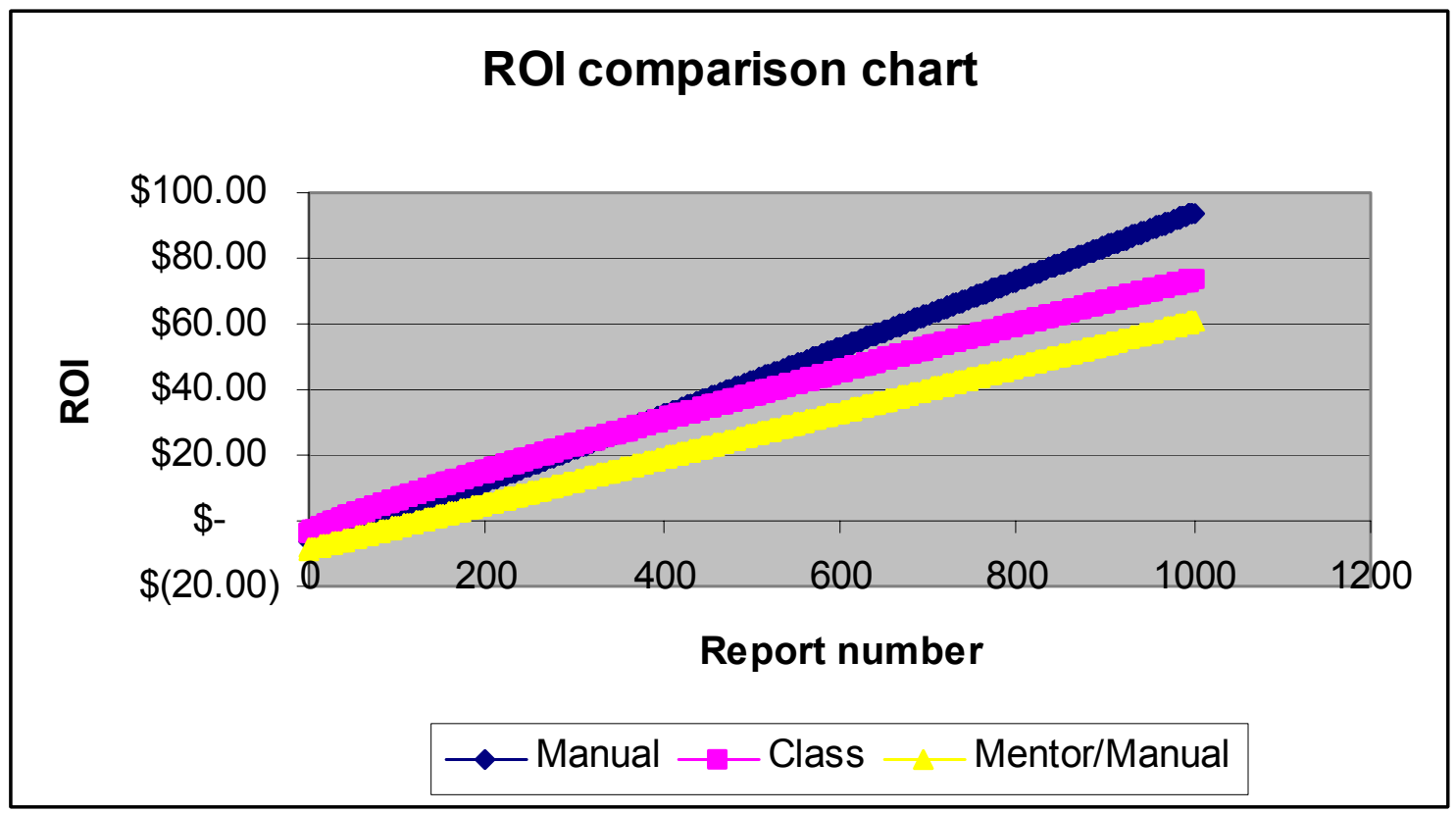

A bigger version of this chart is contained in Appendix N. These charts show when the ROI equations cross the $\mathrm{x}$-axis, or when the training type becomes worth the investment. These break-in periods are indicated in the chart 5.8.

\section{Chart 5.8}

\begin{tabular}{|l|c|}
\hline \multicolumn{2}{|c|}{ Break-even points for ROI equations } \\
\hline Break-in training type & Break-even point \\
\hline Manual & 79 reports \\
\hline Class & 32 reports \\
\hline Mentor/Manual & 126 reports \\
\hline
\end{tabular}

After the break-even point, making an investment in training is better than the traditional training. The best training type to implement depends on the amount of time that the worker is anticipated to stay on the job. For example, if the worker is not expected to stay more than 31 reports, they should be trained traditionally by the observe and do training type. This is because the class training type does not become profitable until the $32^{\text {nd }}$ report. This scenario may be unrealistic because most employees are expected to stick around for more than a couple of hours of work (32 reports may take no 
longer than 3 hours to complete, according to the data gathered). The training type suggestions for the report ranges according to this model are contained chart 5.9.

\section{Chart 5.9}

\begin{tabular}{|l|l|}
\hline \multicolumn{1}{|c|}{ Report range } & \multicolumn{1}{c|}{ Suggested training type } \\
\hline From 0 to 31 reports & Use Observe and Do training type \\
\hline From 32 to 350 reports & Use Class training type \\
\hline From 350 reports and beyond & Use Manual training type \\
\hline
\end{tabular}

The ROI equations can be expanded to show the long-term effects of the break-in training on the model. This chart is located in Appendix N. In that chart, the return for the manual is the best of all the training types for the extended period of time. The return for Mentor/Manual training type improves over the Class training type at the $3,575^{\text {th }}$ report.

Chart 5.9 shows that the mentor/manual training type is never the suggested training type. However, there may be some uncaptured returns from the mentor training type such as benefit to the company's camaraderie. Mentors may help make the company a happier workplace, and therefore encourage employees to stay and others to join. 


\subsection{RETURN PERIODS}

The return periods mentioned in Chapter 4 can be used to evaluate each training type. The chart below uses the data from the ROI charts to capture the financial gain for each training type at the designated return periods. Notice that the Manual training type yields the highest return for longer return periods.

\section{Chart 5.10}

\begin{tabular}{|c|c|c|c|c|c|}
\hline \multicolumn{6}{|c|}{ ROI of each return period according to training type } \\
\hline \multirow[b]{2}{*}{ Return Period } & \multicolumn{4}{|c|}{ ROI } & \multirow{2}{*}{$\begin{array}{l}\text { Highest } \\
\text { return }\end{array}$} \\
\hline & Manual & Class & Me & Manual & \\
\hline 275 reports & 19.43 & $\$ 21.19$ & $\$$ & 10.45 & Class \\
\hline 1921 reports & $\$ 189.46$ & $\$ 134.27$ & $\$$ & 124.16 & Manual \\
\hline 4443 repots & $\$ 451.18$ & $\$ 288.69$ & $\$$ & 295.45 & Manual \\
\hline 10,000 reports & $\$ 1,025.22$ & $\$ 606.12$ & $\$$ & 667.31 & Manual \\
\hline
\end{tabular}




\subsection{SENSITIVITY ANALYSIS}

Sensitivity analysis is testing the effect changes in model factors have on the entire model. A model is considered sensitive to a change in a factor if a small change in the factor causes a big change in the model. The reverse is true as well. If a large change in a factor causes a small change in the model, the model is not as sensitive to changes in that factor. Sensitivity analysis is good to capture the behavior of the model, and compare different scenarios. Sensitivity analysis on this model was performed to see the effect variations of different factors have on the ROI and the break-even periods.

The values of factors such as price and material cost may be different in other situations. The price factor for this model was determined by estimating the approximate price that the reports would sell for on the market. This estimation could be high or low, so it is possible that another price value is more realistic. Therefore, it is necessary to perform sensitivity analysis on the model with the situation that the price has changed. The sensitivity analysis will show how the change in price of the reports affects the ROI that the model determines. Likewise, the material cost is another factor that was estimated in the model and differ. In the model, the material cost was determined by using the actual material cost of the materials. The material cost could be different if the company were to find a cheaper supplier. Sensitivity analysis was performed to determine the effect of a changing material cost on the behavior of the model. The model was also tested for sensitivity of a decrease in material cost as well as price to see the overall effect of the change on the model. Therefore, the ROI model was used with different values of price and material cost to determine the sensitivity of the model.

Three scenarios were used to test the sensitivity of the model in terms of ROI and break-even period. These were:

1. Increasing the price from $\$ 1.00$ to $\$ 1.50$;

2. Decreasing the material cost from $\$ .53$ to $\$ .33$; and,

3. Both increasing the price to $\$ 1.50$ and decreasing the material cost to $\$ .33$. 
The sensitivity of other factors could be tested, but price and material cost were the most variable and therefore good examples to test. Appendix O contains the part of the data that was used in the sensitivity analysis calculations. This data was used to determine the ROI comparisons for each training type under each scenario. The ROI of the sensitivity analysis calculations is included in Appendix P. This data was used to determine the break-even periods of the ROI and later used to determine the sensitivity of the price and material cost.

The model's sensitivity to price was calculated by using a price of $\$ 1.50$ per report instead of a price of $\$ 1.00$. The ROI for each training type was determined. (This is the difference between the profit from the break-in training and the profit from the observe and do training using a price equal to $\$ 1.50$ for each training type.) This increase in price causes the payback period for each training type on its own to be a lot smaller than when the price was $\$ 1.00$. The price increase also improves the ROI for each type of break-in training. The break-even point of the break-in training occurs at fewer reports than before. Table 5.11 shows the break-even points for all training types and in all scenarios.

Table 5.11

\begin{tabular}{|l|c|c|c|c|}
\hline \multicolumn{5}{|c|}{ Sensitivity Analysis: Break-even point comparisons } \\
\hline Training Type & Regular & $\begin{array}{c}\text { Price increase } \\
\text { from } \$ 1.00 \text { to } \\
\mathbf{\$ 1 . 5 0}\end{array}$ & $\begin{array}{c}\text { Material cost } \\
\text { decrease from } \\
\mathbf{\$ . 5 3} \text { to } \$ .33\end{array}$ & Both occur \\
\hline Manual only & 79 & 57 & 84 & 60 \\
\hline Class & 32 & 24 & 33 & 25 \\
\hline Mentor/Manual & 126 & 82 & 133 & 85 \\
\hline
\end{tabular}

When the price increases $\$ .50$, or $50 \%$, the break-even point is about $65 \%$ to $75 \%$ of the previous break-even point. Therefore, the model is moderately sensitive to the price.

The model's sensitivity was also tested for a decrease in material cost from $\$ .53$ to $\$$.33. This decrease considers that the cost for paper and printing changes from 2 cents a page to 1 cent a page. At 20 pages, the reports are 20 cents less than before. As can be 
seen from the chart above, a decrease in the material cost causes the increases in the break-even points. This inverse relationship may seem a little odd, but makes sense because these are comparisons of break-even points that take into consideration the difference in profit from two different training types. The decrease in material cost affects the observe and do training type more than the break-in training types, meaning that it increases the observe and do's profit more than the break-in training. Therefore, the additional profit from break-in training is less than before during the production of the first couple hundred reports and the break-even point is less than previous. Overall, the model is slightly sensitive to the material cost because the additional profit (ROI) decreased slightly due to the decrease in cost.

The scenario with both an increase in price to $\$ 1.50$ per report and decrease in material cost to $\$ .33$ per report decreases the break-even point to almost as low as when only the price was decreased. This follows the sensitivity patterns determined for each independent scenario. The increase in price causes a larger increase in ROI, while a decrease in material cost causes a small decrease in ROI. Therefore, the combination causes a decrease in the break-even point that is just a little less than the decrease amount cause from the increase in price only.

It is important to note that all sensitivity analysis scenarios cause an increase in the profit of a particular training type. The increase in price obviously increases the profit for each report by almost 50 cents each. The decrease in material cost increases the profit for each report by 20 cents each. So the combination of both increases the profit per report by almost 70 cents each. The scenario that increases the extra profit realized from switching from observe and do to break-in is increasing the price. However, all scenarios are preferable for a company looking to increase profits. 


\subsection{INTERPRETING THE RESULTS}

The analysis performed in this section uses the model developed for the subjects tested for this experiment. The model developed in Chapter 4 can be used for actual jobs, noting that the values for the factors will change according to the trade.

Interpreting the data gathered by the experiment yields the following conclusions:

1. The investment in break-in training is beneficial because break-in training will yield returns high enough to pay back the investment and exceed the profit that is made by the traditional training type. The extra investment in training begins to benefit the company additionally after 79,32 , and 126 reports respectively for the manual, class, and mentor/manual training types. Because these low break-even points, companies should make the investment. Note that the break-even points were determined due to data gathered by the experiment, so the actual break-even point may vary.

2. The best training type to use if employee is expected to stay a short time is the class training type. If the company's turnover rate is high, then the class training type is the best investment because of its short break-even period. According to the model, the class training type yields the most returns from 32 to 350 reports. This is because the class training type has lower initial labor costs. The ROI from the class training type is surpassed by the other break-in training types because its improvement in production time is not a drastic (or steep) as the manual and mentor/manual training type. This may be because the class helps the employee learn the technique thoroughly at the beginning so that the initial learning curve isn't as steep. As the employee completes more and more reports, they may not improve in binding time as the manual and mentor/manual training types because they have already established a "perfect" speed due to the class and their ability to improve is hindered. Also, as time passes, they grow further and further away from the training whereas the other breakin training types have the manual or mentor there to help the subjects it they have any 
questions. The mentor/manual's return becomes more than the class's at 3,575 reports.

3. The manual is the best training type after 350 reports because the manual's ROI curve shows the highest returns of the three training types. This is surprising because initially, subjects trained be the manual had production times close to the subjects trained by the observe and do. The learning curve fitted to the manual training type had the steepest slope so that when it was used to project data points to the $10,000^{\text {th }}$ report, it prevailed as the training type with the shortest binding times. These projections may be off, but if they are assumed to be correct, there are two reasons that lead to the manual being the most profitable training type: 1 . The manual training type calls for the subject to figure a lot of the binding process out on of his or her own without much external help. 2. The binder is always available for them to refer to. The combination of these reasons may call for the subject to figure things out and use their brain more than the other training types. When the subject does this they may adapt processes that fit their needs and therefore allow them to produce reports at a faster pace.

Another reason that allows the manual to be so beneficial is that that there were no " $\mathrm{X}$ " defects with the training type and very few "S-" designations. This causes the manual have an advantage over the other training types. Again this could be caused by the subjects being allowed to use their brains and skills to develop the reports as opposed to someone telling them. The skills that produce the quality reports at the beginning of the worker's employment can be transferred to later times when the employee is producing reports at faster speeds. The time they took for quality at the beginning will be paid back in the long term.

4. The mentor/manual training type never prevails as the training type of choice. Some companies feel that a mentor would be beneficial to the morale in the workplace. These effects are not captured in this model. Perhaps, the camaraderie of a mentor 
will convince the employee to stay at the company longer than the employee would if they were not mentored. The mentor option is still a good choice even though the returns are not as great as the manual training type. The mentor's returns are still greater than the observe and do's returns and the uncaptured returns may make this training type worth implementing.

The experiment as a whole yielded some surprising results for the reasons described above. Regardless, the experiment proves that the break-in training is a worthwhile investment by showing the financial benefits. The most important aspect of this research is the development of the ROI model. This model and the methodology behind it can be used companies to project the financial returns of training. This information will be useful in projections and decisions made by company executives that can greatly impact the company's bottom line. 


\section{CHAPTER 6:}

SHOW HOW THE MODEL CAN BE USED ON ACTUAL JOBS 
Companies can use the ROI model and methodology described in this thesis to determine the actual return on investment of break-in training. Company executives may questions whether break-in training is beneficial to their bank account, or if making the investment is a waste of money. The ROI model in this thesis can be used to prove to these company executives that the return they see is actually due to the training. This thesis has isolated training and established a methodology to capture the financial payback from this training.

In order to implement this model on actual jobs in a manufacturing organization, a data gathering stage must take place. This stage is the most time consuming stage of the implementation process. The time for an employee to complete each repetition of the repetitive task that is being tested must be recorded for new employees that received break-in training and who did not receive break-in training. It may be a good to do a time study on employees receiving non-break-in training before the training is implemented because one training is established, going back to non-training will be hard to do. Also, the quality of the tasks completed must be monitored in conjunction with each task completed.

After the data is gathered, the learning curves for both training types should be fit to the data using the process described in Chapter 3. The quality of each training type should be calculated so that quality may be implemented into the model. The labor cost of each training type needs to be calculated per employee. This can be done using the example in chapter four as a guideline.

Finally, a time period needs to be selected. This time period should correspond with the expected length of the employee's time with the task. The time period should be represented by expected number of tasks they will complete. If the there is uncertainty in the number of tasks that they will complete, the time that the employee will stay with the task should be estimated and converted into reports using the learning curve of the traditional training type. If this is done, it should be noted in the results of the model. 
When this is completed, the information should be inputted into the model:

$$
\mathrm{ROI}=T 1-T 2+(F 1-F 2) * P * X+(S 1-S 2) * R *(D / 3600) * X+\sum_{i=1}^{X}\left[(D / 3600) *\left(\left(C a 1 * X^{C b 1}\right)-\left(C a 2 * X^{C b 2}\right)\right)\right]
$$

Where:

$T 1=$ Training cost of the traditional training $(\$)$

$T 2=$ Training cost of the break-in training $(\$)$

$F 1=$ Ratio of defects per task for traditional training

$F 2=$ Ratio of defects per task for break-in training

$P=$ Price that each task sells for (or the amount of the price that the task being tested is

responsible for) ( $\$$ task)

$X=$ Time period in task counts (tasks)

$S 1=$ Ratio of defects per task that can be reworked from traditional training

$S 2=$ Ratio of defects per task that can be reworked from break-in training

$R=$ Repair time for tasks that need reworked (secconds)

$D=$ Labor rate for workers ( $\$$ hour)

$\mathrm{Cal}=$ Learning Curve Constant for traditional training

$C b 1=$ Learning Curve constant for traditional training

$\mathrm{Ca} 2=$ Learning Curve Constant for break-in training

$\mathrm{Cb2}=$ Learning Curve constant for break-in training

The ROI at the end result from this equation is the amount of money the company will earn per employee for making that investment in training. The company can project the additional earnings by establishing expected time period for new employees. The overall benefit from implementing a break-in strategy is the sum of all the employees that will be trained with this break-in strategy. If the company projects the number of new employees and their stay time with the task for a year, the model can be used to capture the financial gain attributed to the break-in training for the entire year. 
Currently, companies are realizing that making investments could be well worth the money up-front. Companies are more apt to spend money today that will give them more financial returns in the future. Using this and other return on investment models will help companies decide on the right investments. The ROI model in this thesis will help companies become one step closer to streamlining efforts and becoming as productive as possible by getting the highest possible utilization from their investments. 


\section{CHAPTER 7:}

SUGGESTIONS FOR FUTHER RESEARCH 


\section{SUGGESTIONS FOR FUTHER RESEARCH}

The research in this thesis focused purely on the effect of different break-in training strategies in a manufacturing organization. The experiment tested the different break-in training strategies, disregarding the possible effects of subject background and continuous learning strategies. These topics and others can be used as topics for further research on the effects of training.

Even though the effects of characteristics such as age, race, gender, and culture were not considered in the model, they may have had a slight impact in the data. Because the experimentation method didn't call for isolation of a particular characteristic, there was no easy way to capture the effects of these factors in the model. However, as the experiment was conducted, the effect of race and culture was noted informally. For example, the two major race/culture of the subjects were Indian and American. The subjects that were Indian tended to produce reports that were much higher in quality than the American subjects. However, the American subjects tended to produce reports at a faster rate than the Indian subjects. Effects of culture and race can be isolated and tested for future research.

There were no apparent differences between male subjects and female subjects producing reports. Further researching the matter may show that there are significant differences in the overall production times of each gender.

Another possible topic to research is the effect of higher levels of training. This means that more training is administered after the break-in period or continuous training is administered. Many companies include administering continuous or higher levels of training in their employee training strategies, so integrating this training into the ROI model of this thesis may make the model a more powerful tool. 
Another possible research topic includes the learning styles of the different subjects, and determining which training strategy is best for a particular individual. This research can focus on the psychological effects of the different training types. Some individuals tend to learn visually, such as using a manual or watching a presentation. Some may learn better if they are able to learn hands-on. Even some may benefit from developing their own techniques. In accordance with the topic of training, new research can develop a process to identify the correct training type for each new employee.

There are a lot more topics available for further research dealing with the topic of break-in training. The ones listed here follow some important issues that were present in the data. The return on investment model developed in this thesis can provide the basis for a lot of this further research because future return on investment models can build on this current model. This thesis can provide some aspiration and present the need for the continuous enhancement of ROI models to streamline production efforts. 


\section{APPENDIX A:}

TABLES 1 AND 2 


\begin{tabular}{|l|l|l|}
\hline \multicolumn{2}{|c|}{ Table 1: Jack Phillip's Five Level Evaluation Model } \\
\hline Level & Level Name & Measurements made at this level \\
\hline 1 & Reaction and Planned Action & $\begin{array}{l}\text { Participant satisfaction, participants' plans for } \\
\text { implementing the training }\end{array}$ \\
\hline 3 & Learning & What the participant learned during training \\
\hline 4 & On-the-job Application & $\begin{array}{l}\text { Assess how the participant applied learning on } \\
\text { the job }\end{array}$ \\
\hline 5 & Business Results & Business results achieved by participants \\
\hline & Return on Investment & $\begin{array}{l}\text { Determine the ROI, compare company's } \\
\text { monetary benefits with cost }\end{array}$ \\
\hline
\end{tabular}

*From Jack Phillip's "ROI: The Search for Best Practices", Training \& Development, February 1996 


\section{Table 2: Approaches to determining the ROI of training by Jack J. Phillips}

\begin{tabular}{|c|c|c|c|}
\hline Approach & Description & Advantages & Disadvantages \\
\hline Use of control groups & $\begin{array}{l}\text { Randomly select control group and experimental group with } \\
\text { similar demographics. Experimental group receives training and a } \\
\text { control group does not. Measure the difference between two } \\
\text { groups. }\end{array}$ & Highly credible. & $\begin{array}{l}\text { Misperception that the } \\
\text { workplace is turning into } \\
\text { a lab. }\end{array}$ \\
\hline Trend-line analysis & $\begin{array}{l}\text { Develop a trendline reflecting an improvement in performance } \\
\text { that continues without training. Compare a post-training } \\
\text { performance to the performance predicted on the trendline. }\end{array}$ & $\begin{array}{l}\text { Provides a reasonable estimate of the training's } \\
\text { effect. Simple, inexpensive, and effortless } \\
\text { approach. }\end{array}$ & $\begin{array}{l}\text { Potential inaccuracy. } \\
\text { Assumes consistent } \\
\text { events influencing } \\
\text { performance other than } \\
\text { training. }\end{array}$ \\
\hline Forecasting & $\begin{array}{l}\text { A linear model is used to calculate a value of the anticipated } \\
\text { performance improvement. }\end{array}$ & Accurate predictor. & $\begin{array}{l}\text { Difficult to implement } \\
\text { when many factors are } \\
\text { included. }\end{array}$ \\
\hline Participant estimation & $\begin{array}{l}\text { Training participants determine how much performance } \\
\text { improvement is due to training. A confidence level is factored in, } \\
\text { also determined by participants. }\end{array}$ & $\begin{array}{l}\text { Reports credible because participants are at center } \\
\text { of the improvement. Inexpensive, timesaving, } \\
\text { and easily understood by most participants. }\end{array}$ & $\begin{array}{l}\text { Input data may be } \\
\text { unreliable since they are } \\
\text { estimates. }\end{array}$ \\
\hline Supervisor estimation & $\begin{array}{l}\text { Same as participant estimation. Can be combined with participant } \\
\text { estimation because by utilizing the lowest value of the two. }\end{array}$ & $\begin{array}{l}\text { Credibility rises when supervisor's estimates are } \\
\text { combined with participant's estimates and when a } \\
\text { confidence level is factored in. }\end{array}$ & $\begin{array}{l}\text { May by viewed } \\
\text { skeptically by } \\
\text { management since } \\
\text { method is subjective. }\end{array}$ \\
\hline $\begin{array}{l}\text { Management } \\
\text { estimation }\end{array}$ & $\begin{array}{l}\text { Top-level manager provide estimates on percent improvement they } \\
\text { attribute to training. }\end{array}$ & Input is from people who provide training funds. & Highly subjective. \\
\hline Customer input & $\begin{array}{l}\text { Question customers because if a customer is lost because of bad } \\
\text { service or product, that is many more dollars lost than spending } \\
\text { money on training an employee. }\end{array}$ & $\begin{array}{l}\text { Focuses directly on what training programs are } \\
\text { designed to prove. }\end{array}$ & \\
\hline Expert estimation & $\begin{array}{l}\text { Carefully selected experts such as independent consultants or } \\
\text { industry sources can estimate the benefit of training programs. }\end{array}$ & & $\begin{array}{l}\text { Can be inaccurate and } \\
\text { lack credibility since } \\
\text { from an external source. }\end{array}$ \\
\hline Subordinate input & $\begin{array}{l}\text { Subordinates can have input on specific changes that have } \\
\text { occurred since supervisor received training. Done through surveys } \\
\text { and interviews. }\end{array}$ & $\begin{array}{l}\text { Subordinates are aware of factors that caused } \\
\text { changes. Provide reliable input about the } \\
\text { magnitude of these changes. Even more credible } \\
\text { when combined with other's approaches. }\end{array}$ & \\
\hline Other factors & $\begin{array}{l}\text { Calculate the effects of factors other than training that may have } \\
\text { contributed to an improvement and conclude that training } \\
\text { accounts for the rest. Appropriate when other factors are easily } \\
\text { identified and their calculation mechanisms are in place. }\end{array}$ & $\begin{array}{l}\text { Highly credible when methods to isolate factors } \\
\text { are credible. }\end{array}$ & \\
\hline
\end{tabular}

*This table was obtained from information in "Was it the Training?" by Jack J. Phillips, Training and Development, March 1996. 
APPENDIX B:

DATA FROM EACH TRAINING TYPE 


\begin{tabular}{|c|c|c|c|c|}
\hline \multicolumn{5}{|c|}{ Observe and Do Training Type } \\
\hline $\begin{array}{l}\text { report No. } \\
\text { demonstration }\end{array}$ & $\begin{array}{c}\text { Monday August 26, } \\
2002 \text { 8:00 am } \\
\text { Time (Secs) } \\
90\end{array}$ & $\begin{array}{c}\text { Monday August 26, } \\
2002 \text { 2:00 pm } \\
\text { Time (Secs) } \\
68\end{array}$ & $\begin{array}{c}\text { Monday August 26, } \\
2002 \text { 5:00 pm } \\
\text { Time (Secs) } \\
61\end{array}$ & $\begin{array}{c}\text { Tuesday August 27, } \\
2002 \text { 8:00 am } \\
\text { Time (Secs) } \\
68\end{array}$ \\
\hline 1 & 199 & $281^{*}$ & $139^{*}$ & 342 \\
\hline 2 & $206^{*}$ & $131^{*}$ & $288^{*}$ & $350 * *$ \\
\hline 3 & 319 & 276 & 124 & $409^{*}$ \\
\hline 4 & 164 & $113^{*}$ & 73 & 183 \\
\hline 5 & 255 & 170 & 87 & 184 \\
\hline 6 & 161 & 98 & $185^{* *}$ & 184 \\
\hline 7 & 160 & $150^{* *}$ & 79 & 149 \\
\hline 8 & 238 & 103 & $79^{* *}$ & $158^{* *}$ \\
\hline 9 & 59 & $98^{*}$ & 73 & 187 \\
\hline 10 & $210^{* *}$ & 66 & $166^{* *}$ & 164 \\
\hline 11 & 160 & 64 & $100^{* *}$ & 187 \\
\hline 12 & 136 & 95 & $128^{* *}$ & 133 \\
\hline 13 & 111 & 62 & 72 & 132 \\
\hline 14 & 117 & $80^{*}$ & 91 & 123 \\
\hline 15 & 307 & 59 & 94 & 155 \\
\hline 16 & $152^{* *}$ & 81 & 62 & 122 \\
\hline 17 & 172 & 79 & 76 & 157 \\
\hline 18 & 138 & $301^{*}$ & $97^{* *}$ & 163 \\
\hline 19 & 149 & 90 & 100 & 183 \\
\hline 20 & $102^{* *}$ & 76 & 63 & $162^{*}$ \\
\hline 21 & 130 & $174^{*}$ & $65^{\star *}$ & 170 \\
\hline 22 & 164 & $78^{*}$ & 77 & 154 \\
\hline 23 & 419 & $97^{* *}$ & 79 & $136^{* *}$ \\
\hline 24 & 167 & $75^{\star *}$ & 56 & $191^{* *}$ \\
\hline 25 & 174 & 102 & 80 & $134^{* *}$ \\
\hline 26 & 113 & 60 & 78 & 187 \\
\hline 27 & 129 & 102 & 72 & 125 \\
\hline 28 & 104 & 143 & 75 & $171^{* *}$ \\
\hline 29 & 163 & 137 & 78 & 100 \\
\hline 30 & 160 & 59 & 78 & 117 \\
\hline 31 & 313 & 101 & 88 & 99 \\
\hline 32 & 287 & 78 & 78 & 99 \\
\hline 33 & 115 & $112^{*}$ & 121 & 170 ** \\
\hline 34 & 242 & 62 & 114 & 127 \\
\hline 35 & 158 & 76 & 90 & \\
\hline 36 & & 73 & 92 & \\
\hline 37 & & 56 & 81 & \\
\hline 38 & & 73 & 87 & \\
\hline 39 & & 98 & 76 & \\
\hline 40 & & 48 & 74 & \\
\hline 41 & & 64 & 71 & \\
\hline 42 & & 58 & 64 & \\
\hline 43 & & 69 & 69 & \\
\hline 44 & & 63 & 56 & \\
\hline 45 & & 68 & 65 & \\
\hline 46 & & 60 & 111 & \\
\hline 47 & & 90 & 92 & \\
\hline 48 & & 49 & 94 & \\
\hline 49 & & 52 & 71 & \\
\hline 50 & & $173^{*}$ & 103 & \\
\hline 51 & & 70 & 64 & \\
\hline 52 & & 77 & 57 & \\
\hline 53 & & 58 & & \\
\hline 54 & & 68 & & \\
\hline 55 & & 81 & & \\
\hline
\end{tabular}

* One asterisk indicates that a report was a defect and received a "X" designation.

** Two asterisks signify a report that received a Satisfactory minus (S-) designation and had to be reworked. 


\begin{tabular}{|c|c|c|c|c|}
\hline \multicolumn{5}{|c|}{ Data for Manual Only Training Type } \\
\hline & $\begin{array}{l}\text { Tuesday, August } \\
27,2002 \text { 2:00 pm }\end{array}$ & $\begin{array}{c}\text { Tuesday, } \\
\text { September 3, } 2002 \\
\text { 5:00 pm }\end{array}$ & $\begin{array}{c}\text { Wednesday, } \\
\text { September 4, } 2002 \\
\text { 8:00 am }\end{array}$ & $\begin{array}{c}\text { Tuesday, } \\
\text { September 24, 2:00 } \\
\text { pm }\end{array}$ \\
\hline Report no. & Time (Secs) & Time (Secs) & Time (Secs) & Time (Secs) \\
\hline read manual & 700 & 505 & 617 & 494 \\
\hline demonstration & 91 & 98 & 112 & 84 \\
\hline 1 & 172 & 777 & 147 & $212^{\star \star}$ \\
\hline 2 & 205 & 282 & 205 & 234 \\
\hline 3 & 120 & 143 & 175 & 216 \\
\hline 4 & 142 & 163 & 183 & 129 \\
\hline 5 & 222 & 128 & 193 & 101 \\
\hline 6 & 120 & 107 & 193 & 49 \\
\hline 7 & 172 & 160 & 179 & 69 \\
\hline 8 & 177 & 109 & 151 & 162 \\
\hline 9 & 124 & 185 & 198 & 97 \\
\hline 10 & 137 & 212 & 158 & 68 \\
\hline 11 & 181 & 204 & 162 & 111 \\
\hline 12 & 147 & 144 & 176 & 104 \\
\hline 13 & 147 & 163 & 255 & 189 \\
\hline 14 & 148 & 115 & 142 & 130 \\
\hline 15 & 143 & 196 & 200 & 62 \\
\hline 16 & 185 & 206 & 135 & 131 \\
\hline 17 & 159 & 116 & 195 & 82 \\
\hline 18 & 146 & 122 & 135 & 53 \\
\hline 19 & 131 & 78 & 179 & 57 \\
\hline 20 & 119 & 94 & 144 & 119 \\
\hline 21 & 147 & 84 & 164 & 58 \\
\hline 22 & 236 & 97 & 147 & 55 \\
\hline 23 & 137 & 133 & 124 & 73 \\
\hline 24 & 90 & 347 & 127 & 94 \\
\hline 25 & 120 & 147.5 & 145 & 50 \\
\hline 26 & 112 & 198 & 108 & 56 \\
\hline 27 & 86 & 66 & 93 & 60 \\
\hline 28 & 94 & 71 & 93 & 47 \\
\hline 29 & 93 & 74 & 93 & 77 \\
\hline 30 & 111 & 93 & 182 & $48^{* \star}$ \\
\hline 31 & 108 & 175 & 162 & 77 \\
\hline 32 & $234^{* *}$ & & 87 & $102^{* *}$ \\
\hline 33 & 172 & & 116 & 58 \\
\hline 34 & 126 & & 117 & 60 \\
\hline 35 & & & 129 & 72 \\
\hline 36 & & & 128 & \\
\hline
\end{tabular}

${ }^{* *}$ Two asterisks signify a report that received a Satisfactory minus (S-) designation and had to be reworked. 


\begin{tabular}{|c|c|c|c|c|}
\hline \multicolumn{5}{|c|}{ Data for Class Training Type } \\
\hline & $\begin{array}{c}\text { Thursday, September } \\
5,20022: 00 \text { pm }\end{array}$ & $\begin{array}{c}\text { Monday, September } \\
23,20023: 30 \mathrm{pm}\end{array}$ & $\begin{array}{c}\text { Tuesday, September } \\
24,2002 \text { 10:00 am }\end{array}$ & $\begin{array}{c}\text { Tuesday, September } \\
24,20024: 30 \mathrm{pm}\end{array}$ \\
\hline $\begin{array}{l}\text { Report No. } \\
\text { demonstration } \\
\text { trial a } \\
\text { trial b }\end{array}$ & $\begin{array}{c}\text { Time (Seconds) } \\
272 \\
117 \\
120\end{array}$ & $\begin{array}{c}\text { Time (Seconds) } \\
178 \\
96 \\
100\end{array}$ & $\begin{array}{c}\text { Time (Seconds) } \\
153 \\
165 \\
105\end{array}$ & $\begin{array}{c}\text { Time (Seconds) } \\
208 \\
146 \\
448\end{array}$ \\
\hline 1 & 104 & $122^{*}$ & 201 & 160 \\
\hline 2 & 89 & 90 & $122^{*}$ & 128 \\
\hline 3 & 85 & 76 & $142^{*}$ & 144 \\
\hline 4 & 75 & 69 & $89^{*}$ & $175^{\star \star}$ \\
\hline 5 & 89 & 72 & 108 & 121 \\
\hline 6 & 78 & $58^{* *}$ & 83 & 79 \\
\hline 7 & 101 & 68 & 129 & 95 \\
\hline 8 & 67 & 45 & 83 & 82 \\
\hline 9 & 68 & 104 & 156 & 80 \\
\hline 10 & 75 & 54 & 82 & 73 \\
\hline 11 & 74 & 61 & 82 & 69 \\
\hline 12 & 109 & $59^{* *}$ & 120 & 86 \\
\hline 13 & 59 & 59 & 82 & 69 \\
\hline 14 & $116^{*}$ & 68 & $72^{* *}$ & 86 \\
\hline 15 & 117 & 57 & 76 & 68 \\
\hline 16 & 62 & 59 & 87 & 214 \\
\hline 17 & 57 & 67 & 126 & 98 \\
\hline 18 & 73 & 52 & 140 & 44 \\
\hline 19 & 97 & 48 & 76 & 75 \\
\hline 20 & 132 & 72 & 73 & 111 \\
\hline 21 & 102 & 59 & 115 & 70 \\
\hline 22 & 89 & 50 & 289 & 62 \\
\hline 23 & 74 & 54 & 122 & 141 \\
\hline 24 & 76 & 82 & 157 & 69 \\
\hline 25 & 61 & 83 & 80 & 65 \\
\hline 26 & $66^{\star *}$ & 65 & 75 & 64 \\
\hline 27 & 75 & 94 & 123 & 57 \\
\hline 28 & 119 & 110 & 90 & 69 \\
\hline 29 & 50 & 78 & 106 & 93 \\
\hline 30 & $60^{* *}$ & 88 & 73 & 52 \\
\hline 31 & 54 & 69 & 91 & 64 \\
\hline 32 & 45 & 88 & 149 & 66 \\
\hline 33 & 48 & 97 & 137 & \\
\hline 34 & 73 & 85 & 118 & \\
\hline 35 & 54 & 95 & 70 & \\
\hline 36 & 49 & 80 & 97 & \\
\hline 37 & 39 & 57 & & \\
\hline 38 & 51 & 71 & & \\
\hline 39 & 47 & 72 & & \\
\hline 40 & 55 & 64 & & \\
\hline 41 & 36 & & & \\
\hline 42 & 57 & & & \\
\hline 43 & 50 & & & \\
\hline 44 & 41 & & & \\
\hline
\end{tabular}

${ }^{*}$ One asterisk indicates that a report was a defect and received a "X" designation.

** Two asterisks signify a report that received a Satisfactory minus (S-) designation and had to be reworked. 


\begin{tabular}{|c|c|c|c|c|}
\hline \multicolumn{5}{|c|}{ Manual with Mentor } \\
\hline $\begin{array}{l}\text { Report No. } \\
\text { reading manual } \\
\text { demonstration }\end{array}$ & $\begin{array}{c}\text { Tuesday, } \\
\text { September 3, } 2002 \\
\text { 8:00 am } \\
\text { Time (Secs) } \\
650 \\
74\end{array}$ & $\begin{array}{c}\text { Tuesday, } \\
\text { September 3, } 2002 \\
\text { 2:00 pm } \\
\text { Time (Secs) } \\
484 \\
63\end{array}$ & $\begin{array}{c}\text { Tuesday, } \\
\text { September 3, } 2002 \\
\text { 11:00 am } \\
\text { Time (Secs) } \\
607 \\
71\end{array}$ & $\begin{array}{c}\text { Wednesday, } \\
\text { September 4, } \\
20022: 00 \text { pm } \\
\text { Time (Secs) } \\
590 \\
73\end{array}$ \\
\hline 1 & 147 & $173^{* *}$ & 214 & 148 \\
\hline 2 & 391 & 92 & 170 & 257 \\
\hline 3 & 138 & 133 & 138 & 270 \\
\hline 4 & 166 & 99 & 190 & 180 \\
\hline 5 & 119 & $55^{*}$ & 129 & 193 \\
\hline 6 & 131 & 97 & 280 & 150 \\
\hline 7 & 191 & 106 & 109 & 110.5 \\
\hline 8 & 146 & 135 & 119 & 110.5 \\
\hline 9 & 159 & 105 & 126 & 201 \\
\hline 10 & 125 & 108 & 117 & 322 \\
\hline 11 & 100 & 85 & 118 & $110.5^{* *}$ \\
\hline 12 & 108 & $109^{\star *}$ & 204 & 110.5 \\
\hline 13 & 93 & $89^{* \star}$ & 130 & 120 \\
\hline 14 & 179 & $90^{* *}$ & 110 & 95 \\
\hline 15 & 109 & 97 & 124 & 86 \\
\hline 16 & 103 & 88 & 90 & 95 \\
\hline 17 & 177 & 92 & 111 & 94 \\
\hline 18 & 96 & 339 & 168 & 92 \\
\hline 19 & $94^{* *}$ & $81^{*}$ & 102 & 99 \\
\hline 20 & 109 & 89 & 181 & 78 \\
\hline 21 & 222 & 115 & 97 & 86 \\
\hline 22 & 100 & 168 & 144 & 77 \\
\hline 23 & 90 & 155 & 188 & 85 \\
\hline 24 & 108 & 114 & 100 & 97 \\
\hline 25 & 95 & 102 & 101 & 118 \\
\hline 26 & 83 & 76 & 93 & 84 \\
\hline 27 & 95 & 89 & 87 & 90 \\
\hline 28 & 92 & $119^{* *}$ & 94 & 99 \\
\hline 29 & 84 & 85 & 81 & 88 \\
\hline 30 & 115 & $0^{*}$ & 83 & 84 \\
\hline 31 & 96 & 145 & 103 & 77 \\
\hline 32 & 153 & 81 & 93 & 91 \\
\hline 33 & 91 & $60^{*}$ & 150 & \\
\hline 34 & 105 & $105^{\star *}$ & 211 & \\
\hline 35 & 100 & 88 & & \\
\hline 36 & & $112^{\star \star}$ & & \\
\hline
\end{tabular}

* One asterisk indicates that a report was a defect and received a "X" designation.

** Two asterisks signify a report that received a Satisfactory minus (S-) designation and had to be rel 
APPENDIX C:

DATA WITH NO DEFECTS AND INDIVIDUAL LEARNING CURVES 


\begin{tabular}{|c|c|}
\hline \multicolumn{2}{|c|}{ Observe and Do Data: QA } \\
\hline \multicolumn{2}{|c|}{ Monday August 26, 2002 8:00 am } \\
\hline $\begin{array}{r}\text { report No. } \\
\text { demonstration }\end{array}$ & $\begin{array}{c}\text { Time (seconds) } \\
90 \\
\end{array}$ \\
\hline 1 & 199 \\
\hline 3 & 319 \\
\hline 4 & 164 \\
\hline 5 & 255 \\
\hline 6 & 161 \\
\hline 7 & 160 \\
\hline 8 & 238 \\
\hline 9 & 59 \\
\hline 10 & 210 \\
\hline 11 & 160 \\
\hline 12 & 136 \\
\hline 13 & 111 \\
\hline 14 & 117 \\
\hline 15 & 307 \\
\hline 16 & 152 \\
\hline 17 & 172 \\
\hline 18 & 138 \\
\hline 19 & 149 \\
\hline 20 & 102 \\
\hline 21 & 130 \\
\hline 22 & 164 \\
\hline 23 & 419 \\
\hline 24 & 167 \\
\hline 25 & 174 \\
\hline 26 & 113 \\
\hline 27 & 129 \\
\hline 28 & 104 \\
\hline 29 & 163 \\
\hline 30 & 160 \\
\hline 31 & 313 \\
\hline 32 & 287 \\
\hline 33 & 115 \\
\hline 34 & 242 \\
\hline 35 & 158 \\
\hline
\end{tabular}

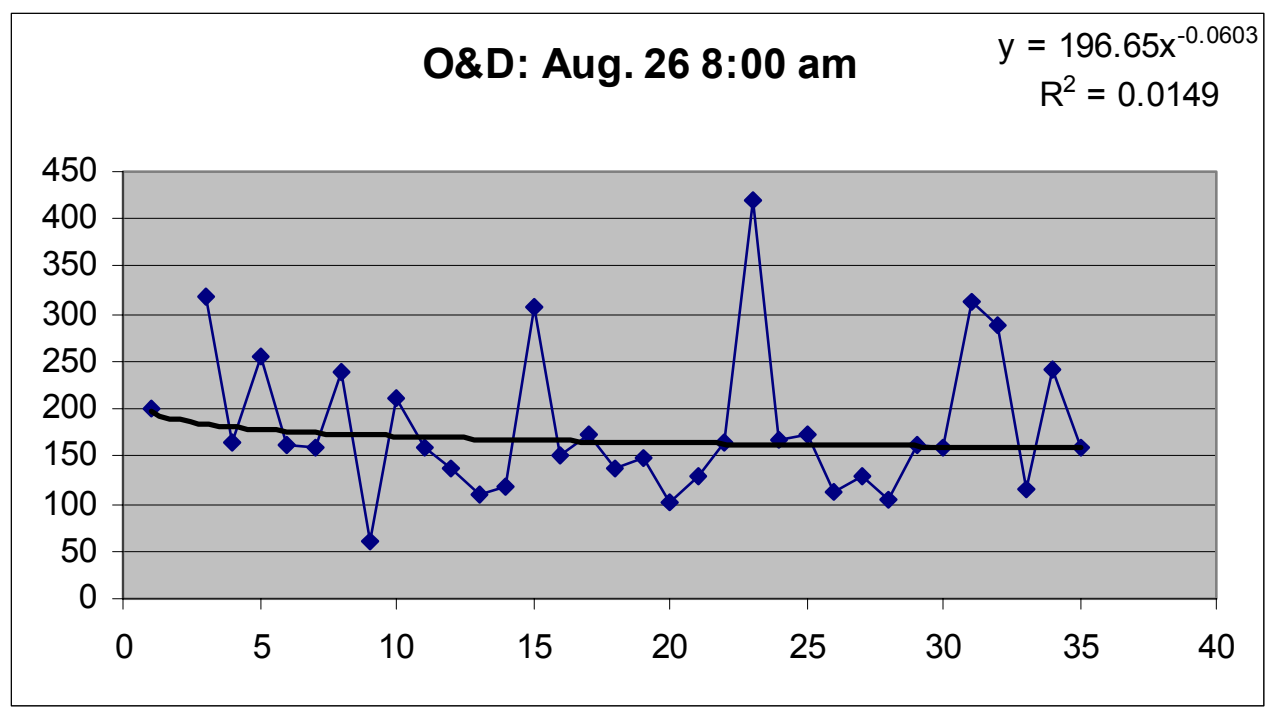




\begin{tabular}{|c|c|}
\hline \multicolumn{2}{|c|}{ Observe and Do Data: QA } \\
\hline \multicolumn{2}{|c|}{ Monday August 26, 2002 2:00 pm } \\
\hline $\begin{array}{r}\text { report No. } \\
\text { demonstration }\end{array}$ & $\begin{array}{c}\text { Time (Secs) } \\
68 \\
\end{array}$ \\
\hline 3 & 276 \\
\hline 5 & 170 \\
\hline 6 & 98 \\
\hline 7 & 150 \\
\hline 8 & 103 \\
\hline 10 & 66 \\
\hline 11 & 64 \\
\hline 12 & 95 \\
\hline 13 & 62 \\
\hline 15 & 59 \\
\hline 16 & 81 \\
\hline 17 & 79 \\
\hline 19 & 90 \\
\hline 20 & 76 \\
\hline 23 & 97 \\
\hline 24 & 75 \\
\hline 25 & 102 \\
\hline 26 & 60 \\
\hline 27 & 102 \\
\hline 28 & 143 \\
\hline 29 & 137 \\
\hline 30 & 59 \\
\hline 31 & 101 \\
\hline 32 & 78 \\
\hline 33 & 112 \\
\hline 34 & 62 \\
\hline 35 & 76 \\
\hline 36 & 73 \\
\hline 37 & 56 \\
\hline 38 & 73 \\
\hline 39 & 98 \\
\hline 40 & 48 \\
\hline 41 & 64 \\
\hline 42 & 58 \\
\hline 43 & 69 \\
\hline 44 & 63 \\
\hline 45 & 68 \\
\hline 46 & 60 \\
\hline 47 & 90 \\
\hline 48 & 49 \\
\hline 49 & 52 \\
\hline 50 & 173 \\
\hline 51 & 70 \\
\hline 52 & 77 \\
\hline 53 & 58 \\
\hline 54 & 68 \\
\hline 55 & 81 \\
\hline
\end{tabular}

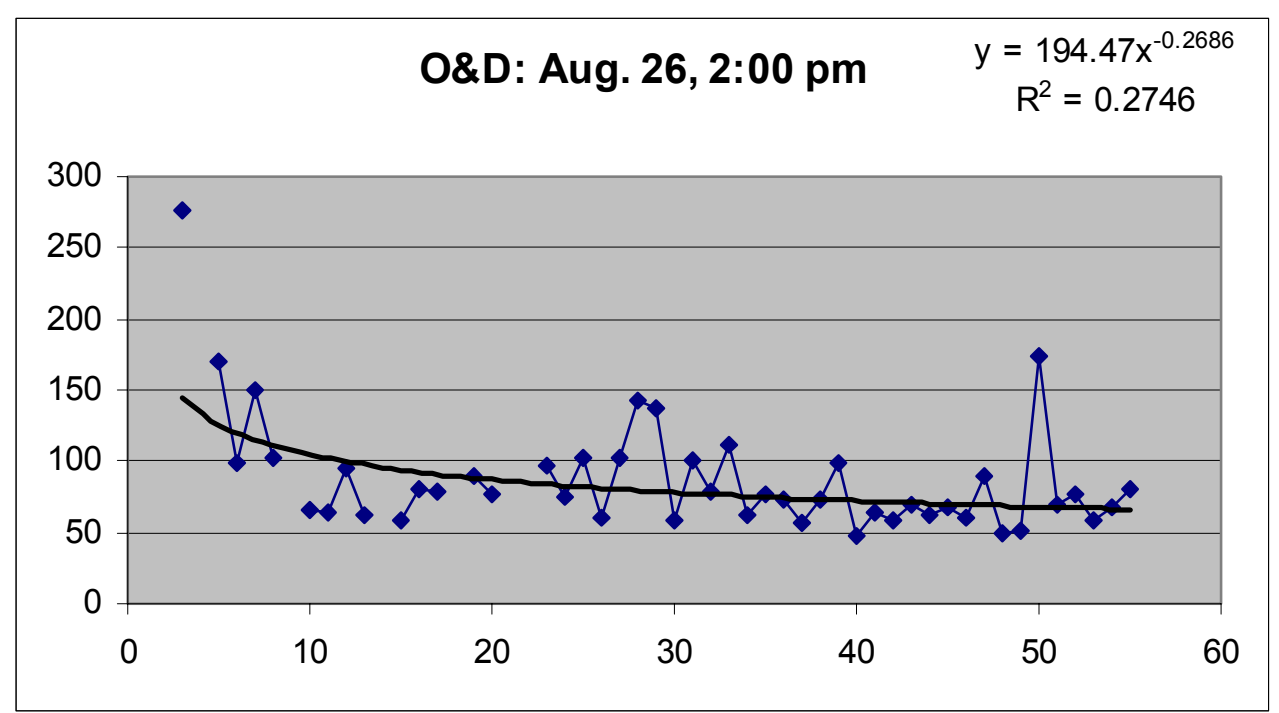




\begin{tabular}{|c|c|}
\hline \multicolumn{2}{|c|}{ Observe and Do Data: QA } \\
\hline \multicolumn{2}{|c|}{ Monday August 26, 2002 5:00 pm } \\
\hline $\begin{array}{r}\text { report No. } \\
\text { demonstration }\end{array}$ & $\begin{array}{c}\text { Time (Secs) } \\
61\end{array}$ \\
\hline 3 & 124 \\
\hline 4 & 73 \\
\hline 5 & 87 \\
\hline 6 & 185 \\
\hline 7 & 79 \\
\hline 8 & 79 \\
\hline 9 & 73 \\
\hline 10 & 166 \\
\hline 11 & 100 \\
\hline 12 & 128 \\
\hline 13 & 72 \\
\hline 14 & 91 \\
\hline 15 & 94 \\
\hline 16 & 62 \\
\hline 17 & 76 \\
\hline 18 & 97 \\
\hline 19 & 100 \\
\hline 20 & 63 \\
\hline 21 & 65 \\
\hline 22 & 77 \\
\hline 23 & 79 \\
\hline 24 & 56 \\
\hline 25 & 80 \\
\hline 26 & 78 \\
\hline 27 & 72 \\
\hline 28 & 75 \\
\hline 29 & 78 \\
\hline 30 & 78 \\
\hline 31 & 88 \\
\hline 32 & 78 \\
\hline 33 & 121 \\
\hline 34 & 114 \\
\hline 35 & 90 \\
\hline 36 & 92 \\
\hline 37 & 81 \\
\hline 38 & 87 \\
\hline 39 & 76 \\
\hline 40 & 74 \\
\hline 41 & 71 \\
\hline 42 & 64 \\
\hline 43 & 69 \\
\hline 44 & 56 \\
\hline 45 & 65 \\
\hline 46 & 111 \\
\hline 47 & 92 \\
\hline 48 & 94 \\
\hline 49 & 71 \\
\hline 50 & 103 \\
\hline 51 & 64 \\
\hline 52 & 57 \\
\hline
\end{tabular}

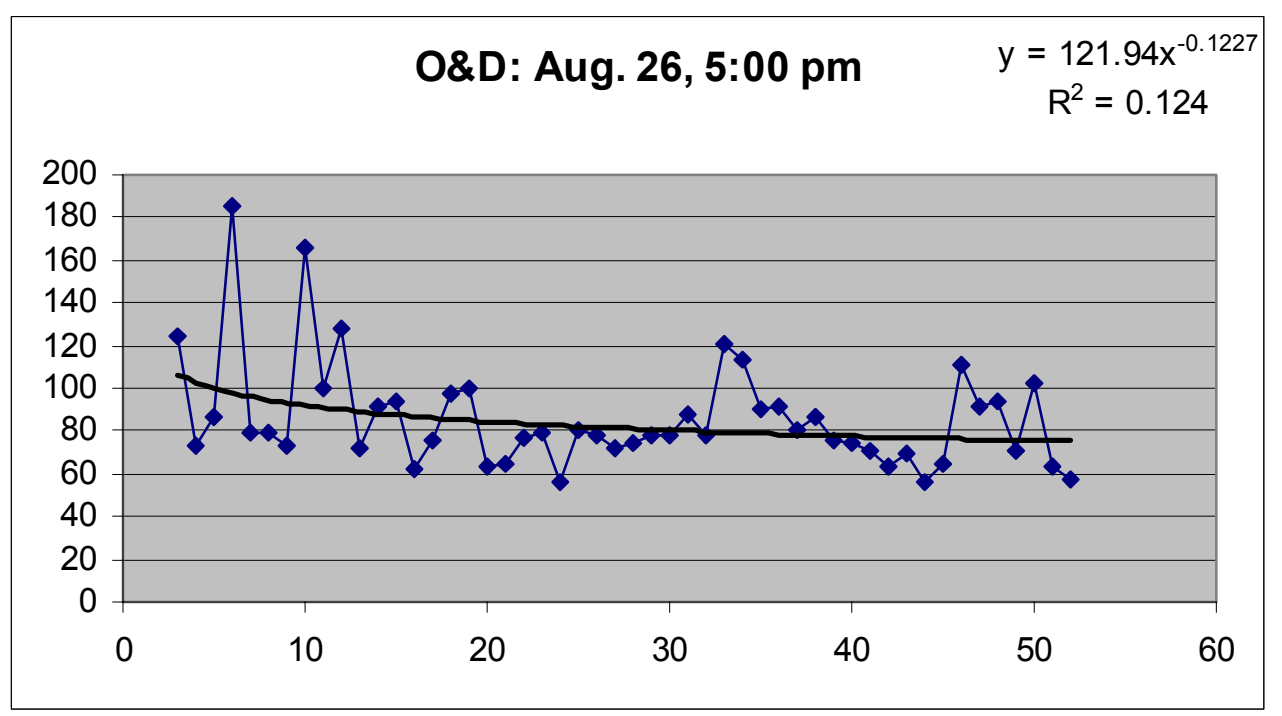




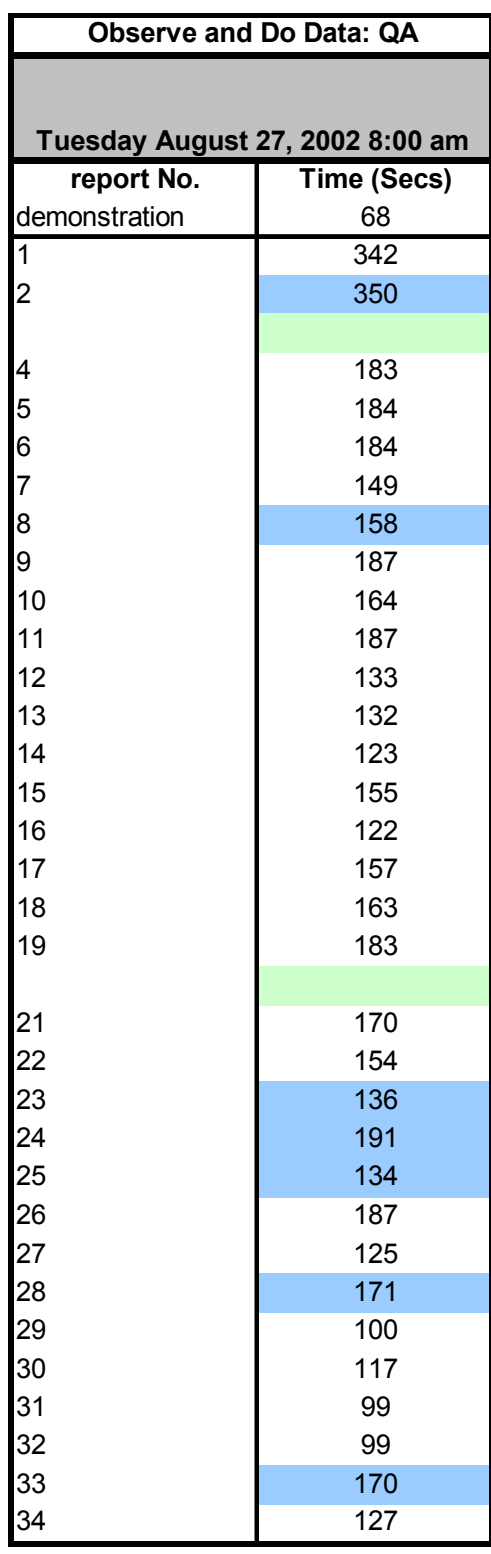

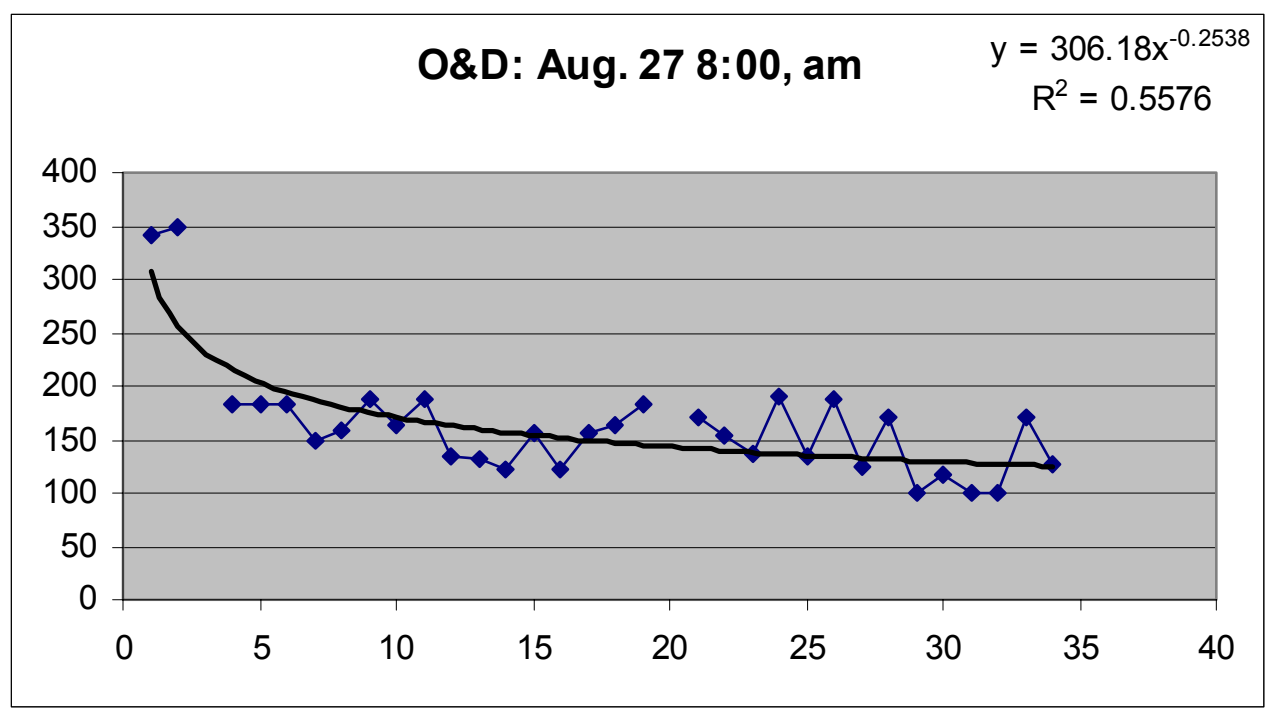




\begin{tabular}{|c|c|}
\hline Manual On & ata: QA \\
\hline Tuesday, August & 2002 2:00 pm \\
\hline $\begin{array}{l}\text { Report number } \\
\text { read manual } \\
\text { demonstration }\end{array}$ & $\begin{array}{c}\text { Time (Secs) } \\
700 \\
91\end{array}$ \\
\hline 1 & 172 \\
\hline 2 & 205 \\
\hline 3 & 120 \\
\hline 4 & 142 \\
\hline 5 & 222 \\
\hline 6 & 120 \\
\hline 7 & 172 \\
\hline 8 & 177 \\
\hline 9 & 124 \\
\hline 10 & 137 \\
\hline 11 & 181 \\
\hline 12 & 147 \\
\hline 13 & 147 \\
\hline 14 & 148 \\
\hline 15 & 143 \\
\hline 16 & 185 \\
\hline 17 & 159 \\
\hline 18 & 146 \\
\hline 19 & 131 \\
\hline 20 & 119 \\
\hline 21 & 147 \\
\hline 22 & 236 \\
\hline 23 & 137 \\
\hline 24 & 90 \\
\hline 25 & 120 \\
\hline 26 & 112 \\
\hline 27 & 86 \\
\hline 28 & 94 \\
\hline 29 & 93 \\
\hline 30 & 111 \\
\hline 31 & 108 \\
\hline 32 & 234 \\
\hline 33 & 172 \\
\hline 34 & 126 \\
\hline
\end{tabular}

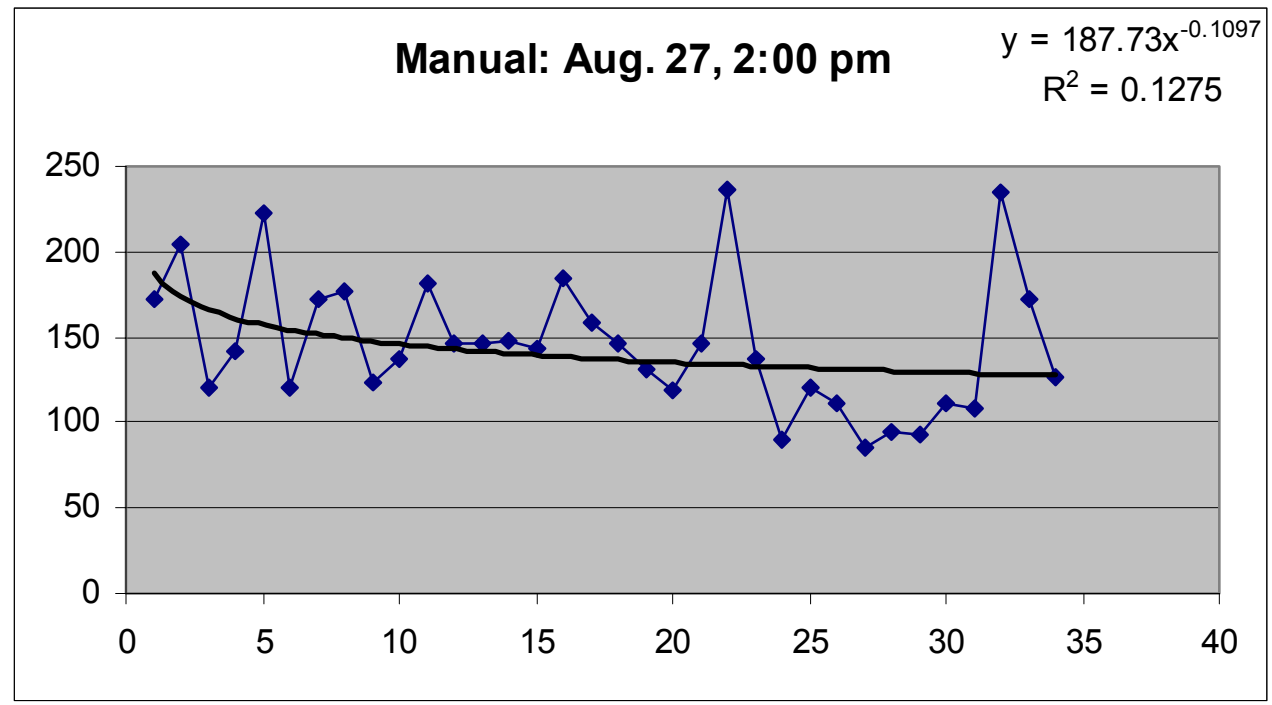




\begin{tabular}{|c|c|}
\hline \multicolumn{2}{|c|}{ Manual Only Data: QA } \\
\hline \multicolumn{2}{|c|}{ Tuesday, September 3, 2002 5:00 pm } \\
\hline $\begin{array}{l}\text { Report number } \\
\text { read manual } \\
\text { demonstration }\end{array}$ & $\begin{array}{c}\text { Time (Secs) } \\
505 \\
98\end{array}$ \\
\hline 1 & 777 \\
\hline 2 & 282 \\
\hline 3 & 143 \\
\hline 4 & 163 \\
\hline 5 & 128 \\
\hline 6 & 107 \\
\hline 7 & 160 \\
\hline 8 & 109 \\
\hline 9 & 185 \\
\hline 10 & 212 \\
\hline 11 & 204 \\
\hline 12 & 144 \\
\hline 13 & 163 \\
\hline 14 & 115 \\
\hline 15 & 196 \\
\hline 16 & 206 \\
\hline 17 & 116 \\
\hline 18 & 122 \\
\hline 19 & 78 \\
\hline 20 & 94 \\
\hline 21 & 84 \\
\hline 22 & 97 \\
\hline 23 & 133 \\
\hline 24 & 347 \\
\hline 25 & 147.5 \\
\hline 26 & 198 \\
\hline 27 & 66 \\
\hline 28 & 71 \\
\hline 29 & 74 \\
\hline 30 & 93 \\
\hline 31 & 175 \\
\hline
\end{tabular}

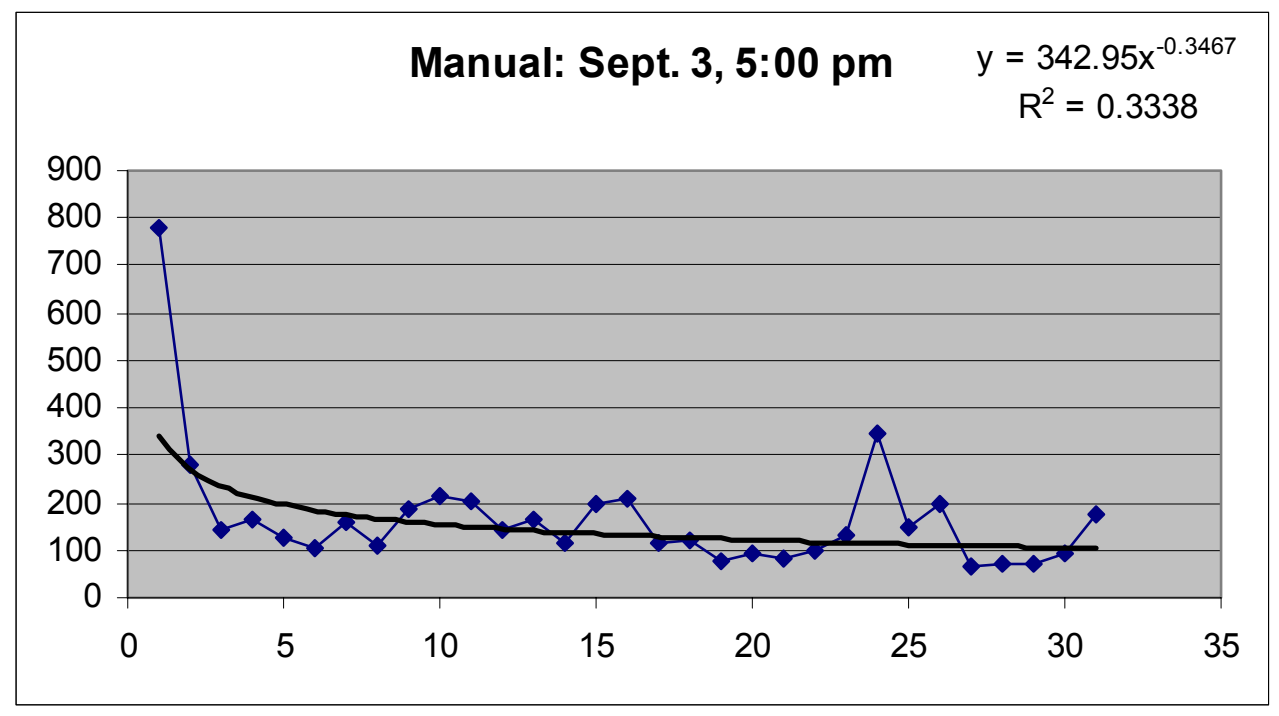




\begin{tabular}{|c|c|}
\hline \multicolumn{2}{|c|}{ Manual Only Data: QA } \\
\hline \multicolumn{2}{|c|}{$\begin{array}{c}\text { Wednesday, September 4, } 2002 \\
\text { 8:00am }\end{array}$} \\
\hline $\begin{array}{l}\text { Report number } \\
\text { read manual } \\
\text { demonstration }\end{array}$ & $\begin{array}{c}\text { Time (Secs) } \\
617 \\
112\end{array}$ \\
\hline 1 & 147 \\
\hline 2 & 205 \\
\hline 3 & 175 \\
\hline 4 & 183 \\
\hline 5 & 193 \\
\hline 6 & 193 \\
\hline 7 & 179 \\
\hline 8 & 151 \\
\hline 9 & 198 \\
\hline 10 & 158 \\
\hline 11 & 162 \\
\hline 12 & 176 \\
\hline 13 & 255 \\
\hline 14 & 142 \\
\hline 15 & 200 \\
\hline 16 & 135 \\
\hline 17 & 195 \\
\hline 18 & 135 \\
\hline 19 & 179 \\
\hline 20 & 144 \\
\hline 21 & 164 \\
\hline 22 & 147 \\
\hline 23 & 124 \\
\hline 24 & 127 \\
\hline 25 & 145 \\
\hline 26 & 108 \\
\hline 27 & 93 \\
\hline 28 & 93 \\
\hline 29 & 93 \\
\hline 30 & 182 \\
\hline 31 & 162 \\
\hline 32 & 87 \\
\hline 33 & 116 \\
\hline 34 & 117 \\
\hline 35 & 129 \\
\hline 36 & 128 \\
\hline
\end{tabular}

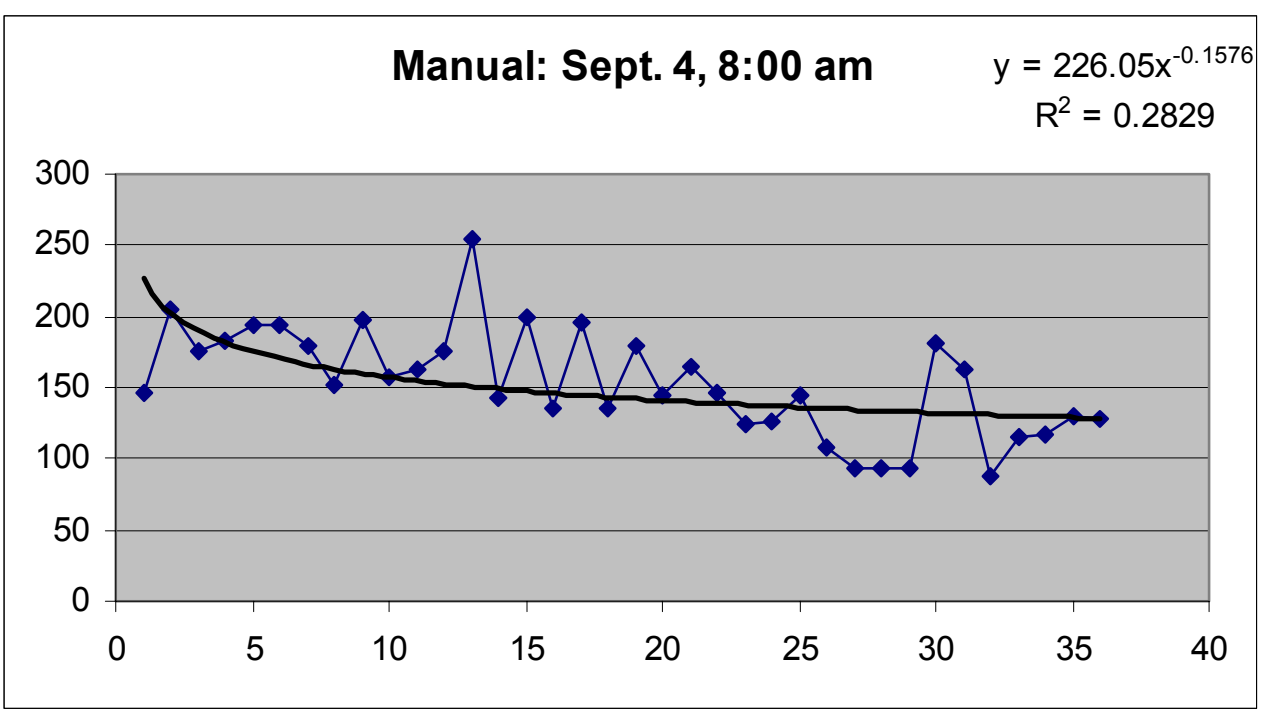




\begin{tabular}{|c|c|}
\hline Manual On & ta: QA \\
\hline Tuesday, Septer & $24,2: 00 \mathrm{pm}$ \\
\hline $\begin{array}{l}\text { Report number } \\
\text { read manual } \\
\text { demonstration }\end{array}$ & $\begin{array}{c}\text { Time (Secs) } \\
494 \\
84\end{array}$ \\
\hline 1 & 212 \\
\hline 2 & 234 \\
\hline 3 & 216 \\
\hline 4 & 129 \\
\hline 5 & 101 \\
\hline 6 & 49 \\
\hline 7 & 69 \\
\hline 8 & 162 \\
\hline 9 & 97 \\
\hline 10 & 68 \\
\hline 11 & 111 \\
\hline 12 & 104 \\
\hline 13 & 189 \\
\hline 14 & 130 \\
\hline 15 & 62 \\
\hline 16 & 131 \\
\hline 17 & 82 \\
\hline 18 & 53 \\
\hline 19 & 57 \\
\hline 20 & 119 \\
\hline 21 & 58 \\
\hline 22 & 55 \\
\hline 23 & 73 \\
\hline 24 & 94 \\
\hline 25 & 50 \\
\hline 26 & 56 \\
\hline 27 & 60 \\
\hline 28 & 47 \\
\hline 29 & 77 \\
\hline 30 & 48 \\
\hline 31 & 77 \\
\hline 32 & 102 \\
\hline 33 & 58 \\
\hline 34 & 60 \\
\hline 35 & 72 \\
\hline
\end{tabular}

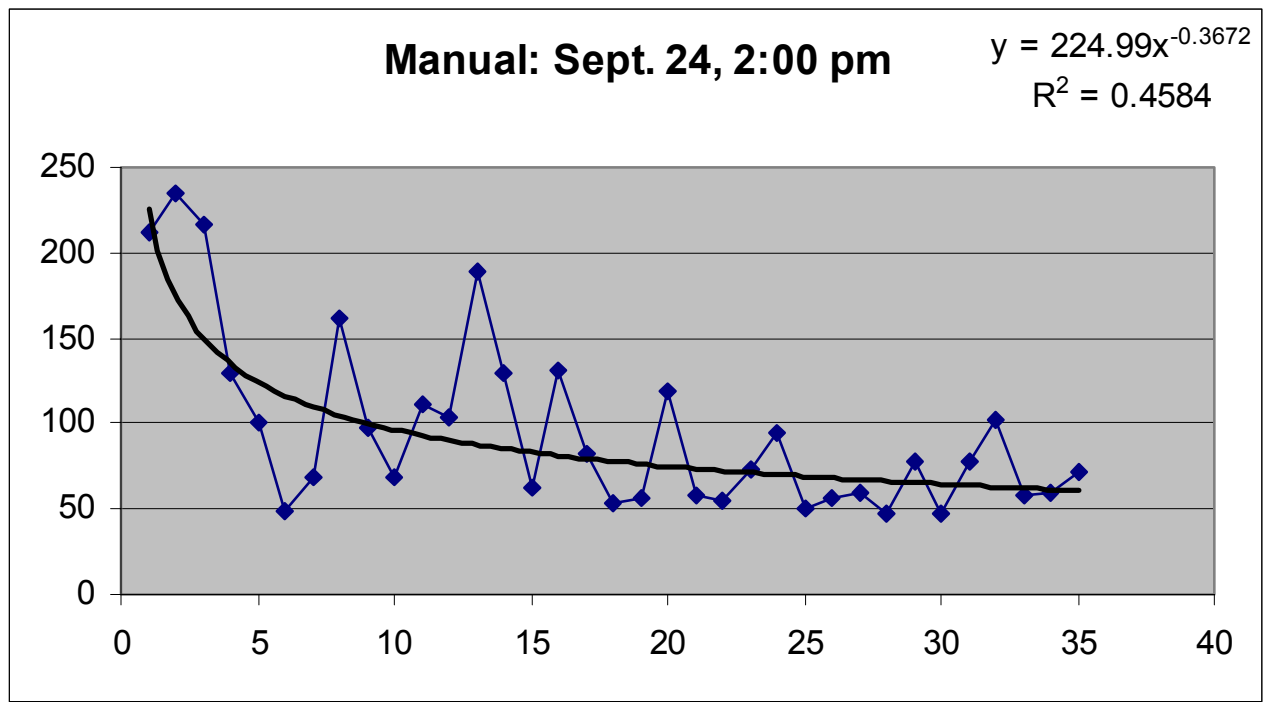




\begin{tabular}{|c|c|}
\hline \multicolumn{2}{|c|}{ Class Data: QA } \\
\hline \multicolumn{2}{|c|}{ Thursday, September 5, 2002 2:00 } \\
\hline Report No. & Time (Seconds) \\
\hline demonstration & 272 \\
\hline trial a & 117 \\
\hline trial b & 120 \\
\hline 1 & 104 \\
\hline 2 & 89 \\
\hline 3 & 85 \\
\hline 4 & 75 \\
\hline 5 & 89 \\
\hline 6 & 78 \\
\hline 7 & 101 \\
\hline 8 & 67 \\
\hline 9 & 68 \\
\hline 10 & 75 \\
\hline 11 & 74 \\
\hline 12 & 109 \\
\hline 13 & 59 \\
\hline 15 & 117 \\
\hline 16 & 62 \\
\hline 17 & 57 \\
\hline 18 & 73 \\
\hline 19 & 97 \\
\hline 20 & 132 \\
\hline 21 & 102 \\
\hline 22 & 89 \\
\hline 23 & 74 \\
\hline 24 & 76 \\
\hline 25 & 61 \\
\hline 26 & 66 \\
\hline 27 & 75 \\
\hline 28 & 119 \\
\hline 29 & 50 \\
\hline 30 & 60 \\
\hline 31 & 54 \\
\hline 32 & 45 \\
\hline 33 & 48 \\
\hline 34 & 73 \\
\hline 35 & 54 \\
\hline 36 & 49 \\
\hline 37 & 39 \\
\hline 38 & 51 \\
\hline 39 & 47 \\
\hline 40 & 55 \\
\hline 41 & 36 \\
\hline 42 & 57 \\
\hline 43 & 50 \\
\hline 44 & 41 \\
\hline
\end{tabular}

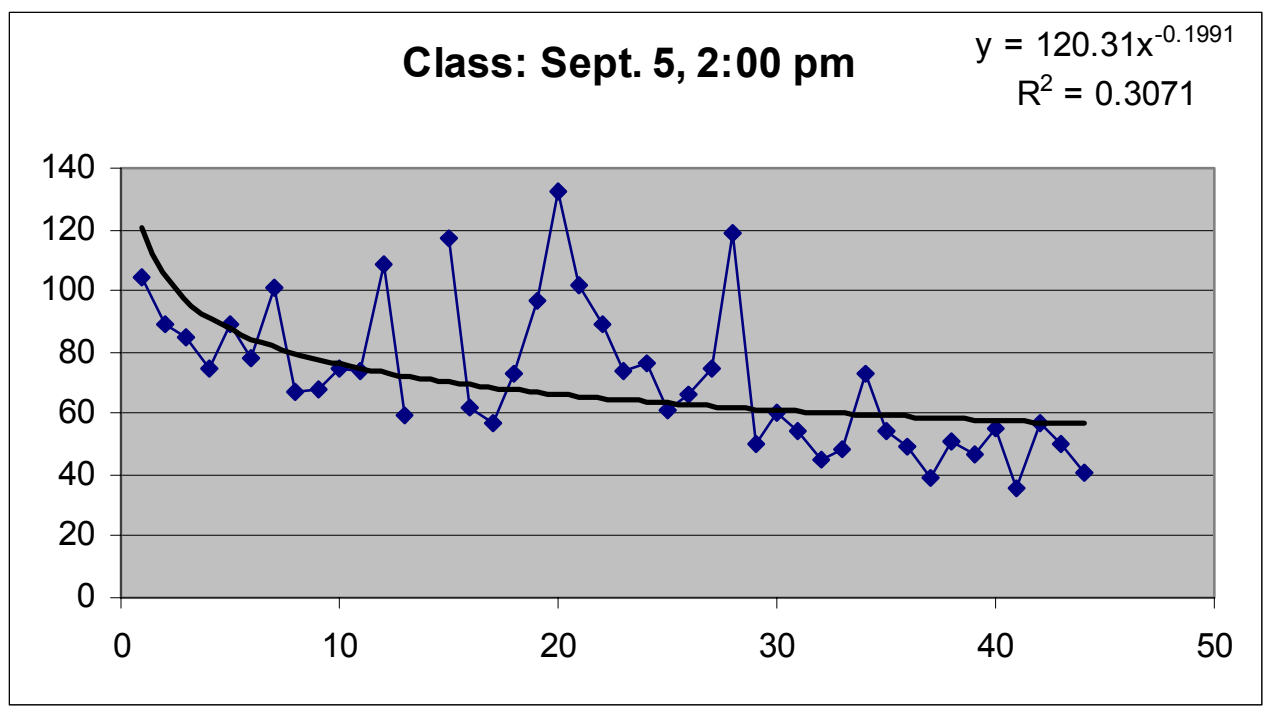




\begin{tabular}{|c|c|}
\hline \multicolumn{2}{|c|}{ Class Data: QA } \\
\hline \multicolumn{2}{|c|}{ Monday, September 23, 2002 3:30 pm } \\
\hline $\begin{array}{l}\text { Report No. } \\
\text { demonstration } \\
\text { trial a } \\
\text { trial b }\end{array}$ & $\begin{array}{c}\text { Time (Seconds) } \\
178 \\
96 \\
100\end{array}$ \\
\hline 2 & 90 \\
\hline 3 & 76 \\
\hline 4 & 69 \\
\hline 5 & 72 \\
\hline 6 & 58 \\
\hline 7 & 68 \\
\hline 8 & 45 \\
\hline 9 & 104 \\
\hline 10 & 54 \\
\hline 11 & 61 \\
\hline 12 & 59 \\
\hline 13 & 59 \\
\hline 14 & 68 \\
\hline 15 & 57 \\
\hline 16 & 59 \\
\hline 17 & 67 \\
\hline 18 & 52 \\
\hline 19 & 48 \\
\hline 20 & 72 \\
\hline 21 & 59 \\
\hline 22 & 50 \\
\hline 23 & 54 \\
\hline 24 & 82 \\
\hline 25 & 83 \\
\hline 26 & 65 \\
\hline 27 & 94 \\
\hline 28 & 110 \\
\hline 29 & 78 \\
\hline 30 & 88 \\
\hline 31 & 69 \\
\hline 32 & 88 \\
\hline 33 & 97 \\
\hline 34 & 85 \\
\hline 35 & 95 \\
\hline 36 & 80 \\
\hline 37 & 57 \\
\hline 38 & 71 \\
\hline 39 & 72 \\
\hline 40 & 64 \\
\hline
\end{tabular}

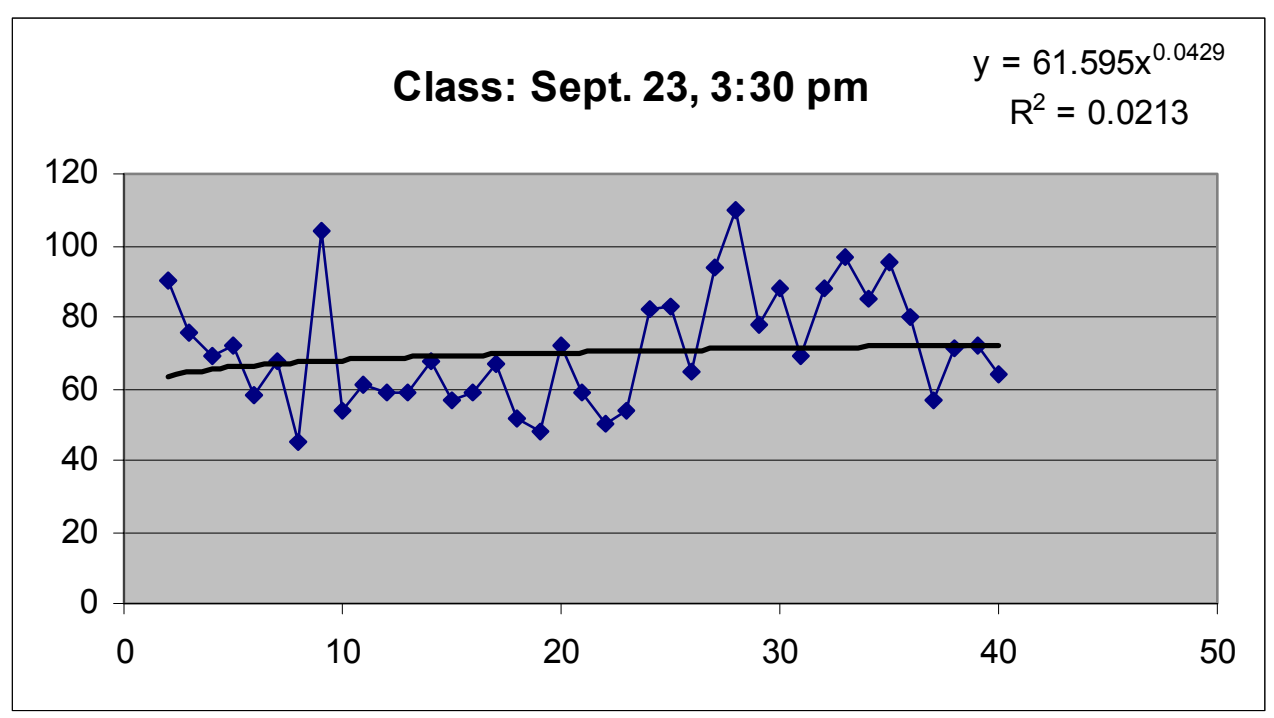




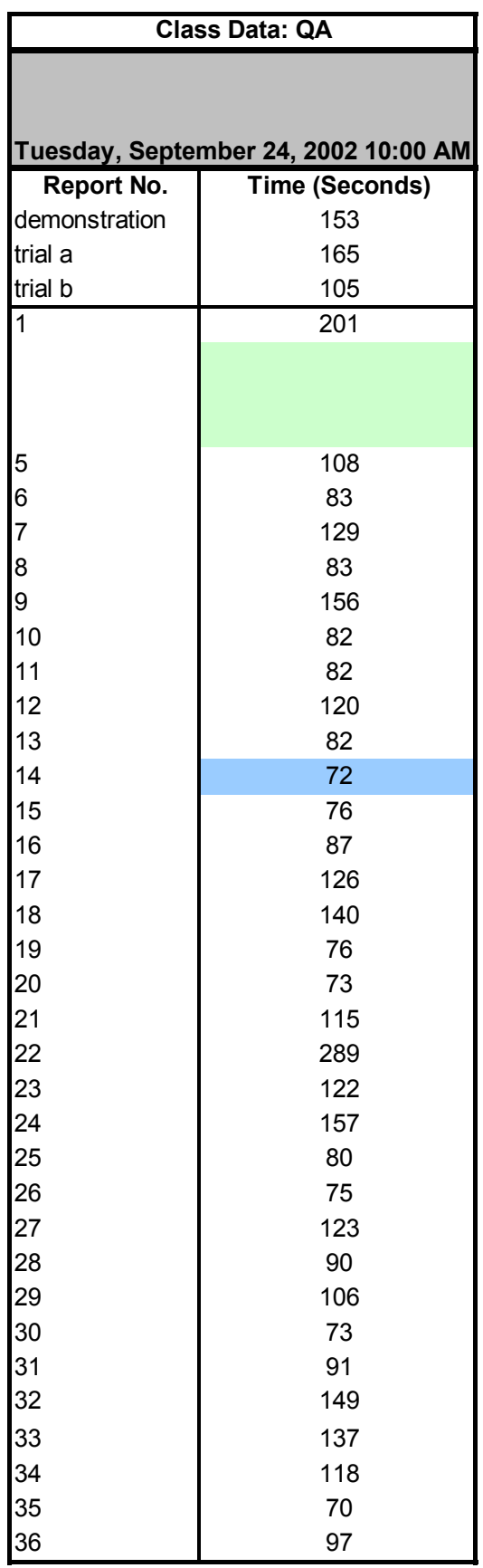

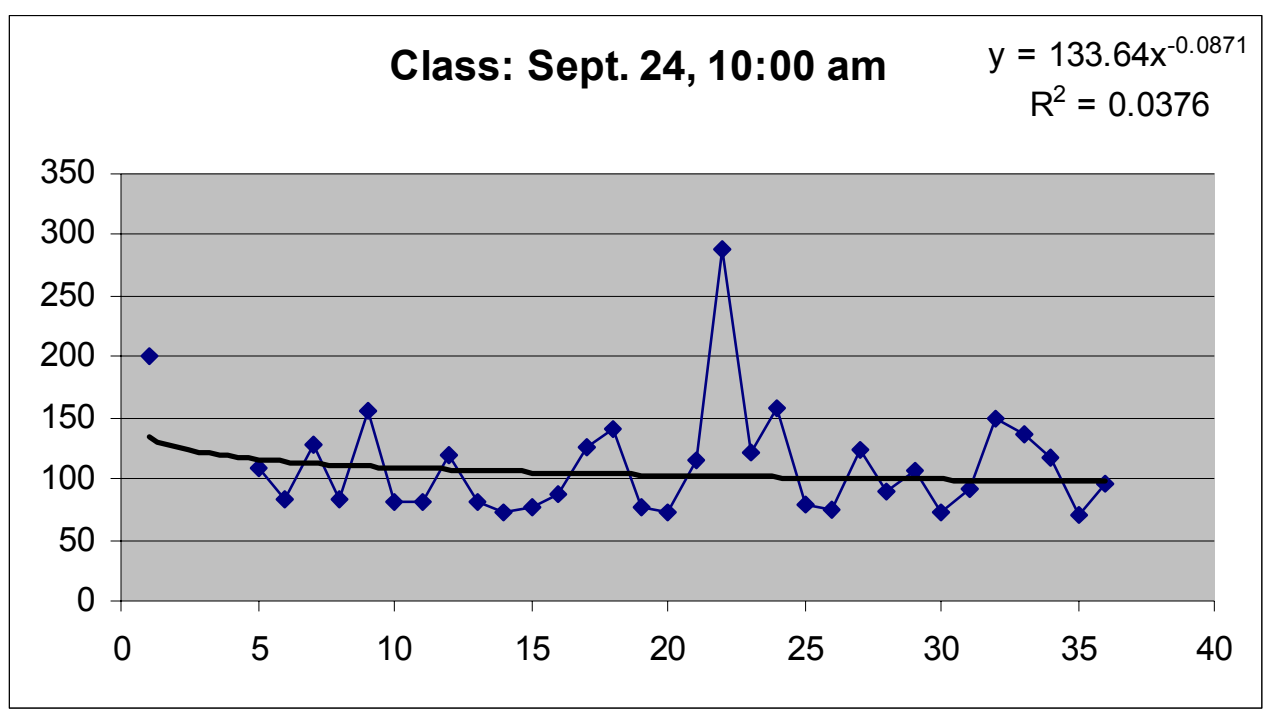




\begin{tabular}{|c|c|}
\hline \multicolumn{2}{|c|}{ Class Data: QA } \\
\hline \multicolumn{2}{|c|}{ Tuesday, September 4, 2002 4:30 } \\
\hline $\begin{array}{l}\text { Report No. } \\
\text { demonstration } \\
\text { trial a } \\
\text { trial b }\end{array}$ & $\begin{array}{c}\text { Time (Seconds) } \\
208 \\
146 \\
448\end{array}$ \\
\hline 1 & 160 \\
\hline 2 & 128 \\
\hline 3 & 144 \\
\hline 4 & 175 \\
\hline 5 & 121 \\
\hline 6 & 79 \\
\hline 7 & 95 \\
\hline 8 & 82 \\
\hline 9 & 80 \\
\hline 10 & 73 \\
\hline 11 & 69 \\
\hline 12 & 86 \\
\hline 13 & 69 \\
\hline 14 & 86 \\
\hline 15 & 68 \\
\hline 16 & 214 \\
\hline 17 & 98 \\
\hline 18 & 44 \\
\hline 19 & 75 \\
\hline 20 & 111 \\
\hline 21 & 70 \\
\hline 22 & 62 \\
\hline 23 & 141 \\
\hline 24 & 69 \\
\hline 25 & 65 \\
\hline 26 & 64 \\
\hline 27 & 57 \\
\hline 28 & 69 \\
\hline 29 & 93 \\
\hline 30 & 52 \\
\hline 31 & 64 \\
\hline 32 & 66 \\
\hline
\end{tabular}

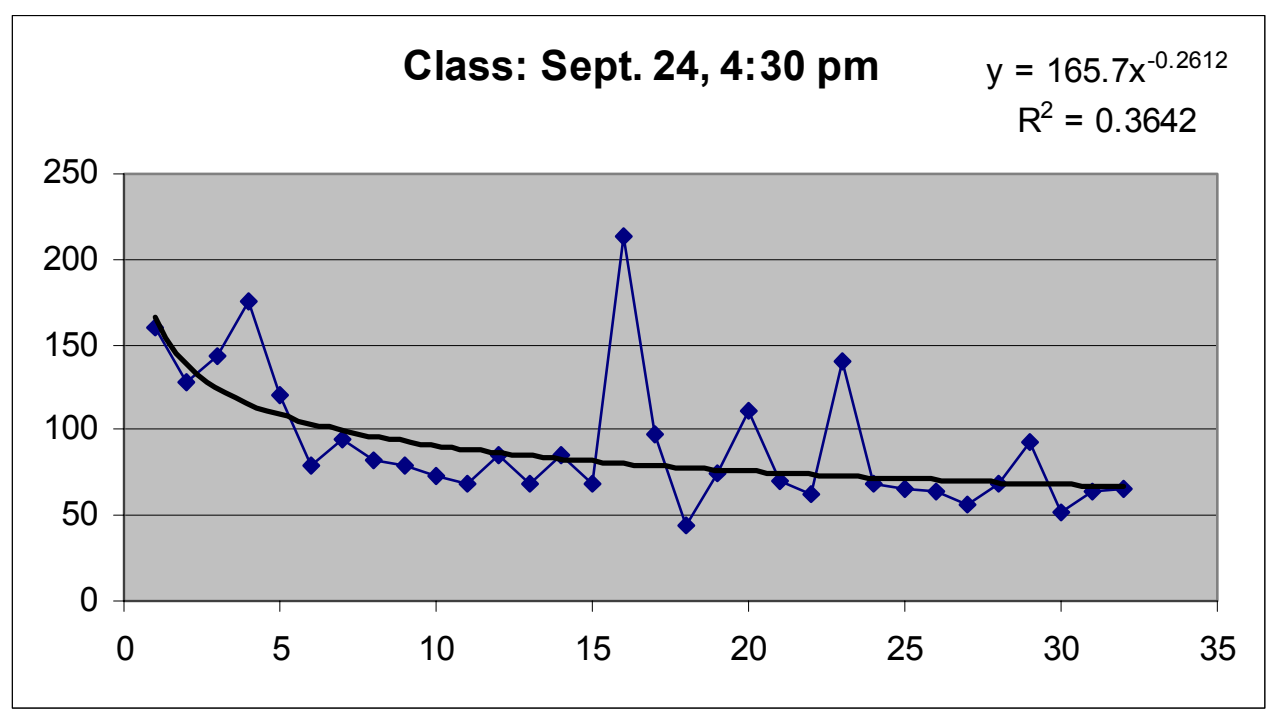




\begin{tabular}{|c|c|}
\hline \multicolumn{2}{|c|}{ Manual with Mentor Data: QA } \\
\hline \multicolumn{2}{|c|}{ Tuesday, September 3, 2002 8:00 am } \\
\hline $\begin{array}{l}\text { Report No. } \\
\text { reading manual }\end{array}$ & $\begin{array}{c}\text { Time (Secs) } \\
650\end{array}$ \\
\hline demonstration & \\
\hline 1 & 147 \\
\hline 2 & 391 \\
\hline 3 & 138 \\
\hline 4 & 166 \\
\hline 5 & 119 \\
\hline 6 & 131 \\
\hline 7 & 191 \\
\hline 8 & 146 \\
\hline 9 & 159 \\
\hline 10 & 125 \\
\hline 11 & 100 \\
\hline 12 & 108 \\
\hline 13 & 93 \\
\hline 14 & 179 \\
\hline 15 & 109 \\
\hline 16 & 103 \\
\hline 17 & 177 \\
\hline 18 & 96 \\
\hline 19 & 94 \\
\hline 20 & 109 \\
\hline 21 & 222 \\
\hline 22 & 100 \\
\hline 23 & 90 \\
\hline 24 & 108 \\
\hline 25 & 95 \\
\hline 26 & 83 \\
\hline 27 & 95 \\
\hline 28 & 92 \\
\hline 29 & 84 \\
\hline 30 & 115 \\
\hline 31 & 96 \\
\hline 32 & 153 \\
\hline 33 & 91 \\
\hline 34 & 105 \\
\hline 35 & 100 \\
\hline
\end{tabular}

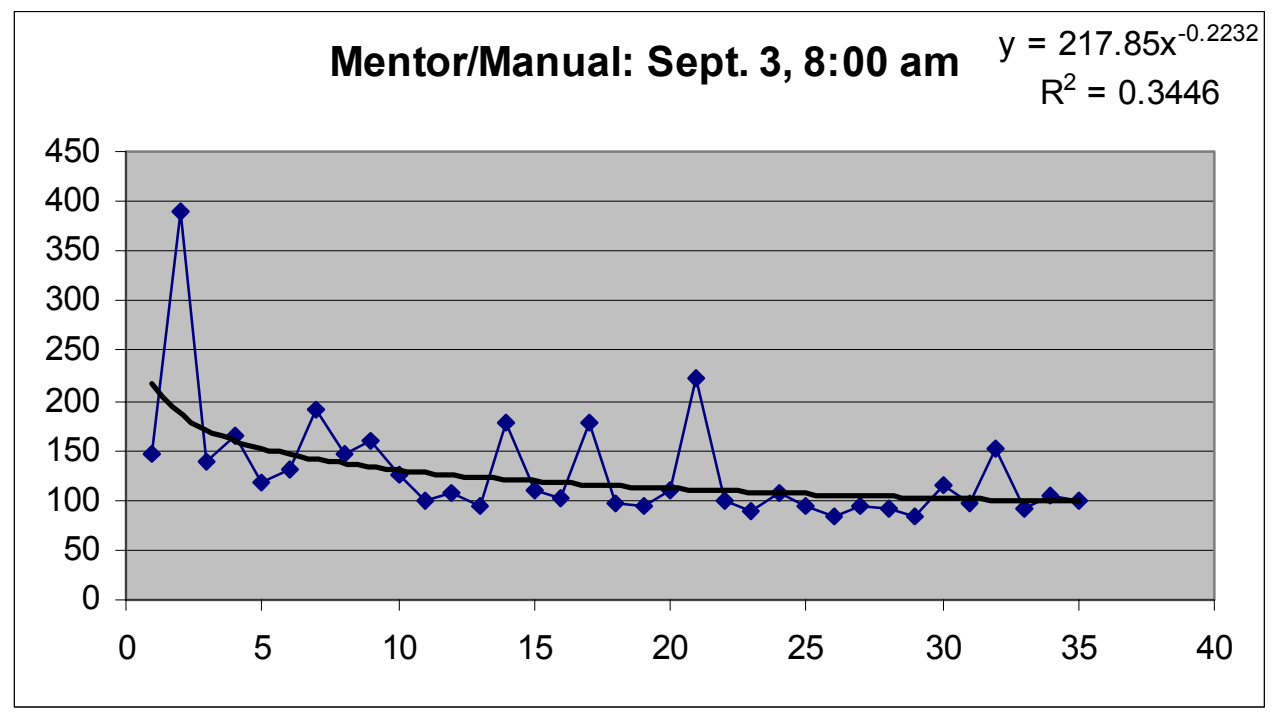




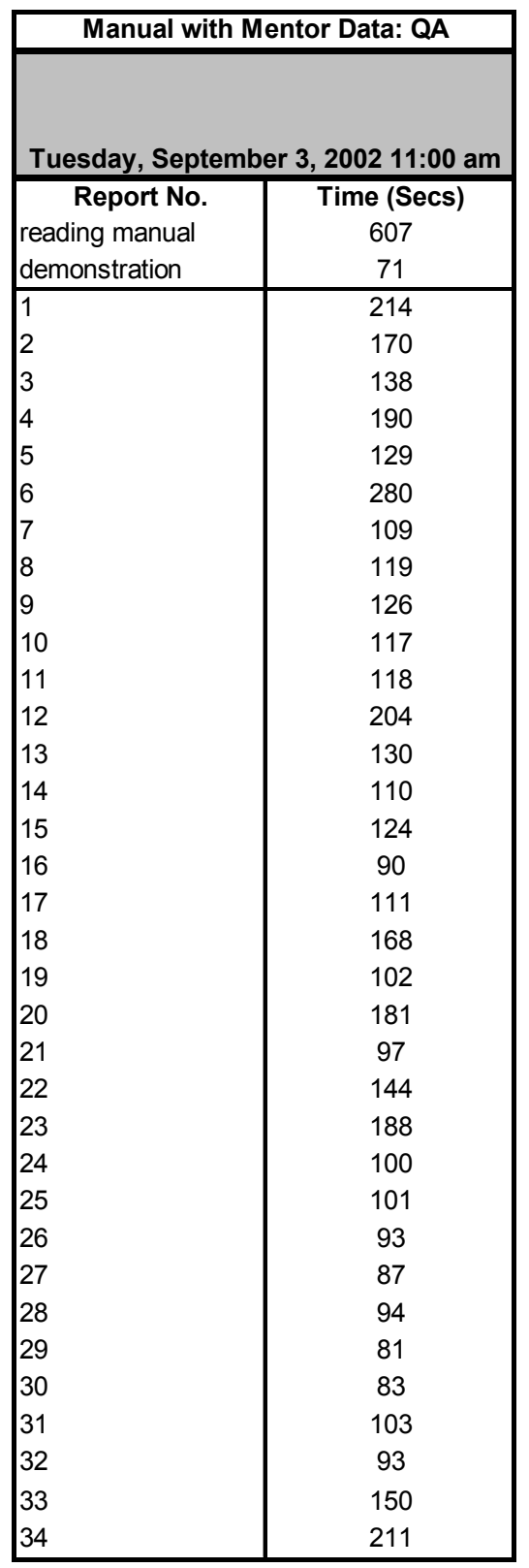

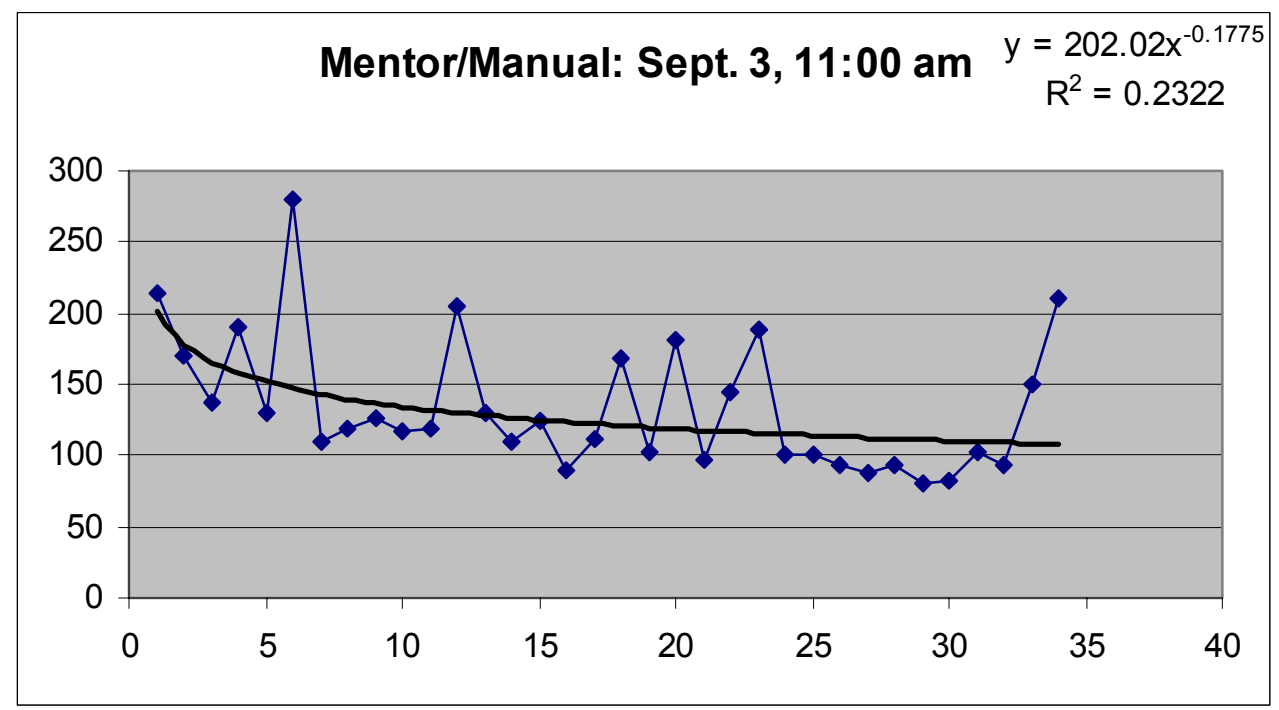

140 


\begin{tabular}{|c|c|}
\hline \multicolumn{2}{|c|}{ Manual with Mentor Data: QA } \\
\hline Tuesday, Sept & 3, $20022: 00 \mathrm{pm}$ \\
\hline $\begin{array}{l}\text { Report No. } \\
\text { reading manual } \\
\text { demonstration }\end{array}$ & $\begin{array}{c}\text { Time (Secs) } \\
484 \\
63\end{array}$ \\
\hline 1 & 173 \\
\hline 2 & 92 \\
\hline 3 & 133 \\
\hline 4 & 99 \\
\hline 6 & 97 \\
\hline 7 & 106 \\
\hline 8 & 135 \\
\hline 9 & 105 \\
\hline 10 & 108 \\
\hline 11 & 85 \\
\hline 12 & 109 \\
\hline 13 & 89 \\
\hline 14 & 90 \\
\hline 15 & 97 \\
\hline 16 & 88 \\
\hline 17 & 92 \\
\hline 18 & 339 \\
\hline 20 & 89 \\
\hline 21 & 115 \\
\hline 22 & 168 \\
\hline 23 & 155 \\
\hline 24 & 114 \\
\hline 25 & 102 \\
\hline 26 & 76 \\
\hline 27 & 89 \\
\hline 28 & 119 \\
\hline 29 & 85 \\
\hline 31 & 145 \\
\hline 32 & 81 \\
\hline 34 & 105 \\
\hline 35 & 88 \\
\hline 36 & 112 \\
\hline
\end{tabular}

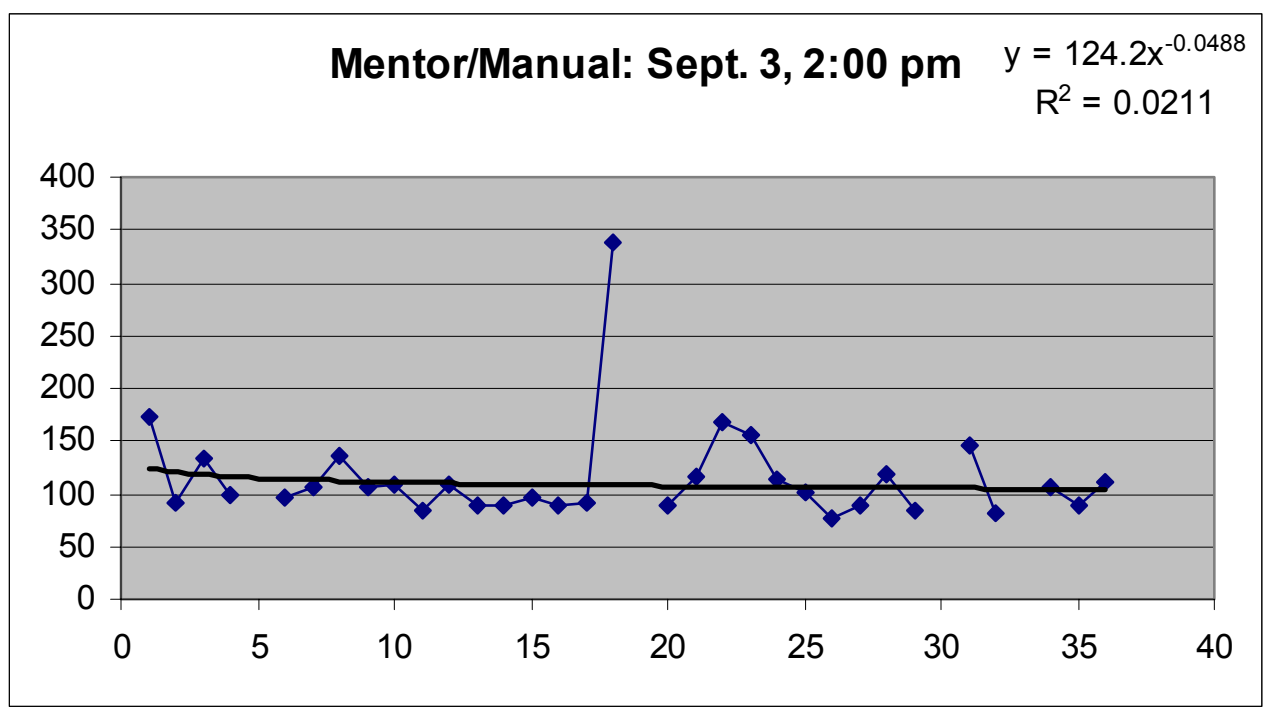




\begin{tabular}{|c|c|}
\hline \multicolumn{2}{|c|}{ Manual with Mentor Data: QA } \\
\hline \multicolumn{2}{|c|}{$\begin{array}{c}\text { Wednesday, September 4, } 2002 \text { 2:00 } \\
\text { pm }\end{array}$} \\
\hline $\begin{array}{l}\text { Report No. } \\
\text { reading manual } \\
\text { demonstration }\end{array}$ & $\begin{array}{c}\text { Time (Secs) } \\
590 \\
73\end{array}$ \\
\hline 1 & 148 \\
\hline 2 & 257 \\
\hline 3 & 270 \\
\hline 4 & 180 \\
\hline 5 & 193 \\
\hline 6 & 150 \\
\hline 7 & 110.5 \\
\hline 8 & 110.5 \\
\hline 9 & 201 \\
\hline 10 & 322 \\
\hline 11 & 110.5 \\
\hline 12 & 110.5 \\
\hline 13 & 120 \\
\hline 14 & 95 \\
\hline 15 & 86 \\
\hline 16 & 95 \\
\hline 17 & 94 \\
\hline 18 & 92 \\
\hline 19 & 99 \\
\hline 20 & 78 \\
\hline 21 & 86 \\
\hline 22 & 77 \\
\hline 23 & 85 \\
\hline 24 & 97 \\
\hline 25 & 118 \\
\hline 26 & 84 \\
\hline 27 & 90 \\
\hline 28 & 99 \\
\hline 29 & 88 \\
\hline 30 & 84 \\
\hline 31 & 77 \\
\hline 32 & 91 \\
\hline
\end{tabular}

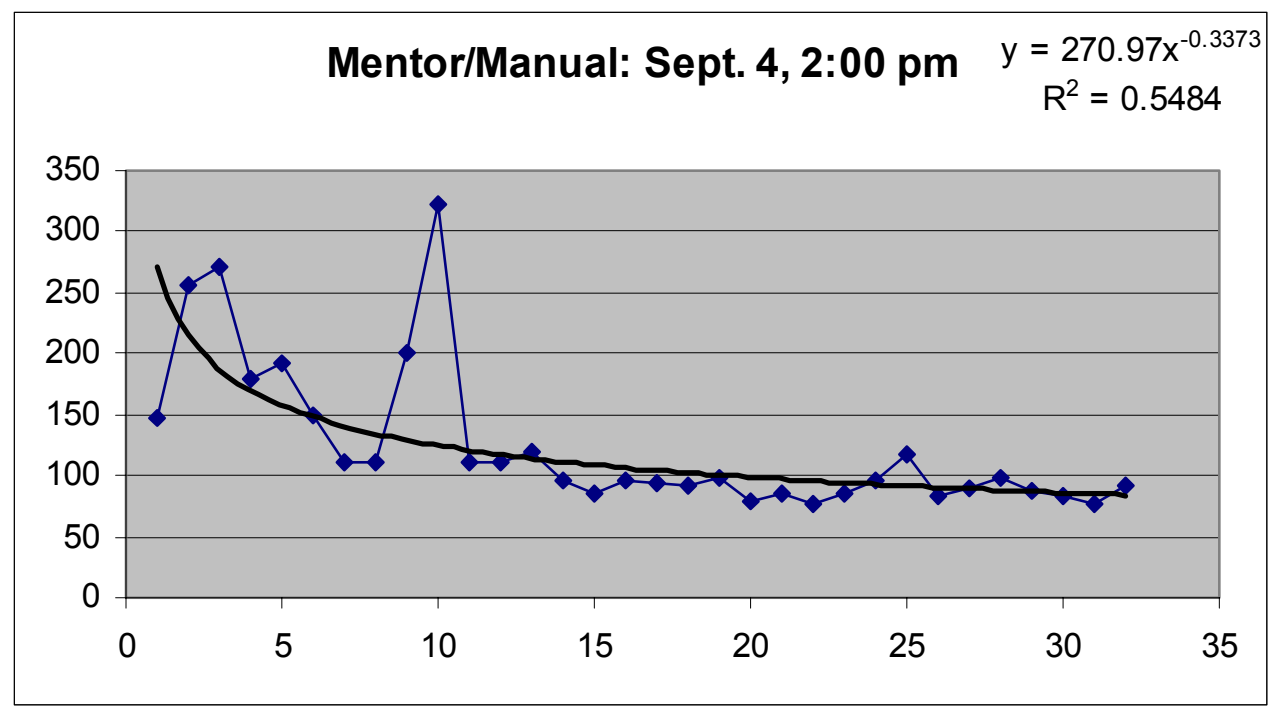




\section{APPENDIX D:}

DATA AND CHARTS FOR PROJECTED TIMES FROM LEARNING CURVES AND AVERAGE LEARNING CURVES 


\begin{tabular}{|c|c|c|c|c|c|}
\hline \multicolumn{6}{|c|}{ Observe and Do Fitted and Average Learning Curve Data } \\
\hline $\begin{array}{l}\text { Report } \\
\text { number }\end{array}$ & $\begin{array}{c}\text { Aug. 26, } \\
8: 00 \text { am } Y \\
= \\
196.65^{\star} X^{\wedge}(- \\
.0603)\end{array}$ & $\begin{array}{c}\text { Aug. 26, } \\
2: 00 \mathrm{pm} \\
= \\
194.47^{\star} \mathrm{X}^{\wedge}(- \\
.2686)\end{array}$ & $\begin{array}{c}\text { Aug. 26, } \\
5: 00 \text { pm } Y \\
= \\
121.94^{*} \mathrm{X}^{\wedge}(- \\
.1227)\end{array}$ & $\begin{array}{c}\text { Aug. 27, } \\
8: 00 \text { am } Y \\
= \\
306.18^{\star} X^{\wedge}(- \\
.2538)\end{array}$ & $\begin{array}{c}\text { Average } Y \\
= \\
201.71^{\star} X^{\wedge}(- \\
.1737)\end{array}$ \\
\hline 1 & 196.65 & 194.47 & 121.94 & 306.18 & 204.81 \\
\hline 2 & 188.60 & 161.43 & 112.00 & 256.79 & 179.71 \\
\hline 3 & 184.04 & 144.78 & 106.56 & 231.68 & 166.77 \\
\hline 4 & 180.88 & 134.01 & 102.87 & 215.36 & 158.28 \\
\hline 5 & 178.46 & 126.21 & 100.09 & 203.51 & 152.07 \\
\hline 6 & 176.51 & 120.18 & 97.87 & 194.30 & 147.22 \\
\hline 7 & 174.88 & 115.31 & 96.04 & 186.85 & 143.27 \\
\hline 8 & 173.48 & 111.25 & 94.48 & 180.62 & 139.96 \\
\hline 9 & 172.25 & 107.78 & 93.12 & 175.30 & 137.11 \\
\hline 10 & 171.16 & 104.77 & 91.93 & 170.68 & 134.63 \\
\hline 11 & 170.18 & 102.13 & 90.86 & 166.60 & 132.44 \\
\hline 12 & 169.29 & 99.77 & 89.89 & 162.96 & 130.48 \\
\hline 13 & 168.47 & 97.64 & 89.02 & 159.68 & 128.70 \\
\hline 14 & 167.72 & 95.72 & 88.21 & 156.71 & 127.09 \\
\hline 15 & 167.02 & 93.96 & 87.47 & 153.99 & 125.61 \\
\hline 16 & 166.37 & 92.35 & 86.78 & 151.49 & 124.25 \\
\hline 17 & 165.77 & 90.86 & 86.13 & 149.17 & 122.98 \\
\hline 18 & 165.20 & 89.47 & 85.53 & 147.02 & 121.81 \\
\hline 19 & 164.66 & 88.18 & 84.97 & 145.02 & 120.71 \\
\hline 20 & 164.15 & 86.98 & 84.43 & 143.14 & 119.68 \\
\hline 21 & 163.67 & 85.84 & 83.93 & 141.38 & 118.71 \\
\hline 22 & 163.21 & 84.78 & 83.45 & 139.72 & 117.79 \\
\hline 23 & 162.77 & 83.77 & 83.00 & 138.16 & 116.92 \\
\hline 24 & 162.36 & 82.82 & 82.56 & 136.67 & 116.10 \\
\hline 25 & 161.96 & 81.92 & 82.15 & 135.26 & 115.32 \\
\hline 26 & 161.57 & 81.06 & 81.76 & 133.92 & 114.58 \\
\hline 27 & 161.21 & 80.24 & 81.38 & 132.65 & 113.87 \\
\hline 28 & 160.85 & 79.46 & 81.02 & 131.43 & 113.19 \\
\hline 29 & 160.51 & 78.71 & 80.67 & 130.26 & 112.54 \\
\hline 30 & 160.19 & 78.00 & 80.33 & 129.15 & 111.92 \\
\hline 31 & 159.87 & 77.32 & 80.01 & 128.08 & 111.32 \\
\hline 32 & 159.56 & 76.66 & 79.70 & 127.05 & 110.74 \\
\hline 33 & 159.27 & 76.03 & 79.40 & 126.06 & 110.19 \\
\hline 34 & 158.98 & 75.42 & 79.11 & 125.11 & 109.66 \\
\hline 35 & 158.70 & 74.84 & 78.83 & 124.19 & 109.14 \\
\hline 36 & 158.43 & 74.27 & 78.56 & 123.31 & 108.64 \\
\hline 37 & 158.17 & 73.73 & 78.29 & 122.45 & 108.16 \\
\hline 38 & 157.92 & 73.20 & 78.04 & 121.63 & 107.70 \\
\hline 39 & 157.67 & 72.69 & 77.79 & 120.83 & 107.25 \\
\hline 40 & 157.43 & 72.20 & 77.55 & 120.05 & 106.81 \\
\hline
\end{tabular}




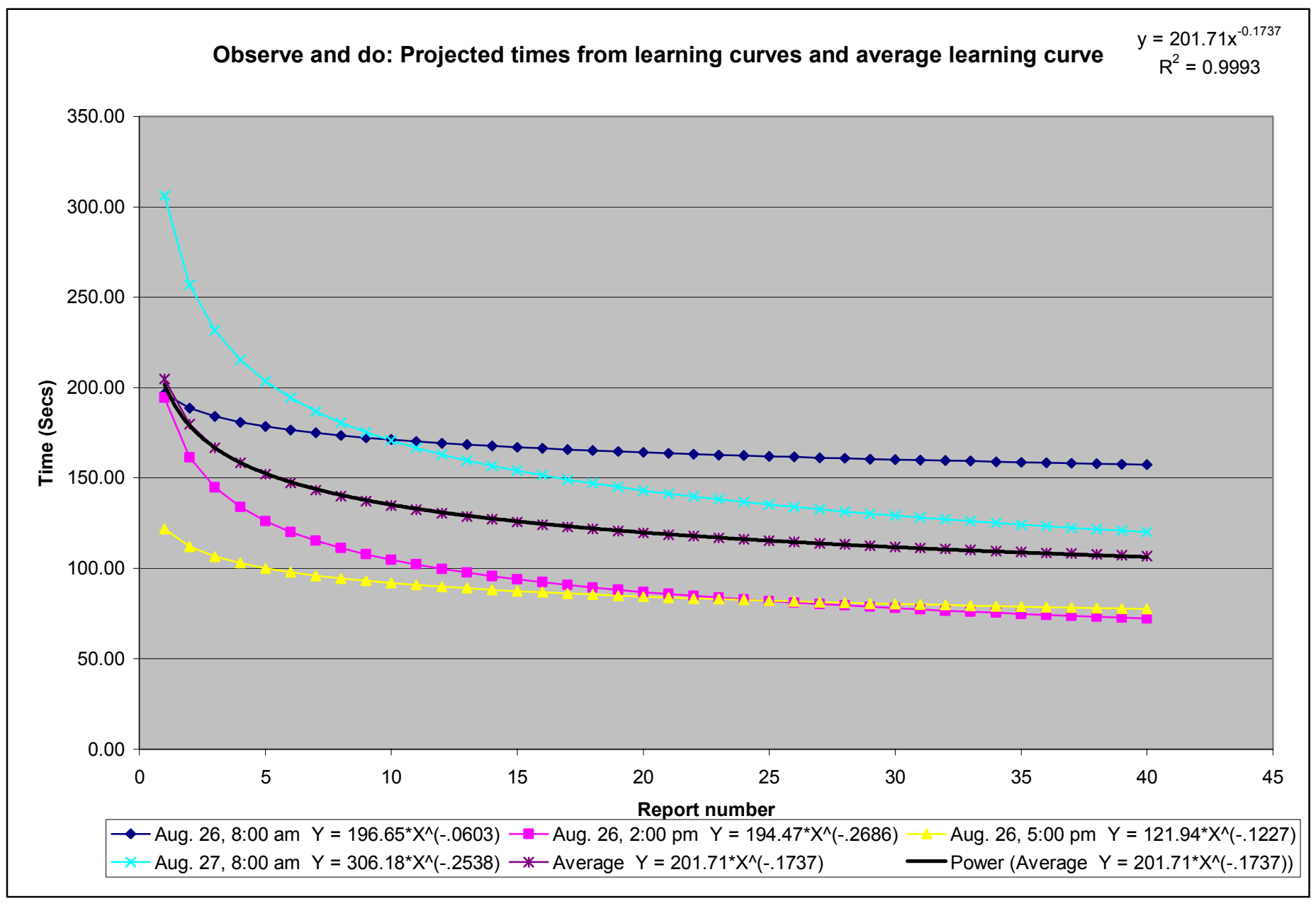




\begin{tabular}{|c|c|c|c|c|c|}
\hline \multicolumn{6}{|c|}{ Manual Only Fitted Learning Curves and Average } \\
\hline $\begin{array}{l}\text { Report } \\
\text { number }\end{array}$ & $\begin{array}{c}\text { Aug 27, } \\
2: 00 \mathrm{pm} \\
\mathrm{Y}= \\
187.73^{*} \mathrm{X}^{\wedge}( \\
.1097)\end{array}$ & $\begin{array}{c}\text { Sept 3, } \\
5: 00 \mathrm{pm} \\
\mathrm{Y}= \\
342.95^{\star} \mathrm{X}^{\wedge}( \\
.3467)\end{array}$ & $\begin{array}{c}\text { Sept 4, } \\
8: 00 \text { am } \\
Y= \\
226.05^{\star} X^{\wedge}( \\
.1576)\end{array}$ & $\begin{array}{c}\text { Sept 24, } \\
2: 00 \text { pm } \\
Y= \\
224.99^{*} X^{\wedge}( \\
.3672)\end{array}$ & $\begin{array}{c}\text { Average } \\
Y= \\
239.86^{\star} X^{\wedge}( \\
.2357)\end{array}$ \\
\hline 1 & 187.73 & 342.95 & 226.05 & 224.99 & 245.43 \\
\hline 2 & 173.98 & 269.69 & 202.66 & 174.43 & 205.19 \\
\hline 3 & 166.42 & 234.32 & 190.11 & 150.30 & 185.29 \\
\hline 4 & 161.25 & 212.08 & 181.69 & 135.23 & 172.56 \\
\hline 5 & 157.35 & 196.29 & 175.41 & 124.60 & 163.41 \\
\hline 6 & 154.23 & 184.27 & 170.44 & 116.53 & 156.37 \\
\hline 7 & 151.64 & 174.68 & 166.35 & 110.11 & 150.70 \\
\hline 8 & 149.44 & 166.77 & 162.88 & 104.85 & 145.99 \\
\hline 9 & 147.52 & 160.10 & 159.89 & 100.41 & 141.98 \\
\hline 10 & 145.83 & 154.36 & 157.26 & 96.60 & 138.51 \\
\hline 11 & 144.31 & 149.34 & 154.91 & 93.27 & 135.46 \\
\hline 12 & 142.94 & 144.90 & 152.80 & 90.34 & 132.75 \\
\hline 13 & 141.69 & 140.94 & 150.89 & 87.72 & 130.31 \\
\hline 14 & 140.54 & 137.36 & 149.13 & 85.37 & 128.10 \\
\hline 15 & 139.48 & 134.12 & 147.52 & 83.23 & 126.09 \\
\hline 16 & 138.50 & 131.15 & 146.03 & 81.28 & 124.24 \\
\hline 17 & 137.58 & 128.42 & 144.64 & 79.50 & 122.53 \\
\hline 18 & 136.72 & 125.90 & 143.34 & 77.84 & 120.95 \\
\hline 19 & 135.91 & 123.56 & 142.13 & 76.31 & 119.48 \\
\hline 20 & 135.15 & 121.38 & 140.98 & 74.89 & 118.10 \\
\hline 21 & 134.43 & 119.35 & 139.90 & 73.56 & 116.81 \\
\hline 22 & 133.74 & 117.44 & 138.88 & 72.31 & 115.59 \\
\hline 23 & 133.09 & 115.64 & 137.91 & 71.14 & 114.45 \\
\hline 24 & 132.47 & 113.95 & 136.99 & 70.04 & 113.36 \\
\hline 25 & 131.88 & 112.35 & 136.11 & 69.00 & 112.33 \\
\hline 26 & 131.31 & 110.83 & 135.27 & 68.01 & 111.36 \\
\hline 27 & 130.77 & 109.39 & 134.47 & 67.08 & 110.43 \\
\hline 28 & 130.25 & 108.02 & 133.70 & 66.19 & 109.54 \\
\hline 29 & 129.75 & 106.71 & 132.96 & 65.34 & 108.69 \\
\hline 30 & 129.27 & 105.47 & 132.25 & 64.53 & 107.88 \\
\hline 31 & 128.80 & 104.27 & 131.57 & 63.76 & 107.10 \\
\hline 32 & 128.36 & 103.13 & 130.92 & 63.02 & 106.36 \\
\hline 33 & 127.92 & 102.04 & 130.28 & 62.31 & 105.64 \\
\hline 34 & 127.51 & 100.99 & 129.67 & 61.63 & 104.95 \\
\hline 35 & 127.10 & 99.98 & 129.08 & 60.98 & 104.28 \\
\hline 36 & 126.71 & 99.01 & 128.51 & 60.35 & 103.64 \\
\hline 37 & 126.33 & 98.07 & 127.95 & 59.75 & 103.03 \\
\hline 38 & 125.96 & 97.17 & 127.42 & 59.17 & 102.43 \\
\hline 39 & 125.60 & 96.30 & 126.90 & 58.60 & 101.85 \\
\hline 40 & 125.25 & 95.45 & 126.39 & 58.06 & 101.29 \\
\hline
\end{tabular}




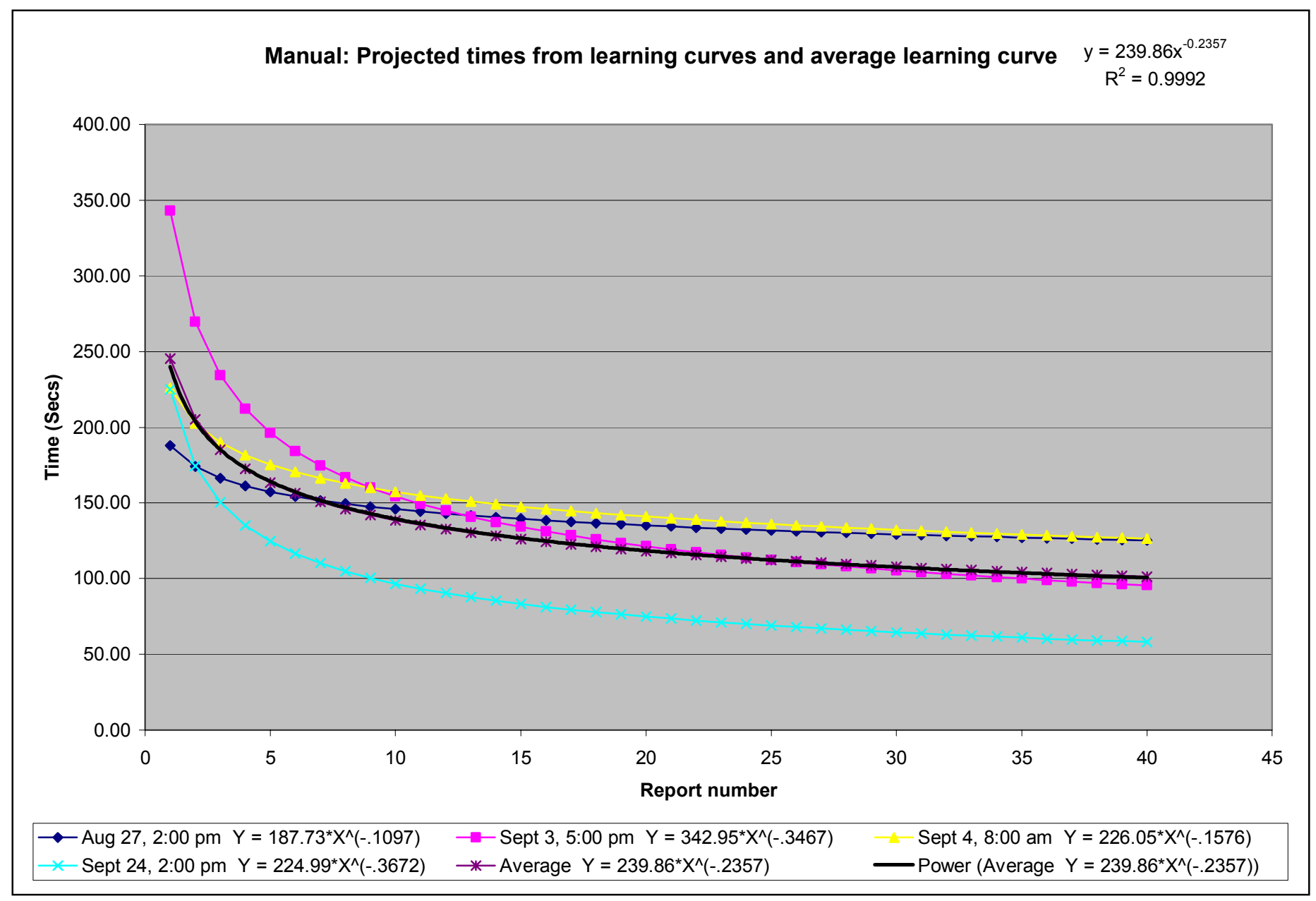




\begin{tabular}{|c|c|c|c|c|c|}
\hline \multicolumn{6}{|c|}{ Class Fitted Learning Curves and Average } \\
\hline $\begin{array}{l}\text { Report } \\
\text { number }\end{array}$ & $\begin{array}{c}\text { Sept 5, } \\
2: 00 \text { pm } Y \\
= \\
120.31^{\star} \mathrm{X}^{\wedge}( \\
.1991)\end{array}$ & $\begin{array}{c}\text { Sept 23, } \\
3: 30 \mathrm{pm} \quad \mathrm{Y} \\
= \\
61.595^{\star} \mathrm{X}^{\wedge}( \\
.0429)\end{array}$ & \begin{tabular}{|c|} 
Sept 24, \\
$10: 00 \mathrm{am}$ \\
$\mathrm{Y}=$ \\
$133.64^{\star} \mathrm{X}^{\wedge}($ \\
$.0871)$
\end{tabular} & $\begin{array}{c}\text { Sept 24, } \\
4: 30 \mathrm{pm} \quad Y \\
= \\
165.70^{\star} \mathrm{X}^{\wedge}( \\
.2512)\end{array}$ & $\begin{array}{c}\text { Average } \\
Y= \\
117.70^{\star} X^{\wedge}( \\
.1333)\end{array}$ \\
\hline 1 & 120.31 & 61.60 & 133.64 & 165.70 & 120.31 \\
\hline 2 & 104.80 & 63.45 & 125.81 & 138.26 & 108.08 \\
\hline 3 & 96.67 & 64.57 & 121.44 & 124.37 & 101.76 \\
\hline 4 & 91.29 & 65.37 & 118.44 & 115.36 & 97.62 \\
\hline 5 & 87.32 & 66.00 & 116.16 & 108.83 & 94.58 \\
\hline 6 & 84.21 & 66.52 & 114.33 & 103.77 & 92.21 \\
\hline 7 & 81.67 & 66.96 & 112.81 & 99.67 & 90.28 \\
\hline 8 & 79.52 & 67.34 & 111.50 & 96.26 & 88.66 \\
\hline 9 & 77.68 & 67.68 & 110.36 & 93.34 & 87.27 \\
\hline 10 & 76.07 & 67.99 & 109.35 & 90.81 & 86.06 \\
\hline 11 & 74.64 & 68.27 & 108.45 & 88.57 & 84.98 \\
\hline 12 & 73.36 & 68.52 & 107.63 & 86.58 & 84.02 \\
\hline 13 & 72.20 & 68.76 & 106.88 & 84.79 & 83.16 \\
\hline 14 & 71.14 & 68.98 & 106.20 & 83.17 & 82.37 \\
\hline 15 & 70.17 & 69.18 & 105.56 & 81.68 & 81.65 \\
\hline 16 & 69.27 & 69.37 & 104.97 & 80.32 & 80.98 \\
\hline 17 & 68.44 & 69.56 & 104.42 & 79.05 & 80.37 \\
\hline 18 & 67.67 & 69.73 & 103.90 & 77.88 & 79.79 \\
\hline 19 & 66.94 & 69.89 & 103.41 & 76.79 & 79.26 \\
\hline 20 & 66.26 & 70.04 & 102.95 & 75.77 & 78.76 \\
\hline 21 & 65.62 & 70.19 & 102.51 & 74.81 & 78.28 \\
\hline 22 & 65.02 & 70.33 & 102.10 & 73.91 & 77.84 \\
\hline 23 & 64.44 & 70.46 & 101.70 & 73.05 & 77.42 \\
\hline 24 & 63.90 & 70.59 & 101.33 & 72.25 & 77.02 \\
\hline 25 & 63.38 & 70.72 & 100.97 & 71.48 & 76.64 \\
\hline 26 & 62.89 & 70.83 & 100.62 & 70.75 & 76.27 \\
\hline 27 & 62.42 & 70.95 & 100.29 & 70.06 & 75.93 \\
\hline 28 & 61.97 & 71.06 & 99.97 & 69.39 & 75.60 \\
\hline 29 & 61.54 & 71.17 & 99.67 & 68.76 & 75.28 \\
\hline 30 & 61.12 & 71.27 & 99.38 & 68.16 & 74.98 \\
\hline 31 & 60.73 & 71.37 & 99.09 & 67.57 & 74.69 \\
\hline 32 & 60.34 & 71.47 & 98.82 & 67.02 & 74.41 \\
\hline 33 & 59.97 & 71.56 & 98.55 & 66.48 & 74.14 \\
\hline 34 & 59.62 & 71.65 & 98.30 & 65.96 & 73.88 \\
\hline 35 & 59.28 & 71.74 & 98.05 & 65.47 & 73.63 \\
\hline 36 & 58.94 & 71.83 & 97.81 & 64.99 & 73.39 \\
\hline 37 & 58.62 & 71.92 & 97.58 & 64.52 & 73.16 \\
\hline 38 & 58.31 & 72.00 & 97.35 & 64.07 & 72.93 \\
\hline 39 & 58.01 & 72.08 & 97.13 & 63.64 & 72.72 \\
\hline 40 & 57.72 & 72.16 & 96.92 & 63.22 & 72.50 \\
\hline
\end{tabular}




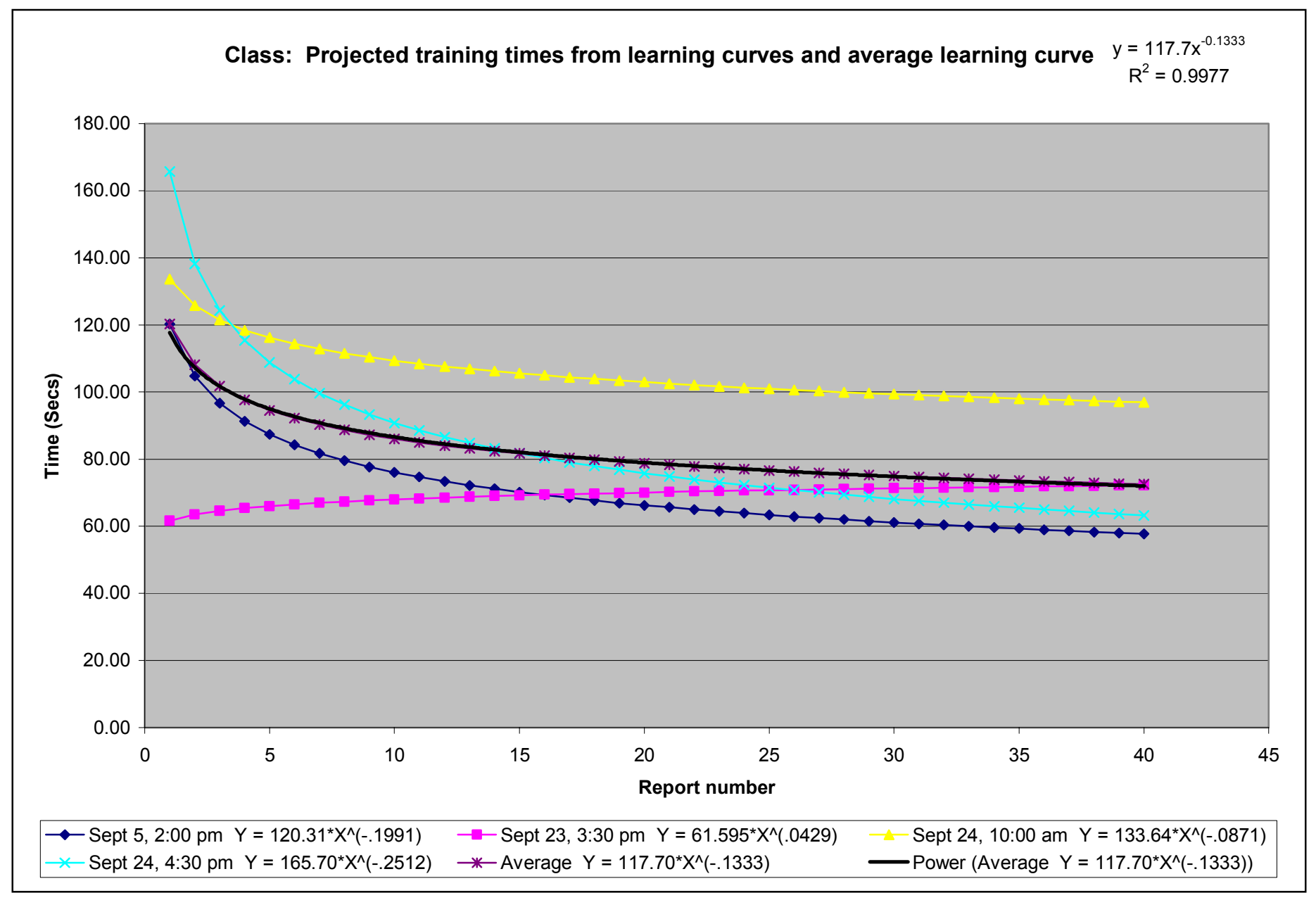




\begin{tabular}{|c|c|c|c|c|c|}
\hline \multicolumn{6}{|c|}{ Mentor and Manual Fitted Learning Curves and Average } \\
\hline Report & $\begin{array}{c}\text { Sept. 3, } \\
8: 00 \text { am } \\
Y= \\
217.85^{\star} X^{\wedge}( \\
.2232)\end{array}$ & $\begin{array}{c}\text { Sept. 3, } \\
11: 00 \mathrm{am} \\
\mathrm{Y}= \\
202.02^{*} \mathrm{X}^{\wedge}( \\
.1775)\end{array}$ & $\begin{array}{c}\text { Sept. 3, } \\
2: 00 \mathrm{pm} \\
Y= \\
124.20^{\star} \mathrm{X}^{\wedge}( \\
.0488)\end{array}$ & $\begin{array}{c}\text { Sept. 4, } \\
2: 00 \mathrm{pm} \\
\mathrm{Y}= \\
270.97^{\star} \mathrm{X}^{\wedge}( \\
.3373)\end{array}$ & $\begin{array}{c}\text { Average } \\
Y= \\
200.03^{*} X^{\wedge}( \\
.2017)\end{array}$ \\
\hline 1 & 217.85 & 202.02 & 124.20 & 270.97 & 203.76 \\
\hline 2 & 186.62 & 178.63 & 120.07 & 214.48 & 174.95 \\
\hline 3 & 170.48 & 166.23 & 117.72 & 187.06 & 160.37 \\
\hline 4 & 159.87 & 157.95 & 116.08 & 169.76 & 150.92 \\
\hline 5 & 152.11 & 151.82 & 114.82 & 157.46 & 144.05 \\
\hline 6 & 146.04 & 146.98 & 113.80 & 148.06 & 138.72 \\
\hline 7 & 141.10 & 143.02 & 112.95 & 140.56 & 134.41 \\
\hline 8 & 136.96 & 139.67 & 112.21 & 134.37 & 130.80 \\
\hline 9 & 133.40 & 136.78 & 111.57 & 129.14 & 127.72 \\
\hline 10 & 130.30 & 134.24 & 111.00 & 124.63 & 125.04 \\
\hline 11 & 127.56 & 131.99 & 110.48 & 120.69 & 122.68 \\
\hline 12 & 125.11 & 129.97 & 110.02 & 117.20 & 120.57 \\
\hline 13 & 122.89 & 128.14 & 109.59 & 114.07 & 118.67 \\
\hline 14 & 120.88 & 126.46 & 109.19 & 111.26 & 116.95 \\
\hline 15 & 119.03 & 124.92 & 108.82 & 108.70 & 115.37 \\
\hline 16 & 117.33 & 123.50 & 108.48 & 106.36 & 113.92 \\
\hline 17 & 115.75 & 122.18 & 108.16 & 104.21 & 112.57 \\
\hline 18 & 114.28 & 120.94 & 107.86 & 102.22 & 111.33 \\
\hline 19 & 112.91 & 119.79 & 107.58 & 100.37 & 110.16 \\
\hline 20 & 111.63 & 118.70 & 107.31 & 98.65 & 109.07 \\
\hline 21 & 110.42 & 117.68 & 107.05 & 97.04 & 108.05 \\
\hline 22 & 109.28 & 116.71 & 106.81 & 95.53 & 107.08 \\
\hline 23 & 108.20 & 115.79 & 106.58 & 94.10 & 106.17 \\
\hline 24 & 107.18 & 114.92 & 106.36 & 92.76 & 105.30 \\
\hline 25 & 106.20 & 114.09 & 106.15 & 91.49 & 104.48 \\
\hline 26 & 105.28 & 113.30 & 105.94 & 90.29 & 103.70 \\
\hline 27 & 104.39 & 112.55 & 105.75 & 89.15 & 102.96 \\
\hline 28 & 103.55 & 111.82 & 105.56 & 88.06 & 102.25 \\
\hline 29 & 102.74 & 111.13 & 105.38 & 87.03 & 101.57 \\
\hline 30 & 101.97 & 110.46 & 105.21 & 86.04 & 100.92 \\
\hline 31 & 101.22 & 109.82 & 105.04 & 85.09 & 100.29 \\
\hline 32 & 100.51 & 109.20 & 104.87 & 84.18 & 99.69 \\
\hline 33 & 99.82 & 108.61 & 104.72 & 83.32 & 99.12 \\
\hline 34 & 99.16 & 108.03 & 104.56 & 82.48 & 98.56 \\
\hline 35 & 98.52 & 107.48 & 104.42 & 81.68 & 98.02 \\
\hline 36 & 97.90 & 106.94 & 104.27 & 80.91 & 97.51 \\
\hline 37 & 97.30 & 106.42 & 104.13 & 80.16 & 97.01 \\
\hline 38 & 96.73 & 105.92 & 104.00 & 79.44 & 96.52 \\
\hline 39 & 96.17 & 105.43 & 103.87 & 78.75 & 96.06 \\
\hline 40 & 95.63 & 104.96 & 103.74 & 78.08 & 95.60 \\
\hline
\end{tabular}




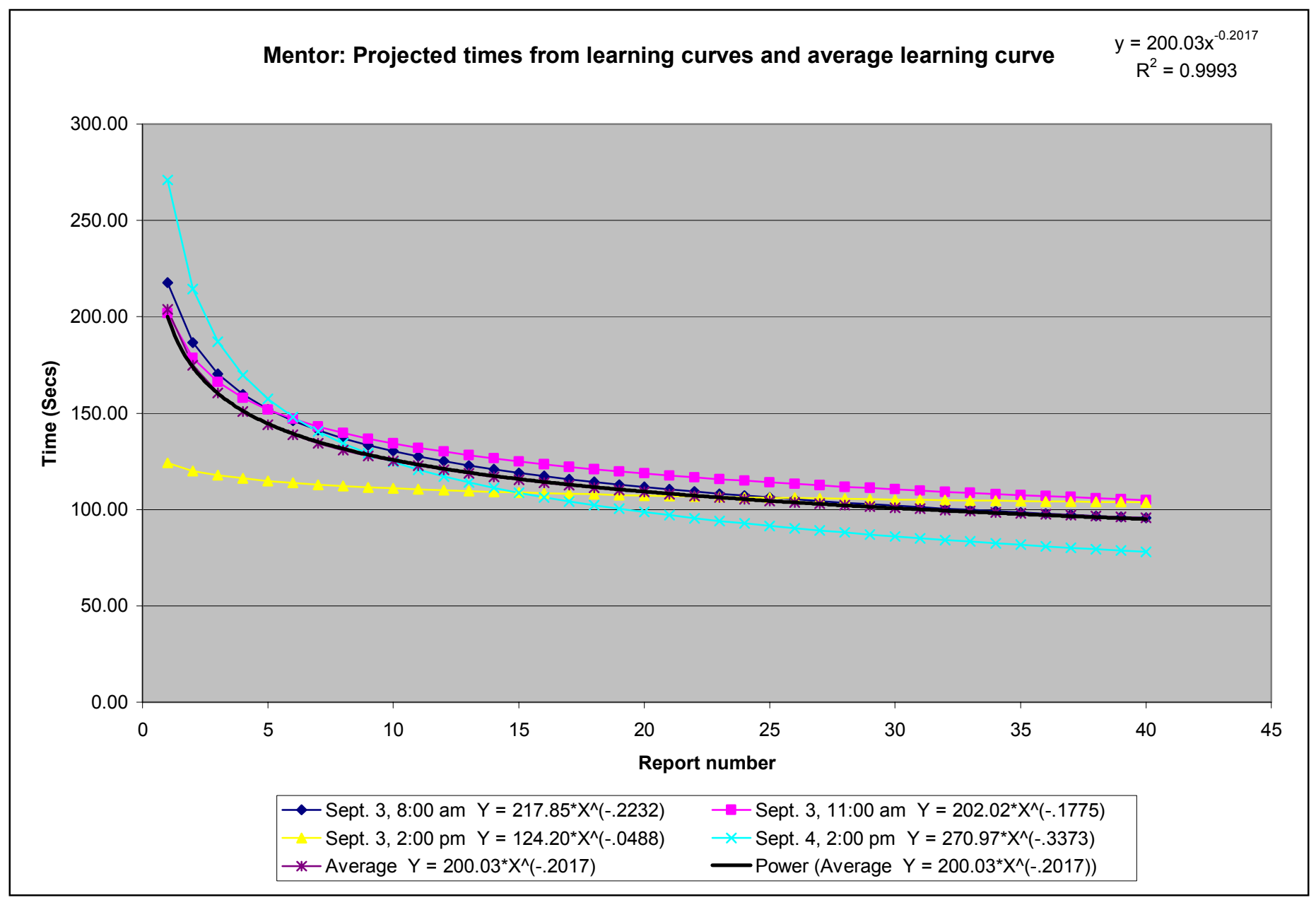


APPENDIX E:

COMBINED CHARTS OF LEARNING CURVES 


\begin{tabular}{|c|c|c|c|c|}
\hline \multicolumn{5}{|c|}{ Projected binding times for each training type } \\
\hline $\begin{array}{l}\text { Report } \\
\text { number }\end{array}$ & $\begin{array}{l}\text { Observe } \\
\text { and do }\end{array}$ & Manual & Class & $\begin{array}{l}\text { Mentor/ } \\
\text { Manual }\end{array}$ \\
\hline 1 & 201.7 & 239.9 & 117.7 & 200.0 \\
\hline 2 & 178.8 & 203.7 & 107.3 & 173.9 \\
\hline 3 & 166.7 & 185.1 & 101.7 & 160.3 \\
\hline 4 & 158.5 & 173.0 & 97.8 & 151.2 \\
\hline 5 & 152.5 & 164.1 & 95.0 & 144.6 \\
\hline 6 & 147.8 & 157.2 & 92.7 & 139.4 \\
\hline 7 & 143.9 & 151.6 & 90.8 & 135.1 \\
\hline 8 & 140.6 & 146.9 & 89.2 & 131.5 \\
\hline 9 & 137.7 & 142.9 & 87.8 & 128.4 \\
\hline 10 & 135.2 & 139.4 & 86.6 & 125.7 \\
\hline 11 & 133.0 & 136.3 & 85.5 & 123.3 \\
\hline 12 & 131.0 & 133.5 & 84.5 & 121.2 \\
\hline 13 & 129.2 & 131.0 & 83.6 & 119.2 \\
\hline 14 & 127.5 & 128.8 & 82.8 & 117.5 \\
\hline 15 & 126.0 & 126.7 & 82.0 & 115.8 \\
\hline 16 & 124.6 & 124.8 & 81.3 & 114.3 \\
\hline 17 & 123.3 & 123.0 & 80.7 & 113.0 \\
\hline 18 & 122.1 & 121.4 & 80.1 & 111.7 \\
\hline 19 & 121.0 & 119.8 & 79.5 & 110.5 \\
\hline 20 & 119.9 & 118.4 & 78.9 & 109.3 \\
\hline 21 & 118.9 & 117.0 & 78.4 & 108.2 \\
\hline 22 & 117.9 & 115.8 & 78.0 & 107.2 \\
\hline 23 & 117.0 & 114.6 & 77.5 & 106.3 \\
\hline 24 & 116.1 & 113.4 & 77.1 & 105.4 \\
\hline 25 & 115.3 & 112.3 & 76.6 & 104.5 \\
\hline 26 & 114.5 & 111.3 & 76.2 & 103.7 \\
\hline 27 & 113.8 & 110.3 & 75.9 & 102.9 \\
\hline 28 & 113.1 & 109.4 & 75.5 & 102.1 \\
\hline 29 & 112.4 & 108.5 & 75.1 & 101.4 \\
\hline 30 & 111.7 & 107.6 & 74.8 & 100.7 \\
\hline 31 & 111.1 & 106.8 & 74.5 & 100.1 \\
\hline 32 & 110.5 & 106.0 & 74.2 & 99.4 \\
\hline 33 & 109.9 & 105.2 & $\begin{array}{l}73.9 \\
\end{array}$ & 98.8 \\
\hline 34 & 109.3 & 104.5 & 73.6 & 98.2 \\
\hline 35 & 108.8 & 103.8 & 73.3 & 97.6 \\
\hline 36 & 108.2 & 103.1 & 73.0 & 97.1 \\
\hline 37 & 107.7 & 102.4 & 72.7 & 96.6 \\
\hline 38 & 107.2 & 101.8 & 72.5 & 96.0 \\
\hline 39 & 106.7 & 101.1 & 72.2 & 95.5 \\
\hline 40 & 106.3 & 100.5 & 72.0 & 95.1 \\
\hline 41 & 105.8 & 100.0 & 71.7 & 94.6 \\
\hline 42 & 105.4 & 99.4 & 71.5 & 94.1 \\
\hline 43 & 105.0 & 98.8 & $\begin{array}{ll}71.3 \\
\end{array}$ & 93.7 \\
\hline 44 & 104.5 & 98.3 & \begin{tabular}{ll|}
71.1 \\
\end{tabular} & 93.2 \\
\hline 45 & 104.1 & 97.8 & 70.9 & 92.8 \\
\hline 46 & 103.7 & 97.3 & 70.7 & 92.4 \\
\hline 47 & 103.3 & 96.8 & 70.5 & 92.0 \\
\hline 48 & 103.0 & 96.3 & 70.3 & 91.6 \\
\hline 49 & 102.6 & 95.8 & 70.1 & 91.2 \\
\hline 50 & 102.2 & 95.4 & 69.9 & 90.9 \\
\hline 51 & 101.9 & 94.9 & 69.7 & 90.5 \\
\hline 52 & 101.5 & 94.5 & 69.5 & 90.2 \\
\hline 53 & 101.2 & 94.1 & 69.3 & 89.8 \\
\hline 54 & 100.9 & 93.7 & 69.2 & 89.5 \\
\hline
\end{tabular}

\begin{tabular}{|c|c|c|c|c|}
\hline $\begin{array}{l}\text { Report } \\
\text { number }\end{array}$ & $\begin{array}{l}\text { Observe } \\
\text { and do }\end{array}$ & Manual & Class & $\begin{array}{l}\text { Mentor/ } \\
\text { Manual }\end{array}$ \\
\hline 55 & 100.6 & 93.3 & 69.0 & 89.1 \\
\hline 56 & 100.2 & 92.9 & 68.8 & 88.8 \\
\hline 57 & 99.9 & 92.5 & 68.7 & 88.5 \\
\hline 58 & 99.6 & 92.1 & 68.5 & 88.2 \\
\hline 59 & 99.3 & 91.7 & 68.3 & 87.9 \\
\hline 60 & 99.1 & 91.4 & 68.2 & 87.6 \\
\hline 61 & 98.8 & 91.0 & 68.0 & 87.3 \\
\hline 62 & 98.5 & 90.7 & 67.9 & 87.0 \\
\hline 63 & 98.2 & 90.3 & 67.8 & 86.7 \\
\hline 64 & 97.9 & 90.0 & 67.6 & 86.5 \\
\hline 65 & 97.7 & 89.7 & 67.5 & 86.2 \\
\hline 66 & 97.4 & 89.3 & 67.3 & 85.9 \\
\hline 67 & 97.2 & 89.0 & 67.2 & 85.7 \\
\hline 68 & 96.9 & 88.7 & 67.1 & 85.4 \\
\hline 69 & 96.7 & 88.4 & 66.9 & 85.2 \\
\hline 70 & 96.4 & 88.1 & 66.8 & 84.9 \\
\hline 71 & 96.2 & 87.8 & 66.7 & 84.7 \\
\hline 72 & 96.0 & 87.5 & 66.6 & 84.4 \\
\hline 73 & 95.7 & 87.3 & 66.4 & 84.2 \\
\hline 74 & 95.5 & 87.0 & 66.3 & 84.0 \\
\hline 75 & 95.3 & 86.7 & 66.2 & 83.7 \\
\hline 76 & 95.1 & 86.4 & 66.1 & 83.5 \\
\hline 77 & 94.9 & 86.2 & 66.0 & 83.3 \\
\hline 78 & 94.6 & 85.9 & 65.9 & 83.1 \\
\hline 79 & 94.4 & 85.6 & 65.7 & 82.9 \\
\hline 80 & 94.2 & 85.4 & 65.6 & 82.6 \\
\hline 81 & 94.0 & 85.1 & 65.5 & 82.4 \\
\hline 82 & 93.8 & 84.9 & 65.4 & 82.2 \\
\hline 83 & 93.6 & 84.7 & 65.3 & 82.0 \\
\hline 84 & 93.4 & 84.4 & 65.2 & 81.8 \\
\hline 85 & 93.2 & 84.2 & 65.1 & 81.6 \\
\hline 86 & 93.0 & 83.9 & 65.0 & 81.5 \\
\hline 87 & 92.9 & 83.7 & 64.9 & 81.3 \\
\hline 88 & 92.7 & 83.5 & 64.8 & 81.1 \\
\hline 89 & 92.5 & 83.3 & 64.7 & 80.9 \\
\hline 90 & 92.3 & 83.1 & 64.6 & 80.7 \\
\hline 91 & 92.1 & 82.8 & 64.5 & 80.5 \\
\hline 92 & 92.0 & 82.6 & 64.4 & 80.4 \\
\hline 93 & 91.8 & 82.4 & 64.3 & 80.2 \\
\hline 94 & 91.6 & 82.2 & 64.2 & 80.0 \\
\hline 95 & 91.5 & 82.0 & 64.1 & 79.8 \\
\hline 96 & 91.3 & 81.8 & 64.1 & 79.7 \\
\hline 97 & 91.1 & 81.6 & 64.0 & 79.5 \\
\hline 98 & 91.0 & 81.4 & 63.9 & 79.3 \\
\hline 99 & 90.8 & 81.2 & 63.8 & 79.2 \\
\hline 100 & 90.6 & 81.0 & 63.7 & 79.0 \\
\hline 101 & 90.5 & 80.8 & 63.6 & 78.9 \\
\hline 102 & 90.3 & 80.6 & 63.5 & 78.7 \\
\hline 103 & 90.2 & 80.5 & 63.5 & 78.5 \\
\hline 104 & 90.0 & 80.3 & 63.4 & 78.4 \\
\hline 105 & 89.9 & 80.1 & 63.3 & 78.2 \\
\hline 106 & 89.7 & 79.9 & 63.2 & 78.1 \\
\hline 107 & 89.6 & 79.7 & 63.1 & 77.9 \\
\hline 108 & 89.4 & 79.6 & 63.1 & 77.8 \\
\hline 109 & 89.3 & 79.4 & 63.0 & 77.7 \\
\hline
\end{tabular}




\begin{tabular}{|c|c|c|c|c|}
\hline $\begin{array}{l}\text { Report } \\
\text { number }\end{array}$ & $\begin{array}{c}\text { Observe } \\
\text { and do }\end{array}$ & Manual & Class & $\begin{array}{l}\text { Mentor/ } \\
\text { Manual }\end{array}$ \\
\hline 110 & 89.2 & 79.2 & 62.9 & 77.5 \\
\hline 111 & 89.0 & 79.0 & 62.8 & 77.4 \\
\hline 112 & 88.9 & 78.9 & 62.8 & 77.2 \\
\hline 113 & 88.7 & 78.7 & 62.7 & 77.1 \\
\hline 114 & 88.6 & 78.5 & 62.6 & 77.0 \\
\hline 115 & 88.5 & 78.4 & 62.5 & 76.8 \\
\hline 116 & 88.3 & 78.2 & 62.5 & 76.7 \\
\hline 117 & 88.2 & 78.1 & 62.4 & 76.5 \\
\hline 118 & 88.1 & 77.9 & 62.3 & 76.4 \\
\hline 119 & 87.9 & 77.8 & 62.2 & 76.3 \\
\hline 120 & 87.8 & 77.6 & 62.2 & 76.2 \\
\hline 121 & 87.7 & 77.5 & 62.1 & 76.0 \\
\hline 122 & 87.6 & 77.3 & 62.0 & 75.9 \\
\hline 123 & 87.4 & 77.2 & 62.0 & 75.8 \\
\hline 124 & 87.3 & 77.0 & 61.9 & 75.7 \\
\hline 125 & 87.2 & 76.9 & 61.8 & 75.5 \\
\hline 126 & 87.1 & 76.7 & 61.8 & 75.4 \\
\hline 127 & 87.0 & 76.6 & 61.7 & 75.3 \\
\hline 128 & 86.8 & 76.4 & 61.6 & 75.2 \\
\hline 129 & 86.7 & 76.3 & 61.6 & 75.1 \\
\hline 130 & 86.6 & 76.2 & 61.5 & 74.9 \\
\hline 131 & 86.5 & 76.0 & 61.5 & 74.8 \\
\hline 132 & 86.4 & 75.9 & 61.4 & 74.7 \\
\hline 133 & 86.3 & 75.7 & 61.3 & 74.6 \\
\hline 134 & 86.1 & 75.6 & 61.3 & 74.5 \\
\hline 135 & 86.0 & 75.5 & 61.2 & 74.4 \\
\hline 136 & 85.9 & 75.3 & 61.1 & 74.3 \\
\hline 137 & 85.8 & 75.2 & 61.1 & 74.2 \\
\hline 138 & 85.7 & 75.1 & 61.0 & 74.0 \\
\hline 139 & 85.6 & 75.0 & 61.0 & 73.9 \\
\hline 140 & 85.5 & 74.8 & 60.9 & 73.8 \\
\hline 141 & 85.4 & 74.7 & 60.9 & 73.7 \\
\hline 142 & 85.3 & 74.6 & 60.8 & 73.6 \\
\hline 143 & 85.2 & 74.5 & 60.7 & 73.5 \\
\hline 144 & 85.1 & 74.3 & 60.7 & 73.4 \\
\hline 145 & 85.0 & 74.2 & 60.6 & 73.3 \\
\hline 146 & 84.9 & 74.1 & 60.6 & 73.2 \\
\hline 147 & 84.8 & 74.0 & 60.5 & 73.1 \\
\hline 148 & 84.7 & 73.9 & 60.5 & 73.0 \\
\hline 149 & 84.6 & 73.7 & 60.4 & 72.9 \\
\hline 150 & 84.5 & 73.6 & 60.4 & 72.8 \\
\hline 151 & 84.4 & 73.5 & 60.3 & 72.7 \\
\hline 152 & 84.3 & 73.4 & 60.2 & 72.6 \\
\hline 153 & 84.2 & 73.3 & 60.2 & 72.5 \\
\hline 154 & 84.1 & 73.2 & 60.1 & 72.4 \\
\hline 155 & 84.0 & 73.1 & 60.1 & 72.3 \\
\hline 156 & 83.9 & 73.0 & 60.0 & 72.2 \\
\hline 157 & 83.8 & 72.8 & 60.0 & 72.1 \\
\hline 158 & 83.7 & 72.7 & 59.9 & 72.0 \\
\hline 159 & 83.6 & 72.6 & 59.9 & 72.0 \\
\hline 160 & 83.5 & 72.5 & 59.8 & 71.9 \\
\hline 161 & 83.4 & 72.4 & 59.8 & 71.8 \\
\hline 162 & 83.4 & 72.3 & 59.7 & 71.7 \\
\hline 163 & 83.3 & 72.2 & 59.7 & 71.6 \\
\hline 164 & 83.2 & 72.1 & 59.6 & 71.5 \\
\hline
\end{tabular}

\begin{tabular}{|c|c|c|c|c|}
\hline $\begin{array}{l}\text { Report } \\
\text { number }\end{array}$ & $\begin{array}{c}\text { Observe } \\
\text { and do }\end{array}$ & Manual & Class & $\begin{array}{l}\text { Mentorl } \\
\text { Manual }\end{array}$ \\
\hline 165 & 83.1 & 72.0 & 59.6 & 71.4 \\
\hline 166 & 83.0 & 71.9 & 59.5 & 71.3 \\
\hline 167 & 82.9 & 71.8 & 59.5 & 71.2 \\
\hline 168 & 82.8 & 71.7 & 59.4 & 71.2 \\
\hline 169 & 82.7 & 71.6 & 59.4 & 71.1 \\
\hline 170 & 82.7 & 71.5 & 59.4 & 71.0 \\
\hline 171 & 82.6 & 71.4 & 59.3 & 70.9 \\
\hline 172 & 82.5 & 71.3 & 59.3 & 70.8 \\
\hline 173 & 82.4 & 71.2 & 59.2 & 70.7 \\
\hline 174 & 82.3 & 71.1 & 59.2 & 70.7 \\
\hline 175 & 82.2 & 71.0 & 59.1 & 70.6 \\
\hline 176 & 82.2 & 70.9 & 59.1 & 70.5 \\
\hline 177 & 82.1 & 70.8 & 59.0 & 70.4 \\
\hline 178 & 82.0 & 70.7 & 59.0 & 70.3 \\
\hline 179 & 81.9 & 70.6 & 58.9 & 70.3 \\
\hline 180 & 81.8 & 70.5 & 58.9 & 70.2 \\
\hline 181 & 81.8 & 70.4 & 58.9 & 70.1 \\
\hline 182 & 81.7 & 70.3 & 58.8 & 70.0 \\
\hline 183 & 81.6 & 70.3 & 58.8 & 69.9 \\
\hline 184 & 81.5 & 70.2 & 58.7 & 69.9 \\
\hline 185 & 81.5 & 70.1 & 58.7 & 69.8 \\
\hline 186 & 81.4 & 70.0 & 58.6 & 69.7 \\
\hline 187 & 81.3 & 69.9 & 58.6 & 69.6 \\
\hline 188 & 81.2 & 69.8 & 58.6 & 69.6 \\
\hline 189 & 81.2 & 69.7 & 58.5 & 69.5 \\
\hline 190 & 81.1 & 69.6 & 58.5 & 69.4 \\
\hline 191 & 81.0 & 69.6 & 58.4 & 69.3 \\
\hline 192 & 80.9 & 69.5 & 58.4 & 69.3 \\
\hline 193 & 80.9 & 69.4 & 58.4 & 69.2 \\
\hline 194 & 80.8 & 69.3 & 58.3 & 69.1 \\
\hline 195 & 80.7 & 69.2 & 58.3 & 69.1 \\
\hline 196 & 80.6 & 69.1 & 58.2 & 69.0 \\
\hline 197 & 80.6 & 69.0 & 58.2 & 68.9 \\
\hline 198 & 80.5 & 69.0 & 58.2 & 68.8 \\
\hline 199 & 80.4 & 68.9 & 58.1 & 68.8 \\
\hline 200 & 80.4 & 68.8 & 58.1 & 68.7 \\
\hline 201 & 80.3 & 68.7 & 58.0 & 68.6 \\
\hline 202 & 80.2 & 68.6 & 58.0 & 68.6 \\
\hline 203 & 80.2 & 68.6 & 58.0 & 68.5 \\
\hline 204 & 80.1 & 68.5 & 57.9 & 68.4 \\
\hline 205 & 80.0 & 68.4 & 57.9 & 68.4 \\
\hline 206 & 79.9 & 68.3 & 57.9 & 68.3 \\
\hline 207 & 79.9 & 68.2 & 57.8 & 68.2 \\
\hline 208 & 79.8 & 68.2 & 57.8 & 68.2 \\
\hline 209 & 79.7 & 68.1 & 57.7 & 68.1 \\
\hline 210 & 79.7 & 68.0 & 57.7 & 68.0 \\
\hline 211 & 79.6 & 67.9 & 57.7 & 68.0 \\
\hline 212 & 79.6 & 67.9 & 57.6 & 67.9 \\
\hline 213 & 79.5 & 67.8 & 57.6 & 67.8 \\
\hline 214 & 79.4 & 67.7 & 57.6 & 67.8 \\
\hline 215 & 79.4 & 67.6 & 57.5 & 67.7 \\
\hline 216 & 79.3 & 67.6 & 57.5 & 67.6 \\
\hline 217 & 79.2 & 67.5 & 57.5 & 67.6 \\
\hline 218 & 79.2 & 67.4 & 57.4 & 67.5 \\
\hline 219 & 79.1 & 67.3 & 57.4 & 67.5 \\
\hline
\end{tabular}




\begin{tabular}{|c|c|c|c|c|}
\hline $\begin{array}{l}\text { Report } \\
\text { number }\end{array}$ & $\begin{array}{l}\text { Observe } \\
\text { and do }\end{array}$ & Manual & Class & $\begin{array}{l}\text { Mentor/ } \\
\text { Manual }\end{array}$ \\
\hline 220 & 79.0 & 67.3 & 57.3 & 67.4 \\
\hline 221 & 79.0 & 67.2 & 57.3 & 67.3 \\
\hline 222 & 78.9 & 67.1 & 57.3 & 67.3 \\
\hline 223 & 78.9 & 67.1 & 57.2 & 67.2 \\
\hline 224 & 78.8 & 67.0 & 57.2 & 67.2 \\
\hline 225 & 78.7 & 66.9 & 57.2 & 67.1 \\
\hline 226 & 78.7 & 66.8 & 57.1 & 67.0 \\
\hline 227 & 78.6 & 66.8 & 57.1 & 67.0 \\
\hline 228 & 78.6 & 66.7 & 57.1 & 66.9 \\
\hline 229 & 78.5 & 66.6 & 57.0 & 66.9 \\
\hline 230 & 78.4 & 66.6 & 57.0 & 66.8 \\
\hline 231 & 78.4 & 66.5 & 57.0 & 66.7 \\
\hline 232 & 78.3 & 66.4 & 56.9 & 66.7 \\
\hline 233 & 78.3 & 66.4 & 56.9 & 66.6 \\
\hline 234 & 78.2 & 66.3 & 56.9 & 66.6 \\
\hline 235 & 78.1 & 66.2 & 56.8 & 66.5 \\
\hline 236 & 78.1 & 66.2 & 56.8 & 66.4 \\
\hline 237 & 78.0 & 66.1 & 56.8 & 66.4 \\
\hline 238 & 78.0 & 66.0 & 56.8 & 66.3 \\
\hline 239 & 77.9 & 66.0 & 56.7 & 66.3 \\
\hline 240 & 77.9 & 65.9 & 56.7 & 66.2 \\
\hline 241 & 77.8 & 65.8 & 56.7 & 66.2 \\
\hline 242 & 77.7 & 65.8 & 56.6 & 66.1 \\
\hline 243 & 77.7 & 65.7 & 56.6 & 66.1 \\
\hline 244 & 77.6 & 65.7 & 56.6 & 66.0 \\
\hline 245 & 77.6 & 65.6 & 56.5 & 65.9 \\
\hline 246 & 77.5 & 65.5 & 56.5 & 65.9 \\
\hline 247 & 77.5 & 65.5 & 56.5 & 65.8 \\
\hline 248 & 77.4 & 65.4 & 56.4 & 65.8 \\
\hline 249 & 77.4 & 65.3 & 56.4 & 65.7 \\
\hline 250 & 77.3 & 65.3 & 56.4 & 65.7 \\
\hline 251 & 77.3 & 65.2 & 56.4 & 65.6 \\
\hline 252 & 77.2 & 65.2 & 56.3 & 65.6 \\
\hline 253 & 77.1 & 65.1 & 56.3 & 65.5 \\
\hline 254 & 77.1 & 65.0 & 56.3 & 65.5 \\
\hline 255 & 77.0 & 65.0 & 56.2 & 65.4 \\
\hline 256 & 77.0 & 64.9 & 56.2 & 65.4 \\
\hline 257 & 76.9 & 64.9 & 56.2 & 65.3 \\
\hline 258 & 76.9 & 64.8 & 56.1 & 65.3 \\
\hline 259 & 76.8 & 64.7 & 56.1 & 65.2 \\
\hline 260 & 76.8 & 64.7 & 56.1 & 65.2 \\
\hline 261 & 76.7 & 64.6 & 56.1 & 65.1 \\
\hline 262 & 76.7 & 64.6 & 56.0 & 65.1 \\
\hline 263 & 76.6 & 64.5 & 56.0 & 65.0 \\
\hline 264 & 76.6 & 64.4 & 56.0 & 65.0 \\
\hline 265 & 76.5 & 64.4 & 55.9 & 64.9 \\
\hline 266 & 76.5 & 64.3 & 55.9 & 64.9 \\
\hline 267 & 76.4 & 64.3 & 55.9 & 64.8 \\
\hline 268 & 76.4 & 64.2 & 55.9 & 64.8 \\
\hline 269 & 76.3 & 64.2 & 55.8 & 64.7 \\
\hline 270 & 76.3 & 64.1 & 55.8 & 64.7 \\
\hline 271 & 76.2 & 64.0 & 55.8 & 64.6 \\
\hline 272 & 76.2 & 64.0 & 55.8 & 64.6 \\
\hline 273 & 76.1 & 63.9 & 55.7 & 64.5 \\
\hline 274 & 76.1 & 63.9 & 55.7 & 64.5 \\
\hline
\end{tabular}

\begin{tabular}{|c|c|c|c|c|}
\hline $\begin{array}{l}\text { Report } \\
\text { number }\end{array}$ & $\begin{array}{l}\text { Observe } \\
\text { and do }\end{array}$ & Manual & Class & $\begin{array}{l}\text { Mentorl } \\
\text { Manual }\end{array}$ \\
\hline 275 & 76.0 & 63.8 & 55.7 & 64.4 \\
\hline 276 & 76.0 & 63.8 & 55.6 & 64.4 \\
\hline 277 & 75.9 & 63.7 & 55.6 & 64.3 \\
\hline 278 & 75.9 & 63.7 & 55.6 & 64.3 \\
\hline 279 & 75.8 & 63.6 & 55.6 & 64.2 \\
\hline 280 & 75.8 & 63.6 & 55.5 & 64.2 \\
\hline 281 & 75.8 & 63.5 & 55.5 & 64.1 \\
\hline 282 & 75.7 & 63.5 & 55.5 & 64.1 \\
\hline 283 & 75.7 & 63.4 & 55.5 & 64.1 \\
\hline 284 & 75.6 & 63.3 & 55.4 & 64.0 \\
\hline 285 & 75.6 & 63.3 & 55.4 & 64.0 \\
\hline 286 & 75.5 & 63.2 & 55.4 & 63.9 \\
\hline 287 & 75.5 & 63.2 & 55.4 & 63.9 \\
\hline 288 & 75.4 & 63.1 & 55.3 & 63.8 \\
\hline 289 & 75.4 & 63.1 & 55.3 & 63.8 \\
\hline 290 & 75.3 & 63.0 & 55.3 & 63.7 \\
\hline 291 & 75.3 & 63.0 & 55.3 & 63.7 \\
\hline 292 & 75.2 & 62.9 & 55.2 & 63.7 \\
\hline 293 & 75.2 & 62.9 & 55.2 & 63.6 \\
\hline 294 & 75.2 & 62.8 & 55.2 & 63.6 \\
\hline 295 & 75.1 & 62.8 & 55.2 & 63.5 \\
\hline 296 & 75.1 & 62.7 & 55.1 & 63.5 \\
\hline 297 & 75.0 & 62.7 & 55.1 & 63.4 \\
\hline 298 & 75.0 & 62.6 & 55.1 & 63.4 \\
\hline 299 & 74.9 & 62.6 & 55.1 & 63.4 \\
\hline 300 & 74.9 & 62.5 & 55.0 & 63.3 \\
\hline 301 & 74.9 & 62.5 & 55.0 & 63.3 \\
\hline 302 & 74.8 & 62.4 & 55.0 & 63.2 \\
\hline 303 & 74.8 & 62.4 & 55.0 & 63.2 \\
\hline 304 & 74.7 & 62.3 & 54.9 & 63.1 \\
\hline 305 & 74.7 & 62.3 & 54.9 & 63.1 \\
\hline 306 & 74.6 & 62.2 & 54.9 & 63.1 \\
\hline 307 & 74.6 & 62.2 & 54.9 & 63.0 \\
\hline 308 & 74.6 & 62.1 & 54.8 & 63.0 \\
\hline 309 & 74.5 & 62.1 & 54.8 & 62.9 \\
\hline 310 & 74.5 & 62.1 & 54.8 & 62.9 \\
\hline 311 & 74.4 & 62.0 & 54.8 & 62.9 \\
\hline 312 & 74.4 & 62.0 & 54.7 & 62.8 \\
\hline 313 & 74.3 & 61.9 & 54.7 & 62.8 \\
\hline 314 & 74.3 & 61.9 & 54.7 & 62.7 \\
\hline 315 & 74.3 & 61.8 & 54.7 & 62.7 \\
\hline 316 & 74.2 & 61.8 & 54.6 & 62.6 \\
\hline 317 & 74.2 & 61.7 & 54.6 & 62.6 \\
\hline 318 & 74.1 & 61.7 & 54.6 & 62.6 \\
\hline 319 & 74.1 & 61.6 & 54.6 & 62.5 \\
\hline 320 & 74.1 & 61.6 & 54.6 & 62.5 \\
\hline 321 & 74.0 & 61.5 & 54.5 & 62.5 \\
\hline 322 & 74.0 & 61.5 & 54.5 & 62.4 \\
\hline 323 & 73.9 & 61.5 & 54.5 & 62.4 \\
\hline 324 & 73.9 & 61.4 & 54.5 & 62.3 \\
\hline 325 & 73.9 & 61.4 & 54.4 & 62.3 \\
\hline 326 & 73.8 & 61.3 & 54.4 & 62.3 \\
\hline 327 & 73.8 & 61.3 & 54.4 & 62.2 \\
\hline 328 & 73.7 & 61.2 & 54.4 & 62.2 \\
\hline 329 & 73.7 & 61.2 & 54.4 & 62.1 \\
\hline
\end{tabular}




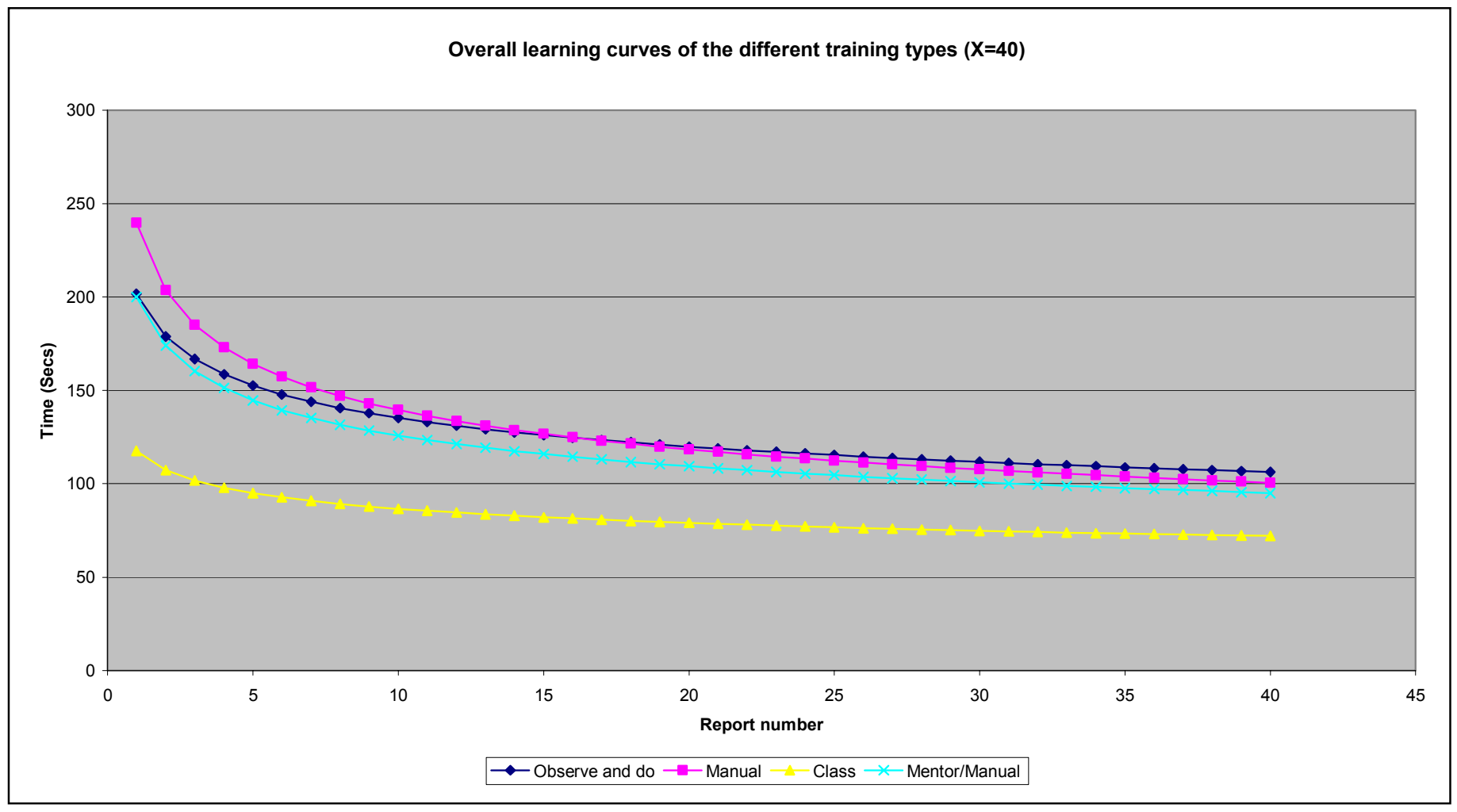




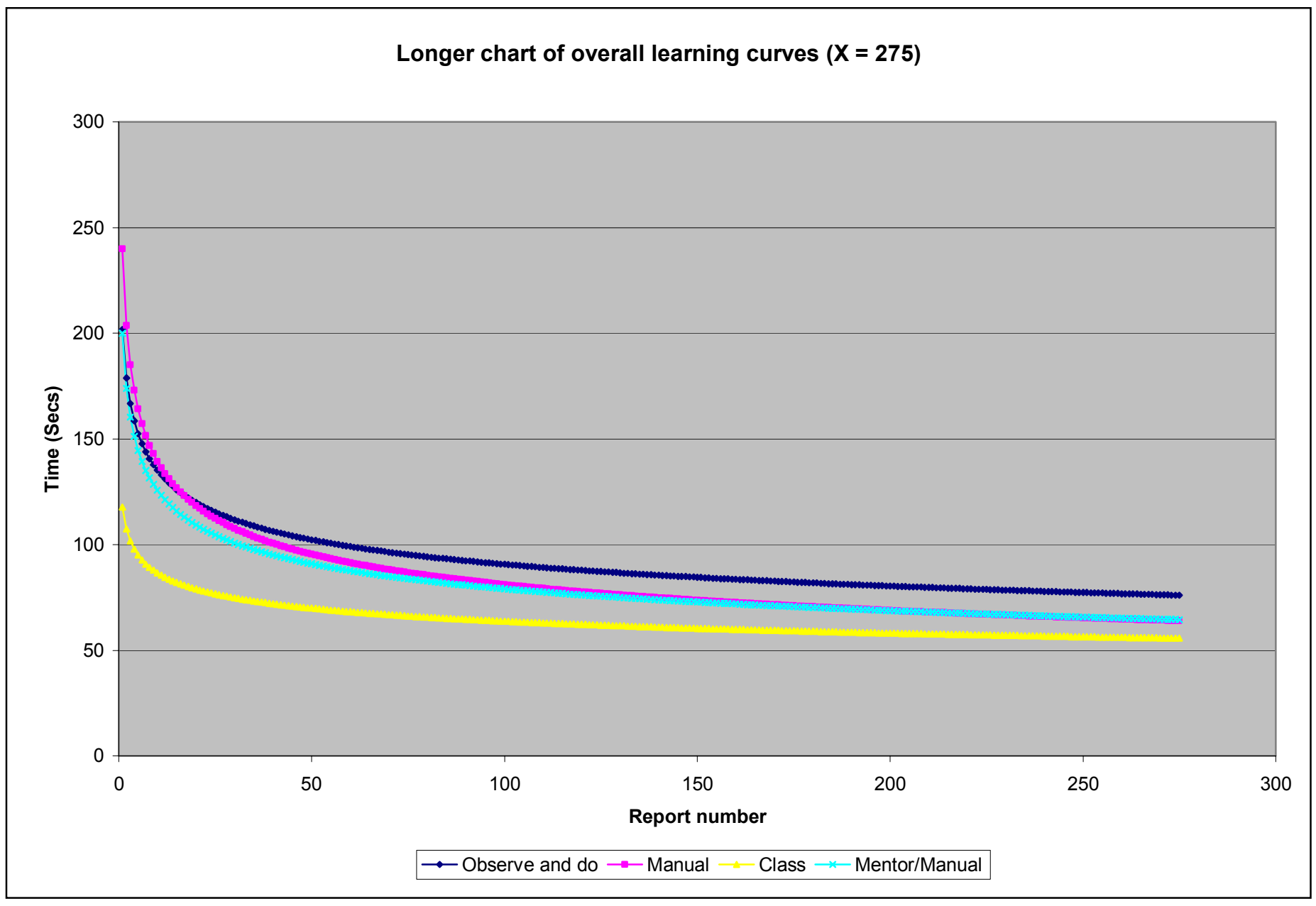




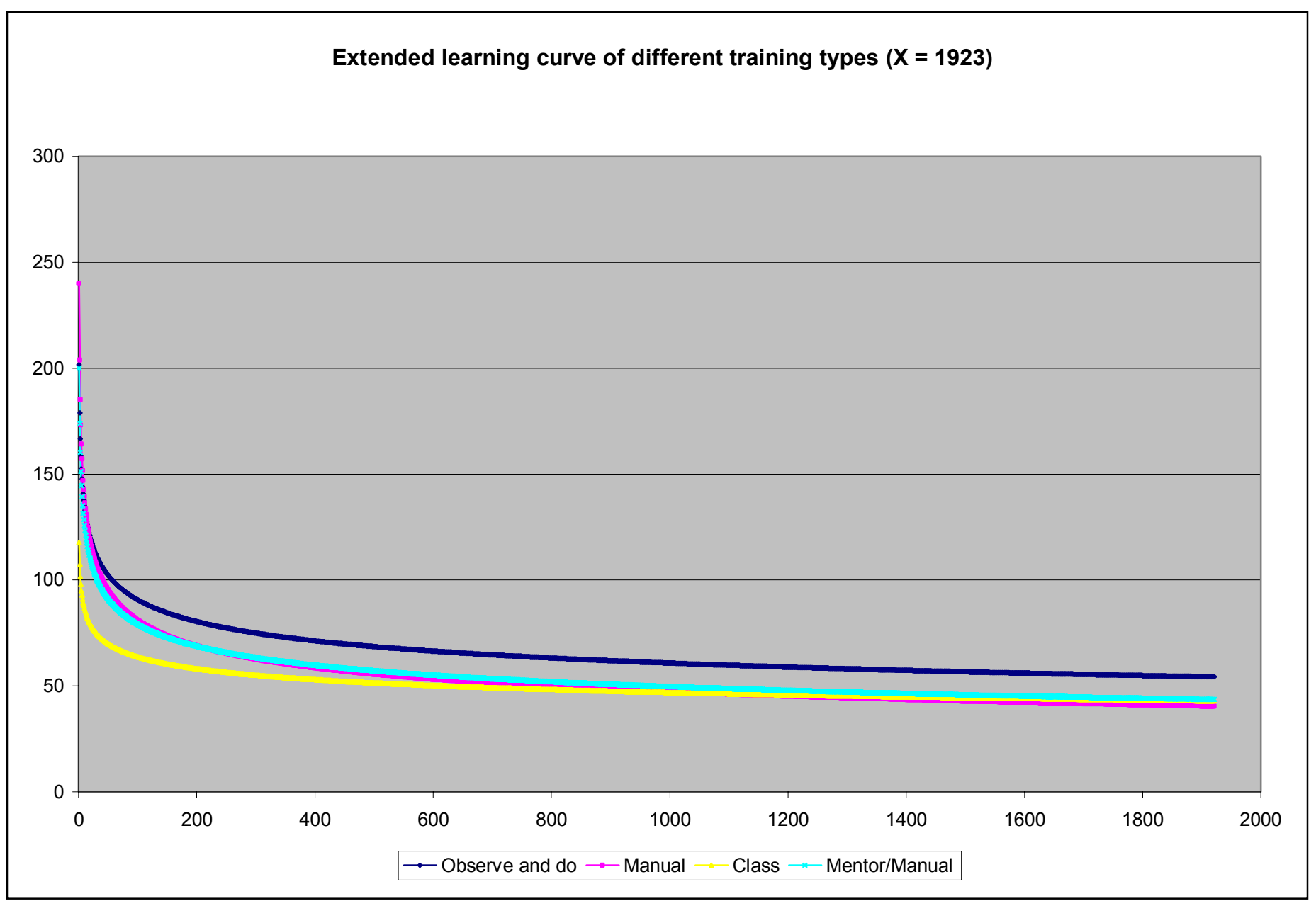




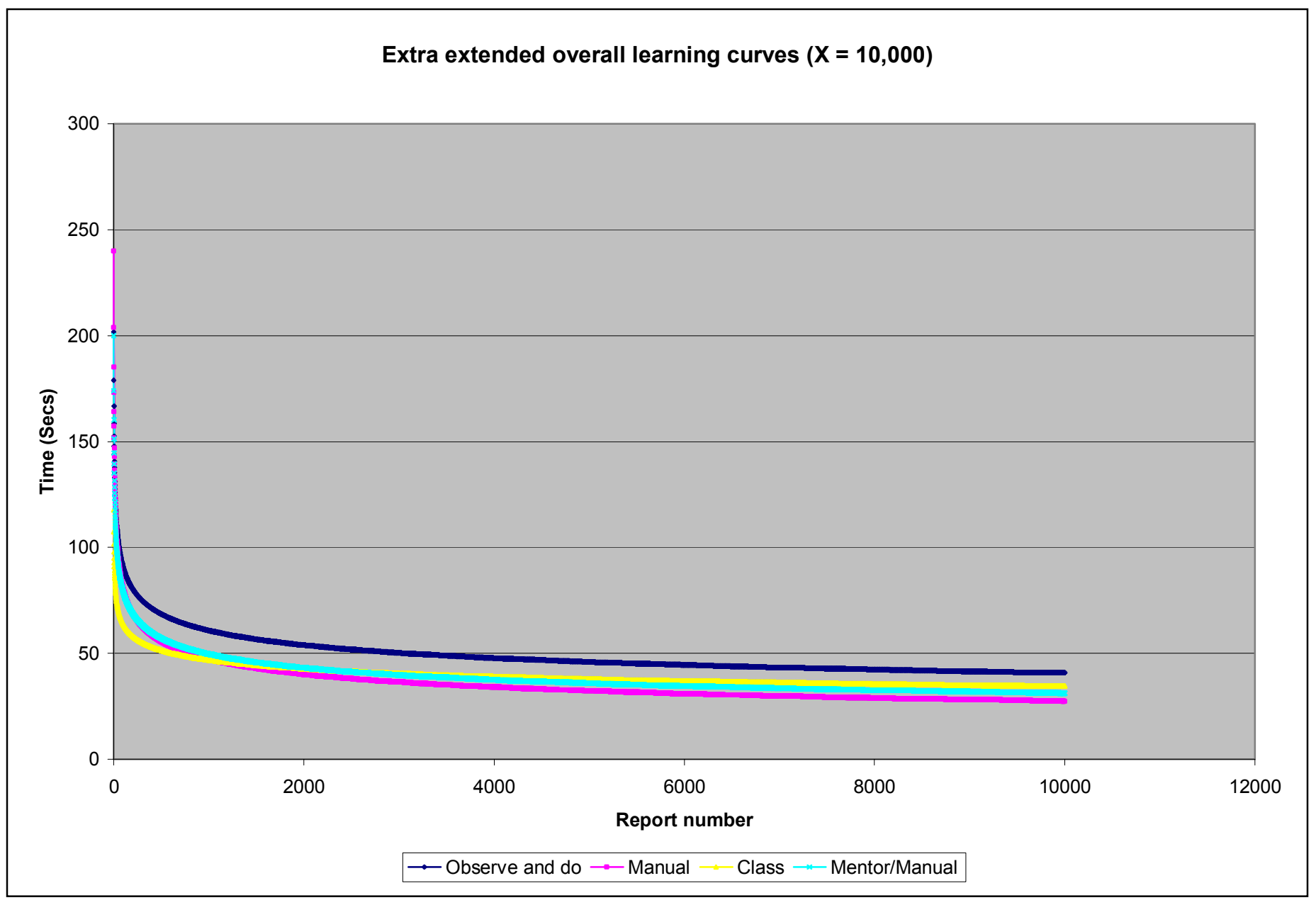




\section{APPENDIX F:}

\section{TRAINING TIME CALCULATIONS}




\begin{tabular}{|l|c|c|c|c|c|}
\hline \multicolumn{7}{|c|}{ Observe and do average training time } \\
\hline & Monday & Monday & Monday & Tuesday & \\
& August & August & August & August & average \\
& $\mathbf{2 6 , 2 0 0 2}$ & $\mathbf{2 6 , 2 0 0 2}$ & $\mathbf{2 6 , 2 0 0 2}$ & $\mathbf{2 7 , 2 0 0 2}$ & training \\
& $\mathbf{8 : 0 0}$ am & $\mathbf{2 : 0 0 ~ p m}$ & $\mathbf{5 : 0 0} \mathbf{~ p m}$ & $\mathbf{8 : 0 0}$ am & time \\
\hline demonstration & 90 & 68 & 61 & 68 & $\mathbf{7 1 . 7 5}$ \\
\hline
\end{tabular}

\begin{tabular}{|l|c|c|c|c|c|}
\hline \multicolumn{7}{|c|}{ Manual average training time (Secs) } \\
\hline & $\begin{array}{c}\text { Tuesday, } \\
\text { August 27, } \\
2002 \text { 2:00 pm }\end{array}$ & $\begin{array}{c}\text { Tuesday, } \\
\text { September 3, } \\
\mathbf{2 0 0 2} \mathbf{5 : 0 0} \mathbf{~ p m}\end{array}$ & $\begin{array}{c}\text { Wednesday, } \\
\text { September 4, } \\
\mathbf{2 0 0 2} \mathbf{8 : 0 0 a m}\end{array}$ & $\begin{array}{c}\text { Tuesday, } \\
\text { September } \\
\mathbf{2 4 , 2 : 0 0 ~ p m ~}\end{array}$ & Average \\
\hline read manual & 700 & 505 & 617 & 494 & 579 \\
\hline demonstration & 91 & 98 & 112 & 84 & 96.25 \\
\hline & & & & & \\
\hline trainer time & 91 & 98 & 112 & 84 & 96.25 \\
\hline employee time & 791 & 603 & 729 & 578 & 675.25 \\
\hline
\end{tabular}

\begin{tabular}{|l|c|c|c|c|c|}
\hline \multicolumn{7}{|c|}{ Class average training time (Secs) } \\
\hline & $\begin{array}{c}\text { Monday, } \\
\text { September }\end{array}$ & $\begin{array}{c}\text { Thursday, } \\
\text { September 5, }\end{array}$ & $\begin{array}{c}\text { Tuesday, } \\
\text { September 4, }\end{array}$ & $\begin{array}{c}\text { Tuesday, } \\
\text { September } \\
\mathbf{2 4 , 2 0 0 2}\end{array}$ & \\
& $\begin{array}{c}\text { 23, 2002 3:30 } \\
\text { pm }\end{array}$ & $\begin{array}{c}\text { Septem } \\
\mathbf{2 0 0 2} \mathbf{2 0 0}\end{array}$ & $\mathbf{2 0 0 2 ~ 4 : 3 0}$ & $\mathbf{1 0 : 0 0 \text { AM }}$ & Average \\
\hline demonstration & 178 & 272 & 208 & 153 & 202.75 \\
\hline trial a & 96 & 117 & 146 & 165 & 131 \\
\hline trial b & 100 & 120 & 448 & 105 & 193.25 \\
\hline total training time & 374 & 509 & 802 & 423 & $\mathbf{5 2 7 . 0 0}$ \\
\hline
\end{tabular}




\begin{tabular}{|c|c|c|c|c|c|}
\hline \multicolumn{6}{|c|}{ Mentor with Manual average training time (Secs) } \\
\hline & $\begin{array}{c}\text { Tuesday, } \\
\text { September 3, } \\
\text { 2002 8:00 am }\end{array}$ & \begin{tabular}{|c|} 
Tuesday, \\
September 3, \\
2002 11:00 \\
am \\
\end{tabular} & $\begin{array}{c}\text { Tuesday, } \\
\text { September } 3 \\
2002 \text { 2:00 pm }\end{array}$ & $\begin{array}{l}\text { Wednesday, } \\
\text { September 4, } \\
\text { 2002 2:00 pm }\end{array}$ & Average \\
\hline \multicolumn{6}{|l|}{ Employee and trainer cost } \\
\hline reading manual & 650 & 607 & 484 & 590 & 583 \\
\hline demonstration & 74 & 71 & 63 & 73 & 70 \\
\hline trainer time & 74 & 71 & 63 & 73 & 70.25 \\
\hline employee time & 724 & 678 & 547 & 663 & 653.00 \\
\hline \multicolumn{6}{|l|}{ Mentor cost } \\
\hline Number of reports produced & 35 & 37 & 36 & 32 & \\
\hline \multirow[t]{8}{*}{ Number of times utilized mentor } & 4 & 2 & 4 & 7 & \\
\hline & 391 & 130 & 173 & 270 & \\
\hline & 166 & 100 & 133 & 180 & \\
\hline & 191 & & 55 & 193 & \\
\hline & 222 & & 339 & 201 & \\
\hline & & & & 322 & \\
\hline & & & & 110.5 & \\
\hline & & & & 97 & \\
\hline total mentor usage (time) & 970 & 230 & 700 & 1373.5 & 818.375 \\
\hline
\end{tabular}

${ }^{* *}$ Note: The use of a mentor phased out towards the end of the subject's experiment time

Therefore, the assumption is that the mentor usage would be the same as it is here for each subject even if the subject continued to produce reports. So the total number of report that each subject produced doesn't have an effect on the amount of time that the mentor was utilized. 
APPENDIX G:

QUALITY 


\begin{tabular}{|c|c|c|c|c|c|c|c|c|c|c|c|c|}
\hline \multicolumn{13}{|c|}{ Report Quality } \\
\hline \multirow[b]{2}{*}{ Training type } & \multirow[b]{2}{*}{ Date and time } & \multirow[b]{2}{*}{$\begin{array}{l}\text { Count of } \\
\text { reports }\end{array}$} & \multicolumn{4}{|c|}{ Designation Counts } & \multirow[b]{2}{*}{$\begin{array}{c}\text { S- per } \\
\text { report ratio }\end{array}$} & \multirow[b]{2}{*}{$\begin{array}{c}\text { S- per } \\
\text { report ratio } \\
\text { average }\end{array}$} & \multirow[b]{2}{*}{$\begin{array}{l}\text { One S- } \\
\text { every }\end{array}$} & \multirow[b]{2}{*}{$\begin{array}{c}X \text { per } \\
\text { report } \\
\text { ratio } \\
\text { average }\end{array}$} & \multirow[b]{2}{*}{$\begin{array}{c}\mathrm{X} \text { per } \\
\text { report ratio } \\
\text { average }\end{array}$} & \multirow[b]{2}{*}{$\begin{array}{l}\text { One X } \\
\text { every }\end{array}$} \\
\hline & & & $\begin{array}{l}\text { Good } \\
\text { (check) }\end{array}$ & $\begin{array}{l}\text { Satis- } \\
\text { factory } \\
\text { (S) }\end{array}$ & $\begin{array}{c}\text { Satis- } \\
\text { factory } \\
\text { minus (S-) }\end{array}$ & $\begin{array}{c}\text { BAD } \\
\text { (X) }\end{array}$ & & & & & & \\
\hline Observe and do & August 26, 2002 8:00am & 35 & 29 & 2 & 3 & 1 & 0.0857 & 0.124 & 8.08 & 0.02857 & 0.075 & 13.41 \\
\hline Observe and do & August 26, 2002 2:00pm & 58 & 35 & 9 & 4 & 10 & 0.0690 & & & 0.17241 & & \\
\hline Observe and do & August 26, 2002 5:00pm & 52 & 42 & 1 & 7 & 2 & 0.1346 & & & 0.03846 & & \\
\hline Observe and do & August 27, 2002 8:00am & 34 & 24 & 1 & 7 & 2 & 0.2059 & & & 0.05882 & & \\
\hline Mentor/manual & September 3, 2002 8:00am & 35 & 32 & 2 & 1 & 0 & 0.0286 & 0.064 & 15.73 & 0.00000 & 0.028 & 36.00 \\
\hline Mentor/manual & September 3, 2002 2:00pm & 36 & 25 & 0 & 7 & 4 & 0.1944 & & & 0.11111 & & \\
\hline Mentor/manual & September 3, 2002 11:00am & 37 & 37 & 0 & 0 & 0 & 0.0000 & & & 0.00000 & & \\
\hline Mentor/manual & September 4, 2002 2:00pm & 32 & 30 & 1 & 1 & 0 & 0.0313 & & & 0.00000 & & \\
\hline Manual only & August 27, 2002 2:00pm & 34 & 29 & 4 & 1 & 0 & 0.0294 & 0.029 & 34.74 & 0.00000 & 0.000 & 0.00 \\
\hline Manual only & September 3, 2002 5:00pm & 31 & 29 & 2 & 0 & 0 & 0.0000 & & & 0.00000 & & \\
\hline Manual only & September 4, 2002 8:00am & 36 & 35 & 1 & 0 & 0 & 0.0000 & & & 0.00000 & & \\
\hline Manual only & September 24, 2002 2:00pm & 35 & 32 & 0 & 3 & 0 & 0.0857 & & & 0.00000 & & \\
\hline Class & September 5, 2002 2:00pm & 44 & 41 & 0 & 2 & 1 & 0.0455 & 0.038 & 26.55 & 0.02273 & 0.035 & 28.51 \\
\hline Class & September 23, 2002 3:30pm & 42 & 39 & 0 & 2 & 1 & 0.0476 & & & 0.02381 & & \\
\hline Class & September 24, 2002 10:00am & 38 & 37 & 0 & 1 & 0 & 0.0263 & & & 0.00000 & & \\
\hline Class & September 24, 2002 4:00pm & 32 & 28 & 0 & 1 & 3 & 0.0313 & & & 0.09375 & & \\
\hline
\end{tabular}


APPENDIX H:

MISSED HOLE REPAIR TIME 


\begin{tabular}{|c|c|}
\hline \multicolumn{2}{|c|}{ Time it takes to fix a missed hole } \\
\hline $\begin{array}{c}\text { Repair time for reports with a S- } \\
\text { quality designation }\end{array}$ \\
\hline Report no. & Time (Secs) \\
\hline 1 & $0: 54$ \\
\hline 2 & $0: 38$ \\
\hline 3 & $0: 31$ \\
\hline 4 & $0: 23$ \\
\hline 5 & $0: 25$ \\
\hline 6 & $0: 45$ \\
\hline 7 & $0: 49$ \\
\hline 8 & $0: 28$ \\
\hline AVERAGE & $\mathbf{0 : 3 6}$ \\
\hline
\end{tabular}


APPENDIX I:

FACTORS IN CUMULATIVE PROFIT AND ROI EQUATIONS 


\begin{tabular}{|c|c|c|c|c|c|c|}
\hline \multicolumn{7}{|c|}{ Observe and Do Training Type } \\
\hline \multicolumn{3}{|c|}{ List of benefits } & \multicolumn{4}{|c|}{ List of Costs } \\
\hline Benefit & Factor & Dollar amount & Cost & Factor & & Dollar amount \\
\hline Price per report & $\mathrm{P}$ & 1.000 & Fixed costs: & & & \\
\hline Less cost of defects $(X)$ per report & $-F 1^{*} \mathrm{P}$ & $(0.075)$ & Training & $\mathrm{T} 1$ & $\$$ & 0.36 \\
\hline \multirow[t]{4}{*}{ Benefit per report } & B1 & 0.925 & Variable costs: & & & \\
\hline & & & Labor per report & $\mathrm{L} 1$ & & $\mathrm{~L}=.3361833^{\star} \mathrm{X}^{\wedge}(-.1737)$ \\
\hline & & & Material cost per report & M & $\$$ & 0.53 \\
\hline & & & Repair of off quality reports (S-) & Q1 & $\$$ & 0.0074 \\
\hline
\end{tabular}

\begin{tabular}{|c|c|c|c|c|c|}
\hline \multicolumn{6}{|c|}{ Manual Training Type } \\
\hline \multicolumn{3}{|c|}{ List of benefits } & \multicolumn{3}{|c|}{ List of Costs } \\
\hline Benefit & Factor & Dollar amount & Cost & Factor & Dollar amount \\
\hline Price per report & $\mathrm{P}$ & $\$ \quad 1.000$ & Fixed costs: & & \\
\hline Less cost of defects $(X)$ per report & $-F 2^{*} P$ & $\$$ & Training & $\mathrm{T} 2$ & 7.11 \\
\hline \multirow[t]{4}{*}{ Benefit per report } & $\mathrm{B} 2$ & 1.000 & Variable costs: & & \\
\hline & & & Labor per report & $\mathrm{L} 2$ & $L=.3997667^{\star} X^{\wedge}(-.2357)$ \\
\hline & & & Material cost per report & M & 0.53 \\
\hline & & & Repair of off quality reports (S-) & Q2 & 0.0017 \\
\hline
\end{tabular}

\begin{tabular}{|c|c|c|c|c|c|}
\hline \multicolumn{6}{|c|}{ Class Training Type } \\
\hline \multicolumn{3}{|c|}{ List of benefits } & \multicolumn{3}{|c|}{ List of Costs } \\
\hline Benefit & Factor & Dollar amount & Cost & Factor & Dollar amount \\
\hline Price per report & $\mathrm{P}$ & 1.000 & Fixed costs: & & \\
\hline Less cost of defects $(X)$ per report & $-F 3^{*} P$ & $(0.035)$ & Training & T3 & 4.23 \\
\hline \multirow[t]{4}{*}{ Benefit per report } & B3 & 0.965 & Variable costs: & & \\
\hline & & & Labor per report & L3 & $L=.1961667^{\star} X^{\wedge}(-.1333)$ \\
\hline & & & Material cost per report & $\mathrm{M}$ & 0.53 \\
\hline & & & Repair of off quality reports (S-) & Q3 & 0.0023 \\
\hline
\end{tabular}

\begin{tabular}{|c|c|c|c|c|c|}
\hline \multicolumn{6}{|c|}{ Mentor/Manual Training Type } \\
\hline \multicolumn{3}{|c|}{ List of benefits } & \multicolumn{3}{|c|}{ List of Costs } \\
\hline Benefit & Factor & Dollar amount & Cost & Factor & Dollar amount \\
\hline Price per report & $\mathrm{P}$ & 1.000 & Fixed costs: & & \\
\hline Less cost of defects $(X)$ per report & $-F 4^{\star} P$ & $(0.028)$ & Training & T4 & 9.03 \\
\hline \multirow[t]{4}{*}{ Benefit per report } & B4 & 0.972 & Variable costs: & & \\
\hline & & & Labor per report & L4 & $L=.3333833^{*} X^{\wedge}(-.2017)$ \\
\hline & & & Material cost per report & M & 0.53 \\
\hline & & & Repair of off quality reports (S-) & Q4 & 0.0038 \\
\hline
\end{tabular}


APPENDIX J:

CUMULATIVE COSTS, CUMULATIVE BENEFITS, AND PROFIT CALCULATIONS 


\begin{tabular}{|c|c|c|c|c|c|c|c|c|c|c|c|c|c|}
\hline \multicolumn{14}{|c|}{ Observe and Do Training Type Cumulative Profit Calculations } \\
\hline \multirow{2}{*}{\begin{tabular}{|c|} 
Report number \\
0 \\
\end{tabular}} & \multirow[t]{2}{*}{$\begin{array}{l}\text { Time to produce } \\
\text { (secs) }\end{array}$} & \multicolumn{2}{|c|}{ Cost } & \multicolumn{2}{|c|}{ Benefit } & \multicolumn{2}{|c|}{$\begin{array}{l}\text { Cumulative } \\
\text { Cost }\end{array}$} & \multicolumn{2}{|c|}{$\begin{array}{l}\text { Cumulative } \\
\text { Benefit }\end{array}$} & \multicolumn{2}{|c|}{$\begin{array}{l}\text { Marginal } \\
\text { Return }\end{array}$} & \multicolumn{2}{|c|}{ Profit } \\
\hline & & $\$$ & 0.360 & $\$$ & - & $\$$ & 0.360 & $\$$ & - & $\$$ & $(0.360)$ & $\$$ & $(0.360)$ \\
\hline 1 & 201.71 & $\$$ & 0.874 & $\$$ & 0.925 & $\$$ & 1.234 & $\$$ & 0.925 & $\$$ & 0.051 & $\$$ & $(0.309)$ \\
\hline 2 & 178.83 & $\$$ & 0.835 & $\$$ & 0.925 & $\$$ & 2.069 & $\$$ & 1.850 & $\$$ & 0.090 & $\$$ & $(0.219)$ \\
\hline 3 & 166.67 & $\$$ & 0.815 & $\$$ & 0.925 & $\$$ & 2.884 & $\$$ & 2.775 & $\$$ & 0.110 & $\$$ & $(0.109)$ \\
\hline 4 & 158.54 & $\$$ & 0.802 & $\$$ & 0.925 & $\$$ & 3.686 & $\$$ & 3.700 & $\$$ & 0.123 & $\$$ & 0.014 \\
\hline 5 & 152.52 & $\$$ & 0.792 & $\$$ & 0.925 & $\$$ & 4.478 & $\$$ & 4.625 & $\$$ & 0.133 & $\$$ & 0.147 \\
\hline 6 & 147.76 & $\$$ & 0.784 & $\$$ & 0.925 & $\$$ & 5.261 & $\$$ & 5.550 & $\$$ & 0.141 & $\$$ & 0.289 \\
\hline 7 & 143.86 & $\$$ & 0.777 & $\$$ & 0.925 & $\$$ & 6.039 & $\$$ & 6.475 & $\$$ & 0.148 & $\$$ & 0.436 \\
\hline 8 & 140.56 & $\$$ & 0.772 & $\$$ & 0.925 & $\$$ & 6.810 & $\$$ & 7.400 & $\$$ & 0.153 & $\$$ & 0.590 \\
\hline 9 & 137.71 & $\$$ & 0.767 & $\$$ & 0.925 & $\$$ & 7.577 & $\$$ & 8.325 & $\$$ & 0.158 & $\$$ & 0.748 \\
\hline 10 & 135.22 & $\$$ & 0.763 & $\$$ & 0.925 & $\$$ & 8.340 & $\$$ & 9.250 & $\$$ & 0.162 & $\$$ & 0.910 \\
\hline 11 & 133.00 & $\$$ & 0.759 & $\$$ & 0.925 & $\$$ & 9.099 & $\$$ & 10.175 & $\$$ & 0.166 & $\$$ & 1.076 \\
\hline 12 & 131.00 & $\$$ & 0.756 & $\$$ & 0.925 & $\$$ & 9.855 & $\$$ & 11.100 & $\$$ & 0.169 & $\$$ & 1.245 \\
\hline 13 & 129.19 & $\$$ & 0.753 & $\$$ & 0.925 & $\$$ & 10.608 & $\$$ & 12.025 & $\$$ & 0.172 & $\$$ & 1.417 \\
\hline 14 & 127.54 & $\$$ & 0.750 & $\$$ & 0.925 & $\$$ & 11.358 & $\$$ & 12.950 & $\$$ & 0.175 & $\$$ & 1.592 \\
\hline 15 & 126.02 & $\$$ & 0.747 & $\$$ & 0.925 & $\$$ & 12.105 & $\$$ & 13.875 & $\$$ & 0.178 & $\$$ & 1.770 \\
\hline 16 & 124.62 & $\$$ & 0.745 & $\$$ & 0.925 & $\$$ & 12.850 & $\$$ & 14.800 & $\$$ & 0.180 & $\$$ & 1.950 \\
\hline 17 & 123.31 & $\$$ & 0.743 & $\$$ & 0.925 & $\$$ & 13.593 & $\$$ & 15.725 & $\$$ & 0.182 & $\$$ & 2.132 \\
\hline 18 & 122.09 & $\$$ & 0.741 & $\$$ & 0.925 & $\$$ & 14.334 & $\$$ & 16.650 & $\$$ & 0.184 & $\$$ & 2.316 \\
\hline 19 & 120.95 & $\$$ & 0.739 & $\$$ & 0.925 & $\$$ & \begin{tabular}{|l|}
15.073 \\
\end{tabular} & $\$$ & 17.575 & $\$$ & 0.186 & $\$$ & 2.502 \\
\hline 20 & 119.88 & $\$$ & 0.737 & $\$$ & 0.925 & $\$$ & \begin{tabular}{|l|}
15.810 \\
\end{tabular} & $\$$ & 18.500 & $\$$ & 0.188 & $\$$ & 2.690 \\
\hline 21 & 118.87 & $\$$ & 0.736 & $\$$ & 0.925 & $\$$ & 16.546 & $\$$ & 19.425 & $\$$ & 0.189 & $\$$ & 2.879 \\
\hline 22 & 117.91 & $\$$ & 0.734 & $\$$ & 0.925 & $\$$ & 17.280 & $\$$ & 20.350 & $\$$ & 0.191 & $\$$ & 3.070 \\
\hline 23 & 117.00 & $\$$ & 0.732 & $\$$ & 0.925 & $\$$ & 18.012 & $\$$ & 21.275 & $\$$ & 0.193 & $\$$ & 3.263 \\
\hline 24 & 116.14 & $\$$ & 0.731 & $\$$ & 0.925 & $\$$ & 18.743 & $\$$ & 22.200 & $\$$ & 0.194 & $\$$ & 3.457 \\
\hline 25 & 115.32 & $\$$ & 0.730 & $\$$ & 0.925 & $\$$ & 19.473 & $\$$ & 23.125 & $\$$ & 0.195 & $\$$ & 3.652 \\
\hline 26 & 114.54 & $\$$ & 0.728 & $\$$ & 0.925 & $\$$ & 20.201 & $\$$ & 24.050 & $\$$ & 0.197 & $\$$ & 3.849 \\
\hline 27 & 113.79 & $\$$ & 0.727 & $\$$ & 0.925 & $\$$ & 20.928 & $\$$ & 24.975 & $\$$ & 0.198 & $\$$ & 4.047 \\
\hline 28 & 113.07 & $\$$ & 0.726 & $\$$ & 0.925 & $\$$ & 21.654 & $\$$ & 25.900 & $\$$ & 0.199 & $\$$ & 4.246 \\
\hline 29 & 112.39 & $\$$ & 0.725 & $\$$ & 0.925 & $\$$ & 22.379 & $\$$ & 26.825 & $\$$ & 0.200 & $\$$ & 4.446 \\
\hline 30 & 111.73 & $\$$ & 0.724 & $\$$ & 0.925 & $\$$ & 23.103 & $\$$ & 27.750 & $\$$ & 0.201 & $\$$ & 4.647 \\
\hline 31 & 111.09 & $\$$ & 0.723 & $\$$ & 0.925 & $\$$ & 23.825 & $\$$ & 28.675 & $\$$ & 0.202 & $\$$ & 4.850 \\
\hline 32 & 110.48 & $\$$ & 0.722 & $\$$ & 0.925 & $\$$ & 24.547 & $\$$ & 29.600 & $\$$ & 0.203 & $\$$ & 5.053 \\
\hline 33 & 109.89 & $\$$ & 0.721 & $\$$ & 0.925 & $\$$ & 25.267 & $\$$ & 30.525 & $\$$ & 0.204 & $\$$ & 5.258 \\
\hline 34 & 109.32 & $\$$ & 0.720 & $\$$ & 0.925 & $\$$ & 25.987 & $\$$ & 31.450 & $\$$ & 0.205 & $\$$ & 5.463 \\
\hline 35 & 108.77 & $\$$ & 0.719 & $\$$ & 0.925 & $\$$ & 26.706 & $\$$ & 32.375 & $\$$ & 0.206 & $\$$ & 5.669 \\
\hline 36 & 108.24 & $\$$ & 0.718 & $\$$ & 0.925 & $\$$ & 27.424 & $\$$ & 33.300 & $\$$ & 0.207 & $\$$ & 5.876 \\
\hline 37 & 107.73 & $\$$ & 0.717 & $\$$ & 0.925 & $\$$ & \begin{tabular}{|l|}
28.141 \\
\end{tabular} & $\$$ & 34.225 & $\$$ & 0.208 & $\$$ & 6.084 \\
\hline 38 & 107.23 & $\$$ & 0.716 & $\$$ & 0.925 & $\$$ & 28.857 & $\$$ & 35.150 & $\$$ & 0.209 & $\$$ & 6.293 \\
\hline 39 & 106.75 & $\$$ & 0.715 & $\$$ & 0.925 & $\$$ & 29.572 & $\$$ & 36.075 & $\$$ & 0.210 & $\$$ & 6.503 \\
\hline 40 & 106.28 & $\$$ & 0.715 & $\$$ & 0.925 & $\$$ & 30.287 & $\$$ & 37.000 & $\$$ & 0.210 & $\$$ & 6.713 \\
\hline 41 & 105.82 & $\$$ & 0.714 & $\$$ & 0.925 & $\$$ & \begin{tabular}{|c|}
31.001 \\
\end{tabular} & $\$$ & 37.925 & $\$$ & 0.211 & $\$$ & 6.924 \\
\hline 42 & 105.38 & $\$$ & 0.713 & $\$$ & 0.925 & $\$$ & 31.714 & $\$$ & 38.850 & $\$$ & 0.212 & $\$$ & 7.136 \\
\hline 43 & 104.95 & $\$$ & 0.712 & $\$$ & 0.925 & $\$$ & 32.426 & $\$$ & 39.775 & $\$$ & 0.213 & $\$$ & 7.349 \\
\hline 44 & 104.53 & $\$$ & 0.712 & $\$$ & 0.925 & $\$$ & \begin{tabular}{|c|}
33.138 \\
\end{tabular} & $\$$ & 40.700 & $\$$ & 0.213 & $\$$ & 7.562 \\
\hline 45 & 104.13 & $\$$ & 0.711 & $\$$ & 0.925 & $\$$ & \begin{tabular}{|c|}
33.849 \\
\end{tabular} & $\$$ & 41.625 & $\$$ & 0.214 & $\$$ & 7.776 \\
\hline 46 & 103.73 & $\$$ & 0.710 & $\$$ & 0.925 & $\$$ & 34.559 & $\$$ & 42.550 & $\$$ & 0.215 & $\$$ & 7.991 \\
\hline 47 & 103.34 & $\$$ & 0.710 & $\$$ & 0.925 & $\$$ & 35.269 & $\$$ & 43.475 & $\$$ & 0.215 & $\$$ & 8.206 \\
\hline 48 & 102.97 & $\$$ & 0.709 & $\$$ & 0.925 & $\$$ & 35.978 & $\$$ & 44.400 & $\$$ & 0.216 & $\$$ & 8.422 \\
\hline 49 & 102.60 & $\$$ & 0.708 & $\$$ & 0.925 & $\$$ & \begin{tabular}{|c|}
36.686 \\
\end{tabular} & $\$$ & 45.325 & $\$$ & 0.217 & $\$$ & 8.639 \\
\hline 50 & 102.24 & $\$$ & 0.708 & $\$$ & 0.925 & $\$$ & \begin{tabular}{|c|}
37.394 \\
\end{tabular} & $\$$ & 46.250 & $\$$ & 0.217 & $\$$ & 8.856 \\
\hline
\end{tabular}




\begin{tabular}{|c|c|c|c|c|c|c|c|c|c|c|c|c|c|}
\hline \multicolumn{14}{|c|}{ Observe and Do Training Type Cumulative Profit Calculations (Continued) } \\
\hline \multirow{2}{*}{$\frac{\text { Report number }}{51}$} & \multirow{2}{*}{$\begin{array}{c}\begin{array}{c}\text { Time to produce } \\
\text { (secs) }\end{array} \\
101.89\end{array}$} & \multicolumn{2}{|c|}{ Cost } & \multicolumn{2}{|c|}{ Benefit } & \multicolumn{2}{|c|}{$\begin{array}{l}\text { Cumulative } \\
\text { Cost }\end{array}$} & \multicolumn{2}{|c|}{$\begin{array}{c}\text { Cumulative } \\
\text { Benefit }\end{array}$} & \multicolumn{2}{|c|}{$\begin{array}{c}\text { Marginal } \\
\text { Return }\end{array}$} & \multicolumn{2}{|c|}{ Profit } \\
\hline & & $\$$ & 0.707 & $\$$ & 0.925 & $\$$ & 38.101 & $\$$ & 47.175 & $\$$ & 0.218 & $\$$ & 9.074 \\
\hline 52 & 101.54 & $\$$ & 0.707 & $\$$ & 0.925 & $\$$ & 38.808 & $\$$ & 48.100 & $\$$ & 0.218 & $\$$ & 9.292 \\
\hline 53 & 101.21 & $\$$ & 0.706 & $\$$ & 0.925 & $\$$ & 39.514 & $\$$ & 49.025 & $\$$ & 0.219 & $\$$ & 9.511 \\
\hline 54 & 100.88 & $\$$ & 0.706 & $\$$ & 0.925 & $\$$ & 40.220 & $\$$ & 49.950 & $\$$ & 0.219 & $\$$ & 9.730 \\
\hline 55 & 100.56 & $\$$ & 0.705 & $\$$ & 0.925 & $\$$ & 40.925 & $\$$ & 50.875 & $\$$ & 0.220 & $\$$ & 9.950 \\
\hline 56 & 100.25 & $\$$ & 0.705 & $\$$ & 0.925 & $\$$ & 41.629 & $\$$ & 51.800 & $\$$ & 0.220 & $\$$ & 10.171 \\
\hline 57 & 99.94 & $\$$ & 0.704 & $\$$ & 0.925 & $\$$ & 42.333 & $\$$ & 52.725 & $\$$ & 0.221 & $\$$ & 10.392 \\
\hline 58 & 99.64 & $\$$ & 0.704 & $\$$ & 0.925 & $\$$ & 43.037 & $\$$ & 53.650 & $\$$ & 0.221 & $\$$ & 10.613 \\
\hline 59 & 99.34 & $\$$ & 0.703 & $\$$ & 0.925 & $\$$ & 43.740 & $\$$ & 54.575 & $\$$ & 0.222 & $\$$ & 10.835 \\
\hline 60 & 99.05 & $\$$ & 0.703 & $\$$ & 0.925 & $\$$ & 44.442 & $\$$ & 55.500 & $\$$ & 0.222 & $\$$ & 11.058 \\
\hline 61 & 98.77 & $\$$ & 0.702 & $\$$ & 0.925 & $\$$ & 45.144 & $\$$ & 56.425 & $\$$ & 0.223 & $\$$ & 11.281 \\
\hline 62 & 98.49 & $\$$ & 0.702 & $\$$ & 0.925 & $\$$ & 45.846 & $\$$ & 57.350 & $\$$ & 0.223 & $\$$ & 11.504 \\
\hline 63 & 98.22 & $\$$ & 0.701 & $\$$ & 0.925 & $\$$ & 46.547 & $\$$ & 58.275 & $\$$ & 0.224 & $\$$ & 11.728 \\
\hline 64 & 97.95 & $\$$ & 0.701 & $\$$ & 0.925 & $\$$ & 47.248 & $\$$ & 59.200 & $\$$ & 0.224 & $\$$ & 11.952 \\
\hline 65 & 97.68 & $\$$ & 0.700 & $\$$ & 0.925 & $\$$ & 47.948 & $\$$ & 60.125 & $\$$ & 0.225 & $\$$ & 12.177 \\
\hline 66 & 97.43 & $\$$ & 0.700 & $\$$ & 0.925 & $\$$ & 48.648 & $\$$ & 61.050 & $\$$ & 0.225 & $\$$ & 12.402 \\
\hline 67 & 97.17 & $\$$ & 0.699 & $\$$ & 0.925 & $\$$ & 49.347 & $\$$ & 61.975 & $\$$ & 0.226 & $\$$ & 12.628 \\
\hline 68 & 96.92 & $\$$ & 0.699 & $\$$ & 0.925 & $\$$ & 50.046 & $\$$ & 62.900 & $\$$ & 0.226 & $\$$ & 12.854 \\
\hline 69 & 96.68 & $\$$ & 0.699 & $\$$ & 0.925 & $\$$ & 50.745 & $\$$ & 63.825 & $\$$ & 0.226 & $\$$ & 13.080 \\
\hline 70 & 96.43 & $\$$ & 0.698 & $\$$ & 0.925 & $\$$ & 51.443 & $\$$ & 64.750 & $\$$ & 0.227 & $\$$ & 13.307 \\
\hline 71 & 96.20 & $\$$ & 0.698 & $\$$ & 0.925 & $\$$ & 52.141 & $\$$ & 65.675 & $\$$ & 0.227 & $\$$ & 13.534 \\
\hline 72 & 95.96 & $\$$ & 0.697 & $\$$ & 0.925 & $\$$ & 52.838 & $\$$ & 66.600 & $\$$ & 0.228 & $\$$ & 13.762 \\
\hline 73 & 95.73 & $\$$ & 0.697 & $\$$ & 0.925 & $\$$ & 53.535 & $\$$ & 67.525 & $\$$ & 0.228 & $\$$ & 13.990 \\
\hline 74 & 95.51 & $\$$ & 0.697 & $\$$ & 0.925 & $\$$ & 54.232 & $\$$ & 68.450 & $\$$ & 0.228 & $\$$ & 14.218 \\
\hline 75 & 95.29 & $\$$ & 0.696 & $\$$ & 0.925 & $\$$ & 54.928 & $\$$ & 69.375 & $\$$ & 0.229 & $\$$ & 14.447 \\
\hline 76 & 95.07 & $\$$ & 0.696 & $\$$ & 0.925 & $\$$ & 55.624 & $\$$ & 70.300 & $\$$ & 0.229 & $\$$ & 14.676 \\
\hline 77 & 94.85 & $\$$ & 0.696 & $\$$ & 0.925 & $\$$ & 56.319 & $\$$ & 71.225 & $\$$ & 0.229 & $\$$ & 14.906 \\
\hline 78 & 94.64 & $\$$ & 0.695 & $\$$ & 0.925 & $\$$ & 57.014 & $\$$ & 72.150 & $\$$ & 0.230 & $\$$ & 15.136 \\
\hline 79 & 94.43 & $\$$ & 0.695 & $\$$ & 0.925 & $\$$ & 57.709 & $\$$ & 73.075 & $\$$ & 0.230 & $\$$ & 15.366 \\
\hline 80 & 94.22 & $\$$ & 0.694 & $\$$ & 0.925 & $\$$ & 58.404 & $\$$ & 74.000 & $\$$ & 0.231 & $\$$ & 15.596 \\
\hline 81 & 94.02 & $\$$ & 0.694 & $\$$ & 0.925 & $\$$ & 59.098 & $\$$ & 74.925 & $\$$ & 0.231 & $\$$ & 15.827 \\
\hline 82 & 93.82 & $\$$ & 0.694 & $\$$ & 0.925 & $\$$ & 59.792 & $\$$ & 75.850 & $\$$ & 0.231 & $\$$ & 16.058 \\
\hline 83 & 93.62 & $\$$ & 0.693 & $\$$ & 0.925 & $\$$ & 60.485 & $\$$ & 76.775 & $\$$ & 0.232 & $\$$ & 16.290 \\
\hline 84 & 93.43 & $\$$ & 0.693 & $\$$ & 0.925 & $\$$ & 61.178 & $\$$ & 77.700 & $\$$ & 0.232 & $\$$ & 16.522 \\
\hline 85 & 93.24 & $\$$ & 0.693 & $\$$ & 0.925 & $\$$ & 61.871 & $\$$ & 78.625 & $\$$ & 0.232 & $\$$ & 16.754 \\
\hline 86 & 93.05 & $\$$ & 0.693 & $\$$ & 0.925 & $\$$ & 62.564 & $\$$ & 79.550 & $\$$ & 0.232 & $\$$ & 16.986 \\
\hline 87 & 92.86 & $\$$ & 0.692 & $\$$ & 0.925 & $\$$ & 63.256 & $\$$ & 80.475 & $\$$ & 0.233 & $\$$ & 17.219 \\
\hline 88 & 92.68 & $\$$ & 0.692 & $\$$ & 0.925 & $\$$ & 63.948 & $\$$ & 81.400 & $\$$ & 0.233 & $\$$ & 17.452 \\
\hline 89 & 92.50 & $\$$ & 0.692 & $\$$ & 0.925 & $\$$ & 64.639 & $\$$ & 82.325 & $\$$ & 0.233 & $\$$ & 17.686 \\
\hline 90 & 92.32 & $\$$ & 0.691 & $\$$ & 0.925 & $\$$ & 65.331 & $\$$ & 83.250 & $\$$ & 0.234 & $\$$ & 17.919 \\
\hline 91 & 92.14 & $\$$ & 0.691 & $\$$ & 0.925 & $\$$ & 66.022 & $\$$ & 84.175 & $\$$ & 0.234 & $\$$ & 18.153 \\
\hline 92 & 91.96 & $\$$ & 0.691 & $\$$ & 0.925 & $\$$ & 66.712 & $\$$ & 85.100 & $\$$ & 0.234 & $\$$ & 18.388 \\
\hline 93 & 91.79 & $\$$ & 0.690 & $\$$ & 0.925 & $\$$ & 67.403 & $\$$ & 86.025 & $\$$ & 0.235 & $\$$ & 18.622 \\
\hline 94 & 91.62 & $\$$ & 0.690 & $\$$ & 0.925 & $\$$ & 68.093 & $\$$ & 86.950 & $\$$ & 0.235 & $\$$ & 18.857 \\
\hline 95 & 91.45 & $\$$ & 0.690 & $\$$ & 0.925 & $\$$ & 68.783 & $\$$ & 87.875 & $\$$ & 0.235 & $\$$ & 19.092 \\
\hline 96 & 91.29 & $\$$ & 0.690 & $\$$ & 0.925 & $\$$ & 69.472 & $\$$ & 88.800 & $\$$ & 0.235 & $\$$ & 19.328 \\
\hline 97 & 91.12 & $\$$ & 0.689 & $\$$ & 0.925 & $\$$ & 70.162 & $\$$ & 89.725 & $\$$ & 0.236 & $\$$ & 19.563 \\
\hline 98 & 90.96 & $\$$ & 0.689 & $\$$ & 0.925 & $\$$ & 70.851 & $\$$ & 90.650 & $\$$ & 0.236 & $\$$ & 19.799 \\
\hline 99 & 90.80 & $\$$ & 0.689 & $\$$ & 0.925 & $\$$ & 71.540 & $\$$ & 91.575 & $\$$ & 0.236 & $\$$ & 20.035 \\
\hline 100 & 90.64 & $\$$ & 0.689 & $\$$ & 0.925 & $\$$ & 72.228 & $\$$ & 92.500 & $\$$ & 0.236 & $\$$ & 20.272 \\
\hline
\end{tabular}




\begin{tabular}{|c|c|c|c|c|c|c|c|c|c|c|c|c|c|}
\hline \multicolumn{14}{|c|}{ Manual Training Type Cumulative Profit Calculations } \\
\hline $\begin{array}{l}\text { Report } \\
\text { number }\end{array}$ & $\mid \begin{array}{c}\text { Time to produce } \\
\text { (secs) }\end{array}$ & & ost & & lefit & & $\begin{array}{l}\text { ulative } \\
\text { ost }\end{array}$ & & $\begin{array}{l}\text { ulative } \\
\text { nefit }\end{array}$ & & $\begin{array}{l}\text { arginal } \\
\text { eturn }\end{array}$ & & Profit \\
\hline 0 & & $\$$ & 7.110 & $\$$ & - & $\$$ & 7.110 & $\$$ & - & $\$$ & $(7.110)$ & $\$$ & $(7.110)$ \\
\hline 1 & 239.86 & $\$$ & 0.932 & $\$$ & 1.000 & $\$$ & 8.042 & $\$$ & 1.000 & $\$$ & 0.068 & $\$$ & $(7.042)$ \\
\hline 2 & 203.71 & $\$$ & 0.871 & $\$$ & 1.000 & $\$$ & 8.913 & $\$$ & 2.000 & $\$$ & 0.129 & $\$$ & $(6.913)$ \\
\hline 3 & 185.14 & $\$$ & 0.840 & $\$$ & 1.000 & $\$$ & 9.753 & $\$$ & 3.000 & $\$$ & 0.160 & $\$$ & $(6.753)$ \\
\hline 4 & 173.00 & $\$$ & 0.820 & $\$$ & 1.000 & $\$$ & 10.573 & $\$$ & 4.000 & $\$$ & 0.180 & $\$$ & $(6.573)$ \\
\hline 5 & 164.14 & $\$$ & 0.805 & $\$$ & 1.000 & $\$$ & 11.378 & $\$$ & 5.000 & $\$$ & 0.195 & $\$$ & $(6.378)$ \\
\hline 6 & 157.23 & $\$$ & 0.794 & $\$$ & 1.000 & $\$$ & 12.172 & $\$$ & 6.000 & $\$$ & 0.206 & $\$$ & (6.172) \\
\hline 7 & 151.62 & $\$$ & 0.784 & $\$$ & 1.000 & $\$$ & 12.957 & $\$$ & 7.000 & $\$$ & 0.216 & $\$$ & $(5.957)$ \\
\hline 8 & 146.93 & $\$$ & 0.777 & $\$$ & 1.000 & $\$$ & 13.733 & $\$$ & 8.000 & $\$$ & 0.223 & $\$$ & $(5.733)$ \\
\hline 9 & 142.90 & $\$$ & 0.770 & $\$$ & 1.000 & $\$$ & 14.503 & $\$$ & 9.000 & $\$$ & 0.230 & $\$$ & $(5.503)$ \\
\hline 10 & 139.40 & $\$$ & 0.764 & $\$$ & 1.000 & $\$$ & 15.267 & $\$$ & 10.000 & $\$$ & 0.236 & $\$$ & $(5.267)$ \\
\hline 11 & 136.30 & $\$$ & 0.759 & $\$$ & 1.000 & $\$$ & 16.026 & $\$$ & 11.000 & $\$$ & 0.241 & $\$$ & $(5.026)$ \\
\hline 12 & 133.53 & $\$$ & 0.754 & $\$$ & 1.000 & $\$$ & 16.780 & $\$$ & 12.000 & $\$$ & 0.246 & $\$$ & $(4.780)$ \\
\hline 13 & 131.04 & $\$$ & 0.750 & $\$$ & 1.000 & $\$$ & 17.531 & $\$$ & 13.000 & $\$$ & 0.250 & $\$$ & $(4.531)$ \\
\hline 14 & 128.77 & $\$$ & 0.746 & $\$$ & 1.000 & $\$$ & 18.277 & $\$$ & 14.000 & $\$$ & 0.254 & $\$$ & $(4.277)$ \\
\hline 15 & 126.69 & $\$$ & 0.743 & $\$$ & 1.000 & $\$$ & 19.020 & $\$$ & 15.000 & $\$$ & 0.257 & $\$$ & $(4.020)$ \\
\hline 16 & 124.78 & $\$$ & 0.740 & $\$$ & 1.000 & $\$$ & 19.760 & $\$$ & 16.000 & $\$$ & 0.260 & $\$$ & (3.760) \\
\hline 17 & 123.01 & $\$$ & 0.737 & $\$$ & 1.000 & $\$$ & 20.496 & $\$$ & 17.000 & $\$$ & 0.263 & $\$$ & $(3.496)$ \\
\hline 18 & 121.36 & $\$$ & 0.734 & $\$$ & 1.000 & $\$$ & 21.230 & $\$$ & 18.000 & $\$$ & 0.266 & $\$$ & $(3.230)$ \\
\hline 19 & 119.83 & $\$$ & 0.731 & $\$$ & 1.000 & $\$$ & 21.962 & $\$$ & 19.000 & $\$$ & 0.269 & $\$$ & $(2.962)$ \\
\hline 20 & 118.39 & $\$$ & 0.729 & $\$$ & 1.000 & $\$$ & 22.691 & $\$$ & 20.000 & $\$$ & 0.271 & $\$$ & $(2.691)$ \\
\hline 21 & 117.03 & $\$$ & 0.727 & $\$$ & 1.000 & $\$$ & 23.418 & $\$$ & 21.000 & $\$$ & 0.273 & $\$$ & $(2.418)$ \\
\hline 22 & 115.76 & $\$$ & 0.725 & $\$$ & 1.000 & $\$$ & 24.142 & $\$$ & 22.000 & $\$$ & 0.275 & $\$$ & $(2.142)$ \\
\hline 23 & 114.55 & $\$$ & 0.723 & $\$$ & 1.000 & $\$$ & 24.865 & $\$$ & 23.000 & $\$$ & 0.277 & $\$$ & $(1.865)$ \\
\hline 24 & 113.41 & $\$$ & 0.721 & $\$$ & 1.000 & $\$$ & 25.586 & $\$$ & 24.000 & $\$$ & 0.279 & $\$$ & (1.586) \\
\hline 25 & 112.32 & $\$$ & 0.719 & $\$$ & 1.000 & $\$$ & 26.305 & $\$$ & 25.000 & $\$$ & 0.281 & $\$$ & $(1.305)$ \\
\hline 26 & 111.29 & $\$$ & 0.717 & $\$$ & 1.000 & $\$$ & 27.022 & $\$$ & 26.000 & $\$$ & 0.283 & $\$$ & $(1.022)$ \\
\hline 27 & 110.30 & $\$$ & 0.716 & $\$$ & 1.000 & $\$$ & 27.737 & $\$$ & 27.000 & $\$$ & 0.284 & $\$$ & $(0.737)$ \\
\hline 28 & 109.36 & $\$$ & 0.714 & $\$$ & 1.000 & $\$$ & 28.451 & $\$$ & 28.000 & $\$$ & 0.286 & $\$$ & $(0.451)$ \\
\hline 29 & 108.46 & $\$$ & 0.713 & $\$$ & 1.000 & $\$$ & 29.164 & $\$$ & 29.000 & $\$$ & 0.287 & $\$$ & $(0.164)$ \\
\hline 30 & 107.60 & $\$$ & 0.711 & $\$$ & 1.000 & $\$$ & 29.875 & $\$$ & 30.000 & $\$$ & 0.289 & $\$$ & 0.125 \\
\hline 31 & 106.77 & $\$$ & 0.710 & $\$$ & 1.000 & $\$$ & 30.585 & $\$$ & 31.000 & $\$$ & 0.290 & $\$$ & 0.415 \\
\hline 32 & 105.97 & $\$$ & 0.708 & $\$$ & 1.000 & $\$$ & 31.293 & $\$$ & 32.000 & $\$$ & 0.292 & $\$$ & 0.707 \\
\hline 33 & 105.21 & $\$$ & 0.707 & $\$$ & 1.000 & $\$$ & 32.000 & $\$$ & 33.000 & $\$$ & 0.293 & $\$$ & 1.000 \\
\hline 34 & 104.47 & $\$$ & 0.706 & $\$$ & 1.000 & $\$$ & 32.706 & $\$$ & 34.000 & $\$$ & 0.294 & $\$$ & 1.294 \\
\hline 35 & 103.76 & $\$$ & 0.705 & $\$$ & 1.000 & $\$$ & 33.411 & $\$$ & 35.000 & $\$$ & 0.295 & $\$$ & 1.589 \\
\hline 36 & 103.07 & $\$$ & 0.704 & $\$$ & 1.000 & $\$$ & 34.114 & $\$$ & 36.000 & $\$$ & 0.296 & $\$$ & 1.886 \\
\hline 37 & 102.41 & $\$$ & 0.702 & $\$$ & 1.000 & $\$$ & 34.817 & $\$$ & 37.000 & $\$$ & 0.298 & $\$$ & 2.183 \\
\hline 38 & 101.77 & $\$$ & 0.701 & $\$$ & 1.000 & $\$$ & 35.518 & $\$$ & 38.000 & $\$$ & 0.299 & $\$$ & 2.482 \\
\hline 39 & 101.14 & $\$$ & 0.700 & $\$$ & 1.000 & $\$$ & 36.218 & $\$$ & 39.000 & $\$$ & 0.300 & $\$$ & 2.782 \\
\hline 40 & 100.54 & $\$$ & 0.699 & $\$$ & 1.000 & $\$$ & 36.918 & $\$$ & 40.000 & $\$$ & 0.301 & $\$$ & 3.082 \\
\hline 41 & 99.96 & $\$$ & 0.698 & $\$$ & 1.000 & $\$$ & 37.616 & $\$$ & 41.000 & $\$$ & 0.302 & $\$$ & 3.384 \\
\hline 42 & 99.39 & $\$$ & 0.697 & $\$$ & 1.000 & $\$$ & 38.313 & $\$$ & 42.000 & $\$$ & 0.303 & $\$$ & 3.687 \\
\hline 43 & 98.84 & $\$$ & 0.696 & $\$$ & 1.000 & $\$$ & 39.010 & $\$$ & 43.000 & $\$$ & 0.304 & $\$$ & 3.990 \\
\hline 44 & 98.31 & $\$$ & 0.696 & $\$$ & 1.000 & $\$$ & 39.705 & $\$$ & 44.000 & $\$$ & 0.304 & $\$$ & 4.295 \\
\hline 45 & 97.79 & $\$$ & 0.695 & $\$$ & 1.000 & $\$$ & 40.400 & $\$$ & 45.000 & $\$$ & 0.305 & $\$$ & 4.600 \\
\hline 46 & 97.28 & $\$$ & 0.694 & $\$$ & 1.000 & $\$$ & 41.094 & $\$$ & 46.000 & $\$$ & 0.306 & $\$$ & 4.906 \\
\hline 47 & 96.79 & $\$$ & 0.693 & $\$$ & 1.000 & $\$$ & 41.787 & $\$$ & 47.000 & $\$$ & 0.307 & $\$$ & 5.213 \\
\hline 48 & 96.31 & $\$$ & 0.692 & $\$$ & 1.000 & $\$$ & 42.479 & $\$$ & 48.000 & $\$$ & 0.308 & $\$$ & 5.521 \\
\hline 49 & 95.85 & $\$$ & 0.691 & $\$$ & 1.000 & $\$$ & 43.171 & $\$$ & 49.000 & $\$$ & 0.309 & $\$$ & 5.829 \\
\hline 50 & 95.39 & $\$$ & 0.691 & $\$$ & 1.000 & $\$$ & 43.862 & $\$$ & 50.000 & $\$$ & 0.309 & $\$$ & 6.138 \\
\hline
\end{tabular}




\begin{tabular}{|c|c|c|c|c|c|c|c|c|c|c|c|c|c|}
\hline \multicolumn{14}{|c|}{ Manual Training Type Cumulative Profit Calculations (Continued) } \\
\hline $\begin{array}{l}\text { Report } \\
\text { number }\end{array}$ & $\begin{array}{c}\text { Time to produce } \\
\text { (secs) }\end{array}$ & & Cost & & nefit & & $\begin{array}{l}\text { Iulative } \\
\text { Cost }\end{array}$ & & $\begin{array}{l}\text { nulative } \\
\text { 3enefit }\end{array}$ & & $\begin{array}{l}\text { rginal } \\
\text { eturn }\end{array}$ & & Profit \\
\hline 51 & 94.95 & $\$$ & 0.690 & $\$$ & 1.000 & $\$$ & 44.552 & $\$$ & 51.000 & $\$$ & 0.310 & $\$$ & 6.448 \\
\hline 52 & 94.51 & $\$$ & 0.689 & $\$$ & 1.000 & $\$$ & 45.241 & $\$$ & 52.000 & $\$$ & 0.311 & $\$$ & 6.759 \\
\hline 53 & 94.09 & $\$$ & 0.689 & $\$$ & 1.000 & $\$$ & 45.929 & $\$$ & 53.000 & $\$$ & 0.311 & $\$$ & 7.071 \\
\hline 54 & 93.68 & $\$$ & 0.688 & $\$$ & 1.000 & $\$$ & 46.617 & $\$$ & 54.000 & $\$$ & 0.312 & $\$$ & 7.383 \\
\hline 55 & 93.27 & $\$$ & 0.687 & $\$$ & 1.000 & $\$$ & 47.304 & $\$$ & 55.000 & $\$$ & 0.313 & $\$$ & 7.696 \\
\hline 56 & 92.88 & $\$$ & 0.687 & $\$$ & 1.000 & $\$$ & 47.991 & $\$$ & 56.000 & $\$$ & 0.313 & $\$$ & 8.009 \\
\hline 57 & 92.49 & $\$$ & 0.686 & $\$$ & 1.000 & $\$$ & 48.677 & $\$$ & 57.000 & $\$$ & 0.314 & $\$$ & 8.323 \\
\hline 58 & 92.11 & $\$$ & 0.685 & $\$$ & 1.000 & $\$$ & 49.362 & $\$$ & 58.000 & $\$$ & 0.315 & $\$$ & 8.638 \\
\hline 59 & 91.74 & $\$$ & 0.685 & $\$$ & 1.000 & $\$$ & 50.047 & $\$$ & 59.000 & $\$$ & 0.315 & $\$$ & 8.953 \\
\hline 60 & 91.38 & $\$$ & 0.684 & $\$$ & 1.000 & $\$$ & 50.731 & $\$$ & 60.000 & $\$$ & 0.316 & $\$$ & 9.269 \\
\hline 61 & 91.02 & $\$$ & 0.683 & $\$$ & 1.000 & $\$$ & 51.414 & $\$$ & 61.000 & $\$$ & 0.317 & $\$$ & 9.586 \\
\hline 62 & 90.68 & $\$$ & 0.683 & $\$$ & 1.000 & $\$$ & 52.097 & $\$$ & 62.000 & $\$$ & 0.317 & $\$$ & 9.903 \\
\hline 63 & 90.33 & $\$$ & 0.682 & $\$$ & 1.000 & $\$$ & 52.779 & $\$$ & 63.000 & $\$$ & 0.318 & $\$$ & 10.221 \\
\hline 64 & 90.00 & $\$$ & 0.682 & $\$$ & 1.000 & $\$$ & 53.461 & $\$$ & 64.000 & $\$$ & 0.318 & $\$$ & 10.539 \\
\hline 65 & 89.67 & $\$$ & 0.681 & $\$$ & 1.000 & $\$$ & 54.142 & $\$$ & 65.000 & $\$$ & 0.319 & $\$$ & 10.858 \\
\hline 66 & 89.35 & $\$$ & 0.681 & $\$$ & 1.000 & $\$$ & 54.823 & $\$$ & 66.000 & $\$$ & 0.319 & $\$$ & 11.177 \\
\hline 67 & 89.03 & $\$$ & 0.680 & $\$$ & 1.000 & $\$$ & 55.503 & $\$$ & 67.000 & $\$$ & 0.320 & $\$$ & 11.497 \\
\hline 68 & 88.72 & $\$$ & 0.680 & $\$$ & 1.000 & $\$$ & 56.183 & $\$$ & 68.000 & $\$$ & 0.320 & $\$$ & 11.817 \\
\hline 69 & 88.42 & $\$$ & 0.679 & $\$$ & 1.000 & $\$$ & 56.862 & $\$$ & 69.000 & $\$$ & 0.321 & $\$$ & 12.138 \\
\hline 70 & 88.12 & $\$$ & 0.679 & $\$$ & 1.000 & $\$$ & 57.540 & $\$$ & 70.000 & $\$$ & 0.321 & $\$$ & 12.460 \\
\hline 71 & 87.82 & $\$$ & 0.678 & $\$$ & 1.000 & $\$$ & 58.219 & $\$$ & 71.000 & $\$$ & 0.322 & $\$$ & 12.781 \\
\hline 72 & 87.54 & $\$$ & 0.678 & $\$$ & 1.000 & $\$$ & 58.896 & $\$$ & 72.000 & $\$$ & 0.322 & $\$$ & 13.104 \\
\hline 73 & 87.25 & $\$$ & 0.677 & $\$$ & 1.000 & $\$$ & 59.573 & $\$$ & 73.000 & $\$$ & 0.323 & $\$$ & 13.427 \\
\hline 74 & 86.97 & $\$$ & 0.677 & $\$$ & 1.000 & $\$$ & 60.250 & $\$$ & 74.000 & $\$$ & 0.323 & $\$$ & 13.750 \\
\hline 75 & 86.70 & $\$$ & 0.676 & $\$$ & 1.000 & $\$$ & 60.926 & $\$$ & 75.000 & $\$$ & 0.324 & $\$$ & 14.074 \\
\hline 76 & 86.43 & $\$$ & 0.676 & $\$$ & 1.000 & $\$$ & 61.602 & $\$$ & 76.000 & $\$$ & 0.324 & $\$$ & 14.398 \\
\hline 77 & 86.16 & $\$$ & 0.675 & $\$$ & 1.000 & $\$$ & 62.277 & $\$$ & 77.000 & $\$$ & 0.325 & $\$$ & 14.723 \\
\hline 78 & 85.90 & $\$$ & 0.675 & $\$$ & 1.000 & $\$$ & 62.952 & $\$$ & 78.000 & $\$$ & 0.325 & $\$$ & 15.048 \\
\hline 79 & 85.64 & $\$$ & 0.674 & $\$$ & 1.000 & $\$$ & 63.627 & $\$$ & 79.000 & $\$$ & 0.326 & $\$$ & 15.373 \\
\hline 80 & 85.39 & $\$$ & 0.674 & $\$$ & 1.000 & $\$$ & 64.301 & $\$$ & 80.000 & $\$$ & 0.326 & $\$$ & 15.699 \\
\hline 81 & 85.14 & $\$$ & 0.674 & $\$$ & 1.000 & $\$$ & 64.975 & $\$$ & 81.000 & $\$$ & 0.326 & $\$$ & 16.025 \\
\hline 82 & 84.89 & $\$$ & 0.673 & $\$$ & 1.000 & $\$$ & 65.648 & $\$$ & 82.000 & $\$$ & 0.327 & $\$$ & 16.352 \\
\hline 83 & 84.65 & $\$$ & 0.673 & $\$$ & 1.000 & $\$$ & 66.321 & $\$$ & 83.000 & $\$$ & 0.327 & $\$$ & 16.679 \\
\hline 84 & 84.41 & $\$$ & 0.672 & $\$$ & 1.000 & $\$$ & 66.993 & $\$$ & 84.000 & $\$$ & 0.328 & $\$$ & 17.007 \\
\hline 85 & 84.18 & $\$$ & 0.672 & $\$$ & 1.000 & $\$$ & 67.665 & $\$$ & 85.000 & $\$$ & 0.328 & $\$$ & 17.335 \\
\hline 86 & 83.95 & $\$$ & 0.672 & $\$$ & 1.000 & $\$$ & 68.337 & $\$$ & 86.000 & $\$$ & 0.328 & $\Phi$ & 17.663 \\
\hline 87 & 83.72 & $\$$ & 0.671 & $\$$ & 1.000 & $\$$ & 69.008 & $\$$ & 87.000 & $\$$ & 0.329 & $\$$ & 17.992 \\
\hline 88 & 83.49 & $\$$ & 0.671 & $\$$ & 1.000 & $\$$ & 69.679 & $\$$ & 88.000 & $\$$ & 0.329 & $\$$ & 18.321 \\
\hline 89 & 83.27 & $\$$ & 0.671 & $\$$ & 1.000 & $\$$ & 70.349 & $\$$ & 89.000 & $\$$ & 0.329 & $\$$ & 18.651 \\
\hline 90 & 83.05 & $\$$ & 0.670 & $\$$ & 1.000 & $\$$ & 71.020 & $\$$ & 90.000 & $\$$ & 0.330 & $\$$ & 18.980 \\
\hline 91 & 82.83 & $\$$ & 0.670 & $\$$ & 1.000 & $\$$ & 71.689 & $\$$ & 91.000 & $\$$ & 0.330 & $\$$ & 19.311 \\
\hline 92 & 82.62 & $\$$ & 0.669 & $\$$ & 1.000 & $\$$ & 72.359 & $\$$ & 92.000 & $\$$ & 0.331 & $\$$ & 19.641 \\
\hline 93 & 82.41 & $\$$ & 0.669 & $\$$ & 1.000 & $\$$ & 73.028 & $\$$ & 93.000 & $\$$ & 0.331 & $\$$ & 19.972 \\
\hline 94 & 82.20 & $\$$ & 0.669 & $\$$ & 1.000 & $\$$ & 73.697 & $\$$ & 94.000 & $\$$ & 0.331 & $\$$ & 20.303 \\
\hline 95 & 82.00 & $\$$ & 0.668 & $\$$ & 1.000 & $\$$ & 74.365 & $\$$ & 95.000 & $\$$ & 0.332 & $\$$ & 20.635 \\
\hline 96 & 81.80 & $\$$ & 0.668 & $\$$ & 1.000 & $\$$ & 75.033 & $\$$ & 96.000 & $\$$ & 0.332 & $\$$ & 20.967 \\
\hline 97 & 81.60 & $\$$ & 0.668 & $\$$ & 1.000 & $\$$ & 75.701 & $\$$ & 97.000 & $\$$ & 0.332 & $\$$ & 21.299 \\
\hline 98 & 81.40 & $\$$ & 0.667 & $\$$ & 1.000 & $\$$ & 76.368 & $\$$ & 98.000 & $\$$ & 0.333 & $\Phi$ & 21.632 \\
\hline 99 & 81.21 & $\$$ & 0.667 & $\$$ & 1.000 & $\$$ & 77.035 & $\$$ & 99.000 & $\$$ & 0.333 & $\$$ & 21.965 \\
\hline 100 & 81.01 & $\$$ & 0.667 & $\$$ & 1.000 & $\$$ & 77.702 & $\$$ & 100.000 & $\$$ & 0.333 & $\$$ & 22.298 \\
\hline
\end{tabular}




\begin{tabular}{|c|c|c|c|c|c|c|c|c|c|c|c|c|c|}
\hline \multicolumn{14}{|c|}{ Class Training Type Cumulative Profit Calculations } \\
\hline $\begin{array}{l}\text { Report } \\
\text { number }\end{array}$ & $\begin{array}{l}\text { Time to produce } \\
\text { (secs) }\end{array}$ & & Cost & & nefit & & $\begin{array}{l}\text { ulative } \\
\text { ost }\end{array}$ & & $\begin{array}{l}\text { ulative } \\
\text { nefit }\end{array}$ & & $\begin{array}{l}\text { Irginal } \\
\text { eturn }\end{array}$ & & Profit \\
\hline 0 & & $\$$ & 4.230 & $\$$ & - & $\$$ & 4.230 & $\$$ & - & $\$$ & $(4.230)$ & $\$$ & $(4.230)$ \\
\hline 1 & 117.70 & $\$$ & 0.728 & $\$$ & 0.965 & $\$$ & 4.958 & $\$$ & 0.965 & $\$$ & 0.237 & $\$$ & $(3.993)$ \\
\hline 2 & 107.31 & $\$$ & 0.711 & $\$$ & 0.965 & $\$$ & 5.670 & $\$$ & 1.930 & $\$$ & 0.254 & $\$$ & $(3.740)$ \\
\hline 3 & 101.67 & $\$$ & 0.702 & $\$$ & 0.965 & $\$$ & 6.371 & $\$$ & 2.895 & $\$$ & 0.263 & $\$$ & $(3.476)$ \\
\hline 4 & 97.84 & $\$$ & 0.695 & $\$$ & 0.965 & $\$$ & 7.067 & $\$$ & 3.860 & $\$$ & 0.270 & $\$$ & (3.207) \\
\hline 5 & 94.97 & $\$$ & 0.691 & $\$$ & 0.965 & $\$$ & 7.757 & $\$$ & 4.825 & $\$$ & 0.274 & $\$$ & $(2.932)$ \\
\hline 6 & 92.69 & $\$$ & 0.687 & $\$$ & 0.965 & $\$$ & 8.444 & $\$$ & 5.790 & $\$$ & 0.278 & $\$$ & $(2.654)$ \\
\hline 7 & 90.81 & $\$$ & 0.684 & $\$$ & 0.965 & $\$$ & 9.128 & $\$$ & 6.755 & $\$$ & 0.281 & $\$$ & $(2.373)$ \\
\hline 8 & 89.21 & $\$$ & 0.681 & $\$$ & 0.965 & $\$$ & 9.809 & $\$$ & 7.720 & $\$$ & 0.284 & $\$$ & $(2.089)$ \\
\hline 9 & 87.82 & $\$$ & 0.679 & $\$$ & 0.965 & $\$$ & 10.487 & $\$$ & 8.685 & $\$$ & 0.286 & $\$$ & $(1.802)$ \\
\hline 10 & 86.59 & $\$$ & 0.677 & $\$$ & 0.965 & $\$$ & 11.164 & $\$$ & 9.650 & $\$$ & 0.288 & $\$$ & $(1.514)$ \\
\hline 11 & 85.50 & $\$$ & 0.675 & $\$$ & 0.965 & $\$$ & 11.839 & $\$$ & 10.615 & $\$$ & 0.290 & $\$$ & $(1.224)$ \\
\hline 12 & 84.51 & $\$$ & 0.673 & $\$$ & 0.965 & $\$$ & 12.512 & $\$$ & 11.580 & $\$$ & 0.292 & $\$$ & $(0.932)$ \\
\hline 13 & 83.62 & $\$$ & 0.672 & $\$$ & 0.965 & $\$$ & 13.183 & $\$$ & 12.545 & $\$$ & 0.293 & $\$$ & $(0.638)$ \\
\hline 14 & 82.79 & $\$$ & 0.670 & $\$$ & 0.965 & $\$$ & 13.854 & $\$$ & 13.510 & $\$$ & 0.295 & $\$$ & $(0.344)$ \\
\hline 15 & 82.04 & $\$$ & 0.669 & $\$$ & 0.965 & $\$$ & 14.523 & $\$$ & 14.475 & $\$$ & 0.296 & $\$$ & $(0.048)$ \\
\hline 16 & 81.33 & $\$$ & 0.668 & $\$$ & 0.965 & $\$$ & 15.190 & $\$$ & 15.440 & $\$$ & 0.297 & $\$$ & 0.250 \\
\hline 17 & 80.68 & $\$$ & 0.667 & $\$$ & 0.965 & $\$$ & 15.857 & $\$$ & 16.405 & $\$$ & 0.298 & $\$$ & 0.548 \\
\hline 18 & 80.07 & $\$$ & 0.666 & $\$$ & 0.965 & $\$$ & 16.523 & $\$$ & 17.370 & $\$$ & 0.299 & $\$$ & 0.847 \\
\hline 19 & 79.49 & $\$$ & 0.665 & $\$$ & 0.965 & $\$$ & 17.188 & $\$$ & 18.335 & $\$$ & 0.300 & $\$$ & 1.147 \\
\hline 20 & 78.95 & $\$$ & 0.664 & $\$$ & 0.965 & $\$$ & 17.852 & $\$$ & 19.300 & $\$$ & 0.301 & $\$$ & 1.448 \\
\hline 21 & 78.44 & $\$$ & 0.663 & $\$$ & 0.965 & $\$$ & 18.515 & $\$$ & 20.265 & $\$$ & 0.302 & $\$$ & 1.750 \\
\hline 22 & 77.95 & $\$$ & 0.662 & $\$$ & 0.965 & $\$$ & 19.177 & $\$$ & 21.230 & $\$$ & 0.303 & $\$$ & 2.053 \\
\hline 23 & 77.49 & $\$$ & 0.661 & $\$$ & 0.965 & $\$$ & 19.838 & $\$$ & 22.195 & $\$$ & 0.304 & $\$$ & 2.357 \\
\hline 24 & 77.05 & $\$$ & 0.661 & $\$$ & 0.965 & $\$$ & 20.499 & $\$$ & 23.160 & $\$$ & 0.304 & $\$$ & 2.661 \\
\hline 25 & 76.64 & $\$$ & 0.660 & $\$$ & 0.965 & $\$$ & 21.159 & $\$$ & 24.125 & $\$$ & 0.305 & $\$$ & 2.966 \\
\hline 26 & 76.24 & $\$$ & 0.659 & $\$$ & 0.965 & $\$$ & 21.818 & $\$$ & 25.090 & $\$$ & 0.306 & $\$$ & 3.272 \\
\hline 27 & 75.85 & $\$$ & 0.659 & $\$$ & 0.965 & $\$$ & 22.477 & $\$$ & 26.055 & $\$$ & 0.306 & $\$$ & 3.578 \\
\hline 28 & 75.49 & $\$$ & 0.658 & $\$$ & 0.965 & $\$$ & 23.135 & $\$$ & 27.020 & $\$$ & 0.307 & $\$$ & 3.885 \\
\hline 29 & 75.13 & $\$$ & 0.658 & $\$$ & 0.965 & $\$$ & 23.793 & $\$$ & 27.985 & $\$$ & 0.307 & $\$$ & 4.192 \\
\hline 30 & 74.80 & $\$$ & 0.657 & $\$$ & 0.965 & $\$$ & 24.450 & $\$$ & 28.950 & $\$$ & 0.308 & $\$$ & 4.500 \\
\hline 31 & 74.47 & $\$$ & 0.656 & $\$$ & 0.965 & $\$$ & 25.106 & $\$$ & 29.915 & $\$$ & 0.309 & $\$$ & 4.809 \\
\hline 32 & 74.15 & $\$$ & 0.656 & $\$$ & 0.965 & $\$$ & 25.762 & $\$$ & 30.880 & $\$$ & 0.309 & $\$$ & 5.118 \\
\hline 33 & 73.85 & $\$$ & 0.655 & $\$$ & 0.965 & $\$$ & 26.417 & $\$$ & 31.845 & $\$$ & 0.310 & $\$$ & 5.428 \\
\hline 34 & 73.56 & $\$$ & 0.655 & $\$$ & 0.965 & $\$$ & 27.072 & $\$$ & 32.810 & $\$$ & 0.310 & $\$$ & 5.738 \\
\hline 35 & 73.27 & $\$$ & 0.654 & $\$$ & 0.965 & $\$$ & 27.726 & $\$$ & 33.775 & $\$$ & 0.311 & $\$$ & 6.049 \\
\hline 36 & 73.00 & $\$$ & 0.654 & $\$$ & 0.965 & $\$$ & 28.380 & $\$$ & 34.740 & $\$$ & 0.311 & $\$$ & 6.360 \\
\hline 37 & 72.73 & $\$$ & 0.654 & $\$$ & 0.965 & $\$$ & 29.034 & $\$$ & 35.705 & $\$$ & 0.311 & $\$$ & 6.671 \\
\hline 38 & 72.48 & $\$$ & 0.653 & $\$$ & 0.965 & $\$$ & 29.687 & $\$$ & 36.670 & $\$$ & 0.312 & $\$$ & 6.983 \\
\hline 39 & 72.23 & $\$$ & 0.653 & $\$$ & 0.965 & $\$$ & 30.340 & $\$$ & 37.635 & $\$$ & 0.312 & $\$$ & 7.295 \\
\hline 40 & 71.98 & $\$$ & 0.652 & $\$$ & 0.965 & $\$$ & 30.992 & $\$$ & 38.600 & $\$$ & 0.313 & $\$$ & 7.608 \\
\hline 41 & 71.75 & $\$$ & 0.652 & $\$$ & 0.965 & $\$$ & 31.644 & $\$$ & 39.565 & $\$$ & 0.313 & $\$$ & 7.921 \\
\hline 42 & 71.52 & $\$$ & 0.651 & $\$$ & 0.965 & $\$$ & 32.295 & $\$$ & 40.530 & $\$$ & 0.314 & $\$$ & 8.235 \\
\hline 43 & 71.29 & $\$$ & 0.651 & $\$$ & 0.965 & $\$$ & 32.946 & $\$$ & 41.495 & $\$$ & 0.314 & $\$$ & 8.549 \\
\hline 44 & 71.07 & $\$$ & 0.651 & $\$$ & 0.965 & $\$$ & 33.597 & $\$$ & 42.460 & $\$$ & 0.314 & $\$$ & 8.863 \\
\hline 45 & 70.86 & $\$$ & 0.650 & $\$$ & 0.965 & $\$$ & 34.247 & $\$$ & 43.425 & $\$$ & 0.315 & $\$$ & 9.178 \\
\hline 46 & 70.65 & $\$$ & 0.650 & $\$$ & 0.965 & $\$$ & 34.897 & $\$$ & 44.390 & $\$$ & 0.315 & $\$$ & 9.493 \\
\hline 47 & 70.45 & $\$$ & 0.650 & $\$$ & 0.965 & $\$$ & 35.547 & $\$$ & 45.355 & $\$$ & 0.315 & $\$$ & 9.808 \\
\hline 48 & 70.25 & $\$$ & 0.649 & $\$$ & 0.965 & $\$$ & 36.196 & $\$$ & 46.320 & $\$$ & 0.316 & $\$$ & 10.124 \\
\hline 49 & 70.06 & $\$$ & 0.649 & $\$$ & 0.965 & $\$$ & 36.846 & $\$$ & 47.285 & $\$$ & 0.316 & $\$$ & 10.439 \\
\hline 50 & 69.87 & $\$$ & 0.649 & $\$$ & 0.965 & $\$$ & 37.494 & $\$$ & 48.250 & $\$$ & 0.316 & $\$$ & 10.756 \\
\hline
\end{tabular}




\begin{tabular}{|c|c|c|c|c|c|c|c|c|c|c|c|c|c|}
\hline \multicolumn{14}{|c|}{ Class Training Type Cumulative Profit Calculations (Continued) } \\
\hline $\begin{array}{l}\text { Report } \\
\text { number }\end{array}$ & $\begin{array}{l}\text { Time to produce } \\
\text { (secs) }\end{array}$ & & ost & & nefit & & $\begin{array}{l}\text { Iulative } \\
\text { ost }\end{array}$ & & $\begin{array}{l}\text { ulative } \\
\text { nefit }\end{array}$ & & $\begin{array}{l}\text { rginal } \\
\text { turn }\end{array}$ & & Profit \\
\hline 51 & 69.69 & $\$$ & 0.648 & $\$$ & 0.965 & $\$$ & 38.143 & $\$$ & 49.215 & $\$$ & 0.317 & $\$$ & 11.072 \\
\hline 52 & 69.51 & $\$$ & 0.648 & $\$$ & 0.965 & $\$$ & 38.791 & $\$$ & 50.180 & $\$$ & 0.317 & $\$$ & 11.389 \\
\hline 53 & 69.33 & $\$$ & 0.648 & $\$$ & 0.965 & $\$$ & 39.439 & $\$$ & 51.145 & $\$$ & 0.317 & $\$$ & 11.706 \\
\hline 54 & 69.16 & $\$$ & 0.648 & $\$$ & 0.965 & $\$$ & 40.086 & $\$$ & 52.110 & $\$$ & 0.317 & $\$$ & 12.024 \\
\hline 55 & 68.99 & $\$$ & 0.647 & $\$$ & 0.965 & $\$$ & 40.733 & $\$$ & 53.075 & $\$$ & 0.318 & $\$$ & 12.342 \\
\hline 56 & 68.82 & $\$$ & 0.647 & $\$$ & 0.965 & $\$$ & 41.380 & $\$$ & 54.040 & $\$$ & 0.318 & $\$$ & 12.660 \\
\hline 57 & 68.66 & $\$$ & 0.647 & $\$$ & 0.965 & $\$$ & 42.027 & $\$$ & 55.005 & $\$$ & 0.318 & $\$$ & 12.978 \\
\hline 58 & 68.50 & $\$$ & 0.646 & $\$$ & 0.965 & $\$$ & 42.674 & $\$$ & 55.970 & $\$$ & 0.319 & $\$$ & 13.296 \\
\hline 59 & 68.35 & $\$$ & 0.646 & $\$$ & 0.965 & $\$$ & 43.320 & $\$$ & 56.935 & $\$$ & 0.319 & $\$$ & 13.615 \\
\hline 60 & 68.19 & $\$$ & 0.646 & $\$$ & 0.965 & $\$$ & 43.966 & $\$$ & 57.900 & $\$$ & 0.319 & $\$$ & 13.934 \\
\hline 61 & 68.04 & $\$$ & 0.646 & $\$$ & 0.965 & $\$$ & 44.611 & $\$$ & 58.865 & $\$$ & 0.319 & $\$$ & 14.254 \\
\hline 62 & 67.90 & $\$$ & 0.645 & $\$$ & 0.965 & $\$$ & 45.257 & $\$$ & 59.830 & $\$$ & 0.320 & $\$$ & 14.573 \\
\hline 63 & 67.75 & $\$$ & 0.645 & $\$$ & 0.965 & $\$$ & 45.902 & $\$$ & 60.795 & $\$$ & 0.320 & $\$$ & 14.893 \\
\hline 64 & 67.61 & $\$$ & 0.645 & $\$$ & 0.965 & $\$$ & 46.547 & $\$$ & 61.760 & $\$$ & 0.320 & $\$$ & 15.213 \\
\hline 65 & 67.47 & $\$$ & 0.645 & $\$$ & 0.965 & $\$$ & 47.192 & $\$$ & 62.725 & $\$$ & 0.320 & $\$$ & 15.533 \\
\hline 66 & 67.33 & $\$$ & 0.645 & $\$$ & 0.965 & $\$$ & 47.836 & $\$$ & 63.690 & $\$$ & 0.320 & $\$$ & 15.854 \\
\hline 67 & 67.20 & $\$$ & 0.644 & $\$$ & 0.965 & $\$$ & 48.481 & $\$$ & 64.655 & $\$$ & 0.321 & $\$$ & 16.174 \\
\hline 68 & 67.07 & $\$$ & 0.644 & $\$$ & 0.965 & $\$$ & 49.125 & $\$$ & 65.620 & $\$$ & 0.321 & $\$$ & 16.495 \\
\hline 69 & 66.94 & $\$$ & 0.644 & $\$$ & 0.965 & $\$$ & 49.768 & $\$$ & 66.585 & $\$$ & 0.321 & $\$$ & 16.817 \\
\hline 70 & 66.81 & $\$$ & 0.644 & $\$$ & 0.965 & $\$$ & 50.412 & $\$$ & 67.550 & $\$$ & 0.321 & $\$$ & 17.138 \\
\hline 71 & 66.68 & $\$$ & 0.643 & $\$$ & 0.965 & $\$$ & 51.055 & $\$$ & 68.515 & $\$$ & 0.322 & $\$$ & 17.460 \\
\hline 72 & 66.56 & $\$$ & 0.643 & $\$$ & 0.965 & $\$$ & 51.699 & $\$$ & 69.480 & $\$$ & 0.322 & $\$$ & 17.781 \\
\hline 73 & 66.43 & $\$$ & 0.643 & $\$$ & 0.965 & $\$$ & 52.342 & $\$$ & 70.445 & $\$$ & 0.322 & $\$$ & 18.103 \\
\hline 74 & 66.31 & $\$$ & 0.643 & $\$$ & 0.965 & $\$$ & 52.985 & $\$$ & 71.410 & $\$$ & 0.322 & $\$$ & 18.425 \\
\hline 75 & 66.20 & $\$$ & 0.643 & $\$$ & 0.965 & $\$$ & 53.627 & $\$$ & 72.375 & $\$$ & 0.322 & $\$$ & 18.748 \\
\hline 76 & 66.08 & $\$$ & 0.642 & $\$$ & 0.965 & $\$$ & 54.270 & $\$$ & 73.340 & $\$$ & 0.323 & $\$$ & 19.070 \\
\hline 77 & 65.96 & $\$$ & 0.642 & $\$$ & 0.965 & $\$$ & 54.912 & $\$$ & 74.305 & $\$$ & 0.323 & $\$$ & 19.393 \\
\hline 78 & 65.85 & $\$$ & 0.642 & $\$$ & 0.965 & $\$$ & 55.554 & $\$$ & 75.270 & $\$$ & 0.323 & $\$$ & 19.716 \\
\hline 79 & 65.74 & $\$$ & 0.642 & $\$$ & 0.965 & $\$$ & 56.196 & $\$$ & 76.235 & $\$$ & 0.323 & $\$$ & 20.039 \\
\hline 80 & 65.63 & $\$$ & 0.642 & $\$$ & 0.965 & $\$$ & 56.837 & $\$$ & 77.200 & $\$$ & 0.323 & $\$$ & 20.363 \\
\hline 81 & 65.52 & $\$$ & 0.641 & $\$$ & 0.965 & $\$$ & 57.479 & $\$$ & 78.165 & $\$$ & 0.324 & $\$$ & 20.686 \\
\hline 82 & 65.41 & $\$$ & 0.641 & $\$$ & 0.965 & $\$$ & 58.120 & $\$$ & 79.130 & $\$$ & 0.324 & $\$$ & 21.010 \\
\hline 83 & 65.31 & $\$$ & 0.641 & $\$$ & 0.965 & $\$$ & 58.761 & $\$$ & 80.095 & $\$$ & 0.324 & $\$$ & 21.334 \\
\hline 84 & 65.20 & $\$$ & 0.641 & $\$$ & 0.965 & $\$$ & 59.402 & $\$$ & 81.060 & $\$$ & 0.324 & $\$$ & 21.658 \\
\hline 85 & 65.10 & $\$$ & 0.641 & $\$$ & 0.965 & $\$$ & 60.043 & $\$$ & 82.025 & $\$$ & 0.324 & $\$$ & 21.982 \\
\hline 86 & 65.00 & $\$$ & 0.641 & $\$$ & 0.965 & $\$$ & 60.684 & $\$$ & 82.990 & $\$$ & 0.324 & $\$$ & 22.306 \\
\hline 87 & 64.90 & $\$$ & 0.640 & $\$$ & 0.965 & $\$$ & 61.324 & $\$$ & 83.955 & $\$$ & 0.325 & $\$$ & 22.631 \\
\hline 88 & 64.80 & $\$$ & 0.640 & $\$$ & 0.965 & $\$$ & 61.964 & $\$$ & 84.920 & $\$$ & 0.325 & $\$$ & 22.956 \\
\hline 89 & 64.70 & $\$$ & 0.640 & $\$$ & 0.965 & $\$$ & 62.604 & $\$$ & 85.885 & $\$$ & 0.325 & $\$$ & 23.281 \\
\hline 90 & 64.61 & $\$$ & 0.640 & $\$$ & 0.965 & $\$$ & 63.244 & $\$$ & 86.850 & $\$$ & 0.325 & $\$$ & 23.606 \\
\hline 91 & 64.51 & $\$$ & 0.640 & $\$$ & 0.965 & $\$$ & 63.884 & $\$$ & 87.815 & $\$$ & 0.325 & $\$$ & 23.931 \\
\hline 92 & 64.42 & $\$$ & 0.640 & $\$$ & 0.965 & $\$$ & 64.524 & $\$$ & 88.780 & $\$$ & 0.325 & $\$$ & 24.256 \\
\hline 93 & 64.32 & $\$$ & 0.639 & $\$$ & 0.965 & $\$$ & 65.163 & $\$$ & 89.745 & $\$$ & 0.326 & $\$$ & 24.582 \\
\hline 94 & 64.23 & $\$$ & 0.639 & $\$$ & 0.965 & $\$$ & 65.803 & $\$$ & 90.710 & $\$$ & 0.326 & $\$$ & 24.907 \\
\hline 95 & 64.14 & $\$$ & 0.639 & $\$$ & 0.965 & $\$$ & 66.442 & $\$$ & 91.675 & $\$$ & 0.326 & $\$$ & 25.233 \\
\hline 96 & 64.05 & $\$$ & 0.639 & $\$$ & 0.965 & $\$$ & 67.081 & $\$$ & 92.640 & $\$$ & 0.326 & $\$$ & 25.559 \\
\hline 97 & 63.96 & $\$$ & 0.639 & $\$$ & 0.965 & $\$$ & 67.720 & $\$$ & 93.605 & $\$$ & 0.326 & $\$$ & 25.885 \\
\hline 98 & 63.88 & $\$$ & 0.639 & $\$$ & 0.965 & $\$$ & 68.358 & $\$$ & 94.570 & $\$$ & 0.326 & $\$$ & 26.212 \\
\hline 99 & 63.79 & $\$$ & 0.639 & $\$$ & 0.965 & $\$$ & 68.997 & $\$$ & 95.535 & $\$$ & 0.326 & $\$$ & 26.538 \\
\hline 100 & 63.71 & $\$$ & 0.638 & $\$$ & 0.965 & $\$$ & 69.636 & $\$$ & 96.500 & $\$$ & 0.327 & $\$$ & 26.864 \\
\hline
\end{tabular}




\begin{tabular}{|c|c|c|c|c|c|c|c|c|c|c|c|c|c|}
\hline \multicolumn{14}{|c|}{ Mentor/Manual Training Type Cumulative Profit Calculations } \\
\hline $\begin{array}{l}\text { Report } \\
\text { number }\end{array}$ & $\begin{array}{l}\text { Time to produce } \\
\text { (secs) }\end{array}$ & & st & & nefit & & $\begin{array}{l}\text { ulative } \\
\text { ost }\end{array}$ & & $\begin{array}{l}\text { ulative } \\
\text { nefit }\end{array}$ & & $\begin{array}{l}\text { Irginal } \\
\text { eturn }\end{array}$ & & ofit \\
\hline 0 & & $\$$ & 9.030 & $\$$ & - & $\$$ & 9.030 & $\$$ & - & & (9.030) & $\$$ & $(9.030)$ \\
\hline 1 & 200.03 & $\$$ & 0.867 & $\$$ & 0.972 & $\$$ & 9.897 & $\$$ & 0.972 & $\$$ & 0.105 & $\$$ & $(8.925)$ \\
\hline 2 & 173.93 & $\$$ & 0.824 & $\$$ & 0.972 & $\$$ & 10.721 & $\$$ & 1.944 & $\$$ & 0.148 & $\$$ & $(8.777)$ \\
\hline 3 & 160.27 & $\$$ & 0.801 & $\$$ & 0.972 & $\$$ & 11.522 & $\$$ & 2.916 & $\$$ & 0.171 & $\$$ & $(8.606)$ \\
\hline 4 & 151.24 & $\$$ & 0.786 & $\$$ & 0.972 & $\$$ & 12.308 & $\$$ & 3.888 & $\$$ & 0.186 & $\$$ & $(8.420)$ \\
\hline 5 & 144.58 & $\$$ & 0.775 & $\$$ & 0.972 & $\$$ & 13.083 & $\$$ & 4.860 & $\$$ & 0.197 & $\$$ & $(8.223)$ \\
\hline 6 & 139.36 & $\$$ & 0.766 & $\$$ & 0.972 & $\$$ & 13.849 & $\$$ & 5.832 & $\$$ & 0.206 & $\$$ & $(8.017)$ \\
\hline 7 & 135.09 & $\$$ & 0.759 & $\$$ & 0.972 & $\$$ & 14.608 & $\$$ & 6.804 & $\$$ & 0.213 & $\$$ & $(7.804)$ \\
\hline 8 & 131.50 & $\$$ & 0.753 & $\$$ & 0.972 & $\$$ & 15.361 & $\$$ & 7.776 & $\$$ & 0.219 & $\$$ & $(7.585)$ \\
\hline 9 & 128.42 & $\$$ & 0.748 & $\$$ & 0.972 & $\$$ & 16.109 & $\$$ & 8.748 & $\$$ & 0.224 & $\$$ & $(7.361)$ \\
\hline 10 & 125.72 & $\$$ & 0.743 & $\$$ & 0.972 & $\$$ & 16.852 & $\$$ & 9.720 & $\$$ & 0.229 & $\$$ & $(7.132)$ \\
\hline 11 & 123.32 & $\$$ & 0.739 & $\$$ & 0.972 & $\$$ & 17.591 & $\$$ & 10.692 & $\$$ & 0.233 & $\$$ & $(6.899)$ \\
\hline 12 & 121.18 & $\$$ & 0.736 & $\$$ & 0.972 & $\$$ & 18.327 & $\$$ & 11.664 & $\$$ & 0.236 & $\$$ & $(6.663)$ \\
\hline 13 & 119.24 & $\$$ & 0.733 & $\$$ & 0.972 & $\$$ & 19.060 & $\$$ & 12.636 & $\$$ & 0.239 & $\$$ & $(6.424)$ \\
\hline 14 & 117.47 & $\$$ & 0.730 & $\$$ & 0.972 & $\$$ & 19.789 & $\$$ & 13.608 & $\$$ & 0.242 & $\$$ & $(6.181)$ \\
\hline 15 & 115.85 & $\$$ & 0.727 & $\$$ & 0.972 & $\$$ & 20.516 & $\$$ & 14.580 & $\$$ & 0.245 & $\$$ & $(5.936)$ \\
\hline 16 & 114.35 & $\$$ & 0.724 & $\$$ & 0.972 & $\$$ & 21.241 & $\$$ & 15.552 & $\$$ & 0.248 & $\$$ & $(5.689)$ \\
\hline 17 & 112.96 & $\$$ & 0.722 & $\$$ & 0.972 & $\$$ & 21.963 & $\$$ & 16.524 & $\$$ & 0.250 & $\$$ & $(5.439)$ \\
\hline 18 & 111.66 & $\$$ & 0.720 & $\$$ & 0.972 & $\$$ & 22.683 & $\$$ & 17.496 & $\$$ & 0.252 & $\$$ & $(5.187)$ \\
\hline 19 & 110.45 & $\$$ & 0.718 & $\$$ & 0.972 & $\$$ & 23.401 & $\$$ & 18.468 & $\$$ & 0.254 & $\$$ & $(4.933)$ \\
\hline 20 & 109.31 & $\$$ & 0.716 & $\$$ & 0.972 & $\$$ & 24.117 & $\$$ & 19.440 & $\$$ & 0.256 & $\$$ & $(4.677)$ \\
\hline 21 & 108.24 & $\$$ & 0.714 & $\$$ & 0.972 & $\$$ & 24.831 & $\$$ & 20.412 & $\$$ & 0.258 & $\$$ & $(4.419)$ \\
\hline 22 & 107.23 & $\$$ & 0.713 & $\$$ & 0.972 & $\$$ & 25.543 & $\$$ & 21.384 & $\$$ & 0.259 & $\$$ & $(4.159)$ \\
\hline 23 & 106.28 & $\$$ & 0.711 & $\$$ & 0.972 & $\$$ & 26.254 & $\$$ & 22.356 & $\$$ & 0.261 & $\$$ & (3.898) \\
\hline 24 & 105.37 & $\$$ & 0.709 & $\$$ & 0.972 & $\$$ & 26.964 & $\$$ & 23.328 & $\$$ & 0.263 & $\$$ & $(3.636)$ \\
\hline 25 & 104.50 & $\$$ & 0.708 & $\$$ & 0.972 & $\$$ & 27.672 & $\$$ & 24.300 & $\$$ & 0.264 & $\$$ & $(3.372)$ \\
\hline 26 & 103.68 & $\$$ & 0.707 & $\$$ & 0.972 & $\$$ & 28.379 & $\$$ & 25.272 & $\$$ & 0.265 & $\$$ & $(3.107)$ \\
\hline 27 & 102.89 & $\$$ & 0.705 & $\$$ & 0.972 & $\$$ & 29.084 & $\$$ & 26.244 & $\$$ & 0.267 & $\$$ & $(2.840)$ \\
\hline 28 & 102.14 & $\$$ & 0.704 & $\$$ & 0.972 & $\$$ & 29.788 & $\$$ & 27.216 & $\$$ & 0.268 & $\$$ & $(2.572)$ \\
\hline 29 & 101.42 & $\$$ & 0.703 & $\$$ & 0.972 & $\$$ & 30.491 & $\$$ & 28.188 & $\$$ & 0.269 & $\$$ & (2.303) \\
\hline 30 & 100.73 & $\$$ & 0.702 & $\$$ & 0.972 & $\$$ & 31.193 & $\$$ & 29.160 & $\$$ & 0.270 & $\$$ & $(2.033)$ \\
\hline 31 & 100.07 & $\$$ & 0.701 & $\$$ & 0.972 & $\$$ & 31.893 & $\$$ & 30.132 & $\$$ & 0.271 & $\$$ & (1.761) \\
\hline 32 & 99.43 & $\$$ & 0.700 & $\$$ & 0.972 & $\$$ & 32.593 & $\$$ & 31.104 & $\$$ & 0.272 & $\$$ & $(1.489)$ \\
\hline 33 & 98.81 & $\$$ & 0.699 & $\$$ & 0.972 & $\$$ & 33.291 & $\$$ & 32.076 & $\$$ & 0.273 & $\$$ & $(1.215)$ \\
\hline 34 & 98.22 & $\$$ & 0.698 & $\$$ & 0.972 & $\$$ & 33.989 & $\$$ & 33.048 & $\$$ & 0.274 & $\$$ & $(0.941)$ \\
\hline 35 & 97.65 & $\$$ & 0.697 & $\$$ & 0.972 & $\$$ & 34.685 & $\$$ & 34.020 & $\$$ & 0.275 & $\$$ & $(0.665)$ \\
\hline 36 & 97.09 & $\$$ & 0.696 & $\$$ & 0.972 & $\$$ & 35.381 & $\$$ & 34.992 & $\$$ & 0.276 & $\$$ & $(0.389)$ \\
\hline 37 & 96.56 & $\$$ & 0.695 & $\$$ & 0.972 & $\$$ & 36.076 & $\$$ & 35.964 & $\$$ & 0.277 & $\$$ & $(0.112)$ \\
\hline 38 & 96.04 & $\$$ & 0.694 & $\$$ & 0.972 & $\$$ & 36.770 & $\$$ & 36.936 & $\$$ & 0.278 & $\$$ & 0.166 \\
\hline 39 & 95.54 & $\$$ & 0.693 & $\$$ & 0.972 & $\$$ & 37.463 & $\$$ & 37.908 & $\$$ & 0.279 & $\$$ & 0.445 \\
\hline 40 & 95.05 & $\$$ & 0.692 & $\$$ & 0.972 & $\$$ & 38.155 & $\$$ & 38.880 & $\$$ & 0.280 & $\$$ & 0.725 \\
\hline 41 & 94.58 & $\$$ & 0.691 & $\$$ & 0.972 & $\$$ & 38.847 & $\$$ & 39.852 & $\$$ & 0.281 & $\$$ & 1.005 \\
\hline 42 & 94.12 & $\$$ & 0.691 & $\$$ & 0.972 & $\$$ & 39.537 & $\$$ & 40.824 & $\$$ & 0.281 & $\$$ & 1.287 \\
\hline 43 & 93.68 & $\$$ & 0.690 & $\$$ & 0.972 & $\$$ & 40.227 & $\$$ & 41.796 & $\$$ & 0.282 & $\$$ & 1.569 \\
\hline 44 & 93.24 & $\$$ & 0.689 & $\$$ & 0.972 & $\$$ & 40.916 & $\$$ & 42.768 & $\$$ & 0.283 & $\$$ & 1.852 \\
\hline 45 & 92.82 & $\$$ & 0.689 & $\$$ & 0.972 & $\$$ & 41.605 & $\$$ & 43.740 & $\$$ & 0.283 & $\$$ & 2.135 \\
\hline 46 & 92.41 & $\$$ & 0.688 & $\$$ & 0.972 & $\$$ & 42.293 & $\$$ & 44.712 & $\$$ & 0.284 & $\$$ & 2.419 \\
\hline 47 & 92.01 & $\$$ & 0.687 & $\$$ & 0.972 & $\$$ & 42.980 & $\$$ & 45.684 & $\$$ & 0.285 & $\$$ & 2.704 \\
\hline 48 & 91.62 & $\$$ & 0.687 & $\$$ & 0.972 & $\$$ & 43.667 & $\$$ & 46.656 & $\$$ & 0.285 & $\$$ & 2.989 \\
\hline 49 & 91.24 & $\$$ & 0.686 & $\$$ & 0.972 & $\$$ & 44.352 & $\$$ & 47.628 & $\$$ & 0.286 & $\$$ & 3.276 \\
\hline 50 & 90.87 & $\$$ & 0.685 & $\$$ & 0.972 & $\$$ & 45.038 & $\$$ & 48.600 & $\$$ & 0.287 & $\$$ & 3.562 \\
\hline
\end{tabular}




\begin{tabular}{|c|c|c|c|c|c|c|c|c|c|c|c|c|c|}
\hline \multicolumn{14}{|c|}{ Mentor/Manual Training Type Cumulative Profit Calculations (Continued) } \\
\hline $\begin{array}{l}\text { Report } \\
\text { number }\end{array}$ & $\begin{array}{l}\text { Time to produce } \\
\text { (secs) }\end{array}$ & & & & nefit & & $\begin{array}{l}\text { ulative } \\
\text { ost }\end{array}$ & & $\begin{array}{l}\text { ulative } \\
\text { nefit }\end{array}$ & & $\begin{array}{l}\text { rginal } \\
\text { turn }\end{array}$ & & fit \\
\hline 51 & 90.51 & $\$$ & 0.685 & $\$$ & 0.972 & $\$$ & 45.722 & $\$$ & 49.572 & $\$$ & 0.287 & $\$$ & 3.850 \\
\hline 52 & 90.15 & $\$$ & 0.684 & $\$$ & 0.972 & $\$$ & 46.407 & $\$$ & 50.544 & $\$$ & 0.288 & $\$$ & 4.137 \\
\hline 53 & 89.81 & $\$$ & 0.684 & $\$$ & 0.972 & $\$$ & 47.090 & $\$$ & 51.516 & $\$$ & 0.288 & $\$$ & 4.426 \\
\hline 54 & 89.47 & $\$$ & 0.683 & $\$$ & 0.972 & $\$$ & 47.773 & $\$$ & 52.488 & $\$$ & 0.289 & $\$$ & 4.715 \\
\hline 55 & 89.14 & $\$$ & 0.682 & \$ & 0.972 & $\$$ & 48.455 & $\$$ & 53.460 & $\$$ & 0.290 & $\$$ & 5.005 \\
\hline 56 & 88.81 & $\$$ & 0.682 & $\$$ & 0.972 & $\$$ & 49.137 & $\$$ & 54.432 & $\$$ & 0.290 & $\$$ & 5.295 \\
\hline 57 & 88.50 & $\$$ & 0.681 & \$ & 0.972 & $\$$ & 49.819 & $\$$ & 55.404 & $\$$ & 0.291 & $\$$ & 5.585 \\
\hline 58 & 88.19 & $\$$ & 0.681 & $\$$ & 0.972 & $\$$ & 50.499 & $\$$ & 56.376 & $\$$ & 0.291 & $\$$ & 5.877 \\
\hline 59 & 87.88 & $\$$ & 0.680 & $\$$ & 0.972 & $\$$ & 51.180 & $\$$ & 57.348 & $\$$ & 0.292 & $\$$ & 6.168 \\
\hline 60 & 87.59 & $\$$ & 0.680 & $\$$ & 0.972 & $\$$ & 51.860 & $\$$ & 58.320 & $\$$ & 0.292 & $\$$ & 6.460 \\
\hline 61 & 87.30 & $\$$ & 0.679 & $\$$ & 0.972 & $\$$ & 52.539 & $\$$ & 59.292 & $\$$ & 0.293 & $\$$ & 6.753 \\
\hline 62 & 87.01 & $\$$ & 0.679 & $\$$ & 0.972 & $\$$ & 53.218 & $\$$ & 60.264 & $\$$ & 0.293 & $\$$ & 7.046 \\
\hline 63 & 86.73 & $\$$ & 0.678 & $\$$ & 0.972 & $\$$ & 53.896 & $\$$ & 61.236 & $\$$ & 0.294 & $\$$ & 7.340 \\
\hline 64 & 86.45 & $\$$ & 0.678 & $\$$ & 0.972 & $\$$ & 54.574 & $\$$ & 62.208 & $\$$ & 0.294 & $\$$ & 7.634 \\
\hline 65 & 86.18 & $\$$ & 0.677 & $\$$ & 0.972 & $\$$ & 55.252 & $\$$ & 63.180 & $\$$ & 0.295 & $\$$ & 7.928 \\
\hline 66 & 85.92 & $\$$ & 0.677 & $\$$ & 0.972 & $\$$ & 55.929 & $\$$ & 64.152 & $\$$ & 0.295 & $\$$ & 8.223 \\
\hline 67 & 85.66 & $\$$ & 0.677 & $\$$ & 0.972 & $\$$ & 56.605 & $\$$ & 65.124 & $\$$ & 0.295 & $\$$ & 8.519 \\
\hline 68 & 85.40 & $\$$ & 0.676 & $\$$ & 0.972 & $\$$ & 57.281 & $\$$ & 66.096 & $\$$ & 0.296 & $\$$ & 8.815 \\
\hline 69 & 85.15 & $\$$ & 0.676 & $\$$ & 0.972 & $\$$ & 57.957 & $\$$ & 67.068 & $\$$ & 0.296 & $\$$ & 9.111 \\
\hline 70 & 84.91 & $\$$ & 0.675 & $\$$ & 0.972 & $\$$ & 58.633 & $\$$ & 68.040 & $\$$ & 0.297 & $\$$ & 9.407 \\
\hline 71 & 84.66 & $\$$ & 0.675 & $\$$ & 0.972 & $\$$ & 59.307 & $\$$ & 69.012 & $\$$ & 0.297 & $\$$ & 9.705 \\
\hline 72 & 84.43 & $\$$ & 0.675 & $\$$ & 0.972 & $\$$ & 59.982 & $\$$ & 69.984 & $\$$ & 0.297 & $\$$ & 10.002 \\
\hline 73 & 84.19 & $\$$ & 0.674 & $\$$ & 0.972 & $\$$ & 60.656 & $\$$ & 70.956 & $\$$ & 0.298 & $\$$ & 10.300 \\
\hline 74 & 83.96 & $\$$ & 0.674 & $\$$ & 0.972 & $\$$ & 61.330 & $\$$ & 71.928 & $\$$ & 0.298 & $\$$ & 10.598 \\
\hline 75 & 83.73 & $\$$ & 0.673 & $\$$ & 0.972 & $\$$ & 62.003 & $\$$ & 72.900 & $\$$ & 0.299 & $\$$ & 10.897 \\
\hline 76 & 83.51 & $\$$ & 0.673 & $\$$ & 0.972 & $\$$ & 62.676 & $\$$ & 73.872 & $\$$ & 0.299 & $\$$ & 11.196 \\
\hline 77 & 83.29 & $\$$ & 0.673 & $\$$ & 0.972 & $\$$ & 63.349 & $\$$ & 74.844 & $\$$ & 0.299 & $\$$ & 11.495 \\
\hline 78 & 83.07 & $\$$ & 0.672 & $\$$ & 0.972 & $\$$ & 64.021 & $\$$ & 75.816 & $\$$ & 0.300 & $\$$ & 11.795 \\
\hline 79 & 82.86 & $\$$ & 0.672 & $\$$ & 0.972 & $\$$ & 64.693 & $\$$ & 76.788 & $\$$ & 0.300 & $\$$ & 12.095 \\
\hline 80 & 82.65 & $\$$ & 0.672 & $\$$ & 0.972 & $\$$ & 65.365 & $\$$ & 77.760 & $\$$ & 0.300 & $\$$ & 12.395 \\
\hline 81 & 82.44 & $\$$ & 0.671 & $\$$ & 0.972 & $\$$ & 66.036 & $\$$ & 78.732 & $\$$ & 0.301 & $\$$ & 12.696 \\
\hline 82 & 82.24 & $\$$ & 0.671 & $\$$ & 0.972 & $\$$ & 66.707 & $\$$ & 79.704 & $\$$ & 0.301 & $\$$ & 12.997 \\
\hline 83 & 82.04 & $\$$ & 0.671 & $\$$ & 0.972 & $\$$ & 67.378 & $\$$ & 80.676 & $\$$ & 0.301 & $\$$ & 13.298 \\
\hline 84 & 81.84 & $\$$ & 0.670 & $\$$ & 0.972 & $\$$ & 68.048 & $\$$ & 81.648 & $\$$ & 0.302 & $\$$ & 13.600 \\
\hline 85 & 81.65 & $\$$ & 0.670 & $\$$ & 0.972 & $\$$ & 68.718 & $\$$ & 82.620 & $\$$ & 0.302 & $\$$ & 13.902 \\
\hline 86 & 81.45 & $\$$ & 0.670 & $\$$ & 0.972 & $\$$ & 69.387 & $\$$ & 83.592 & $\$$ & 0.302 & $\$$ & 14.205 \\
\hline 87 & 81.26 & $\$$ & 0.669 & $\$$ & 0.972 & $\$$ & 70.057 & $\$$ & 84.564 & $\$$ & 0.303 & $\$$ & 14.507 \\
\hline 88 & 81.08 & $\$$ & 0.669 & $\$$ & 0.972 & $\$$ & 70.726 & $\$$ & 85.536 & $\$$ & 0.303 & $\$$ & 14.810 \\
\hline 89 & 80.89 & $\$$ & 0.669 & $\$$ & 0.972 & $\$$ & 71.394 & $\$$ & 86.508 & $\$$ & 0.303 & $\$$ & 15.114 \\
\hline 90 & 80.71 & $\$$ & 0.668 & $\$$ & 0.972 & $\$$ & 72.063 & $\$$ & 87.480 & $\$$ & 0.304 & $\$$ & 15.417 \\
\hline 91 & 80.53 & $\$$ & 0.668 & $\$$ & 0.972 & $\$$ & 72.731 & $\$$ & 88.452 & $\$$ & 0.304 & $\$$ & 15.721 \\
\hline 92 & 80.35 & $\$$ & 0.668 & $\$$ & 0.972 & $\$$ & 73.398 & $\$$ & 89.424 & $\$$ & 0.304 & $\$$ & 16.026 \\
\hline 93 & 80.18 & $\$$ & 0.667 & $\$$ & 0.972 & $\$$ & 74.066 & $\$$ & 90.396 & $\$$ & 0.305 & $\$$ & 16.330 \\
\hline 94 & 80.00 & $\$$ & 0.667 & $\$$ & 0.972 & $\$$ & 74.733 & $\$$ & 91.368 & $\$$ & 0.305 & $\$$ & 16.635 \\
\hline 95 & 79.83 & $\$$ & 0.667 & $\$$ & 0.972 & $\$$ & 75.400 & $\$$ & 92.340 & $\$$ & 0.305 & $\$$ & 16.940 \\
\hline 96 & 79.67 & $\$$ & 0.667 & $\$$ & 0.972 & $\$$ & 76.067 & $\$$ & 93.312 & $\$$ & 0.305 & $\$$ & 17.245 \\
\hline 97 & 79.50 & $\$$ & 0.666 & $\$$ & 0.972 & $\$$ & 76.733 & $\$$ & 94.284 & $\$$ & 0.306 & $\$$ & 17.551 \\
\hline 98 & 79.34 & $\$$ & 0.666 & $\$$ & 0.972 & $\$$ & 77.399 & $\$$ & 95.256 & $\$$ & 0.306 & $\$$ & 17.857 \\
\hline 99 & 79.17 & $\$$ & 0.666 & $\$$ & 0.972 & $\$$ & 78.065 & $\$$ & 96.228 & $\$$ & 0.306 & $\$$ & 18.163 \\
\hline 100 & 79.01 & $\$$ & 0.666 & $\$$ & 0.972 & $\$$ & 78.730 & $\$$ & 97.200 & $\$$ & 0.306 & $\$$ & 18.470 \\
\hline
\end{tabular}


APPENDIX K:

BENEFIT VS. COST CHARTS AND

PROFIT CHARTS 

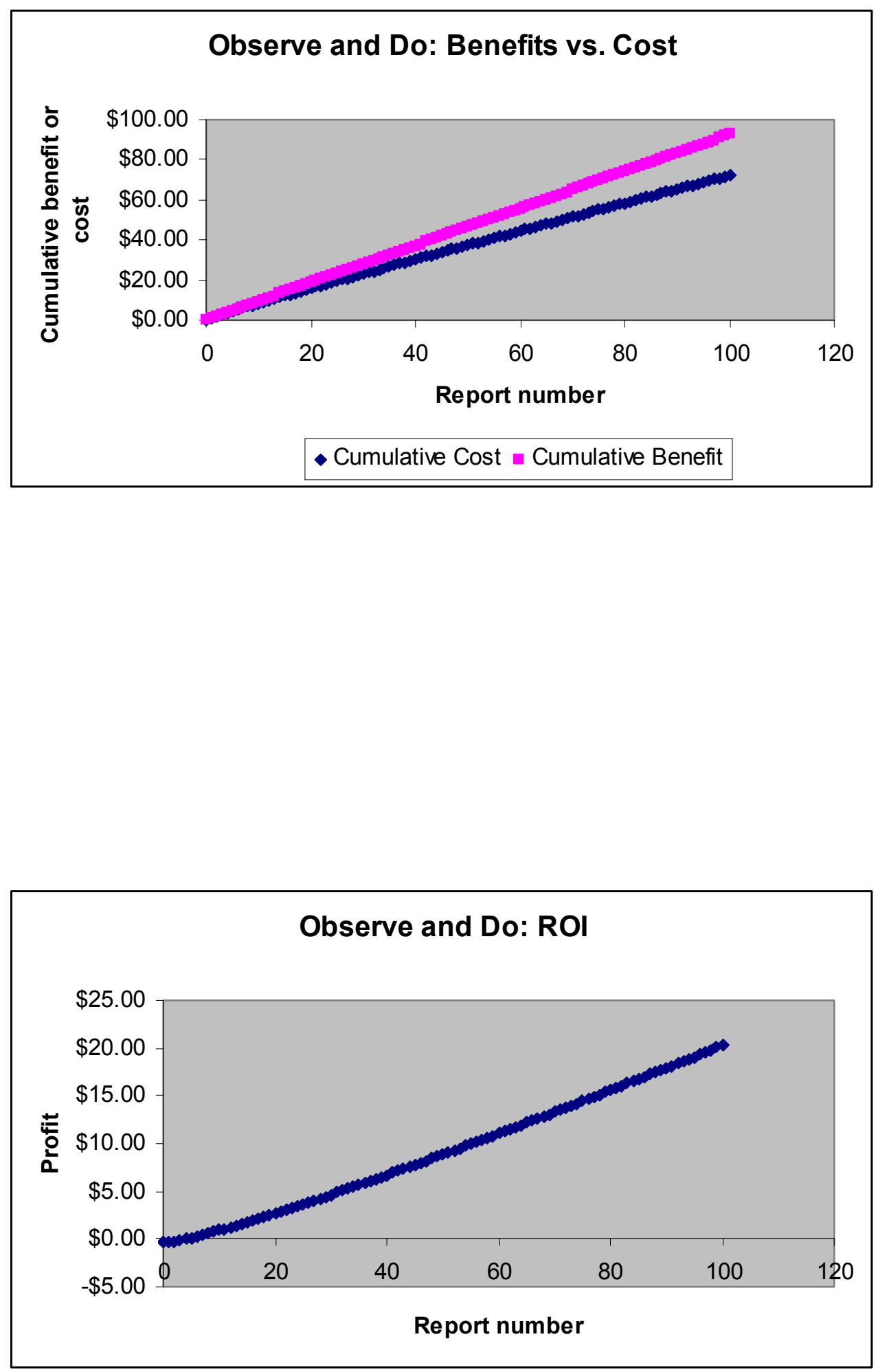

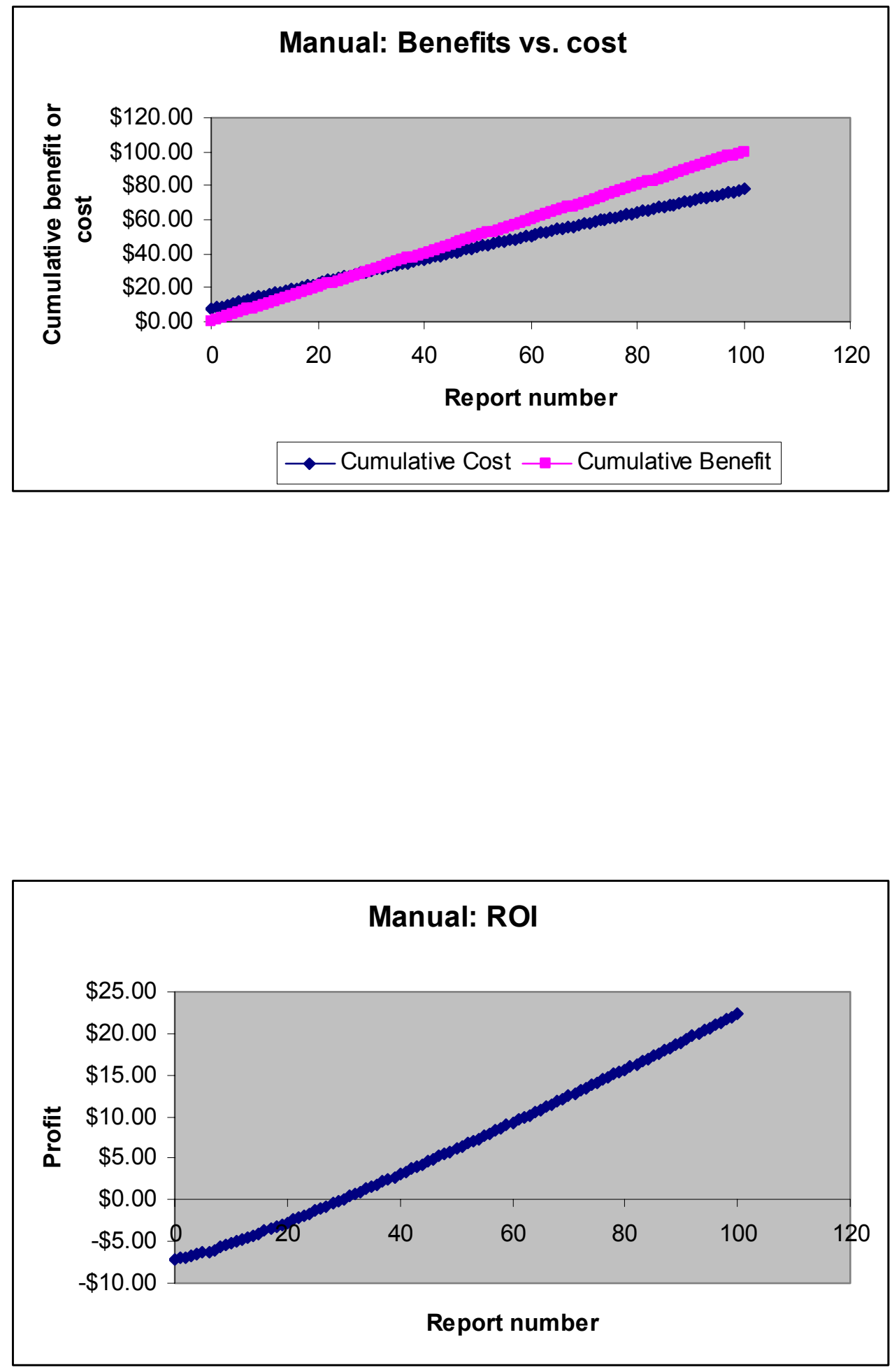

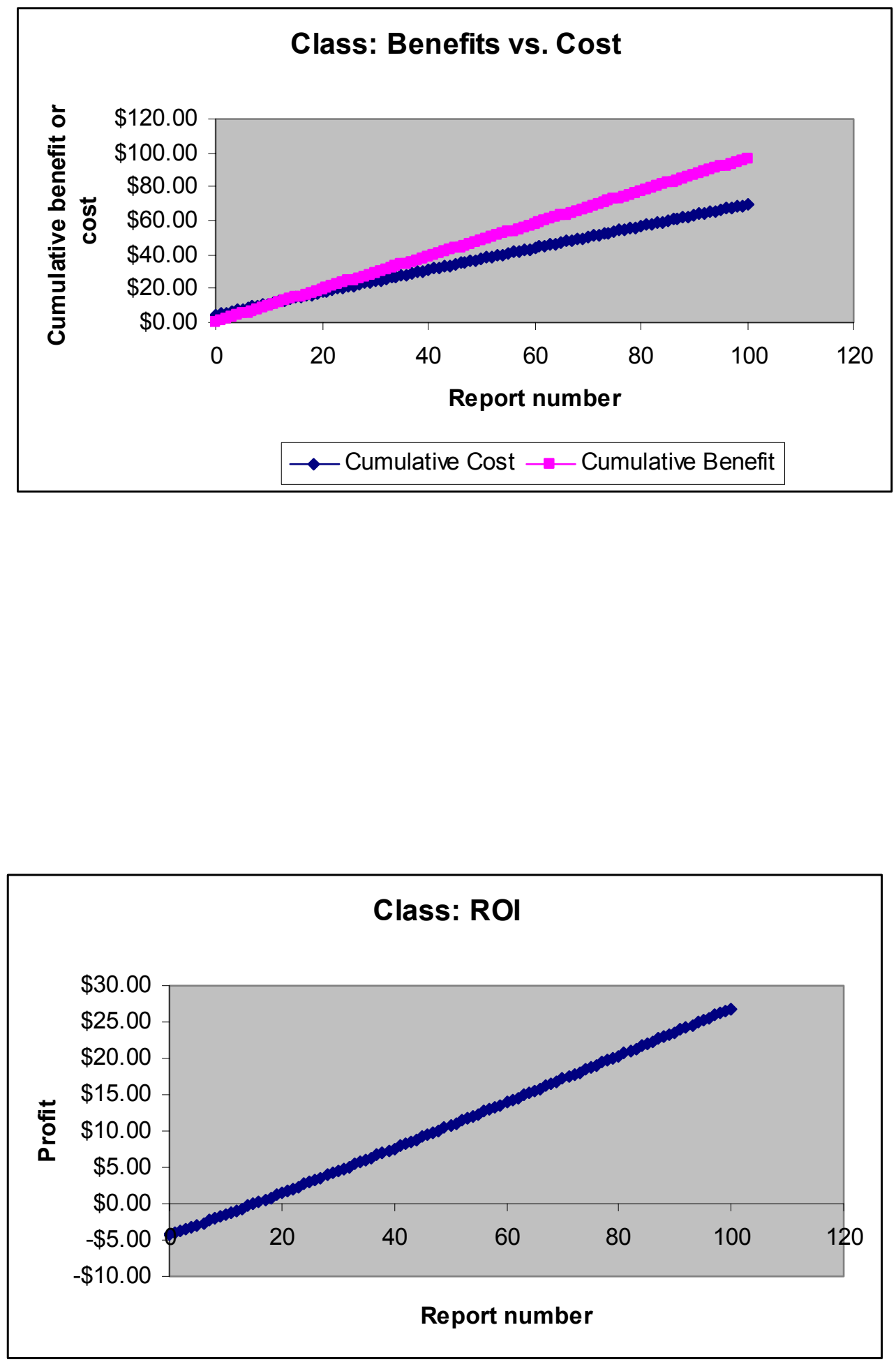

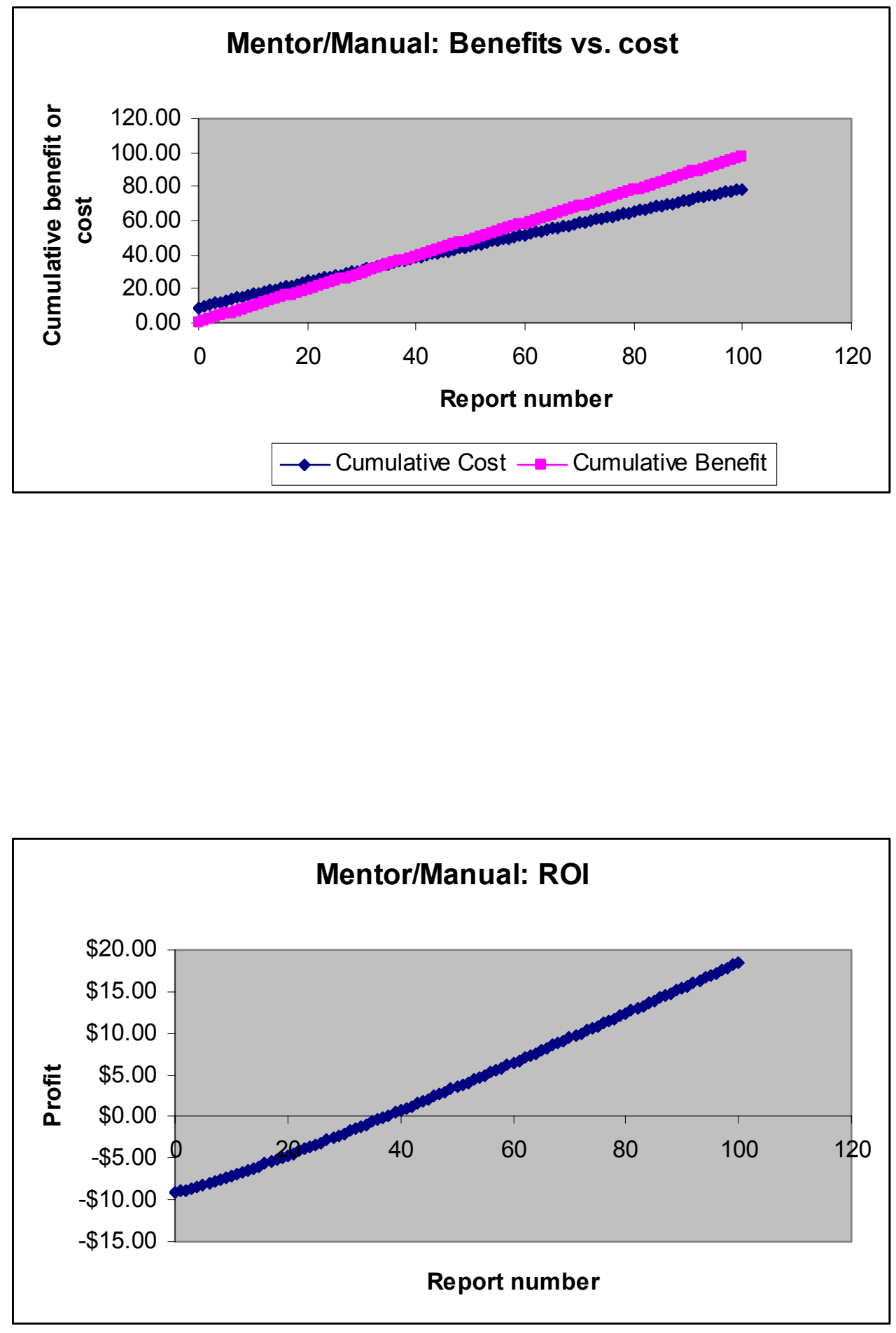
APPENDIX L:

ROI DATA 


\begin{tabular}{|c|c|c|c|c|c|c|c|c|c|c|c|c|c|}
\hline \multicolumn{7}{|c|}{ Manual: Profit } & \multicolumn{7}{|c|}{ Manual: Profit (Continued) } \\
\hline \multirow{2}{*}{$\frac{\text { Report number }}{0}$} & \multicolumn{2}{|c|}{ Manual } & \multicolumn{2}{|c|}{ Observe and Do } & \multicolumn{2}{|c|}{ Difference (ROI) } & \multirow{2}{*}{$\begin{array}{c}\text { Report number } \\
51\end{array}$} & \multicolumn{2}{|c|}{ Manual } & \multicolumn{2}{|c|}{ Observe and Do } & \multicolumn{2}{|c|}{ Difference (ROI) } \\
\hline & $\$$ & $(7.11)$ & $\$$ & $(0.360)$ & $\$$ & $(6.75)$ & & $\$$ & 6.45 & $\$$ & 9.074 & $\$$ & $(2.63)$ \\
\hline 1 & $\$$ & $(7.04)$ & $\$$ & $(0.309)$ & $\$$ & $(6.73)$ & 52 & $\$$ & 6.76 & $\$$ & 9.292 & $\$$ & $(2.53)$ \\
\hline 2 & $\$$ & (6.91) & $\$$ & $(0.219)$ & $\$$ & $(6.69)$ & 53 & $\$$ & 7.07 & $\$$ & 9.511 & $\$$ & $(2.44)$ \\
\hline 3 & $\$$ & $(6.75)$ & $\$$ & $(0.109)$ & $\$$ & $(6.64)$ & 54 & $\$$ & 7.38 & $\$$ & 9.730 & $\$$ & $(2.35)$ \\
\hline 4 & $\$$ & $(6.57)$ & $\$$ & 0.014 & $\$$ & $(6.59)$ & 55 & $\$$ & 7.70 & $\$$ & 9.950 & $\$$ & (2.25) \\
\hline 5 & $\$$ & (6.38) & $\$$ & 0.147 & $\$$ & (6.53) & 56 & $\$$ & 8.01 & $\$$ & 10.171 & $\$$ & $(2.16)$ \\
\hline 6 & $\$$ & (6.17) & $\$$ & 0.289 & $\$$ & (6.46) & 57 & $\$$ & 8.32 & $\$$ & 10.392 & $\$$ & (2.07) \\
\hline 7 & $\$$ & (5.96) & $\$$ & 0.436 & $\$$ & (6.39) & 58 & $\$$ & 8.64 & $\$$ & 10.613 & $\$$ & (1.98) \\
\hline 8 & $\$$ & (5.73) & $\$$ & 0.590 & $\$$ & (6.32) & 59 & $\$$ & 8.95 & $\$$ & 10.835 & $\$$ & (1.88) \\
\hline 9 & $\$$ & $(5.50)$ & $\$$ & 0.748 & $\$$ & $(6.25)$ & 60 & $\$$ & 9.27 & $\$$ & 11.058 & $\$$ & $(1.79)$ \\
\hline 10 & $\$$ & (5.27) & $\$$ & 0.910 & $\$$ & (6.18) & 61 & $\$$ & 9.59 & $\$$ & 11.281 & $\$$ & (1.69) \\
\hline 11 & $\$$ & (5.03) & $\$$ & 1.076 & $\$$ & (6.10) & 62 & $\$$ & 9.90 & $\$$ & 11.504 & $\$$ & $(1.60)$ \\
\hline 12 & $\$$ & (4.78) & $\$$ & 1.245 & $\$$ & $(6.03)$ & 63 & $\$$ & 10.22 & $\$$ & 11.728 & $\$$ & $(1.51)$ \\
\hline 13 & $\$$ & (4.53) & $\$$ & 1.417 & $\$$ & (5.95) & 64 & $\$$ & 10.54 & $\$$ & 11.952 & $\$$ & $(1.41)$ \\
\hline 14 & $\$$ & $(4.28)$ & $\$$ & 1.592 & $\$$ & (5.87) & 65 & $\$$ & 10.86 & $\$$ & 12.177 & $\$$ & (1.32) \\
\hline 15 & $\$$ & $(4.02)$ & $\$$ & 1.770 & $\$$ & $(5.79)$ & 66 & $\$$ & 11.18 & $\$$ & 12.402 & $\$$ & (1.23) \\
\hline 16 & $\$$ & (3.76) & $\$$ & 1.950 & $\$$ & (5.71) & 67 & $\$$ & 11.50 & $\$$ & 12.628 & $\$$ & (1.13) \\
\hline 17 & $\$$ & (3.50) & $\$$ & 2.132 & $\$$ & (5.63) & 68 & $\$$ & 11.82 & $\$$ & 12.854 & $\$$ & $(1.04)$ \\
\hline 18 & $\$$ & (3.23) & $\$$ & 2.316 & $\$$ & (5.55) & 69 & $\$$ & 12.14 & $\$$ & 13.080 & $\$$ & $(0.94)$ \\
\hline 19 & $\$$ & $(2.96)$ & $\$$ & 2.502 & $\$$ & (5.46) & 70 & $\$$ & 12.46 & $\$$ & 13.307 & $\$$ & $(0.85)$ \\
\hline 20 & $\$$ & (2.69) & $\$$ & 2.690 & $\$$ & (5.38) & 71 & $\$$ & 12.78 & $\$$ & 13.534 & $\$$ & $(0.75)$ \\
\hline 21 & $\$$ & $(2.42)$ & $\$$ & 2.879 & $\$$ & (5.30) & 72 & $\$$ & 13.10 & $\$$ & 13.762 & $\$$ & $(0.66)$ \\
\hline 22 & $\$$ & (2.14) & $\$$ & 3.070 & $\$$ & (5.21) & 73 & $\$$ & 13.43 & $\$$ & 13.990 & $\$$ & $(0.56)$ \\
\hline 23 & $\$$ & $(1.86)$ & $\$$ & 3.263 & $\$$ & (5.13) & 74 & $\$$ & 13.75 & $\$$ & 14.218 & $\$$ & $(0.47)$ \\
\hline 24 & $\$$ & $(1.59)$ & $\$$ & 3.457 & $\$$ & (5.04) & 75 & $\$$ & 14.07 & $\$$ & 14.447 & $\$$ & $(0.37)$ \\
\hline 25 & $\$$ & $(1.30)$ & $\$$ & 3.652 & $\$$ & $(4.96)$ & 76 & $\$$ & 14.40 & $\$$ & 14.676 & $\$$ & $(0.28)$ \\
\hline 26 & $\$$ & $(1.02)$ & $\$$ & 3.849 & $\$$ & (4.87) & 77 & $\$$ & 14.72 & $\$$ & 14.906 & $\$$ & $(0.18)$ \\
\hline 27 & $\$$ & $(0.74)$ & $\$$ & 4.047 & $\$$ & $(4.78)$ & 78 & $\$$ & 15.05 & $\$$ & 15.136 & $\$$ & $(0.09)$ \\
\hline 28 & $\$$ & $(0.45)$ & $\$$ & 4.246 & $\$$ & $(4.70)$ & 79 & $\$$ & 15.37 & $\$$ & 15.366 & $\$$ & 0.01 \\
\hline 29 & $\$$ & $(0.16)$ & $\$$ & 4.446 & $\$$ & (4.61) & 80 & $\$$ & 15.70 & $\$$ & 15.596 & $\$$ & 0.10 \\
\hline 30 & $\$$ & 0.12 & $\$$ & 4.647 & $\$$ & $(4.52)$ & 81 & $\$$ & 16.03 & $\$$ & 15.827 & $\$$ & 0.20 \\
\hline 31 & $\$$ & 0.42 & $\$$ & 4.850 & $\$$ & (4.43) & 82 & $\$$ & 16.35 & $\$$ & 16.058 & $\$$ & 0.29 \\
\hline 32 & $\$$ & 0.71 & $\$$ & 5.053 & $\$$ & (4.35) & 83 & $\$$ & 16.68 & $\$$ & 16.290 & $\$$ & 0.39 \\
\hline 33 & $\$$ & 1.00 & $\$$ & 5.258 & $\$$ & $(4.26)$ & 84 & $\$$ & 17.01 & $\$$ & 16.522 & $\$$ & 0.49 \\
\hline 34 & $\$$ & 1.29 & $\$$ & 5.463 & $\$$ & (4.17) & 85 & $\$$ & 17.33 & $\$$ & 16.754 & $\$$ & 0.58 \\
\hline 35 & $\$$ & 1.59 & $\$$ & 5.669 & $\$$ & $(4.08)$ & 86 & $\$$ & 17.66 & $\$$ & 16.986 & $\$$ & 0.68 \\
\hline 36 & $\$$ & 1.89 & $\$$ & 5.876 & $\$$ & (3.99) & 87 & $\$$ & 17.99 & $\$$ & 17.219 & $\$$ & 0.77 \\
\hline 37 & $\$$ & 2.18 & $\$$ & 6.084 & $\$$ & (3.90) & 88 & $\$$ & 18.32 & $\$$ & 17.452 & $\$$ & 0.87 \\
\hline 38 & $\$$ & 2.48 & $\$$ & 6.293 & $\$$ & (3.81) & 89 & $\$$ & 18.65 & $\$$ & 17.686 & $\$$ & 0.97 \\
\hline 39 & $\$$ & 2.78 & $\$$ & 6.503 & $\$$ & (3.72) & 90 & $\$$ & 18.98 & $\$$ & 17.919 & $\$$ & 1.06 \\
\hline 40 & $\$$ & 3.08 & $\$$ & 6.713 & $\$$ & (3.63) & 91 & $\$$ & 19.31 & $\$$ & 18.153 & $\$$ & 1.16 \\
\hline 41 & $\$$ & 3.38 & $\$$ & 6.924 & $\$$ & (3.54) & 92 & $\$$ & 19.64 & $\$$ & 18.388 & $\$$ & 1.25 \\
\hline 42 & $\$$ & 3.69 & $\$$ & 7.136 & $\$$ & (3.45) & 93 & $\$$ & 19.97 & $\$$ & 18.622 & $\$$ & 1.35 \\
\hline 43 & $\$$ & 3.99 & $\$$ & 7.349 & $\$$ & (3.36) & 94 & $\$$ & 20.30 & $\$$ & 18.857 & $\$$ & 1.45 \\
\hline 44 & $\$$ & 4.29 & $\$$ & 7.562 & $\$$ & (3.27) & 95 & $\$$ & 20.63 & $\$$ & 19.092 & $\$$ & 1.54 \\
\hline 45 & $\$$ & 4.60 & $\$$ & 7.776 & $\$$ & (3.18) & 96 & $\$$ & 20.97 & $\$$ & 19.328 & $\$$ & 1.64 \\
\hline 46 & $\$$ & 4.91 & $\$$ & 7.991 & $\$$ & (3.09) & 97 & $\$$ & 21.30 & $\$$ & 19.563 & $\$$ & 1.74 \\
\hline 47 & $\$$ & 5.21 & $\$$ & 8.206 & $\$$ & (2.99) & 98 & $\$$ & 21.63 & $\$$ & 19.799 & $\$$ & 1.83 \\
\hline 48 & $\$$ & 5.52 & $\$$ & 8.422 & $\$$ & $(2.90)$ & 99 & $\$$ & 21.96 & $\$$ & 20.035 & $\$$ & 1.93 \\
\hline 49 & $\$$ & 5.83 & $\$$ & 8.639 & $\$$ & (2.81) & 100 & $\$$ & 22.30 & $\$$ & 20.272 & $\$$ & 2.03 \\
\hline 50 & $\$$ & 6.14 & $\$$ & 8.856 & $\$$ & $(2.72)$ & & & & & & & \\
\hline
\end{tabular}




\begin{tabular}{|c|c|c|c|c|c|c|c|c|c|c|c|c|c|}
\hline \multicolumn{7}{|c|}{ Manual: Profit (Continued) } & \multicolumn{7}{|c|}{ Manual: Profit (Continued) } \\
\hline Report number & & Aanual & & ad Do & & ROI) & Report number & & anual & & d Do & & (ROI) \\
\hline 101 & $\$$ & 22.63 & $\$$ & 20.509 & $\$$ & 2.12 & 151 & $\$$ & 39.64 & $\$$ & 32.626 & $\$$ & 7.02 \\
\hline 102 & $\$$ & 22.97 & $\$$ & 20.746 & $\$$ & 2.22 & 152 & $\$$ & 39.99 & $\$$ & 32.873 & $\$$ & 7.12 \\
\hline 103 & $\$$ & 23.30 & $\$$ & 20.983 & $\$$ & 2.32 & 153 & $\$$ & 40.34 & $\$$ & 33.120 & $\$$ & 7.22 \\
\hline 104 & $\$$ & 23.63 & $\$$ & 21.220 & $\$$ & 2.41 & 154 & $\$$ & 40.68 & $\$$ & 33.367 & $\$$ & 7.32 \\
\hline 105 & $\$$ & 23.97 & $\$$ & 21.458 & $\$$ & 2.51 & 155 & $\$$ & 41.03 & $\$$ & 33.615 & $\$$ & 7.41 \\
\hline 106 & $\$$ & 24.30 & $\$$ & 21.696 & $\$$ & 2.61 & 156 & $\$$ & 41.38 & $\$$ & 33.863 & $\$$ & 7.51 \\
\hline 107 & $\$$ & 24.64 & $\$$ & 21.935 & $\$$ & 2.70 & 157 & $\$$ & 41.72 & $\$$ & 34.111 & $\$$ & 7.61 \\
\hline 108 & $\$$ & 24.97 & $\$$ & 22.173 & $\$$ & 2.80 & 158 & $\$$ & 42.07 & $\$$ & 34.359 & $\$$ & 7.71 \\
\hline 109 & $\$$ & 25.31 & $\$$ & 22.412 & $\$$ & 2.90 & 159 & $\$$ & 42.42 & $\$$ & 34.607 & $\$$ & 7.81 \\
\hline 110 & $\$$ & 25.65 & $\$$ & 22.651 & $\$$ & 3.00 & 160 & $\$$ & 42.76 & $\$$ & 34.855 & $\$$ & 7.91 \\
\hline 111 & $\$$ & 25.98 & $\$$ & 22.890 & $\$$ & 3.09 & 161 & $\$$ & 43.11 & $\$$ & 35.104 & $\$$ & 8.01 \\
\hline 112 & $\$$ & 26.32 & $\$$ & 23.129 & $\$$ & 3.19 & 162 & $\$$ & 43.46 & $\$$ & 35.352 & $\$$ & 8.11 \\
\hline 113 & $\$$ & 26.66 & $\$$ & 23.369 & $\$$ & 3.29 & 163 & $\$$ & 43.81 & $\$$ & 35.601 & $\$$ & 8.21 \\
\hline 114 & $\$$ & 26.99 & $\$$ & 23.609 & $\$$ & 3.39 & 164 & $\$$ & 44.16 & $\$$ & 35.850 & $\$$ & 8.31 \\
\hline 115 & $\$$ & 27.33 & $\$$ & 23.849 & $\$$ & 3.48 & 165 & $\$$ & 44.50 & $\$$ & 36.099 & $\$$ & 8.41 \\
\hline 116 & $\$$ & 27.67 & $\$$ & 24.089 & $\$$ & 3.58 & 166 & $\$$ & 44.85 & $\$$ & 36.348 & $\$$ & 8.50 \\
\hline 117 & $\$$ & 28.01 & $\$$ & 24.330 & $\$$ & 3.68 & 167 & $\$$ & 45.20 & $\$$ & 36.598 & $\$$ & 8.60 \\
\hline 118 & $\$$ & 28.35 & $\$$ & 24.571 & $\$$ & 3.78 & 168 & $\$$ & 45.55 & $\$$ & 36.847 & $\$$ & 8.70 \\
\hline 119 & $\$$ & 28.69 & $\$$ & 24.812 & $\$$ & 3.87 & 169 & $\$$ & 45.90 & $\$$ & 37.097 & $\$$ & 8.80 \\
\hline 120 & $\$$ & 29.02 & $\$$ & 25.053 & $\$$ & 3.97 & 170 & $\$$ & 46.25 & $\$$ & 37.347 & $\$$ & 8.90 \\
\hline 121 & $\$$ & 29.36 & $\$$ & 25.294 & $\$$ & 4.07 & 171 & $\$$ & 46.60 & $\$$ & 37.597 & $\$$ & 9.00 \\
\hline 122 & $\$$ & 29.70 & $\$$ & 25.536 & $\$$ & 4.17 & 172 & $\$$ & 46.95 & $\$$ & 37.847 & $\$$ & 9.10 \\
\hline 123 & $\$$ & 30.04 & $\$$ & 25.778 & $\$$ & 4.26 & 173 & $\$$ & 47.30 & $\$$ & 38.097 & $\$$ & 9.20 \\
\hline 124 & $\$$ & 30.38 & $\$$ & 26.020 & $\$$ & 4.36 & 174 & $\$$ & 47.65 & $\$$ & 38.347 & $\$$ & 9.30 \\
\hline 125 & $\$$ & 30.72 & $\$$ & 26.262 & $\$$ & 4.46 & 175 & $\$$ & 48.00 & $\$$ & 38.598 & $\$$ & 9.40 \\
\hline 126 & $\$$ & 31.06 & $\$$ & 26.504 & $\$$ & 4.56 & 176 & $\$$ & 48.35 & $\$$ & 38.848 & $\$$ & 9.50 \\
\hline 127 & $\$$ & 31.40 & $\$$ & 26.747 & $\$$ & 4.66 & 177 & $\$$ & 48.70 & $\$$ & 39.099 & $\$$ & 9.60 \\
\hline 128 & $\$$ & 31.74 & $\$$ & 26.990 & $\$$ & 4.75 & 178 & $\$$ & 49.05 & $\$$ & 39.350 & $\$$ & 9.70 \\
\hline 129 & $\$$ & 32.09 & $\$$ & 27.233 & $\$$ & 4.85 & 179 & $\$$ & 49.40 & $\$$ & 39.601 & $\$$ & 9.80 \\
\hline 130 & $\$$ & 32.43 & $\$$ & 27.476 & $\$$ & 4.95 & 180 & $\$$ & 49.75 & $\$$ & 39.852 & $\$$ & 9.90 \\
\hline 131 & $\$$ & 32.77 & $\$$ & 27.720 & $\$$ & 5.05 & 181 & $\$$ & 50.10 & $\$$ & 40.103 & $\$$ & 10.00 \\
\hline 132 & $\$$ & 33.11 & $\$$ & 27.963 & $\$$ & 5.15 & 182 & $\$$ & 50.45 & $\$$ & 40.355 & $\$$ & 10.10 \\
\hline 133 & $\$$ & 33.45 & $\$$ & 28.207 & $\$$ & 5.25 & 183 & $\$$ & 50.80 & $\$$ & 40.606 & $\$$ & 10.20 \\
\hline 134 & $\$$ & 33.79 & $\$$ & 28.451 & $\$$ & 5.34 & 184 & $\$$ & 51.15 & $\$$ & 40.858 & $\$$ & 10.29 \\
\hline 135 & $\$$ & 34.14 & $\$$ & 28.695 & $\$$ & 5.44 & 185 & $\$$ & 51.50 & $\$$ & 41.110 & $\$$ & 10.39 \\
\hline 136 & $\$$ & 34.48 & $\$$ & 28.939 & $\$$ & 5.54 & 186 & $\$$ & 51.86 & $\$$ & 41.362 & $\$$ & 10.49 \\
\hline 137 & $\$$ & 34.82 & $\$$ & 29.184 & $\$$ & 5.64 & 187 & $\$$ & 52.21 & $\$$ & 41.614 & $\$$ & 10.59 \\
\hline 138 & $\$$ & 35.17 & $\$$ & 29.429 & $\$$ & 5.74 & 188 & $\$$ & 52.56 & $\$$ & 41.866 & $\$$ & 10.69 \\
\hline 139 & $\$$ & 35.51 & $\$$ & 29.674 & $\$$ & 5.84 & 189 & $\$$ & 52.91 & $\$$ & 42.118 & $\$$ & 10.79 \\
\hline 140 & $\$$ & 35.85 & $\$$ & 29.919 & $\$$ & 5.93 & 190 & $\$$ & 53.26 & $\$$ & 42.371 & $\$$ & 10.89 \\
\hline 141 & $\$$ & 36.20 & $\$$ & 30.164 & $\$$ & 6.03 & 191 & $\$$ & 53.62 & $\$$ & 42.623 & $\$$ & 10.99 \\
\hline 142 & $\$$ & 36.54 & $\$$ & 30.409 & $\$$ & 6.13 & 192 & $\$$ & 53.97 & $\$$ & 42.876 & $\$$ & 11.09 \\
\hline 143 & $\$$ & 36.88 & $\$$ & 30.655 & $\$$ & 6.23 & 193 & $\$$ & 54.32 & $\$$ & 43.129 & $\$$ & 11.19 \\
\hline 144 & $\$$ & 37.23 & $\$$ & 30.901 & $\$$ & 6.33 & 194 & $\$$ & 54.67 & $\$$ & 43.382 & $\$$ & 11.29 \\
\hline 145 & $\$$ & 37.57 & $\$$ & 31.147 & $\$$ & 6.43 & 195 & $\$$ & 55.03 & $\$$ & 43.635 & $\$$ & 11.39 \\
\hline 146 & $\$$ & 37.92 & $\$$ & 31.393 & $\$$ & 6.53 & 196 & $\$$ & 55.38 & $\$$ & 43.888 & $\$$ & 11.49 \\
\hline 147 & $\$$ & 38.26 & $\$$ & 31.639 & $\$$ & 6.62 & 197 & $\$$ & 55.73 & $\$$ & 44.141 & $\$$ & 11.59 \\
\hline 148 & $\$$ & 38.61 & $\$$ & 31.885 & $\$$ & 6.72 & 198 & $\$$ & 56.09 & $\$$ & 44.394 & $\$$ & 11.69 \\
\hline 149 & $\$$ & 38.95 & $\$$ & 32.132 & $\$$ & 6.82 & 199 & $\$$ & 56.44 & $\$$ & 44.648 & $\$$ & 11.79 \\
\hline 150 & $\$$ & 39.30 & $\$$ & 32.379 & $\$$ & 6.92 & 200 & $\$$ & 56.79 & $\$$ & 44.902 & $\$$ & 11.89 \\
\hline
\end{tabular}




\begin{tabular}{|c|c|c|c|c|c|c|}
\hline \multicolumn{7}{|c|}{ Class: Profit } \\
\hline Report number & \multicolumn{2}{|c|}{ Class } & \multicolumn{2}{|c|}{ Observe and Do } & \multicolumn{2}{|c|}{ Difference (ROI) } \\
\hline 0 & $\$$ & $(4.23)$ & $\$$ & $(0.36)$ & $\$$ & $(3.87)$ \\
\hline 1 & $\$$ & (3.99) & $\$$ & $(0.31)$ & $\$$ & (3.68) \\
\hline 2 & $\$$ & $(3.74)$ & $\$$ & $(0.22)$ & $\$$ & $(3.52)$ \\
\hline 3 & $\$$ & $(3.48)$ & $\$$ & $(0.11)$ & $\$$ & (3.37) \\
\hline 4 & $\$$ & (3.21) & $\$$ & 0.01 & $\$$ & $(3.22)$ \\
\hline 5 & $\$$ & $(2.93)$ & $\$$ & 0.15 & $\$$ & (3.08) \\
\hline 6 & $\$$ & (2.65) & $\$$ & 0.29 & $\$$ & $(2.94)$ \\
\hline 7 & $\$$ & $(2.37)$ & $\$$ & 0.44 & $\$$ & $(2.81)$ \\
\hline 8 & $\$$ & (2.09) & $\$$ & 0.59 & $\$$ & $(2.68)$ \\
\hline 9 & $\$$ & $(1.80)$ & $\$$ & 0.75 & $\$$ & $(2.55)$ \\
\hline 10 & $\$$ & (1.51) & $\$$ & 0.91 & $\$$ & $(2.42)$ \\
\hline 11 & $\$$ & $(1.22)$ & $\$$ & 1.08 & $\$$ & $(2.30)$ \\
\hline 12 & $\$$ & $(0.93)$ & $\$$ & 1.25 & $\$$ & $(2.18)$ \\
\hline 13 & $\$$ & $(0.64)$ & $\$$ & 1.42 & $\$$ & $(2.06)$ \\
\hline 14 & $\$$ & $(0.34)$ & $\$$ & 1.59 & $\$$ & $(1.94)$ \\
\hline 15 & $\$$ & $(0.05)$ & $\$$ & 1.77 & $\$$ & $(1.82)$ \\
\hline 16 & $\$$ & 0.25 & $\$$ & 1.95 & $\$$ & $(1.70)$ \\
\hline 17 & $\$$ & 0.55 & $\$$ & 2.13 & $\$$ & $(1.58)$ \\
\hline 18 & $\$$ & 0.85 & $\$$ & 2.32 & $\$$ & $(1.47)$ \\
\hline 19 & $\$$ & 1.15 & $\$$ & 2.50 & $\$$ & $(1.35)$ \\
\hline 20 & $\$$ & 1.45 & $\$$ & 2.69 & $\$$ & $(1.24)$ \\
\hline 21 & $\$$ & 1.75 & $\$$ & 2.88 & $\$$ & $(1.13)$ \\
\hline 22 & $\$$ & 2.05 & $\$$ & 3.07 & $\$$ & $(1.02)$ \\
\hline 23 & $\$$ & 2.36 & $\$$ & 3.26 & $\$$ & $(0.91)$ \\
\hline 24 & $\$$ & 2.66 & $\$$ & 3.46 & $\$$ & $(0.80)$ \\
\hline 25 & $\$$ & 2.97 & $\$$ & 3.65 & $\$$ & $(0.69)$ \\
\hline 26 & $\$$ & 3.27 & $\$$ & 3.85 & $\$$ & $(0.58)$ \\
\hline 27 & $\$$ & 3.58 & $\$$ & 4.05 & $\$$ & $(0.47)$ \\
\hline 28 & $\$$ & 3.88 & $\$$ & 4.25 & $\$$ & $(0.36)$ \\
\hline 29 & $\$$ & 4.19 & $\$$ & 4.45 & $\$$ & $(0.25)$ \\
\hline 30 & $\$$ & 4.50 & $\$$ & 4.65 & $\$$ & $(0.15)$ \\
\hline 31 & $\$$ & 4.81 & $\$$ & 4.85 & $\$$ & $(0.04)$ \\
\hline 32 & $\$$ & 5.12 & $\$$ & 5.05 & $\$$ & 0.07 \\
\hline 33 & $\$$ & 5.43 & $\$$ & 5.26 & $\$$ & 0.17 \\
\hline 34 & $\$$ & 5.74 & $\$$ & 5.46 & $\$$ & 0.28 \\
\hline 35 & $\$$ & 6.05 & $\$$ & 5.67 & $\$$ & 0.38 \\
\hline 36 & $\$$ & 6.36 & $\$$ & 5.88 & $\$$ & 0.48 \\
\hline 37 & $\$$ & 6.67 & $\$$ & 6.08 & $\$$ & 0.59 \\
\hline 38 & $\$$ & 6.98 & $\$$ & 6.29 & $\$$ & 0.69 \\
\hline 39 & $\$$ & 7.30 & $\$$ & 6.50 & $\$$ & 0.79 \\
\hline 40 & $\$$ & 7.61 & $\$$ & 6.71 & $\$$ & 0.89 \\
\hline 41 & $\$$ & 7.92 & $\$$ & 6.92 & $\$$ & 1.00 \\
\hline 42 & $\$$ & 8.23 & $\$$ & 7.14 & $\$$ & 1.10 \\
\hline 43 & $\$$ & 8.55 & $\$$ & 7.35 & $\$$ & 1.20 \\
\hline 44 & $\$$ & 8.86 & $\$$ & 7.56 & $\$$ & 1.30 \\
\hline 45 & $\$$ & 9.18 & $\$$ & 7.78 & $\$$ & 1.40 \\
\hline 46 & $\$$ & 9.49 & $\$$ & 7.99 & $\$$ & 1.50 \\
\hline 47 & $\$$ & 9.81 & $\$$ & 8.21 & $\$$ & 1.60 \\
\hline 48 & $\$$ & 10.12 & $\$$ & 8.42 & $\$$ & 1.70 \\
\hline 49 & $\$$ & 10.44 & $\$$ & 8.64 & $\$$ & 1.80 \\
\hline 50 & $\$$ & 10.76 & $\$$ & 8.86 & $\$$ & 1.90 \\
\hline
\end{tabular}

\begin{tabular}{|c|c|c|c|c|c|c|}
\hline \multicolumn{7}{|c|}{ Class: Profit (Continued) } \\
\hline Report number & & Class & & ad Do & & ROI) \\
\hline 51 & $\$$ & 11.07 & $\$$ & 9.07 & $\$$ & 2.00 \\
\hline 52 & $\$$ & 11.39 & $\$$ & 9.29 & $\$$ & 2.10 \\
\hline 53 & $\$$ & 11.71 & $\$$ & 9.51 & $\$$ & 2.20 \\
\hline 54 & $\$$ & 12.02 & $\$$ & 9.73 & $\$$ & 2.29 \\
\hline 55 & $\$$ & 12.34 & $\$$ & 9.95 & $\$$ & 2.39 \\
\hline 56 & $\$$ & 12.66 & $\$$ & 10.17 & $\$$ & 2.49 \\
\hline 57 & $\$$ & 12.98 & $\$$ & 10.39 & $\$$ & 2.59 \\
\hline 58 & $\$$ & 13.30 & $\$$ & 10.61 & $\$$ & 2.68 \\
\hline 59 & $\$$ & 13.62 & $\$$ & 10.84 & $\$$ & 2.78 \\
\hline 60 & $\$$ & 13.93 & $\$$ & 11.06 & $\$$ & 2.88 \\
\hline 61 & $\$$ & 14.25 & $\$$ & 11.28 & $\$$ & 2.97 \\
\hline 62 & $\$$ & 14.57 & $\$$ & 11.50 & $\$$ & 3.07 \\
\hline 63 & $\$$ & 14.89 & $\$$ & 11.73 & $\$$ & 3.16 \\
\hline 64 & $\$$ & 15.21 & $\$$ & 11.95 & $\$$ & 3.26 \\
\hline 65 & $\$$ & 15.53 & $\$$ & 12.18 & $\$$ & 3.36 \\
\hline 66 & $\$$ & 15.85 & $\$$ & 12.40 & $\$$ & 3.45 \\
\hline 67 & $\$$ & 16.17 & $\$$ & 12.63 & $\$$ & 3.55 \\
\hline 68 & $\$$ & 16.50 & $\$$ & 12.85 & $\$$ & 3.64 \\
\hline 69 & $\$$ & 16.82 & $\$$ & 13.08 & $\$$ & 3.74 \\
\hline 70 & $\$$ & 17.14 & $\$$ & 13.31 & $\$$ & 3.83 \\
\hline 71 & $\$$ & 17.46 & $\$$ & 13.53 & $\$$ & 3.93 \\
\hline 72 & $\$$ & 17.78 & $\$$ & 13.76 & $\$$ & 4.02 \\
\hline 73 & $\$$ & 18.10 & $\$$ & 13.99 & $\$$ & 4.11 \\
\hline 74 & $\$$ & 18.43 & $\$$ & 14.22 & $\$$ & 4.21 \\
\hline 75 & $\$$ & 18.75 & $\$$ & 14.45 & $\$$ & 4.30 \\
\hline 76 & $\$$ & 19.07 & $\$$ & 14.68 & $\$$ & 4.39 \\
\hline 77 & $\$$ & 19.39 & $\$$ & 14.91 & $\$$ & 4.49 \\
\hline 78 & $\$$ & 19.72 & $\$$ & 15.14 & $\$$ & 4.58 \\
\hline 79 & $\$$ & 20.04 & $\$$ & 15.37 & $\$$ & 4.67 \\
\hline 80 & $\$$ & 20.36 & $\$$ & 15.60 & $\$$ & 4.77 \\
\hline 81 & $\$$ & 20.69 & $\$$ & 15.83 & $\$$ & 4.86 \\
\hline 82 & $\$$ & 21.01 & $\$$ & 16.06 & $\$$ & 4.95 \\
\hline 83 & $\$$ & 21.33 & $\$$ & 16.29 & $\$$ & 5.04 \\
\hline 84 & $\$$ & 21.66 & $\$$ & 16.52 & $\$$ & 5.14 \\
\hline 85 & $\$$ & 21.98 & $\$$ & 16.75 & $\$$ & 5.23 \\
\hline 86 & $\$$ & 22.31 & $\$$ & 16.99 & $\$$ & 5.32 \\
\hline 87 & $\$$ & 22.63 & $\$$ & 17.22 & $\$$ & 5.41 \\
\hline 88 & $\$$ & 22.96 & $\$$ & 17.45 & $\$$ & 5.50 \\
\hline 89 & $\$$ & 23.28 & $\$$ & 17.69 & $\$$ & 5.60 \\
\hline 90 & $\$$ & 23.61 & $\$$ & 17.92 & $\$$ & 5.69 \\
\hline 91 & $\$$ & 23.93 & $\$$ & 18.15 & $\$$ & 5.78 \\
\hline 92 & $\$$ & 24.26 & $\$$ & 18.39 & $\$$ & 5.87 \\
\hline 93 & $\$$ & 24.58 & $\$$ & 18.62 & $\$$ & 5.96 \\
\hline 94 & $\$$ & 24.91 & $\$$ & 18.86 & $\$$ & 6.05 \\
\hline 95 & $\$$ & 25.23 & $\$$ & 19.09 & $\$$ & 6.14 \\
\hline 96 & $\$$ & 25.56 & $\$$ & 19.33 & $\$$ & 6.23 \\
\hline 97 & $\$$ & 25.89 & $\$$ & 19.56 & $\$$ & 6.32 \\
\hline 98 & $\$$ & 26.21 & $\$$ & 19.80 & $\$$ & 6.41 \\
\hline 99 & $\$$ & 26.54 & $\$$ & 20.04 & $\$$ & 6.50 \\
\hline 100 & $\$$ & 26.86 & $\$$ & 20.27 & $\$$ & 6.59 \\
\hline
\end{tabular}




\begin{tabular}{|c|c|c|c|c|c|c|}
\hline \multicolumn{7}{|c|}{ Class: Profit (Continued) } \\
\hline Report number & & Class & & nd Do & & (ROI) \\
\hline 101 & $\$$ & 27.19 & $\$$ & 20.51 & $\$$ & 6.68 \\
\hline 102 & $\$$ & 27.52 & $\$$ & 20.75 & $\$$ & 6.77 \\
\hline 103 & $\$$ & 27.84 & $\$$ & 20.98 & $\$$ & 6.86 \\
\hline 104 & $\$$ & 28.17 & $\$$ & 21.22 & $\$$ & 6.95 \\
\hline 105 & $\$$ & 28.50 & $\$$ & 21.46 & $\$$ & 7.04 \\
\hline 106 & $\$$ & 28.83 & $\$$ & 21.70 & $\$$ & 7.13 \\
\hline 107 & $\$$ & 29.15 & $\$$ & 21.93 & $\$$ & 7.22 \\
\hline 108 & $\$$ & 29.48 & $\$$ & 22.17 & $\$$ & 7.31 \\
\hline 109 & $\$$ & 29.81 & $\$$ & 22.41 & $\$$ & 7.40 \\
\hline 110 & $\$$ & 30.14 & $\$$ & 22.65 & $\$$ & 7.49 \\
\hline 111 & $\$$ & 30.47 & $\$$ & 22.89 & $\$$ & 7.58 \\
\hline 112 & $\$$ & 30.79 & $\$$ & 23.13 & $\$$ & 7.66 \\
\hline 113 & $\$$ & 31.12 & $\$$ & 23.37 & $\$$ & 7.75 \\
\hline 114 & $\$$ & 31.45 & $\$$ & 23.61 & $\$$ & 7.84 \\
\hline 115 & $\$$ & 31.78 & $\$$ & 23.85 & $\$$ & 7.93 \\
\hline 116 & $\$$ & 32.11 & $\$$ & 24.09 & $\$$ & 8.02 \\
\hline 117 & $\$$ & 32.44 & $\$$ & 24.33 & $\$$ & 8.11 \\
\hline 118 & $\$$ & 32.76 & $\$$ & 24.57 & $\$$ & 8.19 \\
\hline 119 & $\$$ & 33.09 & $\$$ & 24.81 & $\$$ & 8.28 \\
\hline 120 & $\$$ & 33.42 & $\$$ & 25.05 & $\$$ & 8.37 \\
\hline 121 & $\$$ & 33.75 & $\$$ & 25.29 & $\$$ & 8.46 \\
\hline 122 & $\$$ & 34.08 & $\$$ & 25.54 & $\$$ & 8.55 \\
\hline 123 & $\$$ & 34.41 & $\$$ & 25.78 & $\$$ & 8.63 \\
\hline 124 & $\$$ & 34.74 & $\$$ & 26.02 & $\$$ & 8.72 \\
\hline 125 & $\$$ & 35.07 & $\$$ & 26.26 & $\$$ & 8.81 \\
\hline 126 & $\$$ & 35.40 & $\$$ & 26.50 & $\$$ & 8.90 \\
\hline 127 & $\$$ & 35.73 & $\$$ & 26.75 & $\$$ & 8.98 \\
\hline 128 & $\$$ & 36.06 & $\$$ & 26.99 & $\$$ & 9.07 \\
\hline 129 & $\$$ & 36.39 & $\$$ & 27.23 & $\$$ & 9.16 \\
\hline 130 & $\$$ & 36.72 & $\$$ & 27.48 & $\$$ & 9.24 \\
\hline 131 & $\$$ & 37.05 & $\$$ & 27.72 & $\$$ & 9.33 \\
\hline 132 & $\$$ & 37.38 & $\$$ & 27.96 & $\$$ & 9.42 \\
\hline 133 & $\$$ & 37.71 & $\$$ & 28.21 & $\$$ & 9.50 \\
\hline 134 & $\$$ & 38.04 & $\$$ & 28.45 & $\$$ & 9.59 \\
\hline 135 & $\$$ & 38.37 & $\$$ & 28.70 & $\$$ & 9.68 \\
\hline 136 & $\$$ & 38.70 & $\$$ & 28.94 & $\$$ & 9.76 \\
\hline 137 & $\$$ & 39.03 & $\$$ & 29.18 & $\$$ & 9.85 \\
\hline 138 & $\$$ & 39.37 & $\$$ & 29.43 & $\$$ & 9.94 \\
\hline 139 & $\$$ & 39.70 & $\$$ & 29.67 & $\$$ & 10.02 \\
\hline 140 & $\$$ & 40.03 & $\$$ & 29.92 & $\$$ & 10.11 \\
\hline 141 & $\$$ & 40.36 & $\$$ & 30.16 & $\$$ & 10.20 \\
\hline 142 & $\$$ & 40.69 & $\$$ & 30.41 & $\$$ & 10.28 \\
\hline 143 & $\$$ & 41.02 & $\$$ & 30.65 & $\$$ & 10.37 \\
\hline 144 & $\$$ & 41.35 & $\$$ & 30.90 & $\$$ & 10.45 \\
\hline 145 & $\$$ & 41.69 & $\$$ & 31.15 & $\$$ & 10.54 \\
\hline 146 & $\$$ & 42.02 & $\$$ & 31.39 & $\$$ & 10.62 \\
\hline 147 & $\$$ & 42.35 & $\$$ & 31.64 & $\$$ & 10.71 \\
\hline 148 & $\$$ & 42.68 & $\$$ & 31.89 & $\$$ & 10.80 \\
\hline 149 & $\$$ & 43.01 & $\$$ & 32.13 & $\$$ & 10.88 \\
\hline 150 & $\$$ & 43.34 & $\$$ & 32.38 & $\$$ & 10.97 \\
\hline
\end{tabular}

\begin{tabular}{|c|c|c|c|c|c|c|}
\hline \multicolumn{7}{|c|}{ Class: Profit (Continued) } \\
\hline Report number & & Class & & nd Do & & (ROI) \\
\hline 151 & $\$$ & 43.68 & $\$$ & 32.63 & $\$$ & 11.05 \\
\hline 152 & $\$$ & 44.01 & $\$$ & 32.87 & $\$$ & 11.14 \\
\hline 153 & $\$$ & 44.34 & $\$$ & 33.12 & $\$$ & 11.22 \\
\hline 154 & $\$$ & 44.67 & $\$$ & 33.37 & $\$$ & 11.31 \\
\hline 155 & $\$$ & 45.01 & $\$$ & 33.61 & $\$$ & 11.39 \\
\hline 156 & $\$$ & 45.34 & $\$$ & 33.86 & $\$$ & 11.48 \\
\hline 157 & $\$$ & 45.67 & $\$$ & 34.11 & $\$$ & 11.56 \\
\hline 158 & $\$$ & 46.01 & $\$$ & 34.36 & $\$$ & 11.65 \\
\hline 159 & $\$$ & 46.34 & $\$$ & 34.61 & $\$$ & 11.73 \\
\hline 160 & $\$$ & 46.67 & $\$$ & 34.86 & $\$$ & 11.82 \\
\hline 161 & $\$$ & 47.00 & $\$$ & 35.10 & $\$$ & 11.90 \\
\hline 162 & $\$$ & 47.34 & $\$$ & 35.35 & $\$$ & 11.98 \\
\hline 163 & $\$$ & 47.67 & $\$$ & 35.60 & $\$$ & 12.07 \\
\hline 164 & $\$$ & 48.00 & $\$$ & 35.85 & $\$$ & 12.15 \\
\hline 165 & $\$$ & 48.34 & $\$$ & 36.10 & $\$$ & 12.24 \\
\hline 166 & $\$$ & 48.67 & $\$$ & 36.35 & $\$$ & 12.32 \\
\hline 167 & $\$$ & 49.00 & $\$$ & 36.60 & $\$$ & 12.41 \\
\hline 168 & $\$$ & 49.34 & $\$$ & 36.85 & $\$$ & 12.49 \\
\hline 169 & $\$$ & 49.67 & $\$$ & 37.10 & $\$$ & 12.57 \\
\hline 170 & $\$$ & 50.01 & $\$$ & 37.35 & $\$$ & 12.66 \\
\hline 171 & $\$$ & 50.34 & $\$$ & 37.60 & $\$$ & 12.74 \\
\hline 172 & $\$$ & 50.67 & $\$$ & 37.85 & $\$$ & 12.83 \\
\hline 173 & $\$$ & 51.01 & $\$$ & 38.10 & $\$$ & 12.91 \\
\hline 174 & $\$$ & 51.34 & $\$$ & 38.35 & $\$$ & 12.99 \\
\hline 175 & $\$$ & 51.68 & $\$$ & 38.60 & $\$$ & 13.08 \\
\hline 176 & $\$$ & 52.01 & $\$$ & 38.85 & $\$$ & 13.16 \\
\hline 177 & $\$$ & 52.34 & $\$$ & 39.10 & $\$$ & 13.25 \\
\hline 178 & $\$$ & 52.68 & $\$$ & 39.35 & $\$$ & 13.33 \\
\hline 179 & $\$$ & 53.01 & $\$$ & 39.60 & $\$$ & 13.41 \\
\hline 180 & $\$$ & 53.35 & $\$$ & 39.85 & $\$$ & 13.50 \\
\hline 181 & $\$$ & 53.68 & $\$$ & 40.10 & $\$$ & 13.58 \\
\hline 182 & $\$$ & 54.02 & $\$$ & 40.35 & $\$$ & 13.66 \\
\hline 183 & $\$$ & 54.35 & $\$$ & 40.61 & $\$$ & 13.75 \\
\hline 184 & $\$$ & 54.69 & $\$$ & 40.86 & $\$$ & 13.83 \\
\hline 185 & $\$$ & 55.02 & $\$$ & 41.11 & $\$$ & 13.91 \\
\hline 186 & $\$$ & 55.36 & $\$$ & 41.36 & $\$$ & 13.99 \\
\hline 187 & $\$$ & 55.69 & $\$$ & 41.61 & $\$$ & 14.08 \\
\hline 188 & $\$$ & 56.03 & $\$$ & 41.87 & $\$$ & 14.16 \\
\hline 189 & $\$$ & 56.36 & $\$$ & 42.12 & $\$$ & 14.24 \\
\hline 190 & $\$$ & 56.70 & $\$$ & 42.37 & $\$$ & 14.33 \\
\hline 191 & $\$$ & 57.03 & $\$$ & 42.62 & $\$$ & 14.41 \\
\hline 192 & $\$$ & 57.37 & $\$$ & 42.88 & $\$$ & 14.49 \\
\hline 193 & $\$$ & 57.70 & $\$$ & 43.13 & $\$$ & 14.57 \\
\hline 194 & $\$$ & 58.04 & $\$$ & 43.38 & $\$$ & 14.66 \\
\hline 195 & $\$$ & 58.37 & $\$$ & 43.63 & $\$$ & 14.74 \\
\hline 196 & $\$$ & 58.71 & $\$$ & 43.89 & $\$$ & 14.82 \\
\hline 197 & $\$$ & 59.05 & $\$$ & 44.14 & $\$$ & 14.90 \\
\hline 198 & $\$$ & 59.38 & $\$$ & 44.39 & $\$$ & 14.99 \\
\hline 199 & $\$$ & 59.72 & $\$$ & 44.65 & $\$$ & 15.07 \\
\hline 200 & $\$$ & 60.05 & $\$$ & 44.90 & $\$$ & 15.15 \\
\hline
\end{tabular}


Mentor/Manual: Profit

\begin{tabular}{|l|l|l|l}
\hline Report number & Mentor/Manual & Observe and Do & Difference (ROI)
\end{tabular}

\begin{tabular}{|c|c|c|c|c|c|c|}
\hline 0 & $\$$ & (9.03) & $\$$ & $(0.360)$ & $\$$ & $(8.67)$ \\
\hline 1 & $\$$ & (8.93) & $\$$ & $(0.309)$ & $\$$ & $(8.62)$ \\
\hline 2 & $\$$ & (8.78) & $\$$ & $(0.219)$ & $\$$ & $(8.56)$ \\
\hline 3 & $\$$ & (8.61) & $\$$ & $(0.109)$ & $\$$ & $(8.50)$ \\
\hline 4 & $\$$ & (8.42) & $\$$ & 0.014 & $\$$ & (8.43) \\
\hline 5 & $\$$ & (8.22) & $\$$ & 0.147 & $\$$ & (8.37) \\
\hline 6 & $\$$ & (8.02) & $\$$ & 0.289 & $\$$ & (8.31) \\
\hline 7 & $\$$ & (7.80) & $\$$ & 0.436 & $\$$ & $(8.24)$ \\
\hline 8 & $\$$ & (7.58) & $\$$ & 0.590 & $\$$ & $(8.17)$ \\
\hline 9 & $\$$ & (7.36) & $\$$ & 0.748 & $\$$ & $(8.11)$ \\
\hline 10 & $\$$ & $(7.13)$ & $\$$ & 0.910 & $\$$ & $(8.04)$ \\
\hline 11 & $\$$ & (6.90) & $\$$ & 1.076 & $\$$ & $(7.98)$ \\
\hline 12 & $\$$ & (6.66) & $\$$ & 1.245 & $\$$ & (7.91) \\
\hline 13 & $\$$ & (6.42) & $\$$ & 1.417 & $\$$ & $(7.84)$ \\
\hline 14 & $\$$ & $(6.18)$ & $\$$ & 1.592 & $\$$ & $(7.77)$ \\
\hline 15 & $\$$ & (5.94) & $\$$ & 1.770 & $\$$ & $(7.71)$ \\
\hline 16 & $\$$ & (5.69) & $\$$ & 1.950 & $\$$ & $(7.64)$ \\
\hline 17 & $\$$ & (5.44) & $\$$ & 2.132 & $\$$ & $(7.57)$ \\
\hline 18 & $\$$ & (5.19) & $\$$ & 2.316 & $\$$ & $(7.50)$ \\
\hline 19 & $\$$ & (4.93) & $\$$ & 2.502 & $\$$ & $(7.43)$ \\
\hline 20 & $\$$ & (4.68) & $\$$ & 2.690 & $\$$ & (7.37) \\
\hline 21 & $\$$ & (4.42) & $\$$ & 2.879 & $\$$ & $(7.30)$ \\
\hline 22 & $\$$ & $(4.16)$ & $\$$ & 3.070 & $\$$ & $(7.23)$ \\
\hline 23 & $\$$ & (3.90) & $\$$ & 3.263 & $\$$ & $(7.16)$ \\
\hline 24 & $\$$ & (3.64) & $\$$ & 3.457 & $\$$ & $(7.09)$ \\
\hline 25 & $\$$ & $(3.37)$ & $\$$ & 3.652 & $\$$ & $(7.02)$ \\
\hline 26 & $\$$ & (3.11) & $\$$ & 3.849 & $\$$ & $(6.96)$ \\
\hline 27 & $\$$ & $(2.84)$ & $\$$ & 4.047 & $\$$ & $(6.89)$ \\
\hline 28 & $\$$ & (2.57) & $\$$ & 4.246 & $\$$ & $(6.82)$ \\
\hline 29 & $\$$ & (2.30) & $\$$ & 4.446 & $\$$ & $(6.75)$ \\
\hline 30 & $\$$ & $(2.03)$ & $\$$ & 4.647 & $\$$ & $(6.68)$ \\
\hline 31 & $\$$ & (1.76) & $\$$ & 4.850 & $\$$ & $(6.61)$ \\
\hline 32 & $\$$ & (1.49) & $\$$ & 5.053 & $\$$ & $(6.54)$ \\
\hline 33 & $\$$ & $(1.22)$ & $\$$ & 5.258 & $\$$ & $(6.47)$ \\
\hline 34 & $\$$ & $(0.94)$ & $\$$ & 5.463 & $\$$ & $(6.40)$ \\
\hline 35 & $\$$ & $(0.67)$ & $\$$ & 5.669 & $\$$ & $(6.33)$ \\
\hline 36 & $\$$ & $(0.39)$ & $\$$ & 5.876 & $\$$ & $(6.27)$ \\
\hline 37 & $\$$ & $(0.11)$ & $\$$ & 6.084 & $\$$ & $(6.20)$ \\
\hline 38 & $\$$ & 0.17 & $\$$ & 6.293 & $\$$ & (6.13) \\
\hline 39 & $\$$ & 0.45 & $\$$ & 6.503 & $\$$ & $(6.06)$ \\
\hline 40 & $\$$ & 0.72 & $\$$ & 6.713 & $\$$ & (5.99) \\
\hline 41 & $\$$ & 1.01 & $\$$ & 6.924 & $\$$ & $(5.92)$ \\
\hline 42 & $\$$ & 1.29 & $\$$ & 7.136 & $\$$ & $(5.85)$ \\
\hline 43 & $\$$ & 1.57 & $\$$ & 7.349 & $\$$ & $(5.78)$ \\
\hline 44 & $\$$ & 1.85 & $\$$ & 7.562 & $\$$ & $(5.71)$ \\
\hline 45 & $\$$ & 2.14 & $\$$ & 7.776 & $\$$ & $(5.64)$ \\
\hline 46 & $\$$ & 2.42 & $\$$ & 7.991 & $\$$ & $(5.57)$ \\
\hline 47 & $\$$ & 2.70 & $\$$ & 8.206 & $\$$ & $(5.50)$ \\
\hline 48 & $\$$ & 2.99 & $\$$ & 8.422 & $\$$ & $(5.43)$ \\
\hline 49 & $\$$ & 3.28 & $\$$ & 8.639 & $\$$ & $(5.36)$ \\
\hline 50 & $\$$ & 3.56 & $\$$ & 8.856 & $\$$ & $(5.29)$ \\
\hline
\end{tabular}

Mentor/Manual: Profit (Continued)

\begin{tabular}{|l|l|l|l} 
Report number & Mentor/Manual & Observe and Do & Difference (ROI) \\
\hline
\end{tabular}

\begin{tabular}{l|ll|ll|ll|}
51 & $\$$ & 3.85 & $\$$ & 9.074 & $\$$ & $(5.22)$ \\
\hline 52 & $\$$ & 4.14 & $\$$ & 9.292 & $\$$ & $(5.15)$
\end{tabular}

\begin{tabular}{|l|ll|ll|ll|}
53 & $\$$ & 4.43 & $\$$ & 9.511 & $\$$ & $(5.09)$
\end{tabular}

\begin{tabular}{|l|ll|ll|ll|}
54 & $\$$ & 4.71 & $\$$ & 9.730 & $\$$ & $(5.02)$ \\
\hline
\end{tabular}

\begin{tabular}{l|ll|ll|ll|}
55 & $\$$ & 5.00 & $\$$ & 9.950 & $\$$ & $(4.95)$ \\
\hline
\end{tabular}

\begin{tabular}{l|ll|ll|ll|}
56 & $\$$ & 5.29 & $\$$ & 10.171 & $\$$ & $(4.88)$ \\
\hline
\end{tabular}

\begin{tabular}{l|ll|ll|ll|}
57 & $\$$ & 5.59 & $\$$ & 10.392 & $\$$ & $(4.81)$
\end{tabular}

\begin{tabular}{|l|ll|ll|ll|}
58 & $\$$ & 5.88 & $\$$ & 10.613 & $\$$ & $(4.74)$ \\
\hline
\end{tabular}

\begin{tabular}{l|ll|ll|ll|}
59 & $\$$ & 6.17 & $\$$ & 10.835 & $\$$ & $(4.67)$ \\
\hline 60 & $\$$ & 6.46 & $\$$ & 11.058 & $\$$ & $(4.60)$ \\
\hline
\end{tabular}

\begin{tabular}{|l|llll|ll|}
61 & $\$$ & 6.75 & $\$$ & 11.281 & $\$$ & $(4.53)$ \\
\hline
\end{tabular}

\begin{tabular}{l|ll|ll|ll|}
62 & $\$$ & 7.05 & $\$$ & 11.504 & $\$$ & $(4.46)$ \\
\hline
\end{tabular}

\begin{tabular}{l|ll|ll|ll|}
63 & $\$$ & 7.34 & $\$$ & 11.728 & $\$$ & $(4.39)$ \\
\hline
\end{tabular}

\begin{tabular}{|l|ll|ll|ll|}
64 & $\$$ & 7.63 & $\$$ & 11.952 & $\$$ & $(4.32)$ \\
\hline
\end{tabular}

\begin{tabular}{|l|ll|ll|ll|}
65 & $\$$ & 7.93 & $\$$ & 12.177 & $\$$ & $(4.25)$ \\
\hline
\end{tabular}

\begin{tabular}{l|llllll|}
65 & $\$$ & 7.93 & $\$$ & 12.177 & $\$$ & $(4.25)$ \\
66 & $\$$ & 8.22 & $\$$ & 12.402 & $\$$ & $(4.18)$ \\
\hline
\end{tabular}

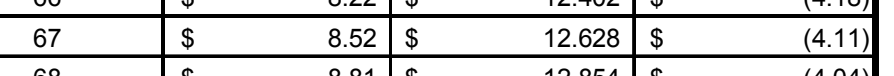

\begin{tabular}{|l|ll|ll|ll|}
68 & $\$$ & 8.81 & $\$$ & 12.854 & $\$$ & $(4.04)$ \\
\hline
\end{tabular}

\begin{tabular}{|l|llll|ll|}
69 & $\$$ & 9.11 & $\$$ & 13.080 & $\$$ & $(3.97)$ \\
\hline
\end{tabular}

\begin{tabular}{|l|ll|ll|ll|}
70 & $\$$ & 9.41 & $\$$ & 13.307 & $\$$ & $(3.90)$ \\
71 & $\$$ & 9.70 & $\$$ & 13.534 & $\$$ & $(3.83)$ \\
\hline
\end{tabular}

\begin{tabular}{|l|lr|ll|ll|}
71 & $\$$ & 9.70 & $\$$ & 13.534 & $\$$ & $(3.83)$ \\
72 & $\$$ & 10.00 & $\$$ & 13.762 & $\$$ & $(3.76)$ \\
\hline
\end{tabular}

\begin{tabular}{|lllll|ll|}
72 & $\$$ & 10.00 & $\$$ & 13.762 & $\$$ & $(3.76)$ \\
73 & $\$$ & 10.30 & $\$$ & 13.990 & $\$$ & $(3.69)$ \\
\hline
\end{tabular}

\begin{tabular}{|lllll|ll|}
74 & $\$$ & 10.30 & $\$$ & 13.990 & $\$$ & $(3.69)$ \\
\hline 75 & $\$$ & 10.60 & $\$$ & 14.218 & $\$$ & $(3.62)$ \\
\hline
\end{tabular}

\begin{tabular}{|l|ll|ll|ll|}
75 & $\$$ & 10.90 & $\$$ & 14.447 & $\$$ & $(3.55)$ \\
76 & $\$$ & 11.20 & $\$$ & 14.676 & $\$$ & $(3.48)$ \\
\hline
\end{tabular}

\begin{tabular}{l|ll|ll|ll|}
76 & $\$$ & 11.20 & $\$$ & 14.676 & $\$$ & $(3.48)$ \\
77 & $\$$ & 11.49 & $\$$ & 14.906 & $\$$ & $(3.41)$ \\
\hline
\end{tabular}

\begin{tabular}{l|llll|ll|}
77 & $\$$ & 11.49 & $\$$ & 14.906 & $\$$ & $(3.41)$ \\
78 & $\$$ & 11.79 & $\$$ & 15.136 & $\$$ & $(3.34)$ \\
\hline
\end{tabular}

\begin{tabular}{l|ll|ll|ll|}
78 & $\$$ & 11.79 & $\$$ & 15.136 & $\$$ & $(3.34)$ \\
79 & $\$$ & 12.09 & $\$$ & 15.366 & $\$$ & $(3.27)$ \\
\hline 80 & $\$$ & 12.40 & $\$$ & 15.596 & $\$$ & $(3.20)$ \\
\hline
\end{tabular}

\begin{tabular}{|lllllll|}
80 & $\$$ & 12.40 & $\$$ & 15.596 & $\$$ & $(3.20)$ \\
81 & $\$$ & 12.70 & $\$$ & 15.827 & $\$$ & $(3.13)$ \\
\hline 82 & $\$$ & 13.00 & $\$$ & 16.058 & $\$$ & $(3.06)$ \\
\hline
\end{tabular}

\begin{tabular}{l|llll|ll|}
81 & $\$$ & 12.70 & $\$$ & 15.827 & $\$$ & $(3.13)$ \\
\hline 82 & $\$$ & 13.00 & $\$$ & 16.058 & $\$$ & $(3.06)$ \\
\hline 83 & $\$$ & 13.30 & $\$$ & 16.290 & $\$$ & $(2.99)$ \\
\hline
\end{tabular}

\begin{tabular}{|l|ll|ll|ll|}
83 & $\$$ & 13.30 & $\$$ & 16.290 & $\$$ & $(2.99)$ \\
84 & $\$$ & 13.60 & $\$$ & 16.522 & $\$$ & $(2.92)$ \\
\hline
\end{tabular}

\begin{tabular}{|l|ll|ll|ll|}
85 & $\$$ & 13.90 & $\$$ & 16.754 & $\$$ & $(2.85)$ \\
\hline
\end{tabular}

\begin{tabular}{l|llll|ll|}
85 & $\$$ & 13.90 & $\$$ & 16.754 & $\$$ & $(2.85)$ \\
86 & $\$$ & 14.20 & $\$$ & 16.986 & $\$$ & $(2.78)$ \\
\hline
\end{tabular}

\begin{tabular}{|l|ll|ll|ll|}
86 & $\$$ & 14.20 & $\$$ & 16.986 & $\$$ & $(2.78)$ \\
\hline 87 & $\$$ & 14.51 & $\$$ & 17.219 & $\$$ & $(2.71)$ \\
88 & $\$$ & 14.81 & $\$$ & 17.452 & $\$$ & $(2.64)$ \\
\hline
\end{tabular}

\begin{tabular}{lllll|ll|}
88 & $\$$ & 14.81 & $\$$ & 17.452 & $\$$ & $(2.64)$ \\
\hline 89 & $\$$ & 15.11 & $\$$ & 17.686 & $\$$ & $(2.57)$ \\
90 & $\$$ & 15.42 & $\$$ & 17.919 & $\$$ & $(2.50)$ \\
\hline 91 & $\$$ & 15.72 & $\$$ & 18.153 & $\$$ & $(2.43)$ \\
\hline 92 & $\$$ & 16.03 & $\$$ & 18.388 & $\$$ & $(2.36)$ \\
\hline 93 & $\$$ & 16.33 & $\$$ & 18.622 & $\$$ & $(2.29)$ \\
\hline 94 & $\$$ & 16.63 & $\$$ & 18.857 & $\$$ & $(2.22)$ \\
\hline 95 & $\$$ & 16.94 & $\$$ & 19.092 & $\$$ & $(2.15)$ \\
\hline 96 & $\$$ & 17.25 & $\$$ & 19.328 & $\$$ & $(2.08)$ \\
\hline 97 & $\$$ & 17.55 & $\$$ & 19.563 & $\$$ & $(2.01)$ \\
\hline 98 & $\$$ & 17.86 & $\$$ & 19.799 & $\$$ & $(1.94)$ \\
\hline 99 & $\$$ & 18.16 & $\$$ & 20.035 & $\$$ & $(1.87)$ \\
\hline 100 & $\$$ & 18.47 & $\$$ & 20.272 & $\$$ & $(1.80)$ \\
\hline
\end{tabular}




\begin{tabular}{|c|c|c|c|c|c|c|c|c|c|c|c|c|c|}
\hline \multicolumn{7}{|c|}{ Mentor/Manual: Profit (Continued) } & \multicolumn{7}{|c|}{ Mentor/Manual: Profit (Continued) } \\
\hline \multirow{2}{*}{$\frac{\text { Report number }}{101}$} & \multicolumn{2}{|c|}{ Mentor/Manual } & \multicolumn{2}{|c|}{ Observe and Do } & \multicolumn{2}{|c|}{ Difference (ROI) } & \multirow{2}{*}{$\begin{array}{c}\text { Report number } \\
151 \\
\end{array}$} & \multicolumn{2}{|c|}{ Mentor/Manual } & \multicolumn{2}{|c|}{ Observe and Do } & \multicolumn{2}{|c|}{ Difference (ROI) } \\
\hline & $\$$ & 18.78 & $\$$ & 20.509 & $\$$ & $(1.73)$ & & $\$$ & 34.39 & $\$$ & 32.626 & $\$$ & 1.77 \\
\hline 102 & $\$$ & 19.08 & $\$$ & 20.746 & $\$$ & $(1.66)$ & 152 & $\$$ & 34.71 & $\$$ & 32.873 & $\$$ & 1.84 \\
\hline 103 & $\$$ & 19.39 & $\$$ & 20.983 & $\$$ & (1.59) & 153 & $\$$ & 35.03 & $\$$ & 33.120 & $\$$ & 1.91 \\
\hline 104 & $\$$ & 19.70 & $\$$ & 21.220 & $\$$ & $(1.52)$ & 154 & $\$$ & 35.35 & $\$$ & 33.367 & $\$$ & 1.98 \\
\hline 105 & $\$$ & 20.01 & $\$$ & 21.458 & $\$$ & $(1.45)$ & 155 & $\$$ & 35.66 & $\$$ & 33.615 & $\$$ & 2.05 \\
\hline 106 & $\$$ & 20.31 & $\$$ & 21.696 & $\$$ & (1.38) & 156 & $\$$ & 35.98 & $\$$ & 33.863 & $\$$ & 2.12 \\
\hline 107 & $\$$ & 20.62 & $\$$ & 21.935 & $\$$ & $(1.31)$ & 157 & $\$$ & 36.30 & $\$$ & 34.111 & $\$$ & 2.19 \\
\hline 108 & $\$$ & 20.93 & $\$$ & 22.173 & $\$$ & $(1.24)$ & 158 & $\$$ & 36.62 & $\$$ & 34.359 & $\$$ & 2.26 \\
\hline 109 & $\$$ & 21.24 & $\$$ & 22.412 & $\$$ & (1.17) & 159 & $\$$ & 36.94 & $\$$ & 34.607 & $\$$ & 2.33 \\
\hline 110 & $\$$ & 21.55 & $\$$ & 22.651 & $\$$ & $(1.10)$ & 160 & $\$$ & 37.25 & $\$$ & 34.855 & $\$$ & 2.40 \\
\hline 111 & $\$$ & 21.86 & $\$$ & 22.890 & $\$$ & (1.03) & 161 & $\$$ & 37.57 & $\$$ & 35.104 & $\$$ & 2.47 \\
\hline 112 & $\$$ & 22.17 & $\$$ & 23.129 & $\$$ & $(0.96)$ & 162 & $\$$ & 37.89 & $\$$ & 35.352 & $\$$ & 2.54 \\
\hline 113 & $\$$ & 22.48 & $\$$ & 23.369 & $\$$ & $(0.89)$ & 163 & $\$$ & 38.21 & $\$$ & 35.601 & $\$$ & 2.61 \\
\hline 114 & $\$$ & 22.79 & $\$$ & 23.609 & $\$$ & $(0.82)$ & 164 & $\$$ & 38.53 & $\$$ & 35.850 & $\$$ & 2.68 \\
\hline 115 & $\$$ & 23.10 & $\$$ & 23.849 & $\$$ & $(0.75)$ & 165 & $\$$ & 38.85 & $\$$ & 36.099 & $\$$ & 2.75 \\
\hline 116 & $\$$ & 23.41 & $\$$ & 24.089 & $\$$ & $(0.68)$ & 166 & $\$$ & 39.17 & $\$$ & 36.348 & $\$$ & 2.82 \\
\hline 117 & $\$$ & 23.72 & $\$$ & 24.330 & $\$$ & $(0.61)$ & 167 & $\$$ & 39.49 & $\$$ & 36.598 & $\$$ & $2.8 \mathrm{~s}$ \\
\hline 118 & $\$$ & 24.03 & $\$$ & 24.571 & $\$$ & $(0.54)$ & 168 & $\$$ & 39.81 & $\$$ & 36.847 & $\$$ & 2.96 \\
\hline 119 & $\$$ & 24.34 & $\$$ & 24.812 & $\$$ & $(0.47)$ & 169 & $\$$ & 40.13 & $\$$ & 37.097 & $\$$ & 3.03 \\
\hline 120 & $\$$ & 24.65 & $\$$ & 25.053 & $\$$ & $(0.40)$ & 170 & $\$$ & 40.45 & $\$$ & 37.347 & $\$$ & 3.10 \\
\hline 121 & $\$$ & 24.96 & $\$$ & 25.294 & $\$$ & $(0.33)$ & 171 & $\$$ & 40.77 & $\$$ & 37.597 & $\$$ & 3.17 \\
\hline 122 & $\$$ & 25.27 & $\$$ & 25.536 & $\$$ & $(0.26)$ & 172 & $\$$ & 41.09 & $\$$ & 37.847 & $\$$ & 3.24 \\
\hline 123 & $\$$ & 25.59 & $\$$ & 25.778 & $\$$ & $(0.19)$ & 173 & $\$$ & 41.41 & $\$$ & 38.097 & $\$$ & 3.31 \\
\hline 124 & $\$$ & 25.90 & $\$$ & 26.020 & $\$$ & $(0.12)$ & 174 & $\$$ & 41.73 & $\$$ & 38.347 & $\$$ & 3.38 \\
\hline 125 & $\$$ & 26.21 & $\$$ & 26.262 & $\$$ & $(0.05)$ & 175 & $\$$ & 42.05 & $\$$ & 38.598 & $\$$ & 3.45 \\
\hline 126 & $\$$ & 26.52 & $\$$ & 26.504 & $\$$ & 0.02 & 176 & $\$$ & 42.37 & $\$$ & 38.848 & $\$$ & 3.52 \\
\hline 127 & $\$$ & 26.84 & $\$$ & 26.747 & $\$$ & 0.09 & 177 & $\$$ & 42.69 & $\$$ & 39.099 & $\$$ & 3.59 \\
\hline 128 & $\$$ & 27.15 & $\$$ & 26.990 & $\$$ & 0.16 & 178 & $\$$ & 43.01 & $\$$ & 39.350 & $\$$ & 3.66 \\
\hline 129 & $\$$ & 27.46 & $\$$ & 27.233 & $\$$ & 0.23 & 179 & $\$$ & 43.33 & $\$$ & 39.601 & $\$$ & 3.73 \\
\hline 130 & $\$$ & 27.77 & $\$$ & 27.476 & $\$$ & 0.30 & 180 & $\$$ & 43.65 & $\$$ & 39.852 & $\$$ & 3.80 \\
\hline 131 & $\$$ & 28.09 & $\$$ & 27.720 & $\$$ & 0.37 & 181 & $\$$ & 43.97 & $\$$ & 40.103 & $\$$ & 3.87 \\
\hline 132 & $\$$ & 28.40 & $\$$ & 27.963 & $\$$ & 0.44 & 182 & $\$$ & 44.30 & $\$$ & 40.355 & $\$$ & 3.94 \\
\hline 133 & $\$$ & 28.72 & $\$$ & 28.207 & $\$$ & 0.51 & 183 & $\$$ & 44.62 & $\$$ & 40.606 & $\$$ & 4.01 \\
\hline 134 & $\$$ & 29.03 & $\$$ & 28.451 & $\$$ & 0.58 & 184 & $\$$ & 44.94 & $\$$ & 40.858 & $\$$ & 4.08 \\
\hline 135 & $\$$ & 29.34 & $\$$ & 28.695 & $\$$ & 0.65 & 185 & $\$$ & 45.26 & $\$$ & 41.110 & $\$$ & 4.15 \\
\hline 136 & $\$$ & 29.66 & $\$$ & 28.939 & $\$$ & 0.72 & 186 & $\$$ & 45.58 & $\$$ & 41.362 & $\$$ & 4.22 \\
\hline 137 & $\$$ & 29.97 & $\$$ & 29.184 & $\$$ & 0.79 & 187 & $\$$ & 45.90 & $\$$ & 41.614 & $\$$ & 4.25 \\
\hline 138 & $\$$ & 30.29 & $\$$ & 29.429 & $\$$ & 0.86 & 188 & $\$$ & 46.23 & $\$$ & 41.866 & $\$$ & 4.36 \\
\hline 139 & $\$$ & 30.60 & $\$$ & 29.674 & $\$$ & 0.93 & 189 & $\$$ & 46.55 & $\$$ & 42.118 & $\$$ & 4.43 \\
\hline 140 & $\$$ & 30.92 & $\$$ & 29.919 & $\$$ & 1.00 & 190 & $\$$ & 46.87 & $\$$ & 42.371 & $\$$ & 4.50 \\
\hline 141 & $\$$ & 31.23 & $\$$ & 30.164 & $\$$ & 1.07 & 191 & $\$$ & 47.19 & $\$$ & 42.623 & $\$$ & 4.57 \\
\hline 142 & $\$$ & 31.55 & $\$$ & 30.409 & $\$$ & 1.14 & 192 & $\$$ & 47.52 & $\$$ & 42.876 & $\$$ & 4.64 \\
\hline 143 & $\$$ & 31.86 & $\$$ & 30.655 & $\$$ & 1.21 & 193 & $\$$ & 47.84 & $\$$ & 43.129 & $\$$ & 4.71 \\
\hline 144 & $\$$ & 32.18 & $\$$ & 30.901 & $\$$ & 1.28 & 194 & $\$$ & 48.16 & $\$$ & 43.382 & $\$$ & 4.78 \\
\hline 145 & $\$$ & 32.50 & $\$$ & 31.147 & $\$$ & 1.35 & 195 & $\$$ & 48.49 & $\$$ & 43.635 & $\$$ & 4.85 \\
\hline 146 & $\$$ & 32.81 & $\$$ & 31.393 & $\$$ & 1.42 & 196 & $\$$ & 48.81 & $\$$ & 43.888 & $\$$ & 4.92 \\
\hline 147 & $\$$ & 33.13 & $\$$ & 31.639 & $\$$ & 1.49 & 197 & $\$$ & 49.13 & $\$$ & 44.141 & $\$$ & 4.99 \\
\hline 148 & $\$$ & 33.44 & $\$$ & 31.885 & $\$$ & 1.56 & 198 & $\$$ & 49.46 & $\$$ & 44.394 & $\$$ & 5.06 \\
\hline 149 & $\$$ & 33.76 & $\$$ & 32.132 & $\$$ & 1.63 & 199 & $\$$ & 49.78 & $\$$ & 44.648 & $\$$ & 5.13 \\
\hline 150 & $\$$ & 34.08 & $\$$ & 32.379 & $\$$ & 1.70 & 200 & $\$$ & 50.10 & $\$$ & 44.902 & $\$$ & 5.20 \\
\hline
\end{tabular}


APPENDIX M:

PROFIT COMPARISON CHARTS 

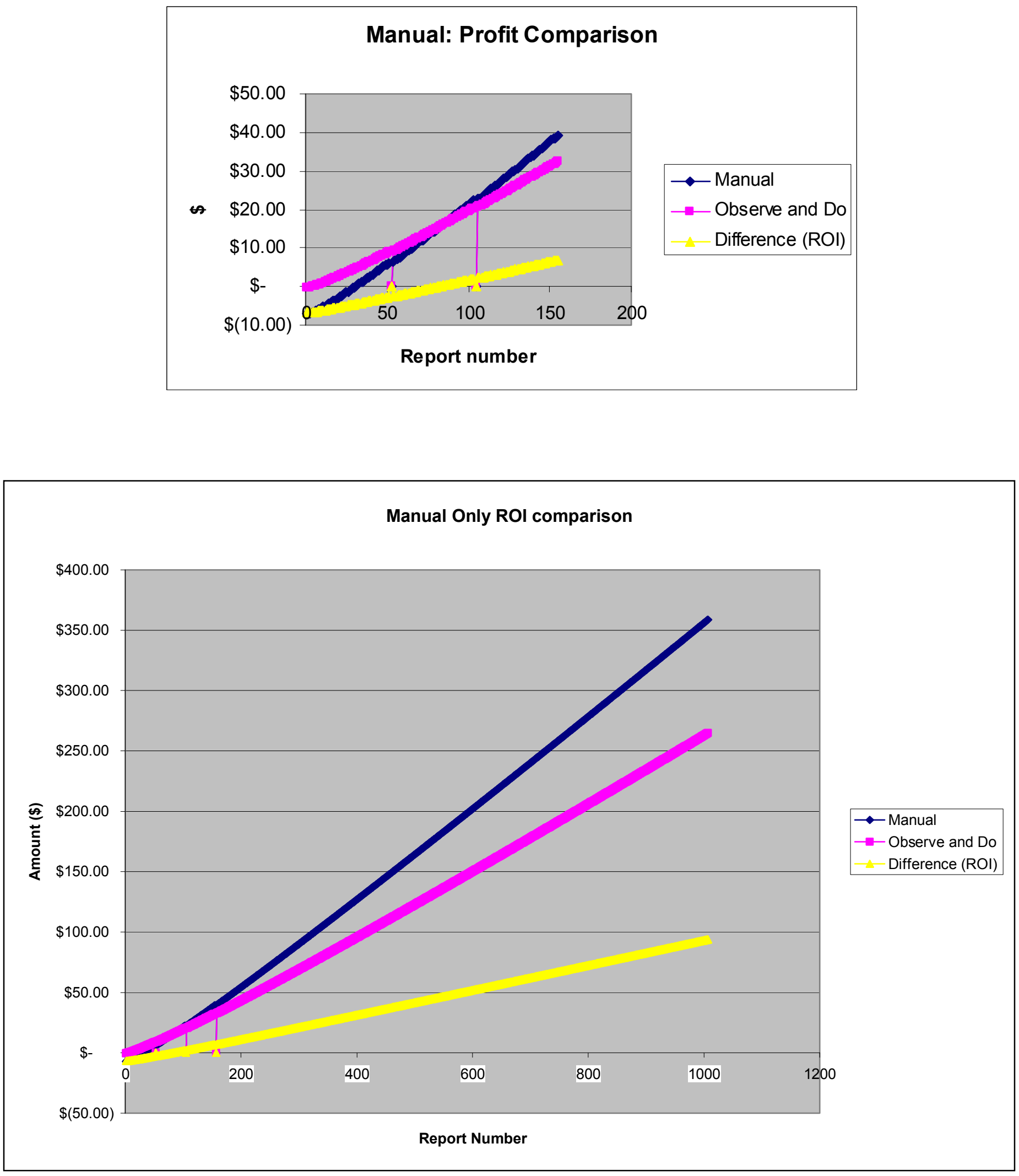

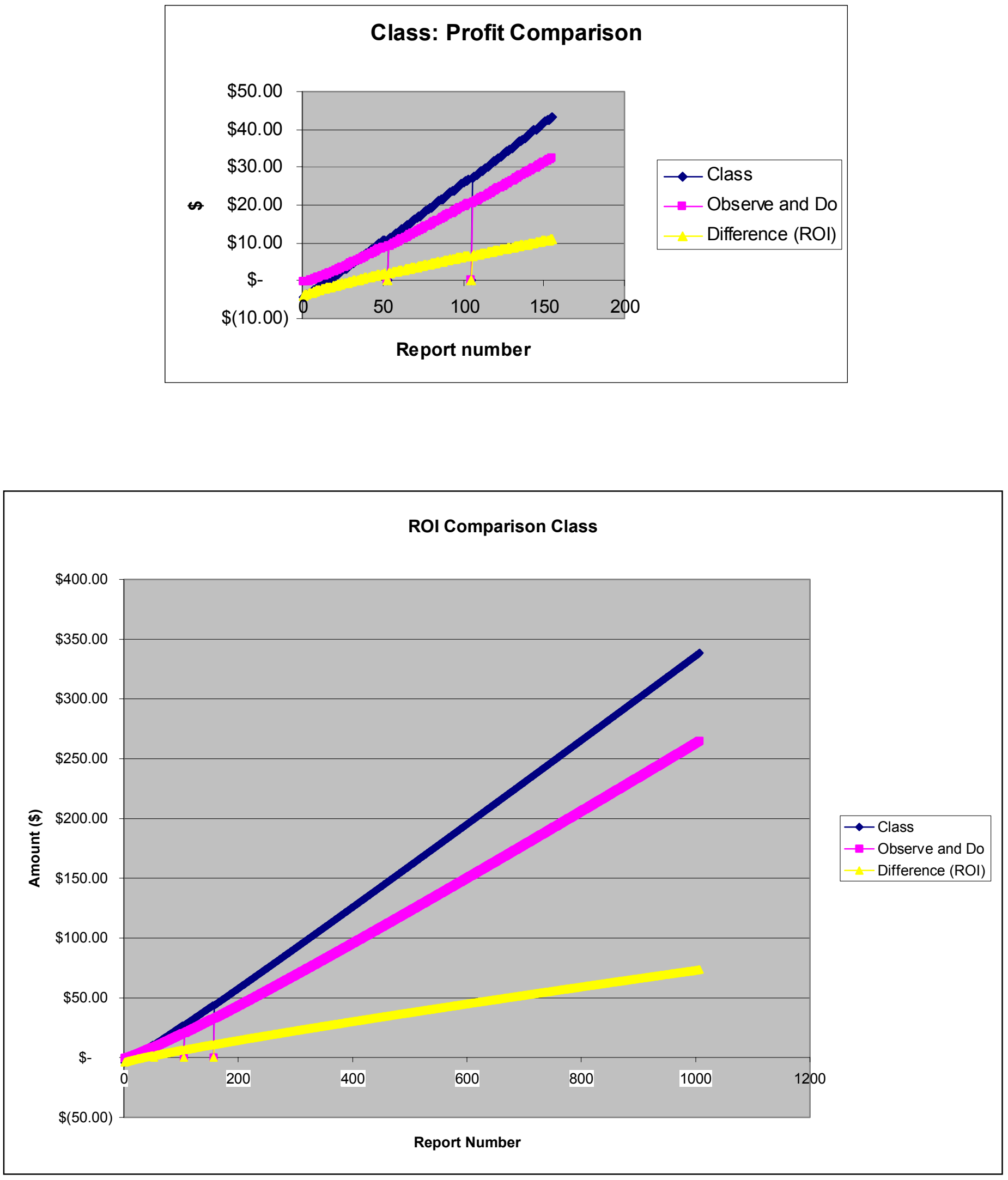

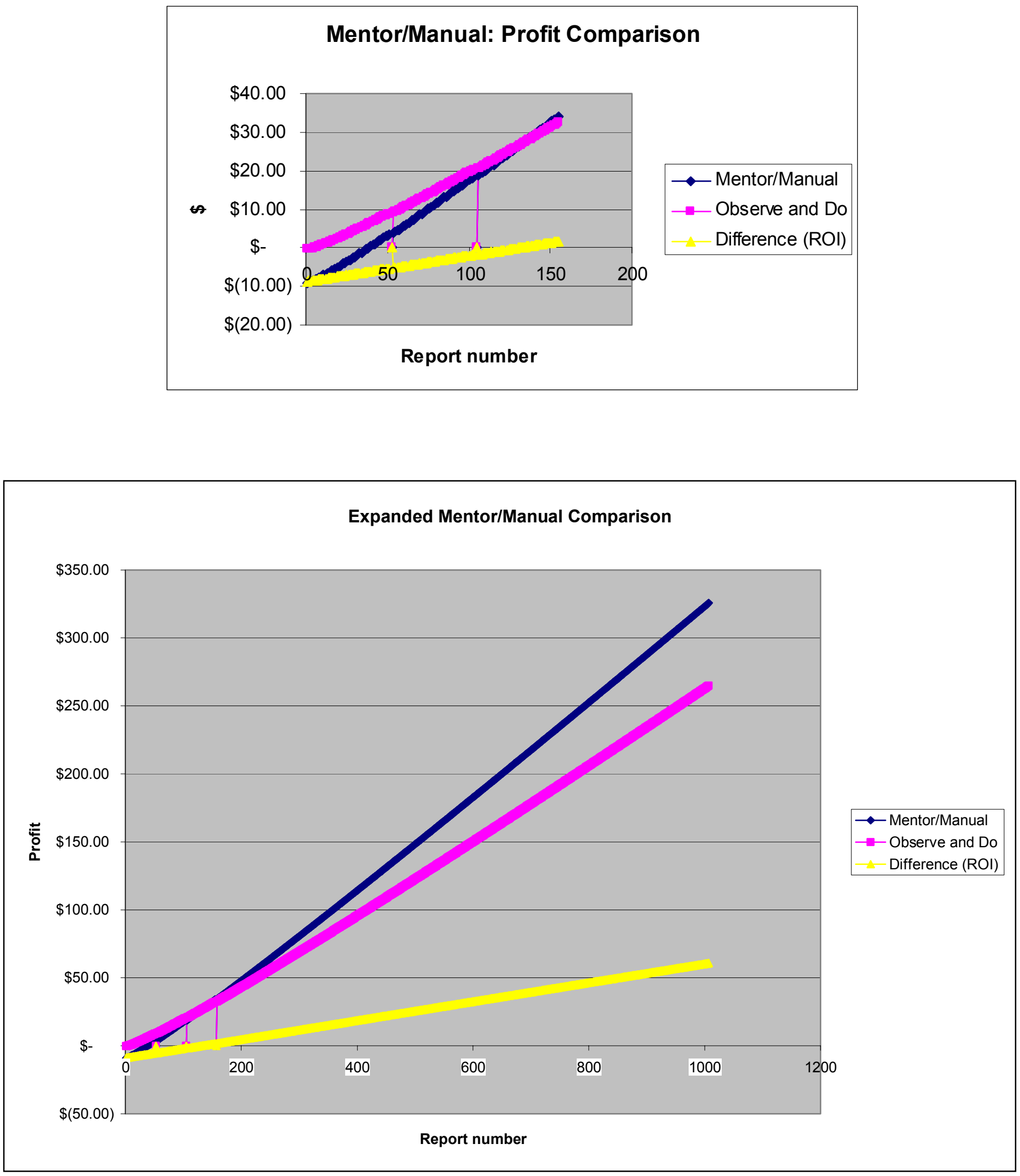
APPENDIX N:

ROI COMPARISON CHART 


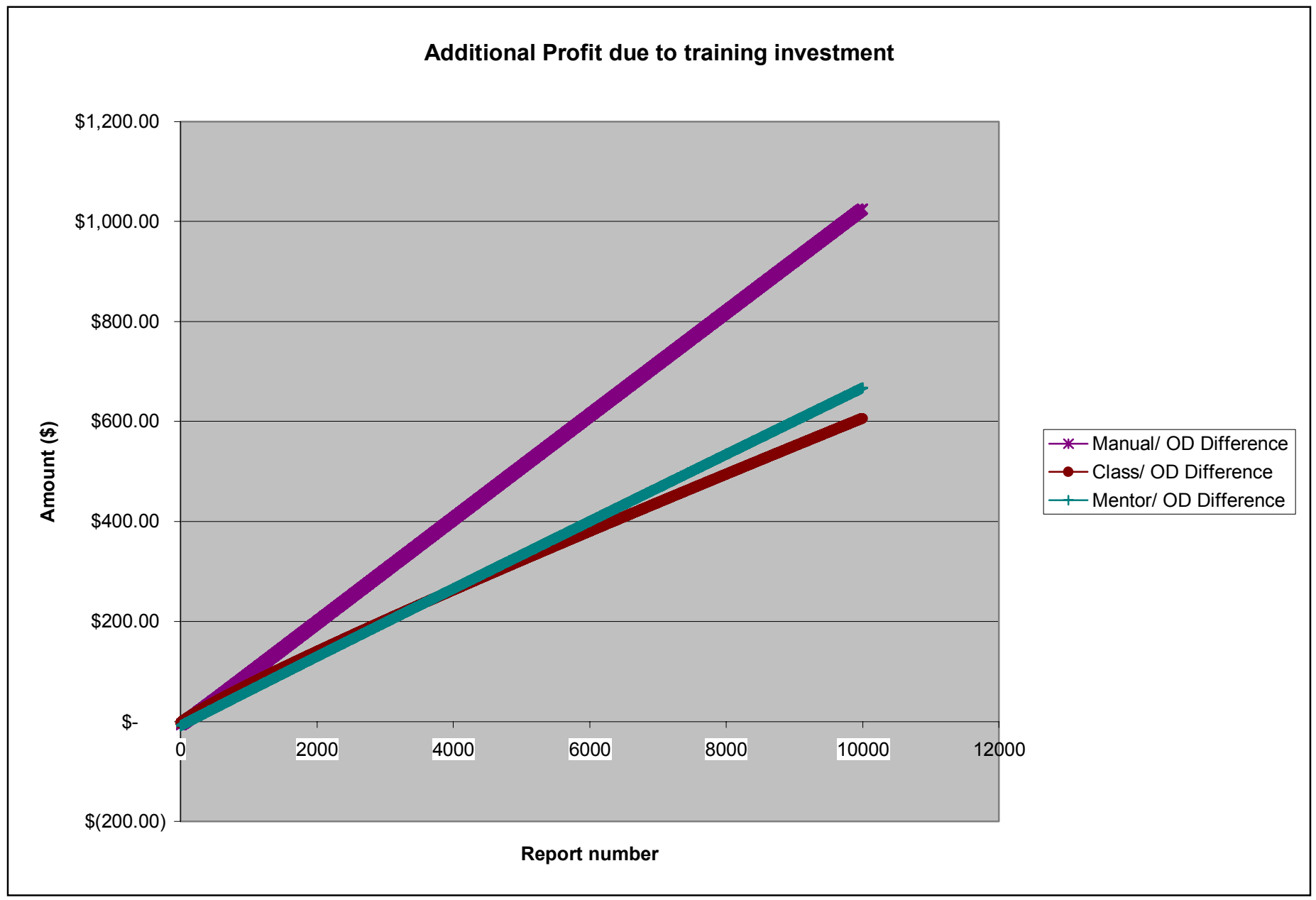


APPENDIX O:

SENSITITVITY ANALYSIS DATA 


\begin{tabular}{|c|c|c|c|c|c|c|c|c|c|c|c|c|c|c|}
\hline \multirow[b]{3}{*}{$\begin{array}{l}\text { Report } \\
\text { number }\end{array}$} & \multicolumn{12}{|c|}{ Observe and Do Sensitivity Analysis Data } & & \multirow[b]{2}{*}{ 3oth occu } \\
\hline & \multicolumn{6}{|c|}{ Price increase from $\$ 1.00$ to $\$ 1.50$} & \multicolumn{6}{|c|}{ Material Cost Decreases from $\$ .53$ to $\$ .33$} & & \\
\hline & \multicolumn{2}{|c|}{ Benefit } & \multicolumn{2}{|c|}{$\begin{array}{c}\text { Cumulative } \\
\text { Benefit }\end{array}$} & \multicolumn{2}{|c|}{ Profit } & \multicolumn{2}{|c|}{ Cost } & & $\begin{array}{l}\text { ulative } \\
\text { ost }\end{array}$ & \multicolumn{2}{|c|}{ Profit } & & Profit \\
\hline 0 & $\$$ & - & $\$$ & - & $\$$ & $(0.360)$ & $\$$ & 0.360 & $\$$ & 0.360 & $\$$ & $(0.360)$ & $\$$ & $(0.360)$ \\
\hline 1 & $\$$ & 1.388 & $\$$ & 1.388 & $\$$ & 0.154 & $\$$ & 0.674 & $\$$ & 1.034 & $\$$ & $(0.109)$ & $\$$ & 0.354 \\
\hline 2 & $\$$ & 1.388 & $\$$ & 2.775 & $\$$ & 0.706 & $\$$ & 0.635 & $\$$ & 1.669 & $\$$ & 0.181 & $\$$ & 1.106 \\
\hline 3 & $\$$ & 1.388 & $\$$ & 4.163 & $\$$ & 1.278 & $\$$ & 0.615 & $\$$ & 2.284 & $\$$ & 0.491 & $\$$ & 1.878 \\
\hline 4 & $\$$ & 1.388 & $\$$ & 5.550 & $\$$ & 1.864 & $\$$ & 0.602 & $\$$ & 2.886 & $\$$ & 0.814 & $\$$ & 2.664 \\
\hline 5 & $\$$ & 1.388 & $\$$ & 6.938 & $\$$ & 2.460 & $\$$ & 0.592 & $\$$ & 3.478 & $\$$ & 1.147 & $\$$ & 3.460 \\
\hline 6 & $\$$ & 1.388 & $\$$ & 8.325 & $\$$ & 3.064 & $\$$ & 0.584 & $\$$ & 4.061 & $\$$ & 1.489 & $\$$ & 4.264 \\
\hline 7 & $\$$ & 1.388 & $\$$ & 9.713 & $\$$ & 3.674 & $\$$ & 0.577 & $\$$ & 4.639 & $\$$ & 1.836 & $\$$ & 5.074 \\
\hline 8 & $\$$ & 1.388 & $\$$ & 11.100 & $\$$ & 4.290 & $\$$ & 0.572 & $\$$ & 5.210 & $\$$ & 2.190 & $\$$ & 5.890 \\
\hline 9 & $\$$ & 1.388 & $\$$ & 12.488 & $\$$ & 4.910 & $\$$ & 0.567 & $\$$ & 5.777 & $\$$ & 2.548 & $\$$ & 6.710 \\
\hline 10 & $\$$ & 1.388 & $\$$ & 13.875 & $\$$ & 5.535 & $\$$ & 0.563 & $\$$ & 6.340 & $\$$ & 2.910 & $\$$ & 7.535 \\
\hline 11 & $\$$ & 1.388 & $\$$ & 15.263 & $\$$ & 6.163 & $\$$ & 0.559 & $\$$ & 6.899 & $\$$ & 3.276 & $\$$ & 8.363 \\
\hline 12 & $\$$ & 1.388 & $\$$ & 16.650 & $\$$ & 6.795 & $\$$ & 0.556 & $\$$ & 7.455 & $\$$ & 3.645 & $\$$ & 9.195 \\
\hline 13 & $\$$ & 1.388 & $\$$ & 18.038 & $\$$ & 7.430 & $\$$ & 0.553 & $\$$ & 8.008 & $\$$ & 4.017 & $\$$ & 10.030 \\
\hline 14 & $\$$ & 1.388 & $\$$ & 19.425 & $\$$ & 8.067 & $\$$ & 0.550 & $\$$ & 8.558 & $\$$ & 4.392 & $\$$ & 10.867 \\
\hline 15 & $\$$ & 1.388 & $\$$ & 20.813 & $\$$ & 8.707 & $\$$ & 0.547 & $\$$ & 9.105 & $\$$ & 4.770 & $\$$ & 11.707 \\
\hline 16 & $\$$ & 1.388 & $\$$ & 22.200 & $\$$ & 9.350 & $\$$ & 0.545 & $\$$ & 9.650 & $\$$ & 5.150 & $\$$ & 12.550 \\
\hline 17 & $\$$ & 1.388 & $\$$ & 23.588 & $\$$ & 9.994 & $\$$ & 0.543 & $\$$ & 10.193 & $\$$ & 5.532 & $\$$ & 13.394 \\
\hline 18 & $\$$ & 1.388 & $\$$ & 24.975 & $\$$ & 10.641 & $\$$ & 0.541 & $\$$ & 10.734 & $\$$ & 5.916 & $\$$ & 14.241 \\
\hline 19 & $\$$ & 1.388 & $\$$ & 26.363 & $\$$ & 11.289 & $\$$ & 0.539 & $\$$ & 11.273 & $\$$ & 6.302 & $\$$ & 15.089 \\
\hline 20 & $\$$ & 1.388 & $\$$ & 27.750 & $\$$ & 11.940 & $\$$ & 0.537 & $\$$ & 11.810 & $\$$ & 6.690 & $\$$ & 15.940 \\
\hline 21 & $\$$ & 1.388 & $\$$ & 29.138 & $\$$ & 12.592 & $\$$ & 0.536 & $\$$ & 12.346 & $\$$ & 7.079 & $\$$ & 16.792 \\
\hline 22 & $\$$ & 1.388 & $\$$ & 30.525 & $\$$ & 13.245 & $\$$ & 0.534 & $\$$ & 12.880 & $\$$ & 7.470 & $\$$ & 17.645 \\
\hline 23 & $\$$ & 1.388 & $\$$ & 31.913 & $\$$ & 13.900 & $\$$ & 0.532 & $\$$ & 13.412 & $\$$ & 7.863 & $\$$ & 18.500 \\
\hline 24 & $\$$ & 1.388 & $\$$ & 33.300 & $\$$ & 14.557 & $\$$ & 0.531 & $\$$ & 13.943 & $\$$ & 8.257 & $\$$ & 19.357 \\
\hline 25 & $\$$ & 1.388 & $\$$ & 34.688 & $\$$ & 15.214 & $\$$ & 0.530 & $\$$ & 14.473 & $\$$ & 8.652 & $\$$ & 20.214 \\
\hline 26 & $\$$ & 1.388 & $\$$ & 36.075 & $\$$ & 15.874 & $\$$ & 0.528 & $\$$ & 15.001 & $\$$ & 9.049 & $\$$ & 21.074 \\
\hline 27 & $\$$ & 1.388 & $\$$ & 37.463 & $\$$ & 16.534 & $\$$ & 0.527 & $\$$ & 15.528 & $\$$ & 9.447 & $\$$ & 21.934 \\
\hline 28 & $\$$ & 1.388 & $\$$ & 38.850 & $\$$ & 17.196 & $\$$ & 0.526 & $\$$ & 16.054 & $\$$ & 9.846 & $\$$ & 22.796 \\
\hline 29 & $\$$ & 1.388 & $\$$ & 40.238 & $\$$ & 17.858 & $\$$ & 0.525 & $\$$ & 16.579 & $\$$ & 10.246 & $\$$ & 23.658 \\
\hline 30 & $\$$ & 1.388 & $\$$ & 41.625 & $\$$ & 18.522 & $\$$ & 0.524 & $\$$ & 17.103 & $\$$ & 10.647 & $\$$ & 24.522 \\
\hline 31 & $\$$ & 1.388 & $\$$ & 43.013 & $\$$ & 19.187 & $\$$ & 0.523 & $\$$ & 17.625 & $\$$ & 11.050 & $\$$ & 25.387 \\
\hline 32 & $\$$ & 1.388 & $\$$ & 44.400 & $\$$ & 19.853 & $\$$ & 0.522 & $\$$ & 18.147 & $\$$ & 11.453 & $\$$ & 26.253 \\
\hline 33 & $\$$ & 1.388 & $\$$ & 45.788 & $\$$ & 20.520 & $\$$ & 0.521 & $\$$ & 18.667 & $\$$ & 11.858 & $\$$ & 27.120 \\
\hline 34 & $\$$ & 1.388 & $\$$ & 47.175 & $\$$ & 21.188 & $\$$ & 0.520 & $\$$ & 19.187 & $\$$ & 12.263 & $\$$ & 27.988 \\
\hline 35 & $\$$ & 1.388 & $\$$ & 48.563 & $\$$ & 21.857 & $\$$ & 0.519 & $\$$ & 19.706 & $\$$ & 12.669 & $\$$ & 28.857 \\
\hline 36 & $\$$ & 1.388 & $\$$ & 49.950 & $\$$ & 22.526 & $\$$ & 0.518 & $\$$ & 20.224 & $\$$ & 13.076 & $\$$ & 29.726 \\
\hline 37 & $\$$ & 1.388 & $\$$ & 51.338 & $\$$ & 23.197 & $\$$ & 0.517 & $\$$ & 20.741 & $\$$ & 13.484 & $\$$ & 30.597 \\
\hline 38 & $\$$ & 1.388 & $\$$ & 52.725 & $\$$ & 23.868 & $\$$ & 0.516 & $\$$ & 21.257 & $\$$ & 13.893 & $\$$ & 31.468 \\
\hline 39 & $\$$ & 1.388 & $\$$ & 54.113 & $\$$ & 24.540 & $\$$ & 0.515 & $\$$ & 21.772 & $\$$ & 14.303 & $\$$ & 32.340 \\
\hline 40 & $\$$ & 1.388 & $\$$ & 55.500 & $\$$ & 25.213 & $\$$ & 0.515 & $\$$ & 22.287 & $\$$ & 14.713 & $\$$ & 33.213 \\
\hline 41 & $\$$ & 1.388 & $\$$ & 56.888 & $\$$ & 25.887 & $\$$ & 0.514 & $\$$ & 22.801 & $\$$ & 15.124 & $\$$ & 34.087 \\
\hline 42 & $\$$ & 1.388 & $\$$ & 58.275 & $\$$ & 26.561 & $\$$ & 0.513 & $\$$ & 23.314 & $\$$ & 15.536 & $\$$ & 34.961 \\
\hline 43 & $\$$ & 1.388 & $\$$ & 59.663 & $\$$ & 27.236 & $\$$ & 0.512 & $\$$ & 23.826 & $\$$ & 15.949 & $\$$ & 35.836 \\
\hline 44 & $\$$ & 1.388 & $\$$ & 61.050 & $\$$ & 27.912 & $\$$ & 0.512 & $\$$ & 24.338 & $\$$ & 16.362 & $\$$ & 36.712 \\
\hline 45 & $\$$ & 1.388 & $\$$ & 62.438 & $\$$ & 28.589 & $\$$ & 0.511 & $\$$ & 24.849 & $\$$ & 16.776 & $\$$ & 37.589 \\
\hline 46 & $\$$ & 1.388 & $\$$ & 63.825 & $\$$ & 29.266 & $\$$ & 0.510 & $\$$ & 25.359 & $\$$ & 17.191 & $\$$ & 38.466 \\
\hline 47 & $\$$ & 1.388 & $\$$ & 65.213 & $\$$ & 29.944 & $\$$ & 0.510 & $\$$ & 25.869 & $\$$ & 17.606 & $\$$ & 39.344 \\
\hline 48 & $\$$ & 1.388 & $\$$ & 66.600 & $\$$ & 30.622 & $\$$ & 0.509 & $\$$ & 26.378 & $\$$ & 18.022 & $\$$ & 40.222 \\
\hline 49 & $\$$ & 1.388 & $\$$ & 67.988 & $\$$ & 31.301 & $\$$ & 0.508 & $\$$ & 26.886 & $\$$ & 18.439 & $\$$ & 41.101 \\
\hline 50 & $\$$ & 1.388 & $\$$ & 69.375 & $\$$ & 31.981 & $\$$ & 0.508 & $\$$ & 27.394 & $\$$ & 18.856 & $\$$ & 41.981 \\
\hline 51 & $\$$ & 1.388 & $\$$ & 70.763 & $\$$ & 32.661 & $\$$ & 0.507 & $\$$ & 27.901 & $\$$ & 19.274 & $\$$ & 42.861 \\
\hline 52 & $\$$ & 1.388 & $\$$ & 72.150 & $\$$ & 33.342 & $\$$ & 0.507 & $\$$ & 28.408 & $\$$ & 19.692 & $\$$ & 43.742 \\
\hline 53 & $\$$ & 1.388 & $\$$ & 73.538 & $\$$ & 34.023 & $\$$ & 0.506 & $\$$ & 28.914 & $\$$ & 20.111 & $\$$ & 44.623 \\
\hline 54 & $\$$ & 1.388 & $\$$ & 74.925 & $\$$ & 34.705 & $\$$ & 0.506 & $\$$ & 29.420 & $\$$ & 20.530 & $\$$ & 45.505 \\
\hline 55 & $\$$ & 1.388 & $\$$ & 76.313 & $\$$ & 35.388 & $\$$ & 0.505 & $\$$ & 29.925 & $\$$ & 20.950 & $\$$ & 46.388 \\
\hline 56 & $\$$ & 1.388 & $\$$ & 77.700 & $\$$ & 36.071 & $\$$ & 0.505 & $\$$ & 30.429 & $\$$ & 21.371 & $\$$ & 47.271 \\
\hline 57 & $\$$ & 1.388 & $\$$ & 79.088 & $\$$ & 36.754 & $\$$ & 0.504 & $\$$ & 30.933 & $\$$ & 21.792 & $\$$ & 48.154 \\
\hline 58 & $\$$ & 1.388 & $\$$ & 80.475 & $\$$ & 37.438 & $\$$ & 0.504 & $\$$ & 31.437 & $\$$ & 22.213 & $\$$ & 49.038 \\
\hline 59 & $\$$ & 1.388 & $\$$ & 81.863 & $\$$ & 38.123 & $\$$ & 0.503 & $\$$ & 31.940 & $\$$ & 22.635 & $\$$ & 49.923 \\
\hline 60 & $\$$ & 1.388 & $\$$ & 83.250 & $\$$ & 38.808 & $\$$ & 0.503 & $\$$ & 32.442 & $\$$ & 23.058 & $\$$ & 50.808 \\
\hline
\end{tabular}




\begin{tabular}{|c|c|c|c|c|c|c|c|c|c|c|c|c|c|c|}
\hline \multirow[b]{3}{*}{$\begin{array}{l}\text { Report } \\
\text { number }\end{array}$} & \multicolumn{13}{|c|}{ Manual Sensitivity Analysis } & \multirow[b]{2}{*}{ 3oth occur } \\
\hline & \multicolumn{6}{|c|}{ Price increase from $\$ 1.00$ to $\$ 1.50$} & \multicolumn{6}{|c|}{$\begin{array}{c}\text { Material Cost Decreases from } \$ .53 \text { to } \\
\$ .33\end{array}$} & & \\
\hline & \multicolumn{2}{|c|}{ Benefit } & \multicolumn{2}{|c|}{$\begin{array}{c}\text { Cumulative } \\
\text { Benefit }\end{array}$} & \multicolumn{2}{|c|}{ Profit } & & ost & & $\begin{array}{l}\text { nulative } \\
\text { Cost }\end{array}$ & \multicolumn{2}{|r|}{ Profit } & \multicolumn{2}{|c|}{ Profit } \\
\hline 0 & $\$$ & - & $\$$ & - & $\$$ & $(7.110)$ & $\$$ & 7.110 & $\$$ & 7.110 & $\$$ & $(7.110)$ & $\$$ & $(7.110)$ \\
\hline 1 & $\$$ & 1.500 & $\$$ & 1.500 & $\$$ & $(6.542)$ & $\$$ & 0.737 & $\$$ & 7.847 & $\$$ & $(6.847)$ & $\$$ & (6.347) \\
\hline 2 & $\$$ & 1.500 & $\$$ & 3.000 & $\$$ & $(5.913)$ & $\$$ & 0.677 & $\$$ & 8.524 & $\$$ & $(6.524)$ & $\$$ & $(5.524)$ \\
\hline 3 & $\$$ & 1.500 & $\$$ & 4.500 & $\$$ & $(5.253)$ & $\$$ & 0.646 & $\$$ & 9.170 & $\$$ & $(6.170)$ & $\$$ & $(4.670)$ \\
\hline 4 & $\$$ & 1.500 & $\$$ & 6.000 & $\$$ & $(4.573)$ & $\$$ & 0.626 & $\$$ & 9.796 & $\$$ & $(5.796)$ & $\$$ & $(3.796)$ \\
\hline 5 & $\$$ & 1.500 & $\$$ & 7.500 & $\$$ & $(3.878)$ & $\$$ & 0.611 & $\$$ & 10.407 & $\$$ & $(5.407)$ & $\$$ & $(2.907)$ \\
\hline 6 & $\$$ & 1.500 & $\$$ & 9.000 & $\$$ & $(3.172)$ & $\$$ & 0.599 & $\$$ & 11.006 & $\$$ & $(5.006)$ & $\$$ & $(2.006)$ \\
\hline 7 & $\$$ & 1.500 & $\$$ & 10.500 & $\$$ & $(2.457)$ & $\$$ & 0.590 & $\$$ & 11.597 & $\$$ & $(4.597)$ & $\$$ & $(1.097)$ \\
\hline 8 & $\$$ & 1.500 & $\$$ & 12.000 & $\$$ & $(1.733)$ & $\$$ & 0.582 & $\$$ & 12.179 & $\$$ & $(4.179)$ & $\$$ & $(0.179)$ \\
\hline 9 & $\$$ & 1.500 & $\$$ & 13.500 & $\$$ & $(1.003)$ & $\$$ & 0.576 & $\$$ & 12.755 & $\$$ & $(3.755)$ & $\$$ & 0.745 \\
\hline 10 & $\$$ & 1.500 & $\$$ & 15.000 & $\$$ & $(0.267)$ & $\$$ & 0.570 & $\$$ & 13.324 & $\$$ & $(3.324)$ & $\$$ & 1.676 \\
\hline 11 & $\$$ & 1.500 & $\$$ & 16.500 & $\$$ & 0.474 & $\$$ & 0.565 & $\$$ & 13.889 & $\$$ & $(2.889)$ & $\$$ & 2.611 \\
\hline 12 & $\$$ & 1.500 & $\$$ & 18.000 & $\$$ & 1.220 & $\$$ & 0.560 & $\$$ & 14.449 & $\$$ & $(2.449)$ & $\$$ & 3.551 \\
\hline 13 & $\$$ & 1.500 & $\$$ & 19.500 & $\$$ & 1.969 & $\$$ & 0.556 & $\$$ & 15.005 & $\$$ & $(2.005)$ & $\$$ & 4.495 \\
\hline 14 & $\$$ & 1.500 & $\$$ & 21.000 & $\$$ & 2.723 & $\$$ & 0.552 & $\$$ & 15.557 & $\$$ & $(1.557)$ & $\$$ & 5.443 \\
\hline 15 & $\$$ & 1.500 & $\$$ & 22.500 & $\$$ & 3.480 & $\$$ & 0.549 & $\$$ & 16.105 & $\$$ & $(1.105)$ & $\$$ & 6.395 \\
\hline 16 & $\$$ & 1.500 & $\$$ & 24.000 & $\$$ & 4.240 & $\$$ & 0.545 & $\$$ & 16.651 & $\$$ & $(0.651)$ & $\$$ & 7.349 \\
\hline 17 & $\$$ & 1.500 & $\$$ & 25.500 & $\$$ & 5.004 & $\$$ & 0.542 & $\$$ & 17.193 & $\$$ & $(0.193)$ & $\$$ & 8.307 \\
\hline 18 & $\$$ & 1.500 & $\$$ & 27.000 & $\$$ & 5.770 & $\$$ & 0.540 & $\$$ & 17.733 & $\$$ & 0.267 & $\$$ & 9.267 \\
\hline 19 & $\$$ & 1.500 & $\$$ & 28.500 & $\$$ & 6.538 & $\$$ & 0.537 & $\$$ & 18.270 & $\$$ & 0.730 & $\$$ & 10.230 \\
\hline 20 & $\$$ & 1.500 & $\$$ & 30.000 & $\$$ & 7.309 & $\$$ & 0.535 & $\$$ & 18.805 & $\$$ & 1.195 & $\$$ & 11.195 \\
\hline 21 & $\$$ & 1.500 & $\$$ & 31.500 & $\$$ & 8.082 & $\$$ & 0.532 & $\$$ & 19.337 & $\$$ & 1.663 & $\$$ & 12.163 \\
\hline 22 & $\$$ & 1.500 & $\$$ & 33.000 & $\$$ & 8.858 & $\$$ & 0.530 & $\$$ & 19.868 & $\$$ & 2.132 & $\$$ & 13.132 \\
\hline 23 & $\$$ & 1.500 & $\$$ & 34.500 & $\$$ & 9.635 & $\$$ & 0.528 & $\$$ & 20.396 & $\$$ & 2.604 & $\$$ & 14.104 \\
\hline 24 & $\$$ & 1.500 & $\$$ & 36.000 & $\$$ & 10.414 & $\$$ & 0.526 & $\$$ & 20.923 & $\$$ & 3.077 & $\$$ & 15.077 \\
\hline 25 & $\$$ & 1.500 & $\$$ & 37.500 & $\$$ & 11.195 & $\$$ & 0.525 & $\$$ & 21.447 & $\$$ & 3.553 & $\$$ & 16.053 \\
\hline 26 & $\$$ & 1.500 & $\$$ & 39.000 & $\$$ & 11.978 & $\$$ & 0.523 & $\$$ & 21.970 & $\$$ & 4.030 & $\$$ & 17.030 \\
\hline 27 & $\$$ & 1.500 & $\$$ & 40.500 & $\$$ & 12.763 & $\$$ & 0.521 & $\$$ & 22.491 & $\$$ & 4.509 & $\$$ & 18.009 \\
\hline 28 & $\$$ & 1.500 & $\$$ & 42.000 & $\$$ & 13.549 & $\$$ & 0.520 & $\$$ & 23.011 & $\$$ & 4.989 & $\$$ & 18.989 \\
\hline 29 & $\$$ & 1.500 & $\$$ & 43.500 & $\$$ & 14.336 & $\$$ & 0.518 & $\$$ & 23.529 & $\$$ & 5.471 & $\$$ & 19.971 \\
\hline 30 & $\$$ & 1.500 & $\$$ & 45.000 & $\$$ & 15.125 & $\$$ & 0.517 & $\$$ & 24.046 & $\$$ & 5.954 & $\$$ & 20.954 \\
\hline 31 & $\$$ & 1.500 & $\$$ & 46.500 & $\$$ & 15.915 & $\$$ & 0.515 & $\$$ & 24.561 & $\$$ & 6.439 & $\$$ & 21.939 \\
\hline 32 & $\$$ & 1.500 & $\$$ & 48.000 & $\$$ & 16.707 & $\$$ & 0.514 & $\$$ & 25.076 & $\$$ & 6.924 & $\$$ & 22.924 \\
\hline 33 & $\$$ & 1.500 & $\$$ & 49.500 & $\$$ & 17.500 & $\$$ & 0.513 & $\$$ & 25.588 & $\$$ & 7.412 & $\$$ & 23.912 \\
\hline 34 & $\$$ & 1.500 & $\$$ & 51.000 & $\$$ & 18.294 & $\$$ & 0.512 & $\$$ & 26.100 & $\$$ & 7.900 & $\$$ & 24.900 \\
\hline 35 & $\$$ & 1.500 & $\$$ & 52.500 & $\$$ & 19.089 & $\$$ & 0.510 & $\$$ & 26.610 & $\$$ & 8.390 & $\$$ & 25.890 \\
\hline 36 & $\$$ & 1.500 & $\$$ & 54.000 & $\$$ & 19.886 & $\$$ & 0.509 & $\$$ & 27.119 & $\$$ & 8.881 & $\$$ & 26.881 \\
\hline 37 & $\$$ & 1.500 & $\$$ & 55.500 & $\$$ & 20.683 & $\$$ & 0.508 & $\$$ & 27.628 & $\$$ & 9.372 & $\$$ & 27.872 \\
\hline 38 & $\$$ & 1.500 & $\$$ & 57.000 & $\$$ & 21.482 & $\$$ & 0.507 & $\$$ & 28.135 & $\$$ & 9.865 & $\$$ & 28.865 \\
\hline 39 & $\$$ & 1.500 & $\$$ & 58.500 & $\$$ & 22.282 & $\$$ & 0.506 & $\$$ & 28.641 & $\$$ & 10.359 & $\$$ & 29.859 \\
\hline 40 & $\$$ & 1.500 & $\$$ & 60.000 & $\$$ & 23.082 & $\$$ & 0.505 & $\$$ & 29.146 & $\$$ & 10.854 & $\$$ & 30.854 \\
\hline 41 & $\$$ & 1.500 & $\$$ & 61.500 & $\$$ & 23.884 & $\$$ & 0.504 & $\$$ & 29.650 & $\$$ & 11.350 & $\$$ & 31.850 \\
\hline 42 & $\$$ & 1.500 & $\$$ & 63.000 & $\$$ & 24.687 & $\$$ & 0.503 & $\$$ & 30.153 & $\$$ & 11.847 & $\$$ & 32.847 \\
\hline 43 & $\$$ & 1.500 & $\$$ & 64.500 & $\$$ & 25.490 & $\$$ & 0.502 & $\$$ & 30.655 & $\$$ & 12.345 & $\$$ & 33.845 \\
\hline 44 & $\$$ & 1.500 & $\$$ & 66.000 & $\$$ & 26.295 & $\$$ & 0.501 & $\$$ & 31.156 & $\$$ & 12.844 & $\$$ & 34.844 \\
\hline 45 & $\$$ & 1.500 & $\$$ & 67.500 & $\$$ & 27.100 & $\$$ & 0.500 & $\$$ & 31.657 & $\$$ & 13.343 & $\$$ & 35.843 \\
\hline 46 & $\$$ & 1.500 & $\$$ & 69.000 & $\$$ & 27.906 & $\$$ & 0.500 & $\$$ & 32.156 & $\$$ & 13.844 & $\$$ & 36.844 \\
\hline 47 & $\$$ & 1.500 & $\$$ & 70.500 & $\$$ & 28.713 & $\$$ & 0.499 & $\$$ & 32.655 & $\$$ & 14.345 & $\$$ & 37.845 \\
\hline 48 & $\$$ & 1.500 & $\$$ & 72.000 & $\$$ & 29.521 & $\$$ & 0.498 & $\$$ & 33.153 & $\$$ & 14.847 & $\$$ & 38.847 \\
\hline 49 & $\$$ & 1.500 & $\$$ & 73.500 & $\$$ & 30.329 & $\$$ & 0.497 & $\$$ & 33.650 & $\$$ & 15.350 & $\$$ & 39.850 \\
\hline 50 & $\$$ & 1.500 & $\$$ & 75.000 & $\$$ & 31.138 & $\$$ & 0.496 & $\$$ & 34.147 & $\$$ & 15.853 & $\$$ & 40.853 \\
\hline 51 & $\$$ & 1.500 & $\$$ & 76.500 & $\$$ & 31.948 & $\$$ & 0.496 & $\$$ & 34.642 & $\$$ & 16.358 & $\$$ & 41.858 \\
\hline 52 & $\$$ & 1.500 & $\$$ & 78.000 & $\$$ & 32.759 & $\$$ & 0.495 & $\$$ & 35.137 & $\$$ & 16.863 & $\$$ & 42.863 \\
\hline 53 & $\$$ & 1.500 & $\$$ & 79.500 & $\$$ & 33.571 & $\$$ & 0.494 & $\$$ & 35.632 & $\$$ & 17.368 & $\$$ & 43.868 \\
\hline 54 & $\$$ & 1.500 & $\$$ & 81.000 & $\$$ & 34.383 & $\$$ & 0.494 & $\$$ & 36.125 & $\$$ & 17.875 & $\$$ & 44.875 \\
\hline 55 & $\$$ & 1.500 & $\$$ & 82.500 & $\$$ & 35.196 & $\$$ & 0.493 & $\$$ & 36.618 & $\$$ & 18.382 & $\$$ & 45.882 \\
\hline 56 & $\$$ & 1.500 & $\$$ & 84.000 & $\$$ & 36.009 & $\$$ & 0.492 & $\$$ & 37.110 & $\$$ & 18.890 & $\$$ & 46.890 \\
\hline 57 & $\$$ & 1.500 & $\$$ & 85.500 & $\$$ & 36.823 & $\$$ & 0.492 & $\$$ & 37.602 & $\$$ & 19.398 & $\$$ & 47.898 \\
\hline 58 & $\$$ & 1.500 & $\$$ & 87.000 & $\$$ & 37.638 & $\$$ & 0.491 & $\$$ & 38.093 & $\$$ & 19.907 & $\$$ & 48.907 \\
\hline 59 & $\$$ & 1.500 & $\$$ & 88.500 & $\$$ & 38.453 & $\$$ & 0.490 & $\$$ & 38.583 & $\$$ & 20.417 & $\$$ & 49.917 \\
\hline 60 & $\$$ & 1.500 & $\$$ & 90.000 & $\$$ & 39.269 & $\$$ & 0.490 & $\$$ & 39.073 & $\$$ & 20.927 & $\$$ & 50.927 \\
\hline
\end{tabular}




\begin{tabular}{|c|c|c|c|c|c|c|c|c|c|c|c|c|c|c|}
\hline \multirow[b]{3}{*}{$\begin{array}{l}\text { Report } \\
\text { number }\end{array}$} & \multicolumn{12}{|c|}{ Class Sensitivity Analysis } & \multirow{2}{*}{\multicolumn{2}{|c|}{ Both occur }} \\
\hline & \multicolumn{6}{|c|}{ Price increase from $\$ 1.00$ to $\$ 1.50$} & \multicolumn{6}{|c|}{$\begin{array}{c}\text { Material Cost Decreases from } \$ .53 \text { to } \\
\$ .33\end{array}$} & & \\
\hline & \multicolumn{2}{|c|}{ Benefit } & \multicolumn{2}{|c|}{$\begin{array}{l}\text { Cumulative } \\
\text { Benefit }\end{array}$} & \multicolumn{2}{|c|}{ Profit } & & ost & & $\begin{array}{l}\text { nulative } \\
\text { Cost }\end{array}$ & \multicolumn{2}{|r|}{ Profit } & \multicolumn{2}{|c|}{ Profit } \\
\hline 0 & $\$$ & - & $\$$ & - & $\$$ & $(4.230)$ & $\$$ & 4.230 & $\$$ & 4.230 & $\$$ & $(4.230)$ & $\$$ & $(4.230)$ \\
\hline 1 & $\$$ & 1.465 & $\$$ & 1.465 & $\$$ & (3.493) & $\$$ & 0.534 & $\$$ & 4.764 & $\$$ & (3.799) & $\$$ & (3.299) \\
\hline 2 & $\$$ & 1.465 & $\$$ & 2.930 & $\$$ & $(2.740)$ & $\$$ & 0.516 & $\$$ & 5.280 & $\$$ & $(3.350)$ & $\$$ & $(2.350)$ \\
\hline 3 & $\$$ & 1.465 & $\$$ & 4.395 & $\$$ & $(1.976)$ & $\$$ & 0.507 & $\$$ & 5.787 & $\$$ & $(2.892)$ & $\$$ & $(1.392)$ \\
\hline 4 & $\$$ & 1.465 & $\$$ & 5.860 & $\$$ & $(1.207)$ & $\$$ & 0.501 & $\$$ & 6.287 & $\$$ & $(2.427)$ & $\$$ & $(0.427)$ \\
\hline 5 & $\$$ & 1.465 & $\$$ & 7.325 & $\$$ & $(0.432)$ & $\$$ & 0.496 & $\$$ & 6.783 & $\$$ & $(1.958)$ & $\$$ & 0.542 \\
\hline 6 & $\$$ & 1.465 & $\$$ & 8.790 & $\$$ & 0.346 & $\$$ & 0.492 & $\$$ & 7.275 & $\$$ & $(1.485)$ & $\$$ & 1.515 \\
\hline 7 & $\$$ & 1.465 & $\$$ & 10.255 & $\$$ & 1.127 & $\$$ & 0.489 & $\$$ & 7.764 & $\$$ & $(1.009)$ & $\$$ & 2.491 \\
\hline 8 & $\$$ & 1.465 & $\$$ & 11.720 & $\$$ & 1.911 & $\$$ & 0.486 & $\$$ & 8.250 & $\$$ & $(0.530)$ & $\$$ & 3.470 \\
\hline 9 & $\$$ & 1.465 & $\$$ & 13.185 & $\$$ & 2.698 & $\$$ & 0.484 & $\$$ & 8.734 & $\$$ & $(0.049)$ & $\$$ & 4.451 \\
\hline 10 & $\$$ & 1.465 & $\$$ & 14.650 & $\$$ & 3.486 & $\$$ & 0.482 & $\$$ & 9.215 & $\$$ & 0.435 & $\$$ & 5.435 \\
\hline 11 & $\$$ & 1.465 & $\$$ & 16.115 & $\$$ & 4.276 & $\$$ & 0.480 & $\$$ & 9.695 & $\$$ & 0.920 & $\$$ & 6.420 \\
\hline 12 & $\$$ & 1.465 & $\$$ & 17.580 & $\$$ & 5.068 & $\$$ & 0.478 & $\$$ & 10.174 & $\$$ & 1.406 & $\$$ & 7.406 \\
\hline 13 & $\$$ & 1.465 & $\$$ & 19.045 & $\$$ & 5.862 & $\$$ & 0.477 & $\$$ & 10.650 & $\$$ & 1.895 & $\$$ & 8.395 \\
\hline 14 & $\$$ & 1.465 & $\$$ & 20.510 & $\$$ & 6.656 & $\$$ & 0.475 & $\$$ & 11.126 & $\$$ & 2.384 & $\$$ & 9.384 \\
\hline 15 & $\$$ & 1.465 & $\$$ & 21.975 & $\$$ & 7.452 & $\$$ & 0.474 & $\$$ & 11.600 & $\$$ & 2.875 & $\$$ & 10.375 \\
\hline 16 & $\$$ & 1.465 & $\$$ & 23.440 & $\$$ & 8.250 & $\$$ & 0.473 & $\$$ & 12.073 & $\$$ & 3.367 & $\$$ & 11.367 \\
\hline 17 & $\$$ & 1.465 & $\$$ & 24.905 & $\$$ & 9.048 & $\$$ & 0.472 & $\$$ & 12.545 & $\$$ & 3.860 & $\$$ & 12.360 \\
\hline 18 & $\$$ & 1.465 & $\$$ & 26.370 & $\$$ & 9.847 & $\$$ & 0.471 & $\$$ & 13.016 & $\$$ & 4.354 & $\$$ & 13.354 \\
\hline 19 & $\$$ & 1.465 & $\$$ & 27.835 & $\$$ & 10.647 & $\$$ & 0.470 & $\$$ & 13.486 & $\$$ & 4.849 & $\$$ & 14.349 \\
\hline 20 & $\$$ & 1.465 & $\$$ & 29.300 & $\$$ & 11.448 & $\$$ & 0.469 & $\$$ & 13.955 & $\$$ & 5.345 & $\$$ & 15.345 \\
\hline 21 & $\$$ & 1.465 & $\$$ & 30.765 & $\$$ & 12.250 & $\$$ & 0.468 & $\$$ & 14.423 & $\$$ & 5.842 & $\$$ & 16.342 \\
\hline 22 & $\$$ & 1.465 & $\$$ & 32.230 & $\$$ & 13.053 & $\$$ & 0.467 & $\$$ & 14.890 & $\$$ & 6.340 & $\$$ & 17.340 \\
\hline 23 & $\$$ & 1.465 & $\$$ & 33.695 & $\$$ & 13.857 & $\$$ & 0.467 & $\$$ & 15.357 & $\$$ & 6.838 & $\$$ & 18.338 \\
\hline 24 & $\$$ & 1.465 & $\$$ & 35.160 & $\$$ & 14.661 & $\$$ & 0.466 & $\$$ & 15.823 & $\$$ & 7.337 & $\$$ & 19.337 \\
\hline 25 & $\$$ & 1.465 & $\$$ & 36.625 & $\$$ & 15.466 & $\$$ & 0.465 & $\$$ & 16.288 & $\$$ & 7.837 & $\$$ & 20.337 \\
\hline 26 & $\$$ & 1.465 & $\$$ & 38.090 & $\$$ & 16.272 & $\$$ & 0.465 & $\$$ & 16.752 & $\$$ & 8.338 & $\$$ & 21.338 \\
\hline 27 & $\$$ & 1.465 & $\$$ & 39.555 & $\$$ & 17.078 & $\$$ & 0.464 & $\$$ & 17.216 & $\$$ & 8.839 & $\$$ & 22.339 \\
\hline 28 & $\$$ & 1.465 & $\$$ & 41.020 & $\$$ & 17.885 & $\$$ & 0.463 & $\$$ & 17.680 & $\$$ & 9.340 & $\$$ & 23.340 \\
\hline 29 & $\$$ & 1.465 & $\$$ & 42.485 & $\$$ & 18.692 & $\$$ & 0.463 & $\$$ & 18.142 & $\$$ & 9.843 & $\$$ & 24.343 \\
\hline 30 & $\$$ & 1.465 & $\$$ & 43.950 & $\$$ & 19.500 & $\$$ & 0.462 & $\$$ & 18.604 & $\$$ & 10.346 & $\$$ & 25.346 \\
\hline 31 & $\$$ & 1.465 & $\$$ & 45.415 & $\$$ & 20.309 & $\$$ & 0.462 & $\$$ & 19.066 & $\$$ & 10.849 & $\$$ & 26.349 \\
\hline 32 & $\$$ & 1.465 & $\$$ & 46.880 & $\$$ & 21.118 & $\$$ & 0.461 & $\$$ & 19.527 & $\$$ & 11.353 & $\$$ & 27.353 \\
\hline 33 & $\$$ & 1.465 & $\$$ & 48.345 & $\$$ & 21.928 & $\$$ & 0.461 & $\$$ & 19.987 & $\$$ & 11.858 & $\$$ & 28.358 \\
\hline 34 & $\$$ & 1.465 & $\$$ & 49.810 & $\$$ & 22.738 & $\$$ & 0.460 & $\$$ & 20.447 & $\$$ & 12.363 & $\$$ & 29.363 \\
\hline 35 & $\$$ & 1.465 & $\$$ & 51.275 & $\$$ & 23.549 & $\$$ & 0.460 & $\$$ & 20.907 & $\$$ & 12.868 & $\$$ & 30.368 \\
\hline 36 & $\$$ & 1.465 & $\$$ & 52.740 & $\$$ & 24.360 & $\$$ & 0.459 & $\$$ & 21.366 & $\$$ & 13.374 & $\$$ & 31.374 \\
\hline 37 & $\$$ & 1.465 & $\$$ & 54.205 & $\$$ & 25.171 & $\$$ & 0.459 & $\$$ & 21.825 & $\$$ & 13.880 & $\$$ & 32.380 \\
\hline 38 & $\$$ & 1.465 & $\$$ & 55.670 & $\$$ & 25.983 & $\$$ & 0.458 & $\$$ & 22.283 & $\$$ & 14.387 & $\$$ & 33.387 \\
\hline 39 & $\$$ & 1.465 & $\$$ & 57.135 & $\$$ & 26.795 & $\$$ & 0.458 & $\$$ & 22.741 & $\$$ & 14.894 & $\$$ & 34.394 \\
\hline 40 & $\$$ & 1.465 & $\$$ & 58.600 & $\$$ & 27.608 & $\$$ & 0.457 & $\$$ & 23.198 & $\$$ & 15.402 & $\$$ & 35.402 \\
\hline 41 & $\$$ & 1.465 & $\$$ & 60.065 & $\$$ & 28.421 & $\$$ & 0.457 & $\$$ & 23.655 & $\$$ & 15.910 & $\$$ & 36.410 \\
\hline 42 & $\$$ & 1.465 & $\$$ & 61.530 & $\$$ & 29.235 & $\$$ & 0.457 & $\$$ & 24.112 & $\$$ & 16.418 & $\$$ & 37.418 \\
\hline 43 & $\$$ & 1.465 & $\$$ & 62.995 & $\$$ & 30.049 & $\$$ & 0.456 & $\$$ & 24.568 & $\$$ & 16.927 & $\$$ & 38.427 \\
\hline 44 & $\$$ & 1.465 & $\$$ & 64.460 & $\$$ & 30.863 & $\$$ & 0.456 & $\$$ & 25.024 & $\$$ & 17.436 & $\$$ & 39.436 \\
\hline 45 & $\$$ & 1.465 & $\$$ & 65.925 & $\$$ & 31.678 & $\$$ & 0.456 & $\$$ & 25.480 & $\$$ & 17.945 & $\$$ & 40.445 \\
\hline 46 & $\$$ & 1.465 & $\$$ & 67.390 & $\$$ & 32.493 & $\$$ & 0.455 & $\$$ & 25.935 & $\$$ & 18.455 & $\$$ & 41.455 \\
\hline 47 & $\$$ & 1.465 & $\$$ & 68.855 & $\$$ & 33.308 & $\$$ & 0.455 & $\$$ & 26.390 & $\$$ & 18.965 & $\$$ & 42.465 \\
\hline 48 & $\$$ & 1.465 & $\$$ & 70.320 & $\$$ & 34.124 & $\$$ & 0.455 & $\$$ & 26.844 & $\$$ & 19.476 & $\$$ & 43.476 \\
\hline 49 & $\$$ & 1.465 & $\$$ & 71.785 & $\$$ & 34.939 & $\$$ & 0.454 & $\$$ & 27.298 & $\$$ & 19.987 & $\$$ & 44.487 \\
\hline 50 & $\$$ & 1.465 & $\$$ & 73.250 & $\$$ & 35.756 & $\$$ & 0.454 & $\$$ & 27.752 & $\$$ & 20.498 & $\$$ & 45.498 \\
\hline 51 & $\$$ & 1.465 & $\$$ & 74.715 & $\$$ & 36.572 & $\$$ & 0.454 & $\$$ & 28.206 & $\$$ & 21.009 & $\$$ & 46.509 \\
\hline 52 & $\$$ & 1.465 & $\$$ & 76.180 & $\$$ & 37.389 & $\$$ & 0.453 & $\$$ & 28.659 & $\$$ & 21.521 & $\$$ & 47.521 \\
\hline 53 & $\$$ & 1.465 & $\$$ & 77.645 & $\$$ & 38.206 & $\$$ & 0.453 & $\$$ & 29.112 & $\$$ & 22.033 & $\$$ & 48.533 \\
\hline 54 & $\$$ & 1.465 & $\$$ & 79.110 & $\$$ & 39.024 & $\$$ & 0.453 & $\$$ & 29.565 & $\$$ & 22.545 & $\$$ & 49.545 \\
\hline 55 & $\$$ & 1.465 & $\$$ & 80.575 & $\$$ & 39.842 & $\$$ & 0.452 & $\$$ & 30.017 & $\$$ & 23.058 & $\$$ & 50.558 \\
\hline 56 & $\$$ & 1.465 & $\$$ & 82.040 & $\$$ & 40.660 & $\$$ & 0.452 & $\$$ & 30.469 & $\$$ & 23.571 & $\$$ & 51.571 \\
\hline 57 & $\$$ & 1.465 & $\$$ & 83.505 & $\$$ & 41.478 & $\$$ & 0.452 & $\$$ & 30.921 & $\$$ & 24.084 & $\$$ & 52.584 \\
\hline 58 & $\$$ & 1.465 & $\$$ & 84.970 & $\$$ & 42.296 & $\$$ & 0.452 & $\$$ & 31.373 & $\$$ & 24.597 & $\$$ & 53.597 \\
\hline 59 & $\$$ & 1.465 & $\$$ & 86.435 & $\$$ & 43.115 & $\$$ & 0.451 & $\$$ & 31.824 & $\$$ & 25.111 & $\$$ & 54.611 \\
\hline 60 & $\$$ & 1.465 & $\$$ & 87.900 & $\$$ & 43.934 & $\$$ & 0.451 & $\$$ & 32.275 & $\$$ & 25.625 & $\$$ & 55.625 \\
\hline
\end{tabular}




\begin{tabular}{|c|c|c|c|c|c|c|c|c|c|c|c|c|c|c|}
\hline \multicolumn{15}{|c|}{ Mentor/Manual Sensitivity Analysis } \\
\hline \multirow[b]{2}{*}{$\begin{array}{l}\text { Report } \\
\text { number }\end{array}$} & \multicolumn{6}{|c|}{ Price increase from $\$ 1.00$ to $\$ 1.50$} & \multicolumn{6}{|c|}{$\begin{array}{c}\text { Material Cost Decreases from } \$ .53 \text { to } \\
\$ .33\end{array}$} & \multicolumn{2}{|c|}{ Both occur } \\
\hline & & nefit & & $\begin{array}{l}\text { nulative } \\
\text { enefit }\end{array}$ & & rofit & & ost & & $\begin{array}{l}\text { Iulative } \\
\text { Sost }\end{array}$ & & rofit & & rofit \\
\hline 0 & $\$$ & - & $\$$ & - & $\$$ & $(9.030)$ & $\$$ & 9.030 & $\$$ & 9.030 & $\$$ & $(9.030)$ & $\$$ & $(9.030)$ \\
\hline 1 & $\$$ & 1.472 & $\$$ & 1.472 & $\$$ & $(8.425)$ & $\$$ & 0.671 & $\$$ & 9.701 & $\$$ & $(8.729)$ & $\$$ & (8.229) \\
\hline 2 & $\$$ & 1.472 & $\$$ & 2.944 & $\$$ & $(7.777)$ & $\$$ & 0.627 & $\$$ & 10.328 & $\$$ & $(8.384)$ & $\$$ & $(7.384)$ \\
\hline 3 & $\$$ & 1.472 & $\$$ & 4.416 & $\$$ & $(7.106)$ & $\$$ & 0.605 & $\$$ & 10.933 & $\$$ & $(8.017)$ & $\$$ & $(6.517)$ \\
\hline 4 & $\$$ & 1.472 & $\$$ & 5.888 & $\$$ & $(6.420)$ & $\$$ & 0.590 & $\$$ & 11.522 & $\$$ & $(7.634)$ & $\$$ & $(5.634)$ \\
\hline 5 & $\$$ & 1.472 & $\$$ & 7.360 & $\$$ & $(5.723)$ & $\$$ & 0.578 & $\$$ & 12.101 & $\$$ & $(7.241)$ & $\$$ & $(4.741)$ \\
\hline 6 & $\$$ & 1.472 & $\$$ & 8.832 & $\$$ & $(5.017)$ & $\$$ & 0.570 & $\$$ & 12.670 & $\$$ & (6.838) & $\$$ & (3.838) \\
\hline 7 & $\$$ & 1.472 & $\$$ & 10.304 & $\$$ & $(4.304)$ & $\$$ & 0.563 & $\$$ & 13.233 & $\$$ & $(6.429)$ & $\$$ & $(2.929)$ \\
\hline 8 & $\$$ & 1.472 & $\$$ & 11.776 & $\$$ & $(3.585)$ & $\$$ & 0.557 & $\$$ & 13.790 & $\$$ & $(6.014)$ & $\$$ & $(2.014)$ \\
\hline 9 & $\$$ & 1.472 & $\$$ & 13.248 & $\$$ & $(2.861)$ & $\$$ & 0.551 & $\$$ & 14.341 & $\$$ & $(5.593)$ & $\$$ & $(1.093)$ \\
\hline 10 & $\$$ & 1.472 & $\$$ & 14.720 & $\$$ & $(2.132)$ & $\$$ & 0.547 & $\$$ & 14.888 & $\$$ & $(5.168)$ & $\$$ & $(0.168)$ \\
\hline 11 & $\$$ & 1.472 & $\$$ & 16.192 & $\$$ & (1.399) & $\$$ & 0.543 & $\$$ & 15.431 & $\$$ & $(4.739)$ & $\$$ & 0.761 \\
\hline 12 & $\$$ & 1.472 & $\$$ & 17.664 & $\$$ & $(0.663)$ & $\$$ & 0.539 & $\$$ & 15.970 & $\$$ & $(4.306)$ & $\$$ & 1.694 \\
\hline 13 & $\$$ & 1.472 & $\$$ & 19.136 & $\$$ & 0.076 & $\$$ & 0.536 & $\$$ & 16.507 & $\$$ & $(3.871)$ & $\$$ & 2.629 \\
\hline 14 & $\$$ & 1.472 & $\$$ & 20.608 & $\$$ & 0.819 & $\$$ & 0.533 & $\$$ & 17.040 & $\$$ & $(3.432)$ & $\$$ & 3.568 \\
\hline 15 & $\$$ & 1.472 & $\$$ & 22.080 & $\$$ & 1.564 & $\$$ & 0.531 & $\$$ & 17.570 & $\$$ & $\begin{array}{l}(2.990) \\
\end{array}$ & $\$$ & 4.510 \\
\hline 16 & $\$$ & 1.472 & $\$$ & 23.552 & $\$$ & 2.311 & $\$$ & 0.528 & $\$$ & 18.098 & $\$$ & $(2.546)$ & $\$$ & 5.454 \\
\hline 17 & $\$$ & 1.472 & $\$$ & 25.024 & $\$$ & 3.061 & $\$$ & 0.526 & $\$$ & 18.624 & $\$$ & $(2.100)$ & $\$$ & 6.400 \\
\hline 18 & $\$$ & 1.472 & $\$$ & 26.496 & $\$$ & 3.813 & $\$$ & 0.524 & $\$$ & 19.148 & $\$$ & (1.652) & $\$$ & 7.348 \\
\hline 19 & $\$$ & 1.472 & $\$$ & 27.968 & $\$$ & 4.567 & $\$$ & 0.522 & $\$$ & 19.669 & $\$$ & $(1.201)$ & $\$$ & 8.299 \\
\hline 20 & $\$$ & 1.472 & $\$$ & 29.440 & $\$$ & 5.323 & $\$$ & 0.520 & $\$$ & 20.189 & $\$$ & $(0.749)$ & $\$$ & 9.251 \\
\hline 21 & $\$$ & 1.472 & $\$$ & 30.912 & $\$$ & 6.081 & $\$$ & 0.518 & $\$$ & 20.707 & $\$$ & $(0.295)$ & $\$$ & 10.205 \\
\hline 22 & $\$$ & 1.472 & $\$$ & 32.384 & $\$$ & 6.841 & $\$$ & 0.516 & $\$$ & 21.223 & $\$$ & 0.161 & $\$$ & 11.161 \\
\hline 23 & $\$$ & 1.472 & $\$$ & 33.856 & $\$$ & 7.602 & $\$$ & 0.515 & $\$$ & 21.737 & $\$$ & 0.619 & $\$$ & 12.119 \\
\hline 24 & $\$$ & 1.472 & $\$$ & 35.328 & $\$$ & 8.364 & $\$$ & 0.513 & $\$$ & 22.250 & $\$$ & 1.078 & $\$$ & 13.078 \\
\hline 25 & $\$$ & 1.472 & $\$$ & 36.800 & $\$$ & 9.128 & $\$$ & 0.512 & $\$$ & 22.762 & $\$$ & 1.538 & $\$$ & 14.038 \\
\hline 26 & $\$$ & 1.472 & $\$$ & 38.272 & $\$$ & 9.893 & $\$$ & 0.510 & $\$$ & 23.272 & $\$$ & 2.000 & $\$$ & 15.000 \\
\hline 27 & $\$$ & 1.472 & $\$$ & 39.744 & $\$$ & 10.660 & $\$$ & 0.509 & $\$$ & 23.781 & $\$$ & 2.463 & $\$$ & 15.963 \\
\hline 28 & $\$$ & 1.472 & $\$$ & 41.216 & $\$$ & 11.428 & $\$$ & 0.508 & $\$$ & 24.289 & $\$$ & 2.927 & $\$$ & 16.927 \\
\hline 29 & $\$$ & 1.472 & $\$$ & 42.688 & $\$$ & 12.197 & $\$$ & 0.506 & $\$$ & 24.795 & $\$$ & 3.393 & $\$$ & 17.893 \\
\hline 30 & $\$$ & 1.472 & $\$$ & 44.160 & $\$$ & 12.967 & $\$$ & 0.505 & $\$$ & 25.301 & $\$$ & 3.859 & $\$$ & 18.859 \\
\hline 31 & $\$$ & 1.472 & $\$$ & 45.632 & $\$$ & 13.739 & $\$$ & 0.504 & $\$$ & 25.805 & $\$$ & 4.327 & $\$$ & 19.827 \\
\hline 32 & $\$$ & 1.472 & $\$$ & 47.104 & $\$$ & 14.511 & $\$$ & 0.503 & $\$$ & 26.308 & $\$$ & 4.796 & $\$$ & 20.796 \\
\hline 33 & $\$$ & 1.472 & $\$$ & 48.576 & $\$$ & 15.285 & $\$$ & 0.502 & $\$$ & 26.810 & $\$$ & 5.266 & $\$$ & 21.766 \\
\hline 34 & $\$$ & 1.472 & $\$$ & 50.048 & $\$$ & 16.059 & $\$$ & 0.501 & $\$$ & 27.311 & $\$$ & 5.737 & $\$$ & 22.737 \\
\hline 35 & $\$$ & 1.472 & $\$$ & 51.520 & $\$$ & 16.835 & $\$$ & 0.500 & $\$$ & 27.811 & $\$$ & 6.209 & $\$$ & 23.709 \\
\hline 36 & $\$$ & 1.472 & $\$$ & 52.992 & $\$$ & 17.611 & $\$$ & 0.499 & $\$$ & 28.311 & $\$$ & 6.681 & $\$$ & 24.681 \\
\hline 37 & $\$$ & 1.472 & $\$$ & 54.464 & $\$$ & 18.388 & $\$$ & 0.498 & $\$$ & 28.809 & $\$$ & 7.155 & $\$$ & 25.655 \\
\hline 38 & $\$$ & 1.472 & $\$$ & 55.936 & $\$$ & 19.166 & $\$$ & 0.498 & $\$$ & 29.307 & $\$$ & 7.629 & $\$$ & 26.629 \\
\hline 39 & $\$$ & 1.472 & $\$$ & 57.408 & $\$$ & 19.945 & $\$$ & 0.497 & $\$$ & 29.803 & $\$$ & 8.105 & $\$$ & 27.605 \\
\hline 40 & $\$$ & 1.472 & $\$$ & 58.880 & $\$$ & 20.725 & $\$$ & 0.496 & $\$$ & 30.299 & $\$$ & 8.581 & $\$$ & 28.581 \\
\hline 41 & $\$$ & 1.472 & $\$$ & 60.352 & $\$$ & 21.505 & $\$$ & 0.495 & $\$$ & 30.794 & $\$$ & 9.058 & $\$$ & 29.558 \\
\hline 42 & $\$$ & 1.472 & $\$$ & 61.824 & $\$$ & 22.287 & $\$$ & 0.494 & $\$$ & 31.288 & $\$$ & 9.536 & $\$$ & 30.536 \\
\hline 43 & $\$$ & 1.472 & $\$$ & 63.296 & $\$$ & 23.069 & $\$$ & 0.494 & $\$$ & 31.782 & $\$$ & 10.014 & $\$$ & 31.514 \\
\hline 44 & $\$$ & 1.472 & $\$$ & 64.768 & $\$$ & 23.852 & $\$$ & 0.493 & $\$$ & 32.275 & $\$$ & 10.493 & $\$$ & 32.493 \\
\hline 45 & $\$$ & 1.472 & $\$$ & 66.240 & $\$$ & 24.635 & $\$$ & 0.492 & $\$$ & 32.767 & $\$$ & 10.973 & $\$$ & 33.473 \\
\hline 46 & $\$$ & 1.472 & $\$$ & 67.712 & $\$$ & 25.419 & $\$$ & 0.491 & $\$$ & 33.258 & $\$$ & 11.454 & $\$$ & 34.454 \\
\hline 47 & $\$$ & 1.472 & $\$$ & 69.184 & $\$$ & 26.204 & $\$$ & 0.491 & $\$$ & 33.749 & $\$$ & 11.935 & $\$$ & 35.435 \\
\hline 48 & $\$$ & 1.472 & $\$$ & 70.656 & $\$$ & 26.989 & $\$$ & 0.490 & $\$$ & 34.239 & $\$$ & 12.417 & $\$$ & 36.417 \\
\hline 49 & $\$$ & 1.472 & $\$$ & 72.128 & $\$$ & 27.776 & $\$$ & 0.490 & $\$$ & 34.729 & $\$$ & 12.899 & $\$$ & 37.399 \\
\hline 50 & $\$$ & 1.472 & $\$$ & 73.600 & $\$$ & 28.562 & $\$$ & 0.489 & $\$$ & 35.218 & $\$$ & 13.382 & $\$$ & 38.382 \\
\hline 51 & $\$$ & 1.472 & $\$$ & 75.072 & $\$$ & 29.350 & $\$$ & 0.488 & $\$$ & 35.706 & $\$$ & 13.866 & $\$$ & 39.366 \\
\hline 52 & $\$$ & 1.472 & $\$$ & 76.544 & $\$$ & 30.137 & $\$$ & 0.488 & $\$$ & 36.194 & $\$$ & 14.350 & $\$$ & 40.350 \\
\hline 53 & $\$$ & 1.472 & $\$$ & 78.016 & $\$$ & 30.926 & $\$$ & 0.487 & $\$$ & 36.681 & $\$$ & 14.835 & $\$$ & 41.335 \\
\hline 54 & $\$$ & 1.472 & $\$$ & 79.488 & $\$$ & 31.715 & $\$$ & 0.487 & $\$$ & 37.167 & $\$$ & 15.321 & $\$$ & 42.321 \\
\hline 55 & $\$$ & 1.472 & $\$$ & 80.960 & $\$$ & 32.505 & $\$$ & 0.486 & $\$$ & 37.653 & $\$$ & 15.807 & $\$$ & 43.307 \\
\hline 56 & $\$$ & 1.472 & $\$$ & 82.432 & $\$$ & 33.295 & $\$$ & 0.485 & $\$$ & 38.139 & $\$$ & 16.293 & $\$$ & 44.293 \\
\hline 57 & $\$$ & 1.472 & $\$$ & 83.904 & $\$$ & 34.085 & $\$$ & 0.485 & $\$$ & 38.624 & $\$$ & 16.780 & $\$$ & 45.280 \\
\hline 58 & $\$$ & 1.472 & $\$$ & 85.376 & $\$$ & 34.877 & $\$$ & 0.484 & $\$$ & 39.108 & $\$$ & 17.268 & $\$$ & 46.268 \\
\hline 59 & $\$$ & 1.472 & $\$$ & 86.848 & $\$$ & 35.668 & $\$$ & 0.484 & $\$$ & 39.592 & $\$$ & 17.756 & $\$$ & 47.256 \\
\hline 60 & $\$$ & 1.472 & $\$$ & 88.320 & $\$$ & 36.460 & $\$$ & 0.483 & $\$$ & 40.076 & $\$$ & 18.244 & $\$$ & 48.244 \\
\hline
\end{tabular}


APPENDIX P:

SENSITIVITY ANALYSIS ROI COMPARISONS 


\begin{tabular}{|c|c|c|c|c|c|c|c|c|}
\hline \multicolumn{9}{|c|}{ Manual - Observe and Do (ROI) } \\
\hline \multirow{2}{*}{$\begin{array}{c}\begin{array}{c}\text { Report } \\
\text { number }\end{array} \\
0\end{array}$} & \multicolumn{2}{|c|}{ Regular ROI } & \multicolumn{2}{|c|}{$\begin{array}{c}\text { Price } \\
\text { increase ROI }\end{array}$} & \multicolumn{2}{|c|}{$\begin{array}{c}\text { Material } \\
\text { Cost } \\
\text { Decrease } \\
\text { ROI }\end{array}$} & \multicolumn{2}{|c|}{$\begin{array}{l}\text { Sesitivity } \\
\text { Analysis } \\
\text { Both ROI }\end{array}$} \\
\hline & $\$$ & $(6.75)$ & $\$$ & $(6.75)$ & $\$$ & $(6.75)$ & $\$$ & $(6.75)$ \\
\hline 1 & $\$$ & (6.73) & $\$$ & $(6.70)$ & $\$$ & $(6.74)$ & $\$$ & (6.70) \\
\hline 2 & $\$$ & $(6.69)$ & $\$$ & $(6.62)$ & $\$$ & $(6.71)$ & $\$$ & $(6.63)$ \\
\hline 3 & $\$$ & (6.64) & $\$$ & (6.53) & $\$$ & (6.66) & $\$$ & $(6.55)$ \\
\hline 4 & $\$$ & (6.59) & $\$$ & $(6.44)$ & $\$$ & (6.61) & $\$$ & $(6.46)$ \\
\hline 5 & $\$$ & (6.53) & $\$$ & $(6.34)$ & $\$$ & $(6.55)$ & $\$$ & (6.37) \\
\hline 6 & $\$$ & $(6.46)$ & $\$$ & $(6.24)$ & $\$$ & $(6.50)$ & $\$$ & $(6.27)$ \\
\hline 7 & $\$$ & (6.39) & $\$$ & (6.13) & $\$$ & $(6.43)$ & $\$$ & $(6.17)$ \\
\hline 8 & $\$$ & $(6.32)$ & $\$$ & $(6.02)$ & $\$$ & (6.37) & $\$$ & (6.07) \\
\hline 9 & $\$$ & $(6.25)$ & $\$$ & (5.91) & $\$$ & (6.30) & $\$$ & $(5.96)$ \\
\hline 10 & $\$$ & $(6.18)$ & $\$$ & $(5.80)$ & $\$$ & (6.23) & $\$$ & $(5.86)$ \\
\hline 11 & $\$$ & $(6.10)$ & $\$$ & (5.69) & $\$$ & $(6.16)$ & $\$$ & (5.75) \\
\hline 12 & $\$$ & $(6.03)$ & $\$$ & (5.58) & $\$$ & $(6.09)$ & $\$$ & $(5.64)$ \\
\hline 13 & $\$$ & (5.95) & $\$$ & $(5.46)$ & $\$$ & $(6.02)$ & $\$$ & $(5.53)$ \\
\hline 14 & $\$$ & $(5.87)$ & $\$$ & $(5.34)$ & $\$$ & $(5.95)$ & $\$$ & $(5.42)$ \\
\hline 15 & $\$$ & (5.79) & $\$$ & (5.23) & $\$$ & $(5.88)$ & $\$$ & (5.31) \\
\hline 16 & $\$$ & (5.71) & $\$$ & (5.11) & $\$$ & $(5.80)$ & $\$$ & $(5.20)$ \\
\hline 17 & $\$$ & $(5.63)$ & $\$$ & $(4.99)$ & $\$$ & (5.73) & $\$$ & $(5.09)$ \\
\hline 18 & $\$$ & $(5.55)$ & $\$$ & $(4.87)$ & $\$$ & $(5.65)$ & $\$$ & (4.97) \\
\hline 19 & $\$$ & $(5.46)$ & $\$$ & $(4.75)$ & $\$$ & $(5.57)$ & $\$$ & $(4.86)$ \\
\hline 20 & $\$$ & $(5.38)$ & $\$$ & $(4.63)$ & $\$$ & $(5.49)$ & $\$$ & $(4.74)$ \\
\hline 21 & $\$$ & $(5.30)$ & $\$$ & $(4.51)$ & $\$$ & $(5.42)$ & $\$$ & (4.63) \\
\hline 22 & $\$$ & $(5.21)$ & $\$$ & $(4.39)$ & $\$$ & $(5.34)$ & $\$$ & $(4.51)$ \\
\hline 23 & $\$$ & (5.13) & $\$$ & $(4.27)$ & $\$$ & $(5.26)$ & $\$$ & $(4.40)$ \\
\hline 24 & $\$$ & $(5.04)$ & $\$$ & $(4.14)$ & $\$$ & $(5.18)$ & $\$$ & $(4.28)$ \\
\hline 25 & $\$$ & $(4.96)$ & $\$$ & $(4.02)$ & $\$$ & $(5.10)$ & $\$$ & $(4.16)$ \\
\hline 26 & $\$$ & $(4.87)$ & $\$$ & $(3.90)$ & $\$$ & $(5.02)$ & $\$$ & $(4.04)$ \\
\hline 27 & $\$$ & $(4.78)$ & $\$$ & $(3.77)$ & $\$$ & $(4.94)$ & $\$$ & (3.93) \\
\hline 28 & $\$$ & $(4.70)$ & $\$$ & $(3.65)$ & $\$$ & $(4.86)$ & $\$$ & (3.81) \\
\hline 29 & $\$$ & $(4.61)$ & $\$$ & (3.52) & $\$$ & $(4.78)$ & $\$$ & (3.69) \\
\hline 30 & $\$$ & $(4.52)$ & $\$$ & $(3.40)$ & $\$$ & $(4.69)$ & $\$$ & (3.57) \\
\hline 31 & $\$$ & $(4.43)$ & $\$$ & (3.27) & $\$$ & $(4.61)$ & $\$$ & $(3.45)$ \\
\hline 32 & $\$$ & $(4.35)$ & $\$$ & $(3.15)$ & $\$$ & $(4.53)$ & $\$$ & (3.33) \\
\hline 33 & $\$$ & $(4.26)$ & $\$$ & $(3.02)$ & $\$$ & $(4.45)$ & $\$$ & (3.21) \\
\hline 34 & $\$$ & $(4.17)$ & $\$$ & $(2.89)$ & $\$$ & $(4.36)$ & $\$$ & (3.09) \\
\hline 35 & $\$$ & $(4.08)$ & $\$$ & $(2.77)$ & $\$$ & $(4.28)$ & $\$$ & (2.97) \\
\hline 36 & $\$$ & (3.99) & $\$$ & $(2.64)$ & $\$$ & $(4.20)$ & $\$$ & $(2.85)$ \\
\hline 37 & $\$$ & $(3.90)$ & $\$$ & $(2.51)$ & $\$$ & $(4.11)$ & $\$$ & $(2.72)$ \\
\hline 38 & $\$$ & $(3.81)$ & $\$$ & $(2.39)$ & $\$$ & $(4.03)$ & $\$$ & $(2.60)$ \\
\hline 39 & $\$$ & (3.72) & $\$$ & $(2.26)$ & $\$$ & $(3.94)$ & $\$$ & $(2.48)$ \\
\hline 40 & $\$$ & (3.63) & $\$$ & $(2.13)$ & $\$$ & $(3.86)$ & $\$$ & (2.36) \\
\hline 41 & $\$$ & $(3.54)$ & $\$$ & $(2.00)$ & $\$$ & $(3.77)$ & $\$$ & $(2.24)$ \\
\hline 42 & $\$$ & (3.45) & $\$$ & $(1.87)$ & $\$$ & $(3.69)$ & $\$$ & (2.11) \\
\hline 43 & $\$$ & (3.36) & $\$$ & $(1.75)$ & $\$$ & $(3.60)$ & $\$$ & (1.99) \\
\hline 44 & $\$$ & (3.27) & $\$$ & $(1.62)$ & $\$$ & $(3.52)$ & $\$$ & (1.87) \\
\hline 45 & $\$$ & (3.18) & $\$$ & $(1.49)$ & $\$$ & $(3.43)$ & $\$$ & (1.75) \\
\hline 46 & $\$$ & (3.09) & $\$$ & $(1.36)$ & $\$$ & (3.35) & $\$$ & $(1.62)$ \\
\hline 47 & $\$$ & $(2.99)$ & $\$$ & $(1.23)$ & $\$$ & $(3.26)$ & $\$$ & $(1.50)$ \\
\hline 48 & \$ & $(2.90)$ & $\$$ & $(1.10)$ & $\$$ & $(3.18)$ & $\$$ & (1.38) \\
\hline
\end{tabular}




\begin{tabular}{|c|c|c|c|c|c|c|c|c|}
\hline \multicolumn{9}{|c|}{ Manual - Observe and Do (ROI) cont. } \\
\hline \multirow{2}{*}{$\begin{array}{c}\begin{array}{c}\text { Report } \\
\text { number }\end{array} \\
49\end{array}$} & \multicolumn{2}{|c|}{ Regular ROI } & \multicolumn{2}{|c|}{$\begin{array}{c}\text { Price } \\
\text { increase ROI }\end{array}$} & \multicolumn{2}{|c|}{$\begin{array}{c}\text { Material } \\
\text { Cost } \\
\text { Decrease } \\
\text { ROI }\end{array}$} & \multicolumn{2}{|c|}{$\begin{array}{l}\text { Sesitivity } \\
\text { Analysis } \\
\text { Both ROI }\end{array}$} \\
\hline & $\$$ & $(2.81)$ & $\$$ & $(0.97)$ & $\$$ & $(3.09)$ & $\$$ & $(1.25)$ \\
\hline 50 & $\$$ & $(2.72)$ & $\$$ & $(0.84)$ & $\$$ & $(3.00)$ & $\$$ & $(1.13)$ \\
\hline 51 & $\$$ & $(2.63)$ & $\$$ & $(0.71)$ & $\$$ & $(2.92)$ & $\$$ & $(1.00)$ \\
\hline 52 & $\$$ & $(2.53)$ & $\$$ & $(0.58)$ & $\$$ & $(2.83)$ & $\$$ & $(0.88)$ \\
\hline 53 & $\$$ & $(2.44)$ & $\$$ & $(0.45)$ & $\$$ & $(2.74)$ & $\$$ & $(0.75)$ \\
\hline 54 & $\$$ & (2.35) & $\$$ & $(0.32)$ & $\$$ & (2.66) & $\$$ & $(0.63)$ \\
\hline 55 & $\$$ & (2.25) & $\$$ & $(0.19)$ & $\$$ & $(2.57)$ & $\$$ & $(0.51)$ \\
\hline 56 & $\$$ & $(2.16)$ & $\$$ & $(0.06)$ & $\$$ & $(2.48)$ & $\$$ & $(0.38)$ \\
\hline 57 & $\$$ & $(2.07)$ & $\$$ & 0.07 & $\$$ & (2.39) & $\$$ & $(0.26)$ \\
\hline 58 & $\$$ & $(1.98)$ & $\$$ & 0.20 & $\$$ & (2.31) & $\$$ & $(0.13)$ \\
\hline 59 & $\$$ & $(1.88)$ & $\$$ & 0.33 & $\$$ & $(2.22)$ & $\$$ & $(0.01)$ \\
\hline 60 & $\$$ & $(1.79)$ & $\$$ & 0.46 & $\$$ & $(2.13)$ & $\$$ & 0.12 \\
\hline 61 & $\$$ & (1.69) & $\$$ & 0.59 & $\$$ & $(2.04)$ & $\$$ & 0.24 \\
\hline 62 & $\$$ & $(1.60)$ & $\$$ & 0.72 & $\$$ & (1.95) & $\$$ & 0.37 \\
\hline 63 & $\$$ & (1.51) & $\$$ & 0.86 & $\$$ & $(1.87)$ & $\$$ & 0.50 \\
\hline 64 & $\$$ & (1.41) & $\$$ & 0.99 & $\$$ & (1.78) & $\$$ & 0.62 \\
\hline 65 & $\$$ & (1.32) & $\$$ & 1.12 & $\$$ & (1.69) & $\$$ & 0.75 \\
\hline 66 & $\$$ & (1.23) & $\$$ & 1.25 & $\$$ & $(1.60)$ & $\$$ & 0.87 \\
\hline 67 & $\$$ & $(1.13)$ & $\$$ & 1.38 & $\$$ & (1.51) & $\$$ & 1.00 \\
\hline 68 & $\$$ & $(1.04)$ & $\$$ & 1.51 & $\$$ & (1.42) & $\$$ & 1.13 \\
\hline 69 & $\$$ & $(0.94)$ & $\$$ & 1.65 & $\$$ & (1.34) & $\$$ & 1.25 \\
\hline 70 & $\$$ & $(0.85)$ & $\$$ & 1.78 & $\$$ & $(1.25)$ & $\$$ & 1.38 \\
\hline 71 & $\$$ & $(0.75)$ & $\$$ & 1.91 & $\$$ & (1.16) & $\$$ & 1.50 \\
\hline 72 & $\$$ & $(0.66)$ & $\$$ & 2.04 & $\$$ & $(1.07)$ & $\$$ & 1.63 \\
\hline 73 & $\$$ & $(0.56)$ & $\$$ & 2.17 & $\$$ & $(0.98)$ & $\$$ & 1.76 \\
\hline 74 & $\$$ & $(0.47)$ & $\$$ & 2.31 & $\$$ & $(0.89)$ & $\$$ & 1.88 \\
\hline 75 & $\$$ & $(0.37)$ & $\$$ & 2.44 & $\$$ & $(0.80)$ & $\$$ & 2.01 \\
\hline 76 & $\$$ & $(0.28)$ & $\$$ & 2.57 & $\$$ & $(0.71)$ & $\$$ & 2.14 \\
\hline 77 & $\$$ & $(0.18)$ & $\$$ & 2.70 & $\$$ & $(0.62)$ & $\$$ & 2.27 \\
\hline 78 & $\$$ & $(0.09)$ & $\$$ & 2.84 & $\$$ & $(0.53)$ & $\$$ & 2.39 \\
\hline 79 & $\$$ & 0.01 & $\$$ & 2.97 & $\$$ & $(0.44)$ & $\$$ & 2.52 \\
\hline 80 & $\$$ & 0.10 & $\$$ & 3.10 & $\$$ & $(0.35)$ & $\$$ & 2.65 \\
\hline 81 & $\$$ & 0.20 & $\$$ & 3.24 & $\$$ & $(0.26)$ & $\$$ & 2.77 \\
\hline 82 & $\$$ & 0.29 & $\$$ & 3.37 & $\$$ & $(0.17)$ & $\$$ & 2.90 \\
\hline 83 & $\$$ & 0.39 & $\$$ & 3.50 & $\$$ & $(0.08)$ & $\$$ & 3.03 \\
\hline 84 & $\$$ & 0.49 & $\$$ & 3.64 & $\$$ & 0.01 & $\$$ & 3.16 \\
\hline 85 & $\$$ & 0.58 & $\$$ & 3.77 & $\$$ & 0.10 & $\$$ & 3.28 \\
\hline 86 & $\$$ & 0.68 & $\$$ & 3.90 & $\$$ & 0.19 & $\$$ & 3.41 \\
\hline 87 & $\$$ & 0.77 & $\$$ & 4.04 & $\$$ & 0.28 & $\$$ & 3.54 \\
\hline 88 & $\$$ & 0.87 & $\$$ & 4.17 & $\$$ & 0.37 & $\$$ & 3.67 \\
\hline 89 & $\$$ & 0.97 & $\$$ & 4.30 & $\$$ & 0.46 & $\$$ & 3.80 \\
\hline 90 & $\$$ & 1.06 & $\$$ & 4.44 & $\$$ & 0.55 & $\$$ & 3.92 \\
\hline 91 & $\$$ & 1.16 & $\$$ & 4.57 & $\$$ & 0.64 & $\$$ & 4.05 \\
\hline 92 & $\$$ & 1.25 & $\$$ & 4.70 & $\$$ & 0.73 & $\$$ & 4.18 \\
\hline 93 & $\$$ & 1.35 & $\$$ & 4.84 & $\$$ & 0.82 & $\$$ & 4.31 \\
\hline 94 & $\$$ & 1.45 & $\$$ & 4.97 & $\$$ & 0.91 & $\$$ & 4.44 \\
\hline 95 & $\$$ & 1.54 & $\$$ & 5.11 & $\$$ & 1.00 & $\$$ & 4.56 \\
\hline 96 & $\$$ & 1.64 & $\$$ & 5.24 & $\$$ & 1.09 & $\$$ & 4.69 \\
\hline 97 & $\$$ & 1.74 & $\$$ & 5.37 & $\$$ & 1.18 & $\$$ & 4.82 \\
\hline 98 & $\$$ & 1.83 & $\$$ & 5.51 & $\$$ & 1.27 & $\$$ & 4.95 \\
\hline 99 & $\$$ & 1.93 & $\$$ & 5.64 & $\$$ & 1.36 & $\$$ & 5.08 \\
\hline 100 & $\$$ & 2.03 & $\$$ & 5.78 & $\$$ & 1.46 & $\$$ & 5.21 \\
\hline
\end{tabular}




\begin{tabular}{|c|c|c|c|c|c|c|c|c|}
\hline \multicolumn{9}{|c|}{ Class - Observe and Do (ROI) } \\
\hline \multirow{2}{*}{$\begin{array}{c}\begin{array}{c}\text { Report } \\
\text { number }\end{array} \\
0 \\
\end{array}$} & \multicolumn{2}{|c|}{ ROI } & \multicolumn{2}{|c|}{$\begin{array}{c}\text { Price } \\
\text { increase ROI }\end{array}$} & \multicolumn{2}{|c|}{$\begin{array}{l}\text { Material } \\
\text { Cost } \\
\text { Decrease } \\
\text { ROI }\end{array}$} & \multicolumn{2}{|c|}{$\begin{array}{l}\text { Sesitivity } \\
\text { Analysis } \\
\text { Both ROI }\end{array}$} \\
\hline & $\$$ & $(3.87)$ & $\$$ & (3.87) & $\$$ & $(3.87)$ & $\$$ & $(3.87)$ \\
\hline 1 & $\$$ & $(3.68)$ & $\$$ & $(3.65)$ & $\$$ & $(3.69)$ & $\$$ & (3.65) \\
\hline 2 & $\$$ & $(3.52)$ & $\$$ & (3.45) & $\$$ & (3.53) & $\$$ & (3.46) \\
\hline 3 & $\$$ & (3.37) & $\$$ & (3.25) & $\$$ & (3.38) & $\$$ & (3.27) \\
\hline 4 & $\$$ & (3.22) & $\$$ & $(3.07)$ & $\$$ & $(3.24)$ & $\$$ & $(3.09)$ \\
\hline 5 & $\$$ & $(3.08)$ & $\$$ & $(2.89)$ & $\$$ & $(3.11)$ & $\$$ & $(2.92)$ \\
\hline 6 & $\$$ & $(2.94)$ & $\$$ & $(2.72)$ & $\$$ & $(2.97)$ & $\$$ & $(2.75)$ \\
\hline 7 & $\$$ & (2.81) & $\$$ & $(2.55)$ & $\$$ & (2.85) & $\$$ & $(2.58)$ \\
\hline 8 & $\$$ & (2.68) & $\$$ & $(2.38)$ & $\$$ & (2.72) & $\$$ & (2.42) \\
\hline 9 & $\$$ & $(2.55)$ & $\$$ & $(2.21)$ & $\$$ & $(2.60)$ & $\$$ & $(2.26)$ \\
\hline 10 & $\$$ & $(2.42)$ & $\$$ & $(2.05)$ & $\$$ & (2.48) & $\$$ & $(2.10)$ \\
\hline 11 & $\$$ & $(2.30)$ & $\$$ & $(1.89)$ & $\$$ & (2.36) & $\$$ & (1.94) \\
\hline 12 & $\$$ & $(2.18)$ & $\$$ & $(1.73)$ & $\$$ & (2.24) & $\$$ & $(1.79)$ \\
\hline 13 & $\$$ & $(2.06)$ & $\$$ & $(1.57)$ & $\$$ & (2.12) & $\$$ & (1.64) \\
\hline 14 & $\$$ & $(1.94)$ & $\$$ & (1.41) & $\$$ & (2.01) & $\$$ & (1.48) \\
\hline 15 & $\$$ & $(1.82)$ & $\$$ & $(1.26)$ & $\$$ & (1.89) & $\$$ & $(1.33)$ \\
\hline 16 & $\$$ & $(1.70)$ & $\$$ & $(1.10)$ & $\$$ & $(1.78)$ & $\$$ & (1.18) \\
\hline 17 & $\$$ & $(1.58)$ & $\$$ & $(0.95)$ & $\$$ & (1.67) & $\$$ & $(1.03)$ \\
\hline 18 & $\$$ & (1.47) & $\$$ & $(0.79)$ & $\$$ & $(1.56)$ & $\$$ & $(0.89)$ \\
\hline 19 & $\$$ & $(1.35)$ & $\$$ & $(0.64)$ & $\$$ & (1.45) & $\$$ & $(0.74)$ \\
\hline 20 & $\$$ & $(1.24)$ & $\$$ & $(0.49)$ & $\$$ & $(1.34)$ & $\$$ & $(0.59)$ \\
\hline 21 & $\$$ & (1.13) & $\$$ & $(0.34)$ & $\$$ & (1.24) & $\$$ & $(0.45)$ \\
\hline 22 & $\$$ & $(1.02)$ & $\$$ & $(0.19)$ & $\$$ & (1.13) & $\$$ & $(0.31)$ \\
\hline 23 & $\$$ & $(0.91)$ & $\$$ & $(0.04)$ & $\$$ & (1.02) & $\$$ & $(0.16)$ \\
\hline 24 & $\$$ & $(0.80)$ & $\$$ & 0.10 & $\$$ & $(0.92)$ & $\$$ & $(0.02)$ \\
\hline 25 & $\$$ & $(0.69)$ & $\$$ & 0.25 & $\$$ & $(0.81)$ & $\$$ & 0.12 \\
\hline 26 & $\$$ & $(0.58)$ & $\$$ & 0.40 & $\$$ & $(0.71)$ & $\$$ & 0.26 \\
\hline 27 & $\$$ & $(0.47)$ & $\$$ & 0.54 & $\$$ & $(0.61)$ & $\$$ & 0.40 \\
\hline 28 & $\$$ & $(0.36)$ & $\$$ & 0.69 & $\$$ & $(0.51)$ & $\$$ & 0.54 \\
\hline 29 & $\$$ & $(0.25)$ & $\$$ & 0.83 & $\$$ & $(0.40)$ & $\$$ & 0.68 \\
\hline 30 & $\$$ & $(0.15)$ & $\$$ & 0.98 & $\$$ & $(0.30)$ & $\$$ & 0.82 \\
\hline 31 & $\$$ & $(0.04)$ & $\$$ & 1.12 & $\$$ & $(0.20)$ & $\$$ & 0.96 \\
\hline 32 & $\$$ & 0.07 & $\$$ & 1.27 & $\$$ & $(0.10)$ & $\$$ & 1.10 \\
\hline 33 & $\$$ & 0.17 & $\$$ & 1.41 & $\$$ & 0.00 & $\$$ & 1.24 \\
\hline 34 & $\$$ & 0.28 & $\$$ & 1.55 & $\$$ & 0.10 & $\$$ & 1.37 \\
\hline 35 & $\$$ & 0.38 & $\$$ & 1.69 & $\$$ & 0.20 & $\$$ & 1.51 \\
\hline 36 & $\$$ & 0.48 & $\$$ & 1.83 & $\$$ & 0.30 & $\$$ & 1.65 \\
\hline 37 & $\$$ & 0.59 & $\$$ & 1.97 & $\$$ & 0.40 & $\$$ & 1.78 \\
\hline 38 & $\$$ & 0.69 & $\$$ & 2.11 & $\$$ & 0.49 & $\$$ & 1.92 \\
\hline 39 & $\$$ & 0.79 & $\$$ & 2.26 & $\$$ & 0.59 & $\$$ & 2.05 \\
\hline 40 & $\$$ & 0.89 & $\$$ & 2.39 & $\$$ & 0.69 & $\$$ & 2.19 \\
\hline 41 & $\$$ & 1.00 & $\$$ & 2.53 & $\$$ & 0.79 & $\$$ & 2.32 \\
\hline 42 & $\$$ & 1.10 & $\$$ & 2.67 & $\$$ & 0.88 & $\$$ & 2.46 \\
\hline 43 & $\$$ & 1.20 & $\$$ & 2.81 & $\$$ & 0.98 & $\$$ & 2.59 \\
\hline 44 & $\$$ & 1.30 & $\$$ & 2.95 & $\$$ & 1.07 & $\$$ & 2.72 \\
\hline 45 & $\$$ & 1.40 & $\$$ & 3.09 & $\$$ & 1.17 & $\$$ & 2.86 \\
\hline 46 & $\$$ & 1.50 & $\$$ & 3.23 & $\$$ & 1.26 & $\$$ & 2.99 \\
\hline 47 & $\$$ & 1.60 & $\$$ & 3.36 & $\$$ & 1.36 & $\$$ & 3.12 \\
\hline 48 & $\$$ & 1.70 & $\$$ & 3.50 & $\$$ & 1.45 & $\$$ & 3.25 \\
\hline
\end{tabular}




\begin{tabular}{|c|c|c|c|c|c|c|c|c|}
\hline \multicolumn{9}{|c|}{ Class - Observe and Do (ROI) cont. } \\
\hline \multirow{2}{*}{$\begin{array}{c}\begin{array}{c}\text { Report } \\
\text { number }\end{array} \\
49\end{array}$} & \multicolumn{2}{|c|}{ ROI } & \multicolumn{2}{|c|}{$\begin{array}{c}\text { Price } \\
\text { increase ROI }\end{array}$} & \multicolumn{2}{|c|}{$\begin{array}{c}\text { Material } \\
\text { Cost } \\
\text { Decrease } \\
\text { ROI }\end{array}$} & \multicolumn{2}{|c|}{$\begin{array}{l}\text { Sesitivity } \\
\text { Analysis } \\
\text { Both ROI }\end{array}$} \\
\hline & $\$$ & 1.80 & $\$$ & 3.64 & $\$$ & 1.55 & $\$$ & 3.39 \\
\hline 50 & $\$$ & 1.90 & $\$$ & 3.77 & $\$$ & 1.64 & $\$$ & 3.52 \\
\hline 51 & $\$$ & 2.00 & $\$$ & 3.91 & $\$$ & 1.74 & $\$$ & 3.65 \\
\hline 52 & $\$$ & 2.10 & $\$$ & 4.05 & $\$$ & 1.83 & $\$$ & 3.78 \\
\hline 53 & $\$$ & 2.20 & $\$$ & 4.18 & $\$$ & 1.92 & $\$$ & 3.91 \\
\hline 54 & $\$$ & 2.29 & $\$$ & 4.32 & $\$$ & 2.01 & $\$$ & 4.04 \\
\hline 55 & $\$$ & 2.39 & $\$$ & 4.45 & $\$$ & 2.11 & $\$$ & 4.17 \\
\hline 56 & $\$$ & 2.49 & $\$$ & 4.59 & $\$$ & 2.20 & $\$$ & 4.30 \\
\hline 57 & $\$$ & 2.59 & $\$$ & 4.72 & $\$$ & 2.29 & $\$$ & 4.43 \\
\hline 58 & $\$$ & 2.68 & $\$$ & 4.86 & $\$$ & 2.38 & $\$$ & 4.56 \\
\hline 59 & $\$$ & 2.78 & $\$$ & 4.99 & $\$$ & 2.48 & $\$$ & 4.69 \\
\hline 60 & $\$$ & 2.88 & $\$$ & 5.13 & $\$$ & 2.57 & $\$$ & 4.82 \\
\hline 61 & $\$$ & 2.97 & $\$$ & 5.26 & $\$$ & 2.66 & $\$$ & 4.95 \\
\hline 62 & $\$$ & 3.07 & $\$$ & 5.39 & $\$$ & 2.75 & $\$$ & 5.07 \\
\hline 63 & $\$$ & 3.16 & $\$$ & 5.53 & $\$$ & 2.84 & $\$$ & 5.20 \\
\hline 64 & $\$$ & 3.26 & $\$$ & 5.66 & $\$$ & 2.93 & $\$$ & 5.33 \\
\hline 65 & $\$$ & 3.36 & $\$$ & 5.79 & $\$$ & 3.02 & $\$$ & 5.46 \\
\hline 66 & $\$$ & 3.45 & $\$$ & 5.93 & $\$$ & 3.11 & $\$$ & 5.59 \\
\hline 67 & $\$$ & 3.55 & $\$$ & 6.06 & $\$$ & 3.20 & $\$$ & 5.71 \\
\hline 68 & $\$$ & 3.64 & $\$$ & 6.19 & $\$$ & 3.29 & $\$$ & 5.84 \\
\hline 69 & $\$$ & 3.74 & $\$$ & 6.32 & $\$$ & 3.38 & $\$$ & 5.97 \\
\hline 70 & $\$$ & 3.83 & $\$$ & 6.46 & $\$$ & 3.47 & $\$$ & 6.09 \\
\hline 71 & $\$$ & 3.93 & $\$$ & 6.59 & $\$$ & 3.56 & $\$$ & 6.22 \\
\hline 72 & $\$$ & 4.02 & $\$$ & 6.72 & $\$$ & 3.65 & $\$$ & 6.35 \\
\hline 73 & $\$$ & 4.11 & $\$$ & 6.85 & $\$$ & 3.74 & $\$$ & 6.47 \\
\hline 74 & $\$$ & 4.21 & $\$$ & 6.98 & $\$$ & 3.83 & $\$$ & 6.60 \\
\hline 75 & $\$$ & 4.30 & $\$$ & 7.11 & $\$$ & 3.91 & $\$$ & 6.73 \\
\hline 76 & $\$$ & 4.39 & $\$$ & 7.24 & $\$$ & 4.00 & $\$$ & 6.85 \\
\hline 77 & $\$$ & 4.49 & $\$$ & 7.38 & $\$$ & 4.09 & $\$$ & 6.98 \\
\hline 78 & $\$$ & 4.58 & $\$$ & 7.51 & $\$$ & 4.18 & $\$$ & 7.10 \\
\hline 79 & $\$$ & 4.67 & $\$$ & 7.64 & $\$$ & 4.27 & $\$$ & 7.23 \\
\hline 80 & $\$$ & 4.77 & $\$$ & 7.77 & $\$$ & 4.35 & $\$$ & 7.35 \\
\hline 81 & $\$$ & 4.86 & $\$$ & 7.90 & $\$$ & 4.44 & $\$$ & 7.48 \\
\hline 82 & $\$$ & 4.95 & $\$$ & 8.03 & $\$$ & 4.53 & $\$$ & 7.60 \\
\hline 83 & $\$$ & 5.04 & $\$$ & 8.16 & $\$$ & 4.62 & $\$$ & 7.73 \\
\hline 84 & $\$$ & 5.14 & $\$$ & 8.29 & $\$$ & 4.70 & $\$$ & 7.85 \\
\hline 85 & $\$$ & 5.23 & $\$$ & 8.42 & $\$$ & 4.79 & $\$$ & 7.98 \\
\hline 86 & $\$$ & 5.32 & $\$$ & 8.55 & $\$$ & 4.88 & $\$$ & 8.10 \\
\hline 87 & $\$$ & 5.41 & $\$$ & 8.67 & $\$$ & 4.96 & $\$$ & 8.23 \\
\hline 88 & $\$$ & 5.50 & $\$$ & 8.80 & $\$$ & 5.05 & $\$$ & 8.35 \\
\hline 89 & $\$$ & 5.60 & $\$$ & 8.93 & $\$$ & 5.14 & $\$$ & 8.47 \\
\hline 90 & $\$$ & 5.69 & $\$$ & 9.06 & $\$$ & 5.22 & $\$$ & 8.60 \\
\hline 91 & $\$$ & 5.78 & $\$$ & 9.19 & $\$$ & 5.31 & $\$$ & 8.72 \\
\hline 92 & $\$$ & 5.87 & $\$$ & 9.32 & $\$$ & 5.39 & $\$$ & 8.84 \\
\hline 93 & $\$$ & 5.96 & $\$$ & 9.45 & $\$$ & 5.48 & $\$$ & 8.97 \\
\hline 94 & $\$$ & 6.05 & $\$$ & 9.58 & $\$$ & 5.57 & $\$$ & 9.09 \\
\hline 95 & $\$$ & 6.14 & $\$$ & 9.70 & $\$$ & 5.65 & $\$$ & 9.21 \\
\hline 96 & $\$$ & 6.23 & $\$$ & 9.83 & $\$$ & 5.74 & $\$$ & 9.34 \\
\hline 97 & $\$$ & 6.32 & $\$$ & 9.96 & $\$$ & 5.82 & $\$$ & 9.46 \\
\hline 98 & $\$$ & 6.41 & $\$$ & 10.09 & $\$$ & 5.91 & $\$$ & 9.58 \\
\hline 99 & $\$$ & 6.50 & $\$$ & 10.22 & $\$$ & 5.99 & $\$$ & 9.70 \\
\hline 100 & $\$$ & 6.59 & $\$$ & 10.34 & $\$$ & 6.08 & $\$$ & 9.83 \\
\hline
\end{tabular}




\begin{tabular}{|c|c|c|c|c|c|c|c|c|}
\hline \multicolumn{9}{|c|}{ Mentor/Manual - Observe and Do (ROI) } \\
\hline \multirow{2}{*}{$\begin{array}{c}\begin{array}{c}\text { Report } \\
\text { number }\end{array} \\
0\end{array}$} & \multicolumn{2}{|c|}{ ROI } & \multicolumn{2}{|c|}{$\begin{array}{c}\text { Price } \\
\text { increase ROI }\end{array}$} & \multicolumn{2}{|c|}{$\begin{array}{c}\text { Material } \\
\text { Cost } \\
\text { Decrease } \\
\text { ROI }\end{array}$} & \multicolumn{2}{|c|}{$\begin{array}{l}\text { Sesitivity } \\
\text { Analysis } \\
\text { Both ROI }\end{array}$} \\
\hline & $\$$ & $(8.67)$ & $\$$ & $(8.67)$ & $\$$ & $(8.67)$ & $\$$ & $(8.67)$ \\
\hline 1 & $\$$ & $(8.62)$ & $\$$ & $(8.58)$ & $\$$ & $(8.62)$ & $\$$ & $(8.58)$ \\
\hline 2 & $\$$ & $(8.56)$ & $\$$ & $(8.48)$ & $\$$ & $(8.57)$ & $\$$ & $(8.49)$ \\
\hline 3 & $\$$ & $(8.50)$ & $\$$ & $(8.38)$ & $\$$ & $(8.51)$ & $\$$ & $(8.39)$ \\
\hline 4 & $\$$ & $(8.43)$ & $\$$ & $(8.28)$ & $\$$ & $(8.45)$ & $\$$ & $(8.30)$ \\
\hline 5 & $\$$ & (8.37) & $\$$ & $(8.18)$ & $\$$ & $(8.39)$ & $\$$ & $(8.20)$ \\
\hline 6 & $\$$ & $(8.31)$ & $\$$ & $(8.08)$ & $\$$ & (8.33) & $\$$ & $(8.10)$ \\
\hline 7 & $\$$ & (8.24) & $\$$ & $(7.98)$ & $\$$ & (8.27) & $\$$ & $(8.00)$ \\
\hline 8 & $\$$ & $(8.17)$ & $\$$ & $(7.87)$ & $\$$ & $(8.20)$ & $\$$ & $(7.90)$ \\
\hline 9 & $\$$ & (8.11) & $\$$ & $(7.77)$ & $\$$ & $(8.14)$ & $\$$ & $(7.80)$ \\
\hline 10 & $\$$ & (8.04) & $\$$ & $(7.67)$ & $\$$ & $(8.08)$ & $\$$ & $(7.70)$ \\
\hline 11 & $\$$ & $(7.98)$ & $\$$ & $(7.56)$ & $\$$ & $(8.01)$ & $\$$ & $(7.60)$ \\
\hline 12 & $\$$ & (7.91) & $\$$ & $(7.46)$ & $\$$ & (7.95) & $\$$ & $(7.50)$ \\
\hline 13 & $\$$ & (7.84) & $\$$ & $(7.35)$ & $\$$ & $(7.89)$ & $\$$ & $(7.40)$ \\
\hline 14 & $\$$ & (7.77) & $\$$ & $(7.25)$ & $\$$ & $(7.82)$ & $\$$ & $(7.30)$ \\
\hline 15 & $\$$ & $(7.71)$ & $\$$ & $(7.14)$ & $\$$ & $(7.76)$ & $\$$ & $(7.20)$ \\
\hline 16 & $\$$ & (7.64) & $\$$ & $(7.04)$ & $\$$ & $(7.70)$ & $\$$ & $(7.10)$ \\
\hline 17 & $\$$ & $(7.57)$ & $\$$ & $(6.93)$ & $\$$ & $(7.63)$ & $\$$ & $(6.99)$ \\
\hline 18 & $\$$ & $(7.50)$ & $\$$ & $(6.83)$ & $\$$ & $(7.57)$ & $\$$ & $(6.89)$ \\
\hline 19 & $\$$ & $(7.43)$ & $\$$ & $(6.72)$ & $\$$ & $(7.50)$ & $\$$ & $(6.79)$ \\
\hline 20 & $\$$ & (7.37) & $\$$ & $(6.62)$ & $\$$ & $(7.44)$ & $\$$ & (6.69) \\
\hline 21 & $\$$ & $(7.30)$ & $\$$ & $(6.51)$ & $\$$ & $(7.37)$ & $\$$ & (6.59) \\
\hline 22 & $\$$ & (7.23) & $\$$ & $(6.40)$ & $\$$ & (7.31) & $\$$ & (6.48) \\
\hline 23 & $\$$ & (7.16) & $\$$ & $(6.30)$ & $\$$ & $(7.24)$ & $\$$ & (6.38) \\
\hline 24 & $\$$ & $(7.09)$ & $\$$ & $(6.19)$ & $\$$ & $(7.18)$ & $\$$ & (6.28) \\
\hline 25 & $\$$ & (7.02) & $\$$ & $(6.09)$ & $\$$ & $(7.11)$ & $\$$ & $(6.18)$ \\
\hline 26 & $\$$ & $(6.96)$ & $\$$ & $(5.98)$ & $\$$ & $(7.05)$ & $\$$ & $(6.07)$ \\
\hline 27 & $\$$ & (6.89) & $\$$ & $(5.87)$ & $\$$ & $(6.98)$ & $\$$ & (5.97) \\
\hline 28 & $\$$ & $(6.82)$ & $\$$ & $(5.77)$ & $\$$ & $(6.92)$ & $\$$ & (5.87) \\
\hline 29 & $\$$ & (6.75) & $\$$ & $(5.66)$ & $\$$ & $(6.85)$ & $\$$ & (5.77) \\
\hline 30 & $\$$ & (6.68) & $\$$ & $(5.55)$ & $\$$ & $(6.79)$ & $\$$ & (5.66) \\
\hline 31 & $\$$ & $(6.61)$ & $\$$ & $(5.45)$ & $\$$ & $(6.72)$ & $\$$ & (5.56) \\
\hline 32 & $\$$ & (6.54) & $\$$ & $(5.34)$ & $\$$ & $(6.66)$ & $\$$ & $(5.46)$ \\
\hline 33 & $\$$ & $(6.47)$ & $\$$ & $(5.24)$ & $\$$ & $(6.59)$ & $\$$ & $(5.35)$ \\
\hline 34 & $\$$ & $(6.40)$ & $\$$ & $(5.13)$ & $\$$ & $(6.53)$ & $\$$ & (5.25) \\
\hline 35 & $\$$ & (6.33) & $\$$ & $(5.02)$ & $\$$ & $(6.46)$ & $\$$ & (5.15) \\
\hline 36 & $\$$ & (6.27) & $\$$ & $(4.92)$ & $\$$ & (6.39) & $\$$ & (5.04) \\
\hline 37 & $\$$ & $(6.20)$ & $\$$ & $(4.81)$ & $\$$ & (6.33) & $\$$ & (4.94) \\
\hline 38 & $\$$ & $(6.13)$ & $\$$ & $(4.70)$ & $\$$ & $(6.26)$ & $\$$ & (4.84) \\
\hline 39 & $\$$ & (6.06) & $\$$ & $(4.60)$ & $\$$ & $(6.20)$ & $\$$ & (4.74) \\
\hline 40 & $\$$ & (5.99) & $\$$ & $(4.49)$ & $\$$ & $(6.13)$ & $\$$ & (4.63) \\
\hline 41 & $\$$ & (5.92) & $\$$ & $(4.38)$ & $\$$ & $(6.07)$ & $\$$ & (4.53) \\
\hline 42 & $\$$ & (5.85) & $\$$ & $(4.27)$ & $\$$ & $(6.00)$ & $\$$ & (4.43) \\
\hline 43 & $\$$ & $(5.78)$ & $\$$ & $(4.17)$ & $\$$ & $(5.93)$ & $\$$ & (4.32) \\
\hline 44 & $\$$ & (5.71) & $\$$ & $(4.06)$ & $\$$ & $(5.87)$ & $\$$ & (4.22) \\
\hline 45 & $\$$ & (5.64) & $\$$ & (3.95) & $\$$ & $(5.80)$ & $\$$ & (4.12) \\
\hline 46 & $\$$ & $(5.57)$ & $\$$ & $(3.85)$ & $\$$ & $(5.74)$ & $\$$ & $(4.01)$ \\
\hline 47 & $\$$ & $(5.50)$ & $\$$ & $(3.74)$ & $\$$ & $(5.67)$ & $\$$ & (3.91) \\
\hline 48 & $\$$ & (5.43) & $\$$ & $(3.63)$ & $\$$ & $(5.61)$ & $\$$ & (3.81) \\
\hline
\end{tabular}




\begin{tabular}{|c|c|c|c|c|c|c|c|c|}
\hline \multicolumn{9}{|c|}{ Mentor/Manual - Observe and Do (ROI) cont. } \\
\hline \multirow{2}{*}{$\begin{array}{c}\begin{array}{c}\text { Report } \\
\text { number }\end{array} \\
49\end{array}$} & \multicolumn{2}{|c|}{ ROI } & \multicolumn{2}{|c|}{$\begin{array}{c}\text { Price } \\
\text { increase ROI }\end{array}$} & \multicolumn{2}{|c|}{$\begin{array}{c}\text { Material } \\
\text { Cost } \\
\text { Decrease } \\
\text { ROI }\end{array}$} & \multicolumn{2}{|c|}{$\begin{array}{l}\text { Sesitivity } \\
\text { Analysis } \\
\text { Both ROI }\end{array}$} \\
\hline & $\$$ & $(5.36)$ & $\$$ & (3.53) & $\$$ & $(5.54)$ & $\$$ & $(3.70)$ \\
\hline 50 & $\$$ & $(5.29)$ & $\$$ & $(3.42)$ & $\$$ & $(5.47)$ & $\$$ & $(3.60)$ \\
\hline 51 & $\$$ & $(5.22)$ & $\$$ & (3.31) & $\$$ & $(5.41)$ & $\$$ & $(3.50)$ \\
\hline 52 & $\$$ & $(5.15)$ & $\$$ & $(3.20)$ & $\$$ & $(5.34)$ & $\$$ & $(3.39)$ \\
\hline 53 & $\$$ & $(5.09)$ & $\$$ & $(3.10)$ & $\$$ & $(5.28)$ & $\$$ & $(3.29)$ \\
\hline 54 & $\$$ & $(5.02)$ & $\$$ & (2.99) & $\$$ & (5.21) & $\$$ & $(3.18)$ \\
\hline 55 & $\$$ & $(4.95)$ & $\$$ & (2.88) & $\$$ & (5.14) & $\$$ & (3.08) \\
\hline 56 & $\$$ & $(4.88)$ & $\$$ & $(2.78)$ & $\$$ & (5.08) & $\$$ & (2.98) \\
\hline 57 & $\$$ & $(4.81)$ & $\$$ & $(2.67)$ & $\$$ & $(5.01)$ & $\$$ & $(2.87)$ \\
\hline 58 & $\$$ & $(4.74)$ & $\$$ & $(2.56)$ & $\$$ & (4.95) & $\$$ & (2.77) \\
\hline 59 & $\$$ & (4.67) & $\$$ & $(2.45)$ & $\$$ & (4.88) & $\$$ & (2.67) \\
\hline 60 & $\$$ & $(4.60)$ & $\$$ & (2.35) & $\$$ & $(4.81)$ & $\$$ & $(2.56)$ \\
\hline 61 & $\$$ & $(4.53)$ & $\$$ & $(2.24)$ & $\$$ & $(4.75)$ & $\$$ & $(2.46)$ \\
\hline 62 & $\$$ & $(4.46)$ & $\$$ & (2.13) & $\$$ & $(4.68)$ & $\$$ & $(2.36)$ \\
\hline 63 & $\$$ & (4.39) & $\$$ & (2.03) & $\$$ & (4.61) & $\$$ & $(2.25)$ \\
\hline 64 & $\$$ & $(4.32)$ & $\$$ & $(1.92)$ & $\$$ & $(4.55)$ & $\$$ & $(2.15)$ \\
\hline 65 & $\$$ & $(4.25)$ & $\$$ & $(1.81)$ & $\$$ & $(4.48)$ & $\$$ & $(2.05)$ \\
\hline 66 & $\$$ & (4.18) & $\$$ & $(1.70)$ & $\$$ & (4.42) & $\$$ & (1.94) \\
\hline 67 & $\$$ & $(4.11)$ & $\$$ & $(1.60)$ & $\$$ & $(4.35)$ & $\$$ & $(1.84)$ \\
\hline 68 & $\$$ & $(4.04)$ & $\$$ & $(1.49)$ & $\$$ & $(4.28)$ & $\$$ & $(1.73)$ \\
\hline 69 & $\$$ & (3.97) & $\$$ & $(1.38)$ & $\$$ & $(4.22)$ & $\$$ & (1.63) \\
\hline 70 & $\$$ & (3.90) & $\$$ & (1.27) & $\$$ & (4.15) & $\$$ & (1.53) \\
\hline 71 & $\$$ & (3.83) & $\$$ & (1.17) & $\$$ & $(4.09)$ & $\$$ & $(1.42)$ \\
\hline 72 & $\$$ & $(3.76)$ & $\$$ & $(1.06)$ & $\$$ & $(4.02)$ & $\$$ & $(1.32)$ \\
\hline 73 & $\$$ & (3.69) & $\$$ & $(0.95)$ & $\$$ & (3.95) & $\$$ & (1.22) \\
\hline 74 & $\$$ & (3.62) & $\$$ & $(0.85)$ & $\$$ & (3.89) & $\$$ & $(1.11)$ \\
\hline 75 & $\$$ & (3.55) & $\$$ & $(0.74)$ & $\$$ & (3.82) & $\$$ & $(1.01)$ \\
\hline 76 & $\$$ & (3.48) & $\$$ & $(0.63)$ & $\$$ & (3.75) & $\$$ & $(0.90)$ \\
\hline 77 & $\$$ & (3.41) & $\$$ & $(0.52)$ & $\$$ & (3.69) & $\$$ & $(0.80)$ \\
\hline 78 & $\$$ & (3.34) & $\$$ & $(0.42)$ & $\$$ & (3.62) & $\$$ & $(0.70)$ \\
\hline 79 & $\$$ & (3.27) & $\$$ & $(0.31)$ & $\$$ & (3.56) & $\$$ & $(0.59)$ \\
\hline 80 & $\$$ & (3.20) & $\$$ & $(0.20)$ & $\$$ & (3.49) & $\$$ & $(0.49)$ \\
\hline 81 & $\$$ & (3.13) & $\$$ & $(0.09)$ & $\$$ & (3.42) & $\$$ & $(0.39)$ \\
\hline 82 & $\$$ & $(3.06)$ & $\$$ & 0.01 & $\$$ & (3.36) & $\$$ & $(0.28)$ \\
\hline 83 & $\$$ & (2.99) & $\$$ & 0.12 & $\$$ & (3.29) & $\$$ & $(0.18)$ \\
\hline 84 & $\$$ & $(2.92)$ & $\$$ & 0.23 & $\$$ & (3.22) & $\$$ & $(0.07)$ \\
\hline 85 & $\$$ & $(2.85)$ & $\$$ & 0.34 & $\$$ & (3.16) & $\$$ & 0.03 \\
\hline 86 & $\$$ & $(2.78)$ & $\$$ & 0.44 & $\$$ & (3.09) & $\$$ & 0.13 \\
\hline 87 & $\$$ & (2.71) & $\$$ & 0.55 & $\$$ & (3.02) & $\$$ & 0.24 \\
\hline 88 & $\$$ & $(2.64)$ & $\$$ & 0.66 & $\$$ & (2.96) & $\$$ & 0.34 \\
\hline 89 & $\$$ & $(2.57)$ & $\$$ & 0.77 & $\$$ & $(2.89)$ & $\$$ & 0.45 \\
\hline 90 & $\$$ & $(2.50)$ & $\$$ & 0.87 & $\$$ & (2.83) & $\$$ & 0.55 \\
\hline 91 & $\$$ & $(2.43)$ & $\$$ & 0.98 & $\$$ & $(2.76)$ & $\$$ & 0.65 \\
\hline 92 & $\$$ & (2.36) & $\$$ & 1.09 & $\$$ & (2.69) & $\$$ & 0.76 \\
\hline 93 & $\$$ & $(2.29)$ & $\$$ & 1.20 & $\$$ & (2.63) & $\$$ & 0.86 \\
\hline 94 & $\$$ & $(2.22)$ & $\$$ & 1.30 & $\$$ & (2.56) & $\$$ & 0.96 \\
\hline 95 & $\$$ & $(2.15)$ & $\$$ & 1.41 & $\$$ & $(2.49)$ & $\$$ & 1.07 \\
\hline 96 & $\$$ & $(2.08)$ & $\$$ & 1.52 & $\$$ & $(2.43)$ & $\$$ & 1.17 \\
\hline 97 & $\$$ & $(2.01)$ & $\$$ & 1.63 & $\$$ & $(2.36)$ & $\$$ & 1.28 \\
\hline 98 & $\$$ & (1.94) & $\$$ & 1.73 & $\$$ & (2.29) & $\$$ & 1.38 \\
\hline 99 & $\$$ & (1.87) & $\$$ & 1.84 & $\$$ & (2.23) & $\$$ & 1.48 \\
\hline 100 & $\$$ & $(1.80)$ & $\$$ & 1.95 & $\$$ & (2.16) & $\$$ & 1.59 \\
\hline
\end{tabular}




\begin{tabular}{|c|c|c|c|c|c|c|c|c|}
\hline \multicolumn{9}{|c|}{ Mentor/Manual - Observe and Do (ROI) cont. } \\
\hline \multirow{2}{*}{$\begin{array}{c}\begin{array}{c}\text { Report } \\
\text { number }\end{array} \\
101\end{array}$} & \multicolumn{2}{|c|}{ ROI } & \multicolumn{2}{|c|}{$\begin{array}{c}\text { Price } \\
\text { increase ROI }\end{array}$} & \multicolumn{2}{|c|}{$\begin{array}{c}\text { Material } \\
\text { Cost } \\
\text { Decrease } \\
\text { ROI }\end{array}$} & \multicolumn{2}{|c|}{$\begin{array}{l}\text { Sesitivity } \\
\text { Analysis } \\
\text { Both ROI }\end{array}$} \\
\hline & $\$$ & $(1.73)$ & $\$$ & 2.06 & $\$$ & $(2.10)$ & $\$$ & 1.69 \\
\hline 102 & $\$$ & $(1.66)$ & $\$$ & 2.16 & $\$$ & $(2.03)$ & $\$$ & 1.80 \\
\hline 103 & $\$$ & $(1.59)$ & $\$$ & 2.27 & $\$$ & $(1.96)$ & $\$$ & 1.90 \\
\hline 104 & $\$$ & $(1.52)$ & $\$$ & 2.38 & $\$$ & $(1.90)$ & $\$$ & 2.00 \\
\hline 105 & $\$$ & $(1.45)$ & $\$$ & 2.49 & $\$$ & $(1.83)$ & $\$$ & 2.11 \\
\hline 106 & $\$$ & $(1.38)$ & $\$$ & 2.59 & $\$$ & $(1.76)$ & $\$$ & 2.21 \\
\hline 107 & $\$$ & (1.31) & $\$$ & 2.70 & $\$$ & (1.70) & $\$$ & 2.32 \\
\hline 108 & $\$$ & $(1.24)$ & $\$$ & 2.81 & $\$$ & $(1.63)$ & $\$$ & 2.42 \\
\hline 109 & $\$$ & $(1.17)$ & $\$$ & 2.92 & $\$$ & $(1.56)$ & $\$$ & 2.52 \\
\hline 110 & $\$$ & $(1.10)$ & $\$$ & 3.02 & $\$$ & $(1.50)$ & $\$$ & 2.63 \\
\hline 111 & $\$$ & (1.03) & $\$$ & 3.13 & $\$$ & (1.43) & $\$$ & 2.73 \\
\hline 112 & $\$$ & $(0.96)$ & $\$$ & 3.24 & $\$$ & $(1.37)$ & $\$$ & 2.83 \\
\hline 113 & $\$$ & $(0.89)$ & $\$$ & 3.35 & $\$$ & $(1.30)$ & $\$$ & 2.94 \\
\hline 114 & $\$$ & $(0.82)$ & $\$$ & 3.45 & $\$$ & $(1.23)$ & $\$$ & 3.04 \\
\hline 115 & $\$$ & $(0.75)$ & $\$$ & 3.56 & $\$$ & $(1.17)$ & $\$$ & 3.15 \\
\hline 116 & $\$$ & $(0.68)$ & $\$$ & 3.67 & $\$$ & $(1.10)$ & $\$$ & 3.25 \\
\hline 117 & $\$$ & $(0.61)$ & $\$$ & 3.78 & $\$$ & $(1.03)$ & $\$$ & 3.35 \\
\hline 118 & $\$$ & $(0.54)$ & $\$$ & 3.88 & $\$$ & $(0.97)$ & $\$$ & 3.46 \\
\hline 119 & $\$$ & $(0.47)$ & $\$$ & 3.99 & $\$$ & $(0.90)$ & $\$$ & 3.56 \\
\hline 120 & $\$$ & $(0.40)$ & $\$$ & 4.10 & $\$$ & $(0.83)$ & $\$$ & 3.67 \\
\hline 121 & $\$$ & $(0.33)$ & $\$$ & 4.21 & $\$$ & $(0.77)$ & $\$$ & 3.77 \\
\hline 122 & $\$$ & $(0.26)$ & $\$$ & 4.31 & $\$$ & $(0.70)$ & $\$$ & 3.87 \\
\hline 123 & $\$$ & $(0.19)$ & $\$$ & 4.42 & $\$$ & $(0.63)$ & $\$$ & 3.98 \\
\hline 124 & $\$$ & $(0.12)$ & $\$$ & 4.53 & $\$$ & $(0.57)$ & $\$$ & 4.08 \\
\hline 125 & $\$$ & $(0.05)$ & $\$$ & 4.64 & $\$$ & $(0.50)$ & $\$$ & 4.19 \\
\hline 126 & $\$$ & 0.02 & $\$$ & 4.74 & $\$$ & $(0.44)$ & $\$$ & 4.29 \\
\hline 127 & $\$$ & 0.09 & $\$$ & 4.85 & $\$$ & $(0.37)$ & $\$$ & 4.39 \\
\hline 128 & $\$$ & 0.16 & $\$$ & 4.96 & $\$$ & $(0.30)$ & $\$$ & 4.50 \\
\hline 129 & $\$$ & 0.23 & $\$$ & 5.07 & $\$$ & $(0.24)$ & $\$$ & 4.60 \\
\hline 130 & $\$$ & 0.30 & $\$$ & 5.17 & $\$$ & $(0.17)$ & $\$$ & 4.71 \\
\hline 131 & $\$$ & 0.37 & $\$$ & 5.28 & $\$$ & $(0.10)$ & $\$$ & 4.81 \\
\hline 132 & $\$$ & 0.44 & $\$$ & 5.39 & $\$$ & $(0.04)$ & $\$$ & 4.91 \\
\hline 133 & $\$$ & 0.51 & $\$$ & 5.50 & $\$$ & 0.03 & $\$$ & 5.02 \\
\hline 134 & $\$$ & 0.58 & $\$$ & 5.60 & $\$$ & 0.10 & $\$$ & 5.12 \\
\hline 135 & $\$$ & 0.65 & $\$$ & 5.71 & $\$$ & 0.16 & $\$$ & 5.23 \\
\hline 136 & $\$$ & 0.72 & $\$$ & 5.82 & $\$$ & 0.23 & $\$$ & 5.33 \\
\hline 137 & $\$$ & 0.79 & $\$$ & 5.93 & $\$$ & 0.30 & $\$$ & 5.43 \\
\hline 138 & $\$$ & 0.86 & $\$$ & 6.03 & $\$$ & 0.36 & $\$$ & 5.54 \\
\hline 139 & $\$$ & 0.93 & $\$$ & 6.14 & $\$$ & 0.43 & $\$$ & 5.64 \\
\hline 140 & $\$$ & 1.00 & $\$$ & 6.25 & $\$$ & 0.49 & $\$$ & 5.74 \\
\hline 141 & $\$$ & 1.07 & $\$$ & 6.36 & $\$$ & 0.56 & $\$$ & 5.85 \\
\hline 142 & $\$$ & 1.14 & $\$$ & 6.46 & $\$$ & 0.63 & $\$$ & 5.95 \\
\hline 143 & $\$$ & 1.21 & $\$$ & 6.57 & $\$$ & 0.69 & $\$$ & 6.06 \\
\hline 144 & $\$$ & 1.28 & $\$$ & 6.68 & $\$$ & 0.76 & $\$$ & 6.16 \\
\hline 145 & $\$$ & 1.35 & $\$$ & 6.79 & $\$$ & 0.83 & $\$$ & 6.26 \\
\hline 146 & $\$$ & 1.42 & $\$$ & 6.89 & $\$$ & 0.89 & $\$$ & 6.37 \\
\hline 147 & $\$$ & 1.49 & $\$$ & 7.00 & $\$$ & 0.96 & $\$$ & 6.47 \\
\hline 148 & $\$$ & 1.56 & $\$$ & 7.11 & $\$$ & 1.03 & $\$$ & 6.58 \\
\hline 149 & $\$$ & 1.63 & $\$$ & 7.22 & $\$$ & 1.09 & $\$$ & 6.68 \\
\hline 150 & $\$$ & 1.70 & $\$$ & 7.32 & $\$$ & 1.16 & $\$$ & 6.78 \\
\hline
\end{tabular}


WORKS CITED 
Belkaoui, Ahmed, The Learning Curve: A Management Accounting Tool. Westport, CT: Quorum Books, 1986.

Bork, James R., "Skills-based Management Offers Insight to Proactively Meet Tomorrow's Work Force.” InfoWorld v 23 n 18, April 30. 2001: 60.

Dunn, Richard L., "Dealing with the Skills Problem.” Plant Engineering, July 1999: 10.

Hoover, Charles W., Jr., "Return On Investment In Continuing Education.” Chemtech, June 1990: 338-341.

Hicks, Sabrina, “Why ROI?”. Training and Development v 54 n 7, July 2000: 59-60.

Finch, Byron J., and Richard L. Luebbe, "Risk Associated with Learning Curve Estimates.” Production and Inventory Management Journal v 32 no 3, 1991: 73 76.

McCarty, Frank H., "Learning Faster and Better.” Manufacturing Engineering, July 1996: 232.

Maloy, T.K., "The IT Learning Curve Expands.” Internet Week, August 14, 2000: 6668.

"Need Skilled Workers? Grow Your Own." Manufacturing Engineering, July 1998: 2836. 
Neter, John, Michael H. Kutner, Christopher J. Nachtsheim, and William Wasserman. Applied Linear Regression Models. The McGraw-Hill Companies, Inc., 1996.

Owen, Jean V., "Best Practices, Best Plants.” Manufacturing Engineering, April 1999: 60-69.

Phillips, Jack J., "How Much Is the Training Worth?". Training and Development v 50 n 4, April 1996: 20-25.

Phillips, Jack J., "ROI: The Search for Best Practices." Training and Development v 50 n 2, February 1995: 42-48.

Phillips, Jack J., "Was it the Training?". Training and Development v $50 \mathrm{n}$ 3, March 1996: 28-33.

"Precis." Monthly Labor Review v 123 n 8, Aug 2000: 40.

Purcell, Amy, “20/20 ROI”. Training and Development v 54 n 7, July 2000: 28-34.

Robinson, Teri, "Mentoring Speeds the Learning Curve." Information Week, April 9, 2001: 77-80.

Self, Kevin, “Learning Curve Boomerangs.” IEEE Spectrum v 32, December 1995: 17.

Sinclair, Gavin, "Make the Learning Curve Work for You." Chemical Engineering Progress v 96 no 2, February 2000: 93-96.

Tanner, John P. "The Learning Curve; A Line on Labor Cost.” Production Engineering 32, May 1985: 72-78. 
Van Buren, Mark E., “Training Goes to the Bottom Line.” Manufacturing Engineering, January 2001: 134. 